\title{
FERNANDO COLOMBO
}

Calibração de Modelos Hidráulicos de Redes de Abastecimento de Água de Sistemas Reais Admitindo Vazamentos

Dissertação apresentada à Escola de Engenharia de São Carlos da Universidade de São Paulo, como parte dos requisitos para obtenção do título de Mestre em Hidráulica e Saneamento.

Área de Concentração: Hidráulica e Saneamento Orientadora: Prof ${ }^{\mathrm{a}}$. Assoc. Luisa Fernanda Ribeiro Reis

São Carlos 

A meus pais Antônio e Neide, e à minha noiva Tatiana, pelo apoio e compreensão. 



\section{AGRADECIMENTOS}

A Deus, meu grande amigo, verdadeiro, fiel, paciente e consolador. Minha inspiração para seguir.

À minha querida mãezinha, Virgem Santíssima, por me segurar nos braços durante esta caminhada.

À Professora Luisa Fernanda Ribeiro Reis, orientadora fiel, pela compreensão e paciência cedidas em todos os momentos.

À SABESP - Companhia de Saneamento Básico do Estado de São Paulo, pelo apoio financeiro imprescindível a realização deste trabalho.

À minha noiva Tatiana, pelo carinho e respeito aos meus ideais. Pela compreensão em relação às ausências para que eu pudesse me dedicar a este trabalho. Sem comentários, te amo.

Aos meus queridos pais, Antônio e Neide, pelo amor irrestrito, apoio total, responsáveis pelo que sou.

Às minhas irmãs, Ana Paula e Renata, princesinhas da minha vida, pela força, incentivo e preocupação despendida. Não foram em vão.

A José Paulo Zamarioli, chefe e amigo, pelo incentivo, confiança. Em especial, pela ajuda no direcionamento, enquanto funcionário da SABESP, no que diz respeito aos acessos as informações necessárias para o trabalho. Espero corresponder as espectativas.

À Mizue Terada, amiga acima de tudo. Responsável pelo meio de campo na aquisição de informações imprescindíveis para a realização deste trabalho. Sem ela, tudo seria mais complicado.

Ao meu grande amigo Alexandre Kepler, mestre nato, responsável pela criação do modelo de calibração usado nesta dissertação. Pelo companheirismo, dedicação e atenção irrestrita as dificuldades relativos a este trabalho.

Aos funcionários da SABESP residentes nas cidades de Guariba e Itirapuã. Mesquita, Dito, Marcão, e tantos outros que ajudaram de maneira substancial a coleta de todas as informações necessárias à realização deste trabalho.

A todos os colegas do Labsin, Serginho, Sergio Siebra, Karina, Melissa, Monique, Luciana, pelo companheirismo e ajuda em "todas" dificuldades que tive em São Carlos. 
A to dos os professores, colegas e funcionários do Departamento de Hidráulica e Saneamento da EESC/USP, em especial à Sá e à Pavi pelo respeito e acessibilidade de que tanto precisei.

Enfim, a todas as pessoas que de alguma forma participaram para a realização deste trabalho, muito obrigado. 


\section{RESUMO}

COLOMBO, F. (2006). Análise de Calibração Admitindo Vazamentos Aplicada a Setores de Abastecimento de Água de Sistemas Reais. Dissertação (Mestrado) - Escola de Engenharia de São Carlos, Universidade de São Paulo, São Carlos, 2006.

Considerando a necessidade do controle mais efetivo dos sistemas de distribuição de água para abastecimento, a calibração constitui etapa fundamental a ser trilhada para garantir a reprodução do comportamento dos sistemas sob as mais diversas condições operacionais. Apesar da importância da calibração e da diversidade de modelos construídos com esse propósito no ambiente acadêmico, essa prática não tem sido amplamente utilizada pelas companhias, que demonstram certa relutância em fazer uso de modelos matemáticos. É interessante, portanto, que os modelos existentes sejam intensivamente testados em sistemas reais para que se possam estabelecer diretrizes para a sua utilização, bem como uma maior confiança no seu emprego.

O presente trabalho de pesquisa visou o estudo de aplicação de um modelo especialmente construído para a calibração de sistemas, através do qual é possível identificar variáveis de campo tais como rugosidades, diâmetros, parâmetros do modelo de vazamentos, etc. O modelo empregado é abrangente o suficiente para incorporar vazamentos e demandas variáveis com a pressão. Através dele, foram realizados dois estudos de caso e discutidas as razões pelas quais discrepâncias entre os valores simulados e observados foram detectadas, apesar da consistência das respostas produzidas via simulação. Algumas recomendações são feitas também no sentido de viabilizar estudos dessa natureza que possam produzir ferramental diretamente utilizável pelas concessionárias de água para abastecimento.

Palavras-chave: calibração, redes de distribuição de água, vazamentos, redes reais. 



\begin{abstract}
COLOMBO, F. (2006). Calibration Analysis Considering Leakage Applied to Existing Water Supply Systems. M. Sc. Dissertation - Escola de Engenharia de São Carlos, Universidade de São Paulo, São Carlos, 2006.

Considering the need for more effective control of water supply distribution systems, the calibration constitutes fundamental step to guarantee that the system behavior under several operational conditions can be reproduced. Instead of the importance of calibration and the variety of models built by the academy for this purpose, this practice has not been broadly used by the water industry, which demonstrates certain reluctance regards the use of mathematical models. It is interesting, hence, that existing models are intensively tested in real systems to establish guidelines and consequent confidence in their use.

The present research focused on the study of a model especially built for the calibration of water supply systems, through which it is possible identify field variables such as roughness, diameters, parameters of leakage model, etc. The model is comprehensive enough to incorporate leakage and pressure driven demands. Two study cases were analyzed supported by the model and discussed the reasons by which disagreement between simulated and observed data were verified, instead of the consistency of results produced by simulation. Some recommendations are made to become practical this kind of study as useful tool for the water industry.
\end{abstract}

Key words: calibration, water distribution network, leakage, existing networks. 



\section{ÍNDICE DE FIGURAS}

Figura 3.1 - Recombinação de um ponto - simples troca ............................................ 13

Figura 3.2 - Recombinação de dois pontos - simples troca .......................................... 13

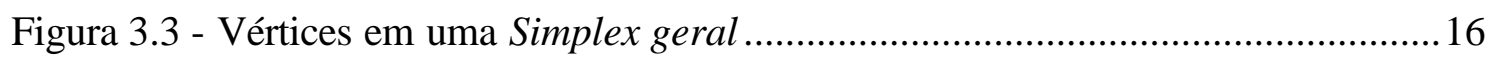

Figura 4.1 - Equipamentos usados na coleta de dados de campo e na alteração do comportamento das redes hidráulicas de Guariba e Itirapuã: (a)Medidor de vazão eletromagnético, (b)Válvula reguladora de pressão-VRP, (c)Medidor de nível ultrasônico, (d)Registro de gaveta, (e)Inversor de freqüência, (f) Calibrador de sinais eletrônicos de tensão e corrente, datalogger e um manômetro padrão de 0-100 $\mathrm{mH}_{2} \mathrm{O} .32$ Figura 4.2 - Fluxograma do processo iterativo proposto para avaliação hidráulica e determinação do fator de consumo para cada padrão (cenário) de demanda. SOARES (2003)

Figura 4.3 - Fluxograma do processo de calibração com os AGs. SOARES (2003)......41 Figura 4.4 - Fluxograma do processo de calibração com o modelo híbrido. SOARES (2003)

Figura 4.5 - Tela principal de geração de relatórios de pesquisa do software HydroControl

Figura 4.6 - Exemplo de disposição das quadras e posição das numerações residenciais

Figura 4.7 - Tela de operação e monitoramento do sistema de Guariba .50

Figura 4.8 - Tela de operação e monitoramento do sistema de Itirapuã 51

Figura 5.1. Esquema de posicionamento dos medidores eletromagnéticos e Dataloggers de pressão na rede de distribuição de água da cidade de Guariba 55 Figura 5.2. Comportamento da vazão e pressão na entrada do setor Zona Baixa coletados a montante da VRP

Figura 5.3 - Dispersão vazão x pressão na entrada do setor Zona Baixa coletados a montante da VRP 57

Figura 5.4 - Comportamento da vazão e pressão na entrada do setor Zona Média .57

Figura 5.5 - Dispersão vazão x pressão na entrada do setor Zona Média 58 
Figura 5.6 - Comportamento da vazão e pressão na entrada do setor Zona Alta I ........ 59

Figura 5.7 - Dispersão vazão x pressão na entrada do setor Zona Alta I ...................... 59

Figura 5.8 - Esquema de posicionamento de equipamentos usados na monitoração da rede de distribuição de água da cidade de Itirapuã

Figura 5.9 - Comportamento da vazão e pressão na entrada do setor de abastecimento de

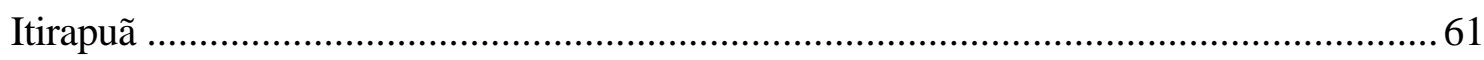

Figura 5.10 - Dispersão vazão x pressão na entrada do setor de abastecimento de Itirapuã 61

Figura 5.11 - Fotos da caixa de inspeção construída na entrada do setor ZM 62

Figura 5.12 - Registro de pressão e vazão na entrada do setor Zona Baixa à jusante da válvula reguladora de pressão. 63

Figura 5.13 - Esquema de ligação elétrica do sistema de monitoramento de pressão eletrônico. 64

Figura 5.14 - Registro de pressão e vazão na entrada da rede do setor Zona Média .....64

Figura 5.15 - Registro de pressão e vazão na entrada do setor Zona Alta I.................... 65

Figura 5.16 - Registro de pressão e vazão na entrada do setor Zona Alta I................... 66

Figura 5.17 - Registro de pressão e vazão na entrada do setor Zona Alta I. 67

Figura 5.18 - Setor $\mathbb{Z} \mathbf{M}$ do Sistema de abastecimento da cidade de Guariba no modo gráfico do simulador EPANET. 69

Figura 5.19 - Sistema de abastecimento da cidade de Itirapuã no modo gráfico do simulador EPANET .70

Figura 5.20 - Localização dos padrões de vazão em função do tempo para a cidade de Guariba.... .74

Figura 5.21 - Localização dos padrões de vazão em função do tempo para a cidade de Itirapuã .76

Figura 5.22 - Localização do nó na rede de distribuição de água da cidade de Guariba82 Figura 5.23 - Pressões simuladas e observadas para o padrão 1 (AG Geracional Elitista)

Figura 5.24 - Pressões simuladas e observadas para o padrão 2 (AG Geracional Elitista) 86

Figura 5.25 - Pressões simuladas e observadas para o padrão 3 (AG Geracional Elitista)

Figura 5.26 - Pressões simuladas e observadas para o padrão 4 (AG Geracional Elitista) 
Figura 5.27 - Vazões simuladas e observadas para os diversos padrões (AG Geracional Elitista) 88

Figura 5.28 - Pressões simuladas e observadas para o padrão 1 (AG Steady-State).......89

Figura 5.29 - Pressões simuladas e observadas para o padrão 2 (AG Steady-State)....... 90

Figura 5.30 - Pressões simuladas e observadas para o padrão 3 (AG Steady-State)....... 90

Figura 5.31 - Pressões simuladas e observadas para o padrão 4 (AG Steady-State).......91

Figura 5.32 - Vazões simuladas e observadas para os diversos padrões (AG SteadyState). .92

Figura 5.33 - Pressões simuladas e observadas para o padrão 1 (AG Geracional Elitista) para populações iniciais distintas de soluções

Figura 5.34 - Pressões simuladas e observadas para o padrão 2 (AG Geracional Elitista) para populações iniciais distintas de soluções

Figura 5.35 - Pressões simuladas e observadas para o padrão 3 (AG Geracional Elitista) para populações iniciais distintas de soluções

Figura 5.36 - Pressões simuladas e observadas para o padrão 4 (AG Geracional Elitista) para populações iniciais distintas de soluções

Figura 5.37 - Pressões simuladas e observadas para o padrão 1 (AG Steady-State) para populações iniciais distintas de soluções . .98

Figura 5.38 - Pressões simuladas e observadas para o padrão 2 (AG Steady-State) para populações iniciais distintas de soluções 99

Figura 5.39 - Pressões simuladas e observadas para o padrão 3 (AG Steady-State) para populações iniciais distintas de soluções

Figura 5.40 - Pressões simuladas e observadas para o padrão 4 (AG Steady-State) para populações iniciais distintas de soluções 101

Figura An.1 - Planta da Cidade de Guariba.

Figura An.2 - Planta do setor Zona Alta I de Guariba. 114

Figura An.3 - Planta do setor Zona Alta II de Guariba. 115

Figura An.4 - Planta do setor Zona Baixa de Guariba. 116

Figura An.5 - Planta do setor Zona Média de Guariba. 117

Figura An.6 - Planta da Cidade de Itirapuã..... 121

Figura Ap.1 - Curvas de nível respectivas ao setor Zona Média de Guariba. 131

Figura Ap.2 - Representação 3D da topografia do setor Zona Média de Guariba........131

Figura Ap.3 - Curvas de nível respectivas à cidade de Itirapuã. 132

Figura Ap.4 - Representação 3D da topografia da cidade de Itirapuã. 132 
Figura Ap.5 - Pressões nos nós 8, 11, 13, 31, 38 e 48 observadas na rede de Guariba 155

Figura Ap.6 - Pressões nos nós 75, 79, 97, 99, 102 e 112 observadas na rede de Guariba. 156

Figura Ap.7 - Pressões nos nós 114, 119, 132, 153, 154 e 169 observadas na rede de Guariba. 157

Figura Ap.8 - Pressões nos nós 178, 193, 195, 198, 203, 208 e 211 observadas na rede de Guariba. 158

Figura Ap.9 - Pressões nos nós 112, 15 e 168 observadas na rede de Itirapuã 161

Figura Ap.10 - Pressões nos nós 80, 149 e 89 observadas na rede de Itirapuã 162

Figura Ap.11 - Pressões nos nós 30, 34 e 122 observadas na rede de Itirapuã 163

Figura Ap.12 - Pressões nos nós 148, 17 e 75 observadas na rede de Itirapuã 164

Figura Ap.13 - Pressão no nó 134 observada na rede de Itirapuã 165

Figura Ap.14 - Curvas das pressões dinâmicas e estáticas observadas em Guariba para os padrões 1,2 e 3 169

Figura Ap.15 - Curvas das pressões dinâmicas e estáticas observadas em Guariba para os padrões 4,5 e 6 . 170

Figura Ap.16 - Curvas das pressões dinâmicas e estáticas observadas em Itirapuã para os padrões 1 e 2 . 173

Figura Ap.17 - Curvas das pressões dinâmicas e estáticas observadas em Itirapuã para os padrões 3 e 4 . .174 


\section{INDICE DE TABELAS}

Tabela 3.1. Quadro resumo dos fatores ? sugeridos pelos diversos autores 24

Tabela 4.1. Comprimento da rede de abastecimento de água em relação à zona de pressão e o material que a compõe para a cidade de Guariba.

Tabela 4.2. Comprimento da rede de abastecimento de água em relação ao material que a compõe para a cidade de Itirapuã

Tabela 5.1 - Valores representativos de vazões e pressões do setor Zona Baixa durante os testes noturnos de vazamento

Tabela 5.2 - Valores representativos de vazões e pressões do setor Zona Média durante os testes noturnos de vazamento

Tabela 5.3 - Valores representativos de vazões e pressões do setor Zona Alta durante os testes noturnos de vazamento . .66

Tabela 5.4 - Rugosidades adotadas para os diversos tipos de materiais de tubulações ..68

Tabela 5.5 - Dias e horários das medidas usadas como padrões na calibração da cidade de Guariba 72

Tabela 5.6 - Valores do nível e carga hidráulica do reservatório; e vazão de entrada observadas no sistema de Guariba .73

Tabela 5.7 - Pressões dinâmicas observadas no sistema de Guariba .73

Tabela 5.8 - Dias e horários das medidas usadas como padrões na calibração da cidade de Itirapuã . .75

Tabela 5.9 - Valores do nível e carga hidráulica do reservatório; e vazão de entrada observadas no sistema de Itirapuã .75

Tabela 5.10 - Pressões dinâmicas observadas no sistema de Itirapuã. .76

Tabela 5.11 - Pressões estáticas nos nós monitorados no setor ZM da cidade de Guariba

Tabela 5.12 - Pressões estáticas nos nós monitorados na cidade de Itirapuã...................78

Tabela 5.13 - Divisão dos setores segundo o material que o compõem...

Tabela 5.14 - Limites de rugosidade absoluta para os municípios de Guariba e Itirapuã

Tabela 5.15 - Limites do coeficiente de perda para os municípios de Guariba e Itirapuã 
Tabela 5.16 - Expoente de perda e demanda total para os municípios de Guariba e Itirapuã 80

Tabela 5.17 - Parametros dos AGs para as simulações da rede de Guariba .80

Tabela 5.18 - Resultado da calibração das pressões do sistema com o modelo de SOARES (2003) para o padrão 2 da rede de Guariba .................................................... 81

Tabela 5.19 - Resultados obtidos em termos dos valores dos parâmetros calibrados.... 81

Tabela 5.20 - Resultados da simulação no EPANET com rugosidades médias dos tubos 83

Tabela 5.21 - Resultados da simulação no EPANET com rugosidades mínimas dos tubos 83

Tabela 5.22 - Parâmetros adotados para os testes de tamanho da população .................. 84

Tabela 5.23 - Valores da função objetivo para diversas simulação ................................. 84

Tabela 5.24 - Desvios entre pressões simuladas e observadas para o padrão 1 (AG

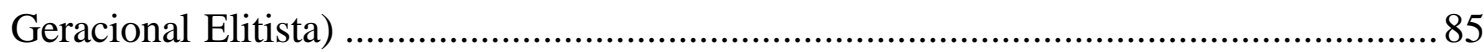

Tabela 5.25 - Desvios entre pressões simuladas e observadas para o padrão 2 (AG Geracional Elitista) 86

Tabela 5.26 - Desvios entre pressões simuladas e observadas para o padrão 3 (AG Geracional Elitista) .86

Tabela 5.27 - Desvios entre pressões simuladas e observadas para o padrão 4 (AG Geracional Elitista) 87

Tabela 5.28 - Desvios entre vazões simuladas e observadas para os diversos padrões (AG Geracional Elitista) 88

Tabela 5.29 - Valores das variáveis de decisão obtidos para simulações com AG geracional elitista 88

Tabela 5.30 - Desvios entre pressões simuladas e observadas para o padrão 1 (AG Steady-State) .89

Tabela 5.31 - Desvios entre pressões simuladas e observadas para o padrão 2 (AG Steady-State) .89

Tabela 5.32 - Desvios entre pressões simuladas e observadas para o padrão 3 (AG Steady-State) 90

Tabela 5.33 - Desvios entre pressões simuladas e observadas para o padrão 4 (AG Steady-State) .91

Tabela 5.34 - Desvios entre vazões simuladas e observadas para os diversos padrões (AG Steady-State) 
Tabela 5.35 - Valores das variáveis de decisão obtidos para simulação com AG Steady State

Tabela 5.36 - Parametrização dos AGs para as simulações alterando sementes aleatórias

Tabela 5.37 - Valores da função objetivo para variação da semente aleatória para as diversas simulações.

Tabela 5.38 - Desvios entre pressões simuladas e observadas para o padrão 1 (AG Geracional Elitista).

Tabela 5.39 - Desvios entre pressões simuladas e observadas para o padrão 2 (AG Geracional Elitista) para populações iniciais distintas de soluções

Tabela 5.40 - Desvios entre pressões simuladas e observadas para o padrão 3 (AG Geracional Elitista) para populações iniciais distintas de soluções .95

Tabela 5.41 - Desvios entre pressões simuladas e observadas para o padrão 4 (AG Geracional Elitista) para populações iniciais distintas de soluções .96

Tabela 5.42 - Resultados obtidos das variáveis de decisão usando AG híbrido (Geracional Elitista + Nelder-Mead).

Tabela 5.43 - Desvios entre pressões simuladas e observadas para o padrão 1 (AG Steady-State) para populações iniciais distintas de soluções . .98

Tabela 5.44 - Desvios entre pressões simuladas e observadas para o padrão 2 (AG Steady-State) para populações iniciais distintas de soluções

Tabela 5.45 - Desvios entre pressões simuladas e observadas para o padrão 3 (AG Steady-State) para populações iniciais distintas de soluções 100

Tabela 5.46 - Desvios entre pressões simuladas e observadas para o padrão 4 (AG Steady-State) para populações iniciais distintas de soluções 101

Tabela 5.47 - Resultados obtidos das variáveis de decisão usando AG híbrido (Steady

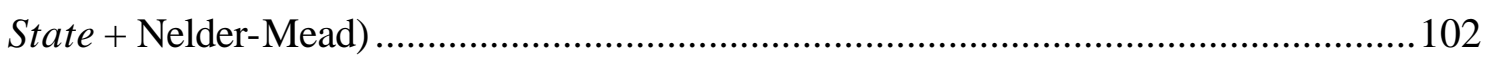

Tabela 5.48 - Simulações variando o parâmetro ? do modelo de vazamentos 103

Tabela 5.49 - Valores observados e simulados para pressões nodais e vazões abastecidas simulação 1 variando o parâmetro ? do modelo de vazamentos 104 Tabela 5.50 - Valores observados e simulados para pressões nodais e vazões abastecidas simulação 2 variando o parâmetro ? do modelo de vazamentos 105 Tabela 5.51 - Valores observados e simulados para pressões nodais e va zões abastecidas simulação 3 variando o parâmetro ? do modelo de vazamentos 106 
Tabela Ap.1 - Características das tubulações da rede do setor Zona Média de Guariba 135

Tabela Ap.2 - Características dos nós da rede do setor Zona Média de Guariba...........142

Tabela Ap.3 - Características das tubulações da rede da cidade de Itirapuã..................147

Tabela Ap.4 - Características dos nós da rede da cidade de Itirapuã............................151 


\section{LISTA DE SÍMBOLOS}

A matriz Jacobiana

a parâmetro de ajuste temporal do número de quebras, coeficiente do modelo pressão x demanda, coeficiente do escalonamento linear

$b \quad$ coeficiente do modelo pressão $\mathrm{x}$ demanda, coeficiente da recombinação aritmética, coeficiente do escalonamento linear

$c \quad$ coeficiente de vazamento, coeficiente do escalonamento

C demanda de consumo

$c_{1} \quad$ coeficiente de vazamento para a rede modelada

$c_{2} \quad$ coeficiente de vazamento para a rede não-modelada

D diâmetro da tubulação

D' demanda (variável de decisão)

$d^{*} \quad$ demanda de referência

$d \quad$ expoente dependente do valor do diâmetro, demanda requerida

$f \quad$ função de aptidão, nó, fator de atrito

$f$ ' função de aptidão com escalonamento

$F \quad$ vetor de balanço de massa

FE fator multiplicador da demanda (correção espacial)

FO função objetivo

FT fator multiplicador da demanda (temporal)

$g$ aceleração da gravidade

$h \quad$ perda de carga total

$H \quad$ carga hidráulica, vetor de incógnitas em termos das cargas hidráulicas

I vetor coeficiente de perda e rugosidade absoluta

ID identificação da tubulação que contém registro

Id número de medidas

$J \quad$ conjunto dos nós conectados a um nó

Jd conjunto de nós com demandas

Jf conjunto de nós com carga hidráulica constante

JS conjunto de nós

$k \quad$ coeficiente auxiliar no cálculo da perda de carga, coeficiente dependente do tipo de material e instalação, instante da simulação, tubulação 
$K \quad$ coeficiente de descarga do orifício, coeficie nte de vazamento no nó, coeficiente de perda de carga localizada

$L \quad$ comprimento da tubulação

Le comprimento equivalente

$\log$ logaritmo

$m$ instante da simulação, coeficiente de perda de carga localizada

M número de tubulações ligadas ao um nó, função do método Simplex

$\max$ maximizar

min minimizar

$N \quad$ número de nós, distribuição normal

$n$ número de variáveis, expoente do modelo pressão x demanda, cromossomos (soluções), número de vértices

NF nós com carga hidráulica fixa

$N P$ número de tubulações da rede, padrão de demanda

$n^{P D} \quad$ número de padrões de demanda observados

$N^{P N} \quad$ número de nós com carga hidráulica desconhecida

$n^{Q} \quad$ número de padrões de demanda com observações de vazão

nvd número total das variáveis de decisão

$n T \quad$ número de registros

$n_{z} \quad$ número de nós com cotas topográficas homogêneas

$n_{\beta} \quad$ número de tubulações com expoentes de vazamento homogêneos

$n_{e} \quad$ número de tubulações com rugosidades absolutas homogêneas

$n$ ? número de tubulações com coeficientes de vazamento homogêneos

$p \quad$ cromossomo pai, média

$P \quad$ pressão

PNA parcela da demanda que não é atendida

$q \quad$ vazamento

$Q \quad$ vazão

$q_{1} \quad$ vazamento na rede modelada

$q_{2} \quad$ vazamento na rede não-modelada

$\bar{q}_{1} \quad$ vazamento médio para a rede modelada

$q_{2} \quad$ vazamento médio para a rede não-modelada 
$Q_{c} \quad$ vazão abastecida total

$Q_{d} \quad$ demanda efetivamente abastecida

$Q_{s} \quad$ vazão injetada controlada

$R \quad$ conjunto dos nós conectados a um nó, coeficiente de resistência da tubulação

$r \quad$ termo constante da equação de perda de carga distribuída

$R^{0}(V i j)$ perda localizada de uma válvula

$s \quad$ cromossomo filho

sen seno

sgn sinal

$T$ número de intervalos na simulação

TD demanda total efetivamente abastecida

TDP demanda potencial total

TS vazão total abastecida

$T S^{*} \quad$ demanda total de referência

$v \quad$ vazamento, velocidade

$V \quad$ vazamento total, válvula

$V k \quad$ abertura da válvula

$w^{P} \quad$ peso atribuído às pressões observadas

$w^{Q} \quad$ peso atribuído às vazões observadas

$z \quad$ cota topográfica

Z função objetivo, conjunto de variáveis de decisão, valor do evento

$a$ coeficiente função do diâmetro, auxiliar no intervalo de variação

$\beta \quad$ expoente de perda por vazamento

? expoente do modelo pressão x demanda

? desvio

.h perda de carga distribuída

.$H \quad$ perda de carga localizada

d vetor auxiliar

$d_{l} \quad$ coeficiente de análise da pressão no nó

$e \quad$ rugosidade absoluta da tubulação

? coeficiente de perda por vazamento

? coeficiente auxiliar no cálculo da rugosidade relativa

$\mu \quad$ coeficiente de reflexão

$p \quad$ número pi, coeficiente de proporção de vazamento 
$p_{1} \quad$ porcentagem de vazamento na rede modelada

$p_{2} \quad$ porcentagem de vazamento na rede não-modelada

? fator multiplicador do modelo pressão $\mathrm{x}$ demanda

$s \quad$ desvio padrão

$S \quad$ somatório

$t \quad$ idade da tubulação

? coeficiente de contração

? coeficiente de expansão

? pertence

\section{Subscritos}

$i$ nó, tubulação, gene, solução (cromossomo), vértice, variável de decisão

j nó, tubulação, gene

$n \quad$ vértices

$t$ padrão de consumo

\section{Sobrescritos}

- $\quad$ valor médio

* valor observado

av valor médio

C contração

des desejável

exp expoente do operador escalonamento

E expansão

$H \quad$ vértice com maior valor da função objetivo

$L \quad$ vértice com o menor valor da função objetivo

máx máximo

mín mínimo

$n \quad$ expoente da fórmula de perda de carga

$s \quad$ setor da rede

$S \quad$ vértice com o segundo maior valor da função objetivo 


\section{SUMÁRIO}

1. INTRODUÇÃ

2 OBJETIVOS ........................................................................................................

3 REVISÃO BIBLIOGRÁFICA...................................................................

3.1 MÉTODOS DECALIBRAÇÃO....................................................................

3.2 FERRAMENTAS DEOTIMIZAÇÃO .......................................................

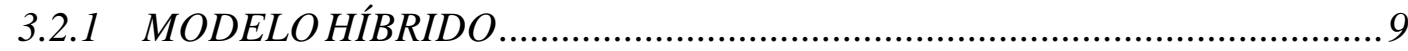

3.2.2 ALGORITMOS GENÉTICOS............................................................

3.2.2.1 OPERADORES GENÉTICOS ………………….......................... 12

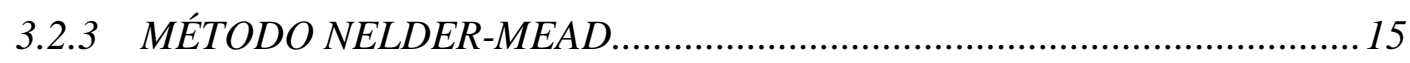

3.3 OS VAZAMENTOS E A MODELAGEM ……………….............................

3.3.1 OS VAZAMENTOS ............................................................................. 17

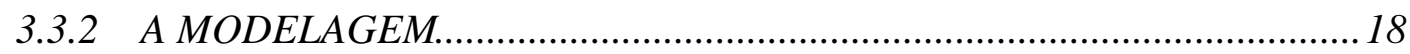

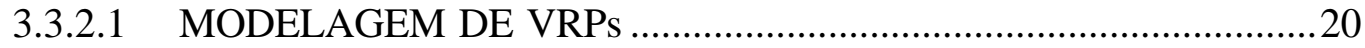

3.3.3 MODELOS DE VAZAMENTO E DEMANDA VARIÁVEL COM A

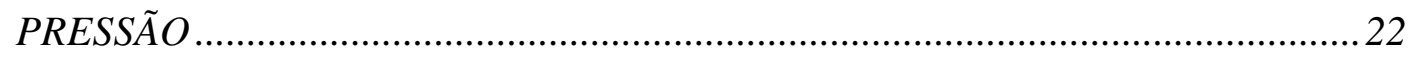

3.3.4 A PROBLEMÁTICA DA LOCALIZAÇÃO DOS PONTOS DE

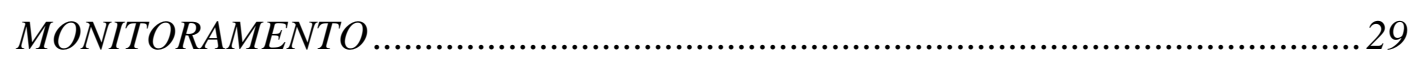

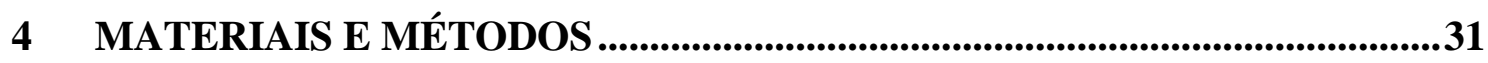

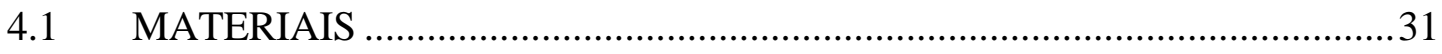

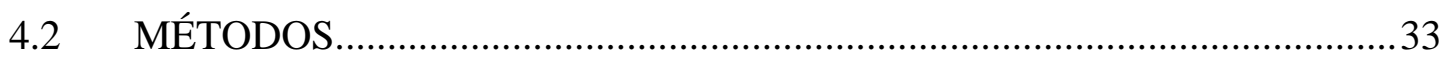

4.2.1 DESCRIÇÃO DO MODELO INVERSO DE SOARES (2003).....................33

4.2.2 MODELO DE SIMULAÇÃO HIDRÁULICA ………………………............

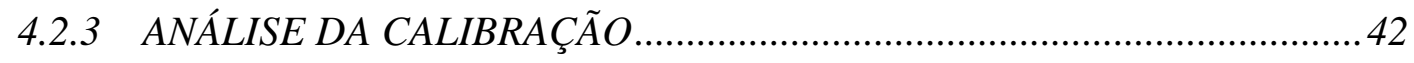

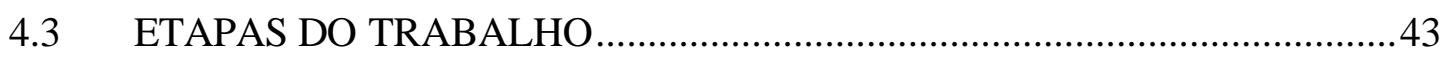

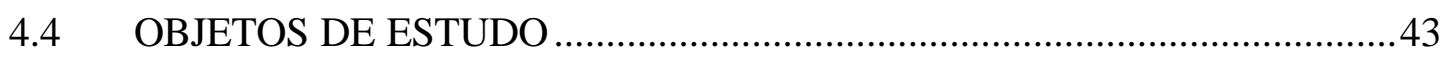

4.4.1 PRIMEIRO SISTEMA ESTUDADO......................................................43

4.4.1.1 CARACTERÍSTICAS GERAIS DA CIDADE DE GUARIBA .........44

4.4.1.2 DESCRIÇÃO DO SISTEMA DA CIDADE DE GUARIBA ...............44

4.4.2 SEGUNDO SISTEMA ESTUDADO....................................................... 
4.4.2.1 CARACTERÍSTICAS GERAIS DA CIDADE DE ITIRAPUÃ........ 45

4.4.2.2 DESCRIÇÃO DO SISTEMA DA CIDADE DE ITIRAPUÃ ............. 46

4.4.3 LEVANTAMENTO DOS DADOS EXISTENTES .................................... 47

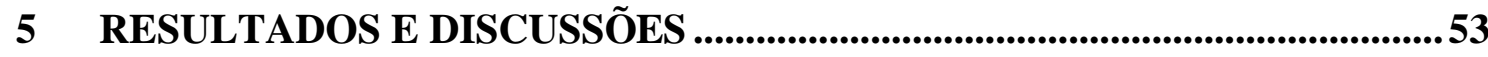

5.1 DELIMITAÇÕES DAS ZONAS DE PRESSÃO PARA A CIDADE DE

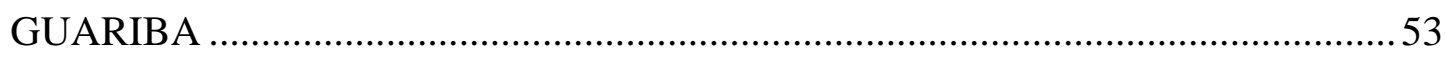

5.1.1 MONITORAMENTO DE PRESSÕES E VAZÕES NA ENTRADA DOS

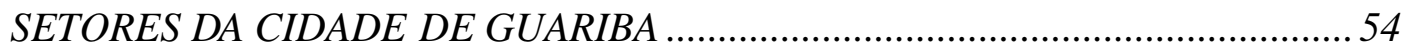

5.1.2 MONITORAMENTO DE PRESSÕES E VAZÕES NA ENTRADA DO

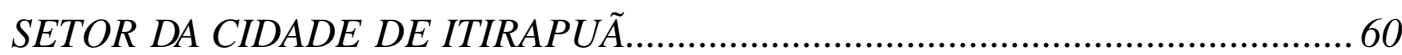

5.2 TESTES NOTURNOS DE VAZAMENTOS …............................................. 61

5.3 ANÁLISE DETALHADA (CALIBRAÇÃO) DOS MODELOS ..................... 67

5.3.1 CONSTRUÇÃO DO SISTEMA HIDRÁULICO A TRATAR ........................ 68

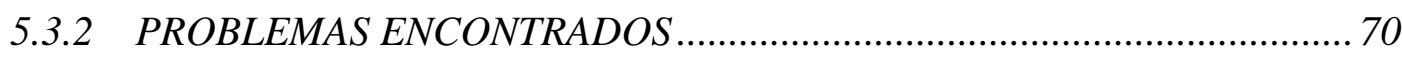

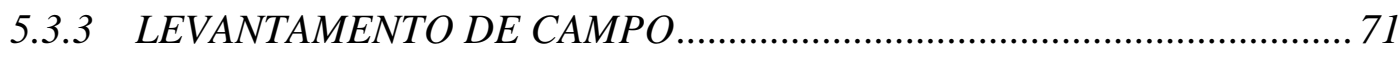

5.3.3.1 VERIFICAÇÃO DA CONSISTÊNCIA DOS DADOS DE CAMPO 76

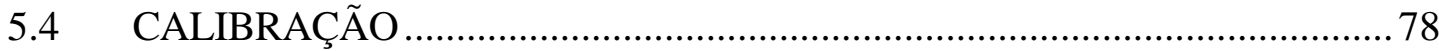

5.4.1 RESULTADOS DA CALIBRAÇÃO DA REDE DE GUARIBA …............... 80

5.4.2 RESULTADOS DA CALIBRAÇÃO DA REDE DE ITIRAPUÃ .................. 83

5.4.2.1 TAMANHO DA POPULAÇÃO DE SOLUÇÕES ........................... 84

5.4.2.2 POPULAÇÃO DE SOLUÇÕES INICIAIS (DISTINTAS SEMENTES

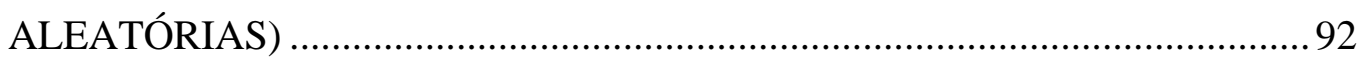

5.4.2.3 PARÂMETRO ? DO MODELO DE VAZAMENTOS .................... 102

6 CONCLUS ÕES E RECOMENDAÇÕES ................................................ 107

ANEXO A - ILUSTRAÇÃO DA CIDADE E DOS SETORES DE GUARIBA.... 111

ANEXO B - ILUSTRAÇÃO DA CIDADE DE ITIRAPUÃ ..................................... 119

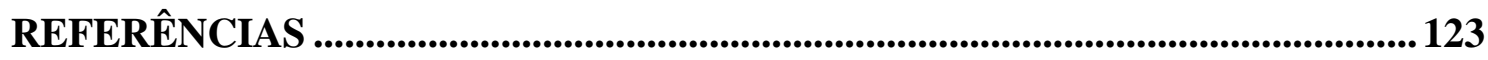

APÊNDICE A - CURVA DE NÍVEL E REPRESENTAÇÃO GRÁFICA 3D DO SETOR ZONA MÉDIA DE GUARIBA E ITIRAPUÃ ..................................... 129

APÊNDICE B - INFORMAÇÕES DA SETORIZAÇÃO REDE DE ABASTECIMENTO DE ÁGUA DA CIDADE DE GUARIBA............................... 133 
APÊNDICE D - GRÁFICOS DAS PRESSÕES OBSERVADAS NO SETOR ZONA MÉDIA DE GUARIBA ..............................................................................153

APÊNDICE E - GRÁFICOS DAS PRESSÕES OBSERVADAS NOS NÓS DA CIDADE DE ITIRAPUÃ...............................................................................159

APÊNDICE F - CURVAS DOS PADRÕES DE PRESSÃo OBSERVADAS E ESTÁTICAS DA CIDADE DE GUARIBA ................................................................167

APÊNDICE G - CURVAS dOS PADRÕES DE PRESSÃo OBSERVADAS E ESTÁTICAS DA CIDADE DE ITIRAPŨ̃ 171 



\section{INTRODUÇÃO}

Do ponto de vista da sustentabilidade dos recursos hídricos, o controle das perdas por vazamento deve constituir foco de atenção em qualquer sistema de abastecimento de água. Dessa maneira, grande interesse vem sendo demonstrado em ampliar os conhecimentos sobre os vazamentos, suas causas e maneiras de exercer um controle efetivo sobre os mesmos.

Deve-se admitir que os conhecimentos em torno do assunto são escassos, porém suficientes para que se afirme que não há rede estanque, em função de haver um limite para que o controle dos vazamentos possa ser considerado economicamente viável. Assim, tem-se tentado minimizar o problema de ocorrência dos vazamentos, reduzindoos a níveis considerados aceitáveis, através do monitoramento das pressões no interior dos sistemas de distribuição de água para abastecimento. Uma das maneiras mais usuais de fazê-lo é por meio do emprego de válvulas redutoras de pressão, as quais visam o rebaixamento do plano piezométrico das redes durante períodos em que o consumo é pequeno e a pressão excessiva faz com que as fugas sejam elevadas. Essa é uma providência que as concessionárias de água têm tomando com sucesso considerável, por saber que os vazamentos são função da pressão atuante no interior de tais sistemas, apesar de desconhecer o comportamento exato dessa função. Acredita-se, portanto, que, mesmo com o relativo sucesso obtido com a implantação das válvulas redutoras de pressão (VRP) nos sistemas de abastecimento, melhor desempenho pode ser obtido se tais dispositivos forem devidamente ajustados e localizados. Mas, tal objetivo só pode ser alcançado se houver maior conhecimento do comportamento hidráulico dos sistemas.

Vários pesquisadores vêm estudando o problema de reprodução fiel do comportamento hidráulico das redes de distribuição de água para abastecimento, evidenciando a necessidade de considerar tanto os vazamentos como as demandas variáveis com a pressão nos modelos de simulação hidráulica. Assim, a literatura apresenta modelos alternativos para expressar tais relações, sem que haja um consenso sobre o tema. 
O presente projeto de pesquisa visa realizar um estudo do problema, tomando sistemas de distribuição em que as perdas por vazamento são expressivas e há necessidade de uma avaliação mais detalhada do seu comportamento. 


\section{OBJETIVOS}

Define-se como objetivo do presente trabalho de pesquisa a realização de um estudo do comportamento de sistemas de abastecimento de água, enfocando as perdas por vazamento, compreendendo:

-o estudo das vazões noturnas dos diversos setores que compõem o sistema de abastecimento de água da cidade de Guariba, identificando, assim, o mais crítico deles para estudo;

-a modelagem do setor identificado como mais crítico da cidade de Guariba e também a modelagem da rede de abastecimento de água da cidade de Itirapuã;

- a coleta de dados de pressão e vazão dos setores estudados por meio de equipamentos eletrônicos instalados durante visitas realizadas às cidades;

-a utilização do software desenvolvido por Soares (SOARES, 2003) que contempla vazamentos e demanda variável com a pressão de maneira iterativa, alimentando-o com os dados coletados em campo;

-a calibração dos modelos em questão, reproduzindo comportamentos dinâmicos, em conformidade com as variações operacionais a que os mesmos foram submetidos, visando identificar uma estratégia de redução de suas perdas;

-a proposição de medidas que auxiliem na redução de perdas por vazamento nas redes de abastecimento de água das cidades de Guariba e Itirapuã. 


\section{REVISÃO BIBLIOGRÁFICA}

A revisão bibliográfica aqui desenvolvida versará sobre os métodos de calibração, ferramentas de otimização utilizadas para esse fim e a modelagem hidráulica incluindo vazamentos e demandas variáveis com a pressão.

\subsection{MÉTODOS DE CALIBRAÇÃO}

A determinação dos parâmetros do modelo de simulação de um sistema, também chamada calibração do modelo, é um processo que visa à obtenção de resultados de simulação do comportamento da rede o mais próximo possível dos valores observados.

De acordo com Walsky (1986) o processo de calibração consiste de duas etapas: (1) comparar valores simulados e observados nas mesmas condições de operação do sistema e (2) ajustar os parâmetros de entrada do modelo, a fim de obter a melhor concordância entre dados simulados e observados. Segundo o autor, um modelo pode ser considerado calibrado, para uma condição específica de operação, se ele puder prever vazões e pressões com razoável precisão, embora ele próprio tenha encontrado divergência na literatura sobre os critérios de avaliação da precisão a partir dos quais um modelo possa ser considerado calibrado.

Com o intuito de conhecer os processos de calibração disponíveis e escolher o procedimento mais adequado ao desenvolvimento do presente trabalho de pesquisa, foi realizada uma pesquisa bibliográfica. Alguns dos trabalhos examinados são brevemente discutidos a seguir.

Basicamente os métodos de calibração podem ser classificados em iterativos, explícitos (também conhecidos como analíticos ou diretos) e implícitos (ou inversos).

\section{Método Iterativo}

No processo iterativo a calibração é baseada na tentativa e erro, ou seja, parâmetros de calibração são ajustados a cada iteração usando comparações entre pressões e vazões medidas e simuladas. 
O método de calibração iterativo foi foco de estudo para WALSKY (1983) e BHAVE (1988).

O trabalho de WALSKY (1983) foi um dos pioneiros no assunto, e abordou análise de sensibilidade e critérios para avaliar a precisão da calibração de modelos, especialmente com respeito ao coeficiente C de Hazen-Wiliams, salientando a importância da coleta de dados em condições normais e extremas de operação da rede.

\section{Método explícito (analítico ou direto)}

O método explícito, como o próprio nome já diz, traz o resultado da calibração diretamente, sem uso das iterações. Isso é feito por meio da resolução de um conjunto de equações que descrevam com maior fidelidade o comportamento hidráulico da rede. A desvantagem é que não se trata de um procedimento geral, ou seja, cada problema deve ser tratado com as suas peculiaridades e, portanto, constitui um problema diferente.

Em 1986, Walski procurou demonstrar que é possível calibrar um modelo complexo com precisão, desde que se disponha de dados de boa qualidade. Embora isto pareça óbvio, o autor sustenta que muitos modelos podem apresentar aparente calibração precisa, apenas porque não foram testados em uma maior diversidade de condições de operação. Ele aplicou seu método a uma rede composta por 307 trechos, 271 nós, 9 válvulas redutoras de pressão e 6 reservatórios, localizada em Oneonta, New York. O autor salienta que especial atenção com relação à coleta de dados é necessária, tanto em condições normais de uso quanto durante testes de hidrante e, preferencialmente, em períodos curtos o suficiente para que as condições de contorno sejam constantes.

De acordo com BHAVE (1988), a calibração de redes de distribuição de água é importante para prever seu funcionamento sob diferentes condições de operação, e também para planejar expansões na rede. Segundo o autor, entre os dados utilizados para a calibração, as demandas nodais e os coeficientes de rugosidade são os que apresentam maior imprecisão, e são geralmente ajustados por tentativa e erro. No trabalho, o autor apresenta um método iterativo baseado na proposta de WALSKI (1983) para o ajuste destes dois parâmetros. O método proposto apresentou bons resultados para o sistema analisado, embora não seja adequado para análise do 
comportamento de um único nó ou tubulação individual, o que também ocorre para outros métodos de calibração.

ORMSBEE e WOOD (1986), BOULOS e WOOD (1990) e ULANICKI et al (2000) descrevem experiências com parametrização de modelos hidráulicos por meio do método de calibração explícito.

Em 1986, ORMSBEE e WOOD apresentaram uma metodologia geral para projeto de redes de distribuição de água, específica para determinadas aplicações. Eles também se basearam no método de WALSKI (1983), no entanto desenvolveram um método de calibração baseado na solução de um sistema não linear de equações de conservação de massa e energia na rede de distribuição, com base no diâmetro e na vazão, utilizando método de Newton Raphson.

BOULOS e WOOD (1990) apresentaram um algoritmo para a determinação direta de parâmetros, baseado na reformulação das equações de equilíbrio no regime permanente em termos de parâmetros específicos do sistema. Eles também utilizaram o método de Newton Raphson para a resolução do sistema não linear de equações. O procedimento visa eliminar a necessidade de tentativas sucessivas de ajuste e fornecer um meio eficiente para a modelagem em tempo real.

Acreditando na eficácia do método explícito, ULANICKI et al (2000) apresentam um modelo de vazamentos para formular e investigar métodos de planejamento e implementação de estratégias de controle de previsões de vazamentos em áreas com grande concentração de VRPs e outros pontos alvos.

O terceiro método, mais comumente usado na determinação de parâmetros de calibração de sistemas de abastecimento, é o processo inverso, ou método implícito, que consiste na minimização do erro entre valores simulados e observados, através de otimização. Como geralmente os resultados dos modelos de simulação hidráulica de redes são expressos em termos dos valores das variáveis de estado pressão e vazão, o método inverso de otimização é aplicado à determinação dos parâmetros do sistema, tais como rugosidades, diâmetros, demandas, etc., de maneira a minimizar os desvios entre os valores observados e os correspondentes valores simulados das referidas variáveis. A vantagem do método inverso é que se trata de um procedimento geral, que pode calibrar quantas variáveis fizerem-se necessárias. A dificuldade é que, quanto maior for o número de variáveis, maior será o grau de indeterminação do problema. 
Método implícito ( ou inverso)

REDDY, SRIDHARAN e RAO (1996) fazem uso do método inverso através da técnica de minimização Gauss-Newton como forma de estimar parâmetros em redes de distribuição de água. Elementos de resistência, coeficiente de Hazen-Williams e consumos são os parâmetros considerados pelos autores. Para as medições, REDDY, SRIDHARAN e RAO (1996) consideram as pressões nos nós, vazões dos tubos, perda de carga nos tubos e as vazões de entrada. Os resultados do trabalho mostram que medições incorretas, se houver, podem ser identificadas e removidas dos dados de entrada, e o problema pode ser resolvido novamente usando pesos baseados na variância do erro para obter limites confiáveis dos parâmetros.

Outro exemplo do uso do método implícito para calibração de modelos de redes hidráulicas é proposto por GRECO e GIUDICE (1999). O trabalho demonstra o ajuste das rugosidades dos tubos através de simulações tendo como base os valores observados no campo. Os autores aplicam o algoritmo em uma rede exemplo e o resultado da calibração da rede é testado para diferentes condições operacionais. Os resultados de alguns testes demonstraram a habilidade e bom desempenho do modelo para diferentes casos.

TODINI (1999) apresentou uma técnica para estimar coeficientes de rugosidade não conhecidos em redes de distribuição de água, a partir de supostos valores. A formulação apresentada converte o problema em um problema de estimação linear utilizando o Filtro de Kalman. TODINI (1999) descreve que as condições observadas para este Filtro de Kalman sustentam que um número suficiente de ajustes independentes para observações em regime permanente é feito, obtendo a solução mais próxima dos valores supostos inicialmente satisfazendo as restrições de cargas piezométricas.

Um trabalho mais atual, no que diz respeito à identificação de vazamentos em redes de distribuição de água fazendo uso do modelo inverso, é proposto por HOLNICKI-SZULC, KOLAKOWSKI e NASHER (2005). Os autores assumem que as cargas hidráulicas dos nós da rede podem ser medidas em diferentes localizações da área de inspeção. Assim, fazendo uso de um modelo hidráulico e utilizando o proposto método de distorção virtual, vazamentos podem ser detectados e identificados no sistema. Os autores ainda citam que a metodologia de identificação adotada por eles leva vantagem sobre a técnica de otimização baseada no gradiente. 


\subsection{FERRAMENTAS DE OTIMIZAÇÃO}

Pelas razões já mencionadas, a calibração implícita constitui o procedimento mais usual e foi também utilizada no desenvolvimento deste trabalho. Assim, a minimização dos desvios entre valores de pressão e vazão observados e simulados via modelo hidráulico impõe o uso de uma técnica de otimização por busca direta, por tratar-se de problema irrestrito. O processo de otimização por busca direta consiste no aprimoramento sucessivo das soluções, visando satisfazer o objetivo do problema. Com o objetivo de agilizar o processo de otimização, ou seja, de busca da solução ótima, novas ferramentas matemáticas têm sido propostas. As principais classes de métodos de otimização são: Gerar-e-Testar ou Método de Busca Aleatória, Métodos Analíticos, Subida de Encosta e os algoritmos estocásticos de busca, dentre os quais os Algoritmos Genéticos (AGs) são os mais conhecidos (SOARES (2003)).

\subsubsection{MODELO HÍBRIDO}

SOARES (2003) optou por utilizar um modelo híbrido, que consiste da combinação de dois métodos de busca direta, com o objetivo de diminuir o tempo computacional e a eficiência do modelo de otimização. O motivo é que os AGs apresentam a característica de serem eficazes na avaliação do espaço de soluções, porém são lentos e oscilam em torno da solução ótima. Para suprir esta deficiência, o método Nelder-Mead foi utilizado. De maneira geral, o modelo híbrido utiliza os AGs como ponto de partida em um número determinado de gerações para que o espaço de busca seja "varrido". Em seguida utilizar o método Nelder-Mead para a parte final do processo, poupando tempo computacional e melhorando a precisão dos resultados.

Os tópicos seguintes são dedicados ao detalhamento dos dois métodos usados por SOARES (2003) em seu modelo híbrido; os AGs e Nelder-Mead.

\subsubsection{ALGORITMOS GENÉTICOS}

Os Algoritmos Genéticos (AGs) são exemplos clássicos de técnicas de programação evolucionária inspiradas nos mecanismos de evolução de populações de seres vivos. Desenvolvido na Alemanha por RECHENBERG (1973), em paralelo com HOLLAND (1975) e popularizado por GOLDBERG (1989), estes algoritmos seguem o 
princípio da seleção natural e sobrevivência do mais apto, conceito introduzido pelo naturalista e fisiologista Charles Darwin em 1859. De acordo com a literatura revisada (GOLDBERG (1989); MICHALEWICZ (1994); LACERDA e CARVALHO (1999); SOARES (2003)), pode-se descrever os termos dos AGs da seguinte forma:

Cromossomo e Genoma: têm o mesmo significado e representam a estrutura de dados que codifica uma solução para um problema, ou seja, representam um simples ponto no espaço de busca.

Gene: é um parâmetro codificado no cromossomo, ou seja, um elemento do vetor que representa o cromossomo.

Alelo: representa os valores que um gene pode assumir.

Indivíduo: é um simples membro da população, formado pelo cromossomo e sua aptidão.

Genótipo: representa a informação contida no cromossomo ou genoma (composição genética contida no genoma).

Fenótipo: representa o objeto, estrutura ou organismo construído a partir das informações do genótipo. É o cromossomo decodificado.

Epistasia: interação entre genes do cromossomo, isto é, quando o valor de um gene influencia o valor de outro.

Elitismo: se baseia na transferência do melhor cromossomo de uma geração para outra sem alterações, foi implantado por DeJong em 1975 por perceber que o melhor cromossomo pode ser perdido devido à aplicação dos operadores recombinação e mutação. A utilização do elitismo no AG faz com que o Algoritmo encontre a solução mais rapidamente do que quando o elitismo não é utilizado.

Um Algoritmo Genético típico consiste primeiramente da geração de uma população inicial de cromossomos, formada integralmente por cromossomos aleatórios. No processo evolutivo, a população inicial gerada é avaliada de acordo com o espaço de busca definido pelas configurações do cromossomo. Assim, cada cromossomo recebe uma nota (aptidão), de acordo com qualidade da solução que ele representa. Então, os cromossomos mais aptos são selecionados e os menos aptos são descartados. É possível ainda fazer com que os cromossomos selecionados sofram modificações em suas características fundamentais para que descendentes de uma próxima geração sejam criados. Isto é feito através dos operadores seleção (crossover), reprodução e mutação. Em geral, este processo é repetido até que uma solução satisfatória seja encontrada. 
WU e SIMPSON (1999) apresentam um exemplo de aplicação de algoritmo genético para uma otimização de projeto e reabilitação de um sistema de distribuição de água. O trabalho emprega um competente algoritmo de genética evolucionária, classificado como algoritmo genético messy, que garante a eficiência do processo de otimização. Os resultados obtidos mostram que o número de tentativas de projetos requerido pelo algoritmo genético messy é consistentemente menor do que para outros algoritmos genéticos.

VÍTKOVSKÝ, SIMPSON e LAMBERT (2000) também usam AGs para detecção de vazamentos e calibração. Eles comentam que a maior incerteza no desenvolvimento de modelos computacionais é a condição do interior do tubo na rede de distribuição, especialmente se elas forem velhas. O trabalho usa técnicas de AG em conjunto com o método de transiente inverso para detectar vazamentos e coeficientes de atrito no sistema de distribuição de água. Como resultado, o trabalho mostra que o método de transiente inverso usando a técnica do algoritmo genético é eficaz na busca da localização e magnitude do vazamento enquanto simultaneamente busca os fatores de atrito para diferentes comprimentos de dados de transientes.

Segundo Zyl, Savic e Walters (2004, p. 160) "Os algoritmos genéticos têm características de convergência inicial boas, mas uma convergência consideravelmente baixa dentro da região de soluções ótimas identificada.". No intuito de suprir esta deficiência, ZYL, SAVIC E WALTERS (2004) melhoram a eficiência da otimização operacional do AG através de um método híbrido que combina o método AG com uma estratégia de busca hillclimber. A função da estratégia hillclimber é complementar ao AG no que diz respeito a eficiência em encontrar um ótimo local. Os autores descrevem que, depois de aplicar os dois métodos para um problema teste e para vários sistemas de distribuição de água, o método híbrido prova ser superior ao AG puro por encontrar uma boa solução rapidamente.

SOARES (2003) empregou o método de Nelder-Mead para refinar as soluções obtidas por AG com sucesso.

Segundo GOLDBERG (1989), os AGs apresentam quatro principais vantagens em relação a outros métodos de otimização e processos de busca: buscam a partir de uma população de pontos e não a partir de um simples ponto; usam regras de transição probabilísticas e não determinísticas; trabalham com a codificação dos parâmetros e não com os parâmetros propriamente ditos; e usam informações da função objetivo diretamente e não das derivadas. Mas, a literatura reporta tentativas de sucesso no 
aprimoramento das soluções apontadas pelo AG através de algoritmos de busca clássicos como os do tipo hillclimber.

Porém, muitas outras vantagens podem ser citadas em relação aos Algoritmos Genéticos sobre os métodos de busca direta convencionais. Não é necessário conhecimento matemático complexo, sendo de fácil implementação; são capazes de otimizar um número grande de variáveis, trabalhando com funções objetivo com superfícies complexas, reduzindo a incidência de mínimos ou máximos locais; adaptamse bem a técnicas de computação paralela; fornecem uma gama de parâmetros ótimos e não uma simples solução; pode-se aplicar a hibridização facilmente com outras técnicas, e tem a característica de "varrer" o espaço de soluções de maneira eficaz quando o número de variáveis de decisão do problema é grande.

Porém, os AGs apresentam uma grande desvantagem. Apesar de serem eficazes na avaliação do espaço de soluções, são lentos e oscilam em torno da solução ótima.

\subsubsection{OPERADORES GENÉTICOS}

Três são os operadores genéticos disponíveis na biblioteca GAlib $C++$ : recombinação, seleção e mutação.

Recombinação pode ser realizada por meio dos Operadores Convencionais ou Operadores Aritméticos.

Os Operadores Convencionais são os mais conhecidos e são formados pelos operadores de recombinação de $n$ pontos e uniforme. Na recombinação de $n$ pontos, os tipos disponíveis na biblioteca são o de um ponto e o de dois pontos. O procedimento destes operadores é "cortar" os cromossomos pais em uma (Figura 3.1) ou duas posições aleatórias (Figura 3.2) para recombinação de um ponto e de dois pontos respectivamente. O resultado é recombinado, gerando dois novos cromossomos chamados filhos. A probabilidade da recombinação pode variar, a cada par de cromossomos selecionado, entre 70 e $100 \%$ na prática. 
Ponto de Recombinação

\begin{tabular}{ll|l|l|l|l|} 
& \multicolumn{2}{c|}{} & \multicolumn{3}{c|}{} \\
Pai $_{1}$ & 2,345 & 0,359 & 5,010 & 7,993 & 3,597 \\
Pai $_{2}$ & 1,184 & 4,421 & 6,253 & 0,011 & 8,571 \\
\hline & \multicolumn{4}{|c|}{} \\
Filho $_{1}$ & 2,345 & 0,359 & 6,253 & 0,011 & 8,571 \\
\hline Filho $_{2}$ & 1,184 & 4,421 & 5,010 & 7,993 & 3,597 \\
\hline
\end{tabular}

Figura 3.1 - Recombinação de um ponto - simples troca

Ponto de Recombinação Ponto de Recombinação

\begin{tabular}{|c|c|c|c|c|c|}
\hline $\mathrm{Pai}_{1}$ & 2,345 & 0,359 & 5,010 & 7,993 & 3,597 \\
\hline $\mathrm{Pai}_{2}$ & 1,184 & 4,421 & 6,253 & 0,011 & 8,571 \\
\hline Filho $_{1}$ & 2,345 & 0,359 & 6,253 & 0,011 & 3,597 \\
\hline Filho $_{2}$ & 1,184 & 4,421 & 5,010 & 7,993 & 8,571 \\
\hline
\end{tabular}

Figura 3.2 - Recombinação de dois pontos - simples troca

Mas os Operadores Convencionais apresentam uma desvantagem. Funcionam bem na representação binária, mas na representação real apenas trocam valores e não geram novas informações. Assim, os Operadores Aritméticos podem ser considerados a melhor solução para a codificação real. Os tipos de recombinação disponíveis são a recombinação aritmética e a recombinação $B L X-a$ ou recombinação mistura (Blend crossover).

A recombinação aritmética, assim como para a recombinação de um ou dois pontos, gera dois cromossomos filhos, mas por meio de uma combinação linear entre os cromossomos pais da seguinte forma:

$$
\begin{aligned}
& \text { Filho1 }=b * \mathrm{Pai}_{1}+(1-b) * \mathrm{Pai}_{2} \\
& \text { Filho2 }=(1-b)^{*} \mathrm{Pai}_{1}+b * \mathrm{Pai}_{2}
\end{aligned}
$$

sendo o valor de $b$ variando entre 0 a 1 .

Para a recombinação $B L X$ - $a$ ou mistura, o novo cromossomo produzido a partir de dois cromossomos segue a combinação: 


$$
\text { Filho }=\text { Pai } 1+b *\left(\mathrm{Pai}_{2}-\mathrm{Pai}_{1}\right)
$$

sendo $b$ pertencente ao intervalo $(-a, 1+a)$, podendo variar para cada par de ge nes.

Mutação ocorre por meio do operador seleção, em que o valor de um gene é substituído por outro valor aleatório da faixa admissível para cada variável de uma distribuição normal, ou seja, dado um cromossomo pai $p$ com o $j$-ésimo gene selecionado para mutação, é produzido um cromossomo filho $s$ da seguinte forma:

$$
\begin{array}{ll}
s_{i}=N(p i, \mathrm{~s}) & \text { se } i=j \\
s i=p i & \text { caso contrário }
\end{array}
$$

sendo $N\left(p_{i, s}\right)$ uma distribuição normal com média $p_{i}$ e desvio padrão $s$, considerado 1 para este trabalho. Pode-se ainda diminuir o valor do desvio padrão à medida que o número de gerações aumenta.

Seleção segue a mesma idéia do processo de seleção natural dos seres vivos, ou seja, o AG seleciona os melhores cromossomos da população para gerar cromossomos filhos por meio dos operadores recombinação e mutação, sendo geralmente os pais, selecionados com probabilidade proporcional à sua aptidão. Pode-se classificar como; Roda da Roleta, Ordenamento, Torneio, Uniforme, Amostragem Determinística e Stochastic Remainder Sampling (SRS) os tipos de seleção mais usuais.

Para o algoritmo Roda da Roleta, as probabilidades de seleção para cada cromossomo são calculadas de acordo com a razão de sua aptidão e da aptidão da população acumulada. Então, é gerado um número aleatório no intervalo de zero ao valor da aptidão acumulada. Por fim os operadores recombinação e mutação atuam sobre a solução selecionada. A desvantagem deste método é que aptidões negativas não são toleradas e problemas de convergência prematura podem acontecer.

Seleção Ordenamento, como o próprio nome diz, ordena os cromossomos na população. Ele define uma aptidão arbitrária máxima para o primeiro cromossomo e uma aptidão arbitrária mínima para o último cromossomo da população. A partir daí, as demais aptidões são calculadas interpolando os dois extremos por uma reta.

A seleção por Torneio se baseia na escolha aleatória de $n$ cromossomos da população (geralmente $n=2$ ), com probabilidades iguais, comparando entre si os respectivos valores de aptidão. Nesta comparação, o melhor cromossomo é selecionado. Este tipo de seleção não requer o escalonamento e o ordenamento da aptidão.

A seleção Uniforme não considera a aptidão do cromossomo, mas considera a mesma probabilidade de seleção para todos os cromossomos da população. Tem como 
característica "escolher" aleatoriamente os cromossomos a sofrerem recombinação e mutação.

A seleção por Amostragem Determinística calcula as probabilidades de seleção da mesma maneira que na Roda da Roleta, e em seguida, multiplica cada probabilidade pelo número de cromossomos da população. Cada cromossomo é selecionado de acordo com a parte inteira do valor calculado, e a população ordenada de acordo com a parte decimal deste mesmo valor. O restante da população é selecionado do topo da lista ordenada. Posteriormente, selecionam-se uniformemente os cromossomos que sofrerão a ação dos operadores genéticos.

A Stochastic Remainder Sampling (SRS) inicia o processo de maneira idêntica ao da Amostragem Determinística e difere no tratamento das partes fracionárias, que são consideradas probabilidades. Assim, se um cromossomo tiver aptidão 1,5, uma cópia idêntica na população intermediária será gerada e uma probabilidade de $50 \%$ de ter outra cópia acontecerá. A partir daí, os cromossomos são selecionados uniformemente.

Os AGs da biblioteca GAlib $C++$ possibilitam o emprego de escalonamento (scaling) na função objetivo. Trata-se de uma vantagem, uma vez que a função objetivo nem sempre é adequada para ser utilizada como valor de aptidão. Segundo MICHALEWICZ (1994), este mecanismo de mapeamento da função objetivo é dividido em três tipos: Escalonamento Linear que transforma os valores das aptidões de tal modo que a aptidão média torna-se igual ao valor médio da função objetivo, e a aptidão máxima igual a $c$ vezes (tipicamente $1,2=c=2,0$ ) a aptidão média. Tem como principal desvantagem a geração de valores negativos para as aptidões, forçando a limitação do valor mínimo da função aptidão; Escalonamento com Truncamento Sigma que sana as deficiências do escalonamento linear, pois, possíveis valores negativos da função aptidão são adotados como zero; e o Escalonamento Exponencial (Power Law Scaling) que eleva a uma potência o valor inicial da função aptidão.

\subsubsection{MÉTODO NELDER-MEAD}

Segundo DIXON (1972), o método Nelder-Mead é o método mais eficiente, dentre os métodos diretos de Rosenbrock, Hooke e Jeeves e Direções Conjugadas, para otimização onde os problemas apresentam funções complexas ou com descontinuidades. O método Nelder-Mead foi proposto por NELDER e MEAD (1965) como método 
Simplex utilizado em problemas de programação não linear, tendo como característica não considerar derivadas no processo de otimização, assim como fazem os AGs.

Como o método proposto apresenta restrições quanto aos valores máximos e mínimos das variáveis de decisão, o método Nelder-Mead também deverá contê-las. Partindo do mesmo princípio, SUBRAHMANYAM (1989) apresenta algumas modificações no método.

O método Simplex é baseado na comparação dos valores da função objetivo de $n+1$ vértices de uma região no espaço onde os vértices não são eqüidistantes (Simplex geral Figura 3.3) e "mover" estes pontos para o ponto ótimo, sendo necessário, para isto, a aplicação dos operadores: reflexão, contração e expansão.

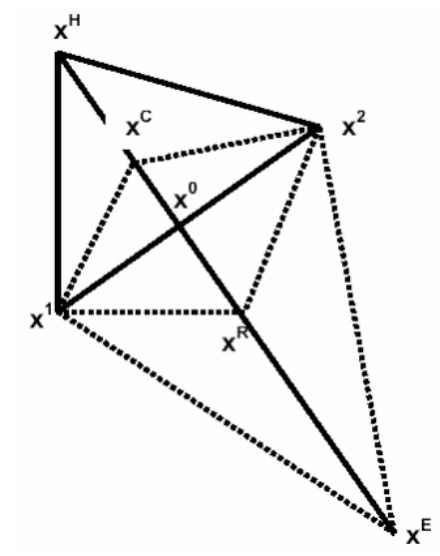

Figura 3.3 - Vértices em uma Simplex geral

A seguinte notação é utilizada para os vértices:

$x^{H}$ é o vértice correspondente ao maior valor da função objetivo:

$\left.M\left(x^{H}\right)=\max _{i}\left(x^{i}\right), \quad i=1, \ldots,(n+1)\right)$

$x^{0}$ é o centróide de todos os pontos, exceto $x^{H}$, dado por:

$$
x^{0}=\frac{1}{n} \sum_{\substack{i=1 \\ i \neq H}}^{n+1} x^{i}
$$

Os três operadores do método (reflexão, contração e expansão) são aplicados da seguinte maneira:

Reflexão: $x^{H}$ é substituído por:

$$
x^{R}=(1+\mu) \cdot x^{0}-\mu \cdot x^{H}, \quad \mu>0
$$

Expansão: $x^{R}$ é expandido na direção cuja melhora é esperada dada por:

$$
x^{E}=\omega \cdot x^{R}+(1-\omega) \cdot x^{0}, \quad \omega>1
$$


Contração: dado por:

$$
x^{C}=\psi \cdot x^{H}+(1-\psi) \cdot x^{0}, \quad 0<\psi<1
$$

SUBRAHMANYAM (1989) sugere valores para os coeficientes: $\mu=0,95, ?=2$ $\mathrm{e} ?=0,5$.

Dada uma estimativa inicial do valor mínimo $\mathbf{x}=\left(x_{1}, x_{2}, x_{3}, \ldots, x_{n}\right)$, uma região é formada usando um vetor auxiliar d e um vetor e unitário na direção $\mathbf{x}$ :

Assim, os $n+1$ vértices da região são dados por:

$\mathrm{x}^{1}=\left(1-\mathrm{d}_{1}\right) \cdot \mathrm{x}$

$\mathrm{x}^{\mathrm{i}}=\mathrm{x}+\mathrm{e}_{\mathrm{i}-1} \cdot \mathrm{d}_{\mathrm{i}-1} \cdot \mathrm{x}_{\mathrm{i}-1}, \quad i=2, \ldots, n+1$

Caso algum vértice esteja fora da região factível, o vetor d é modificado, aumentando seu valor se o limite inferior da variável seja violado, ou diminuindo se limite superior da variável é ultrapassado.

Para critério de convergência, pode-se comparar o desvio padrão da função nos $n+1$ vértices com uma tolerância. Assim:

$$
\left\{\sum_{i=1}^{n+1} \frac{\left[M\left(x^{i}\right)-M\left(x^{0}\right)\right]^{2}}{n}\right\}^{\frac{1}{2}} \leq \text { tolerância }
$$

\subsection{OS VAZAMENTOS E A MODELAGEM}

\subsubsection{OS VAZAMENTOS}

Acreditando que uma significativa proporção do vazamento é atribuída à grande quantidade de pequenos vazamentos e que o controle operacional da pressão é uma ação de custo efetivo para reduzir tais vazamentos, ULANICKI et al (2000) formulam e investigam métodos e implementações on-line de estratégias de controles preventivos para áreas com muitas válvulas redutoras de pressão e outros pontos alvos. Os resultados das simulações confirmaram que o controle preventivo permite realizar reduções de vazamentos futuros através de estudos de planejamento ótimo em até $50 \%$ dos níveis de vazamentos originais.

Um outro método para detectar a magnitude do vazamento em pequenas zonas residenciais de serviço de um sistema de distribuição de água é apresentado por BUCHBERGER e NADIMPALLI (2004). O estudo é feito a partir de medições continuas de vazão da linha principal de abastecimento (adutora) das zonas residenciais de serviço durante os períodos noturnos, em que a demanda é mínima. Os autores 
descrevem que na presença de um vazamento incerto, o método estima valores máximos e mínimos para o vazamento ao invés de simples taxas médias. Também comentam que previsões mais precisas são esperadas e que os esforços computacionais são menores do que os que os modelos hidráulicos dinâmicos necessitam.

CABRERA et al. (2005) apresentam uma metodologia para quantificação de perda de água baseada na discriminação de dois componentes de consumo não controlados em redes de distribuição de água; as perdas físicas em adutoras e conexões de serviço, e o volume de água consumido, mas não medido pelos medidores. Consideram para o balanço hídrico que todo o consumo não medido é consumo não controlado e, portanto vazamento aparente. A metodologia presume que perdas reais ocorrem em função da pressão, enquanto que as perdas aparentes, definidas como consumos de água não medidos, são função dos padrões de consumo (doméstico, industrial, etc.). Os autores concluem que a aplicação desta metodologia em redes de distribuição de água resultará em um melhor conhecimento dos componentes das taxas de vazões não controladas; das perdas reais e das perdas aparentes, incluindo demandas relativas a erros de medição do sistema.

\subsubsection{A MODELAGEM}

Modelos hidráulicos para análise de sistemas de abastecimento de água são usados há muitos anos, como ferramentas de análise do comportamento de redes. Entretanto, esses modelos exigem que parâmetros tais como rugosidades, diâmetros e demandas, etc. sejam adequadamente avaliados para produzir resultados condizentes com as condições de campo, variáveis ao longo do tempo. Muitos modelos de calibração foram propostos ao longo das últimas décadas, por acreditar que o fator primordial para o bom desempenho dos mesmos diz respeito à precisão com que os referidos parâmetros são determinados.

ORMSBEE e LINGIREDDY (1997) estabelecem que a calibração de um modelo de rede de abastecimento de água deve compreender sete etapas básicas. A primeira etapa tem como objetivo identificar o modelo de simulação hidráulica que se pretende usar, qual a finalidade do uso (ex: estudo operacional, estudo de qualidade da água, estudos de reabilitação) associado com o tipo de análise hidráulica que o sistema será submetido (regime permanente ou período estendido). A segunda etapa consiste em estimar valores iniciais para parametrização do modelo primário levando-se em 
consideração que na maioria dos modelos há incerteza associada a parâmetros tais como coeficiente de rugosidade dos tubos e a demanda associada a cada nó. A terceira etapa compreende a coleta e análise dos primeiros dados do modelo. Isto é feito executando o modelo com os valores dos parâmetros inicialmente estimados comparando seus resultados com os dados observados em campo. Estudar a precisão dos primeiros resultados do modelo seria o objetivo da quarta etapa. A quinta etapa consiste em analisar a performance deste primeiro nível de calibração (macrocalibração). Nesta etapa é possível, por exemplo, identificar que se os valores modelados mostram uma discrepância maior que $30 \%$, provavelmente o erro vem dos valores de rugosidade do tubo e da demanda de cada nó adotado inicialmente para os parâmetros do modelo. A análise de sensibilidade do modelo faz parte da sexta etapa, que consiste em variar os parâmetros de entrada para avaliar qual deles tem maior impacto nos resultados do modelo. Na sétima e última etapa realiza-se uma calibração mais detalhada do modelo (microcalibração). Os parâmetros a serem ajustados nesta etapa são a rugosidade do tubo e a demanda de cada nó. Em muitos casos, é aconselhável que seja dividida em outros dois passos: a calibração em regime permanente (steady-state) e em período estendido (extended-period).

XU e GOULTER (1999) propõem uma otimização para sistemas de abastecimento de água baseada em confiabilidade capaz de identificar a incerteza nas demandas nodais, capacidade dos tubos e o efeito de falha mecânica de componentes do sistema. O modelo também incorpora uma estratégia de identificação de nós críticos em que as restrições de confiabilidade são impostas para minimização de custos. Os testes numéricos indicaram que a modificação no algoritmo tem excelente estabilidade e eficiência.

A literatura reporta diversos trabalhos de calibração de redes de distribuição de água para abastecimento, conforme a revisão do estado da arte realizada por SILVA (2003) e SOARES (2003). Entretanto, poucos trabalhos incluem a determinação de parâmetros que possam expressar o comportamento dos vazamentos em tais sistemas.

BASCIÀ e TUCCIARELLI (1999) apresentam um método para setorizar e calibrar simultaneamente os parâmetros de rede de tubulações em regime permanente aplicando-o na determinação dos coeficientes de resistência dos tubos. A metodologia visa o agrupamento dos parâmetros de todos os tubos dentro de um pequeno número de zonas de parâmetros restritos para manter a diferença entre as cargas hidráulicas medidas e as calculadas abaixo de uma dada tolerância. Os autores concluem que a 
aplicação do procedimento proposto a um pequeno sistema hipotético e o experimento laboratorial mostraram boas estimativas dos coeficientes de resistência da rede de abastecimento.

SOARES (2003) construiu uma rotina computacional utilizando o problema inverso para calibração de redes de abastecimento em termos das rugosidades absolutas, diâmetros, cotas topográficas, demandas, parâmetros do modelo de vazamentos e a localização de componentes hidráulicos. $\mathrm{O}$ algoritmo de calibração apresentou bons resultados quando aplicado a sistemas hipotéticos (Soares, 2003) e reais (Soares et al, 2005), uma vez que foi capaz de determinar simultaneamente parâmetros de diversas naturezas, embora a rede de amostragem não fosse otimizada e o problema indeterminado por natureza.

KAPELAN, SAVIC e WALTERS (2004) resolveram um problema de calibração via modelo inverso, usando uma técnica de otimização por busca híbrida e modelo hidráulico para regime transiente de escoamento. Os autores comentam que o modelo inverso foi desenvolvido principalmente para a detecção de vazamentos em redes de distribuição de água. Neste trabalho, duas técnicas de otimização são testadas: Algoritmo Genético (AG) e o método de Levenberg-Marquardt (LM). A partir daí um novo algoritmo genético híbrido (AGH) foi desenvolvido, combinando as vantagens dos dois métodos anteriores. O AGH é então comparado com o AG e LM em dois estudos de casos. KAPELAN, SAVIC e WALTERS (2004) concluem que o AGH é mais estável que o método LM, mais preciso e muito mais rápido que o modelo de transiente inverso AG.

Apesar disso, só recentemente tem-se preocupado em admitir vazamentos e demanda variável com a pressão no modelo de simulação hidráulica.A revisão da literatura aqui apresentada visa apontar trabalhos mais importantes nessa direção.

\subsubsection{MODELAGEM DE VRPS}

GERMANOPOULOS e JOWITT (1989) apresentam uma metodologia para a determinação de aberturas ótimas das válvulas de controle para minimizar excessos de pressão em rede de distribuição de água. A minimização das pressões excessivas é dependente das características hidráulicas da rede expressas na forma de equações de continuidade nos nós, e dependentes também das restrições de operação da rede de abastecimento de água. O método da teoria linear é usado para uma linearização 
iterativa das restrições do problema, conduzindo a solução de sucessivos programas lineares até a localização da posição ótima da válvula de controle e as correspondentes cargas e vazões. Os autores destacam que o trabalho traz benefícios como supressão de consumos desnecessários e a redução na incidência de arrebentamentos de tubos.

REIS, PORTO e CHAUDHRY (1997) tratam do problema de determinação de ótima localização e aberturas otimizadas de válvulas de controle em redes de distribuição de água via algoritmo genético $(\mathrm{AG})$ e a teoria linear para obter a redução máxima de vazamento para dadas demandas nodais e níveis de reservatórios. Os autores comentam que uma das vantagens desta aplicação da formulação do algoritmo genético é que ele produz muitas opções desejáveis economicamente, equivalentes em termos do vazamento produzido, mas envolvendo menor número de válvulas.

VAIRAVAMOORTHY e LUMBERS (1998) descrevem um método de otimização, adotando vazamento dependente da pressão, para minimização de vazamento em sistemas de distribuição de água através do mais efetivo desempenho das válvulas reguladoras de vazão. Os autores concluem que a minimização de vazamento requer que ele seja introduzido explicitamente no modelo e que técnicas de otimização formais podem ser aplicadas sucessivamente para identificar estados ótimos de válvulas para chegar a níveis mínimos de pressões requeridas. Também concluem que o estudo proposto permite um menor desvio de pressão em torno do alvo, controlado pelas restrições de pressão de uma função objetivo alternativa.

REIS e CHAUDHRY (1999) estudam o desempenho de válvulas reguladoras de pressão em resposta a variações espaciais de demanda da rede. O trabalho traz uma variedade de combinações de condições de operação em termos das demandas nodais, demanda total da rede e níveis do reservatório que são usados para avaliar os valores de parâmetros de controle de válvulas necessários para a minimização do vazamento. Os autores descrevem que o coeficiente de descarga indicado pela simulação mostra características típicas das válvulas redutoras de pressão em termos dos parâmetros de controle de válvula obtidos a partir do modelo de minimização de vazamento.

PRESCOTT e ULANICKI (2003) desenvolveram quatro modelos dinâmicos (dois de fenômenos lógicos, um comportamental e um linear) para representar o comportamento de VRP’s em sistemas de abastecimento de água. Descrevem que a condição da VRP é afetada pela pressão de entrada e de saída, pela posição de abertura em que a mesma se encontra e pela vazão que passa através dela, e que, como essas variáveis são determinadas levando-se em consideração a interação entre a VRP e a 
rede, é inapropriado modela-la sem levar em consideração as características da rede em questão.

\subsubsection{MODELOS DE VAZAMENTO E DEMANDA VARIÁVEL COM A PRESSÃO}

A eficiência hidráulica das redes de distribuição de água para abastecimento (razão entre volume medido e volume produzido) não é a mesma em períodos diurnos, que têm uma maior demanda e menor pressão, e em períodos noturnos, com menor demanda e maior pressão. O vazamento e a demanda (em maior ou menor grau, dependendo das características do sistema) dependem simultaneamente da pressão, apesar de poderem apresentar vazões de grandezas discrepantes, fato que geralmente não é levado em consideração pelos modelos dinâmicos convencionais. Vairavamoorthy e Lumbers (1998, p. 1146) citam que "A inclusão de vazamento dependente da pressão em redes de abastecimento permite a aplicação de técnicas de otimização para identificar a forma mais efetiva de reduzir perdas de água em sistemas de distribuição". Assim, para se construir um modelo dinâmico confiável de um sistema de abastecimento de água, julga-se necessário integrar o vazamento e simultaneamente considerar a demanda dependente da pressão.

Com o objetivo de estudar as causas e conseqüentes efeitos de falhas em tubulações em redes de distribuição de água e ilustrar a possibilidade de modelagem desses impactos, JOWITT (1995) desenvolveu duas aproximações para o problema, nas quais um modelo de dependência das demandas com a pressão é incorporado.

$$
Q_{d, i}=d_{i}\left[1-a_{i} \cdot \exp \left(-b_{i} \cdot \frac{H_{i}}{H_{i}^{d e s}}\right)\right]
$$

onde $a_{i}$ é um coeficiente que varia de 3 a 10 e $b_{i}$ é igual a 5 .

FUJIWARA e LI (1998) apresentaram um modelo de demandas para a análise de confiabilidade em redes de distribuição de água, descrito a seguir:

$$
\begin{array}{ll}
Q_{d, i}=d_{i} & \text { se } H_{i} \geq H_{i}^{\text {des }} \\
Q_{d, i}=d_{i}\left[\frac{\left(H_{i}-H_{i}^{\min }\right)^{2}\left(3 . H_{i}^{\text {des }}-2 . H_{i}-H_{i}^{\mathrm{min}}\right)}{\left.\left(H_{i}^{\text {des }}-H_{i}^{\min }\right)^{3}\right]}\right] & \text { se } H_{i}^{\text {min }}<H_{i}<H_{i}^{\text {des }} \\
Q_{d, i}=0 & \text { se } H_{i} \leq H_{i}^{\text {min }}
\end{array}
$$


Destaca-se no trabalho de TUCCIARELLI, CRIMINISI e TERMINI (1999) a utilização de um modelo de demanda no processo de calibração de um modelo de rede de distribuição de água, propondo um modelo pressão x demanda senoidal de acordo com a seguinte relação:

$$
\begin{array}{ll}
Q_{d, i}=d_{i} & \text { se } H_{i} \geq H_{i}^{\text {des }} \\
Q_{d, i}=d_{i} \cdot \operatorname{sen}^{2}\left[\frac{H_{i}}{2 \cdot H_{i}^{\text {des }}} \pi\right] & \text { se } H_{i}^{\mathrm{min}}<H_{i}<H_{i}^{\text {des }} \\
Q_{d, i}=0 & \text { se } H_{i} \leq H_{i}^{\text {min }}
\end{array}
$$

O expoente da relação pressão x demanda assumiu uma variação nos trabalhos de TABESH e KARIMZADEH (2000) e TANYIMBOH, TABESH e BURROWS (2001) deduzindo as seguintes equações:

$$
\begin{array}{ll}
Q_{d, i}=d_{i} & \text { se } H_{i} \geq H_{i}^{\text {des }} \\
Q_{d, i}=d_{i}\left[\frac{H_{i}-H_{i}^{\min }}{H_{i}^{d e s}-H_{i}^{\min }}\right]^{\frac{1}{n}} & \text { se } H_{i}^{\text {min }}<H_{i}<H_{i}^{\text {des }} \\
Q_{d, i}=0 & \text { se } H_{i} \leq H_{i}^{\text {min }}
\end{array}
$$

SOARES (2003) realiza uma revisão bastante aprofundada e abrangente sobre o tema, apresentando um resumo das formulações sugeridas por JOWITT (1995), FUJIWARA e LI (1998), TUCCIARELLI, CRIMINISI e TERMINI (1999), TABESH e KARIMZADEH (2000) e MARTÍNEZ, CONEJOS e VERCHER (1999) para modelar a dependência da pressão sobre a demanda. Os mencionados autores estabeleceram que há valores de referência para a pressão mínima, $H^{\text {min }}$ - abaixo do qual a demanda não é atendida, e para a pressão desejada, $H^{\text {des }}$ - a partir do qual a demanda é integralmente atendida. Para valores intermediários de pressão, dentro dessa faixa, sugerem um fator, ?, de correção para a demanda, conforme indica a Tabela 3.1. Assim, multiplicando-se ? pela demanda potencial de cada nó, tem-se a demanda efetivamente atendida.

TUCCIARELLI, CRIMINISI e TERMINI (1999) apresentaram um processo iterativo de dois passos para realizar a estimativa dos parâmetros do modelo de perda de água por pequenos vazamentos em diferentes áreas de tubos de redes de distribuição de água, admitindo também a demanda variável com a pressão. $\mathrm{O}$ primeiro passo do processo compreende a estimativa de parâmetros do modelo de simulação da rede e o 
segundo passo otimiza as aberturas das válvulas reguladoras de pressão da rede de distribuição.

Tabela 3.1. Quadro resumo dos fatores ? sugeridos pelos diversos autores

\begin{tabular}{|c|c|c|c|c|}
\hline Modelo & $H_{i} \leq H_{i}^{\min }$ & $H_{i}^{\min }<H_{i}<H_{i}^{d e s}$ & $H_{i} \geq H_{i}^{d e s}$ & Obs. \\
\hline JOWITT (1995) & 0 & $1-a_{i} \times \exp \left(-b_{i} \frac{H_{i}}{H_{i}^{d e s}}\right)$ & 1 & $\begin{array}{c}a_{i}=3 \quad \text { a } 10 \\
b_{i}=5 \quad e \\
H^{d e s}=20 \text { a } 35 \mathrm{~m}\end{array}$ \\
\hline $\begin{array}{l}\text { FUJIWARA e } \\
\text { LI (1998) }\end{array}$ & 0 & $\frac{\left(H_{i}-H_{i}^{\min }\right)^{2}\left(3 H_{i}^{\text {des }}-2 H_{i}-H_{i}^{\min }\right)}{\left(H_{i}^{\text {des }}-H_{i}^{\min }\right)^{3}}$ & 1 & $H_{i}^{\min } \approx 5 m$ \\
\hline $\begin{array}{c}\text { TUCCIARELLI, } \\
\text { CRIMINISI e } \\
\text { TERMINI } \\
\text { (1999) }\end{array}$ & 0 & $\operatorname{sen}^{2}\left(\pi \frac{H_{i}}{2 H_{i}^{d e s}}\right.$ & 1 & $H_{j}^{\min }=0$ \\
\hline $\begin{array}{c}\text { TABESHe } \\
\text { KARIMZADEH } \\
\text { (2000) }\end{array}$ & 0 & $\left(\frac{H_{i}-H_{i}^{\min }}{H_{i}^{d e s}-H_{i}^{\min }}\right)^{\frac{1}{n}}$ & 1 & $\begin{array}{c}1,5 \leq n \leq 2 \\
H_{i}^{\min }=5 \text { a } 6 m\end{array}$ \\
\hline $\begin{array}{l}\text { MARTÍNEZ, } \\
\text { CONEJOS e } \\
\text { VERCHER } \\
\text { (1999) }\end{array}$ & 0 & $K_{i}\left(H^{i}-H_{i}^{\min }\right.$ & & $\begin{array}{c}?=0,5 \text { (descarga } \\
\text { para atmosfera) } \\
?=0,21 \text { (Valencia, } \\
\text { Espanha) }\end{array}$ \\
\hline
\end{tabular}

Fonte: Soares (2003)

O modelo de simulação usado por TUCCIARELLI, CRIMINISI e TERMINI (1999) no processo de calibração utiliza relações conhecidas entre os parâmetros da rede e as variáveis de estado (vazão e carga hidráulica). O modelo assume ainda a condição de regime permanente (steady-state) e combina as equações da continuidade e de momento:

$$
\sum_{j=1}^{M i} \frac{H_{j}-H_{i}}{\sqrt{R_{i j}\left(H_{j}-H_{i}\right)}}-\delta_{1} Q_{i}-P S_{i}=0, \quad i=1, \ldots, N
$$

sendo $N=$ número total de nós; $M_{i}=$ número total de tubos ligados ao nó $i ; H_{i}=$ carga hidráulica total; $Q_{i}=$ vazamento por unidade de tempo no nó $i, d_{l}$ é igual a 1 ou 0 se a carga total no nó $i$ é maior ou menor que a cota topográfica; $P=$ demanda total; e $S_{i}=$ fator de distribuição espacial da demanda total no nó $i$. O termo $Q_{i}$ é computado 
assumindo que no tubo de cada zona exista uma área de vazamento constante por unidade de área da superfície do tubo, conforme a idéia de que a idade da tubulação é uniforme em toda a parede do tubo. Isto fornece:

$$
Q_{i}=\left(H_{j}-z_{i}\right)^{a} \sum_{j=1}^{M i} \frac{\pi}{2} D_{i j} \theta_{i j} L_{i j}
$$

sendo $z_{i}$ a cota topográfica; $a$ o expoente de perda; $L_{i j}$ o comprimento do tubo; $D_{i j}$ o diâmetro do tubo; e ? $i j$ o vazamento por unidade de superfície do tubo que liga os nós $i$ e $j$. $R_{i j}$ é o coeficiente de resistência do tubo que liga o nó $i$ ao nó $j$ e é igual, de acordo com a fórmula de Prandtl-Nikuradse, a:

$$
R_{i j}=R^{0}\left(V_{i j}\right)+0,0826 \frac{L_{i j}}{\lambda D_{i j}^{5}}
$$

sendo? igual a:

$$
\lambda=4\left[\log \left(\frac{\varepsilon_{i j}}{3,71 D_{i j}}\right)\right]^{2}
$$

sendo $R^{0}\left(V_{i j}\right)$ a perda local referente a uma possível válvula $V_{i j}$ no tubo que liga os nós $i$ e $j$ e $e_{i j}$ o fator de rugosidade absoluta da tubulação entre os nós $i$ e $j$.

O termo $q_{i}$ é calculado assumindo que nas tubulações em cada zona há valores constantes de vazamento por área de superfície de tubo. Assim:

$$
q_{i}=\left(H_{i}-z_{i}\right)^{\beta} \sum_{j=1}^{M_{i}} \frac{\pi}{2} D_{i j} \theta_{i j} L_{i j}
$$

onde $\beta$ é o expoente de perda e $?_{i j}$ é a taxa de vazamento por unidade de superfície da tubulação ligando o nó $i$ ao nó $j$. Avaliando a perda de água através da solução do problema inverso, o valor de $q_{i}$ pode ser calculado através das estimativas dos parâmetros $C, \beta, ?_{i j}$, e $\mathrm{e}_{i j}$. A estimativa desses parâmetros pode ser feita por medições das cargas hidráulicas totais e vazões para determinados nós e tubulações, respectivamente.

Os autores relatam que a robustez do processo é testada com experimentos numéricos e a estimativa de água perdida em uma rede de distribuição real com medições fictícias (valores de pressões produzidos via simulação hidráulica).

MARTÍNEZ, CONEJOS e VERCHER (1999) construíram um modelo para a cidade de Valência, Espanha, que incorpora tanto as demandas variáveis com a pressão como os vazamentos explicitamente. 
Assumindo-se que a demanda engloba as parcelas autorizada (tarifada ou não) e não autorizada (clandestinas), que podem ser agrupadas em um termo chamado demanda total $Q_{d, i}$, esses autores assumiram que o consumo total $Q_{c, i}$ em um nó $i$ do modelo no instante $k$ inclui a demanda e os vazamentos.

$$
Q_{c, i}(k)=Q_{d, i}(k)+q_{i}(k)
$$

MARTÍNEZ, CONEJOS e VERCHER (1999) fixam um consumo padrão para cada tipo de consumidor através da expressão

$$
Q_{d, i}(k)=\sum_{U} P_{u}(k) r_{u} \bar{Q}_{d, i}
$$

sendo $\bar{Q}_{d, i}$ demanda média registrada em um dado nó durante o período simulado, $r_{u} \mathrm{o}$ fator correspondente ao consumidor tipo $u, P_{u}(k)$ o fator de modulação deste tipo de demanda no instante $k$ e $U$ é o número de tipos de consumidores considerado.

MARTÍNEZ, CONEJOS e VERCHER (1999) reconhecem a importância de se separar a rede de maneira a considerar somente os diâmetros maiores, ou seja, mais significativos para efeito da modelagem. Essa parte da rede é denominada modelada e os demais tubos como integrantes da parcela da rede dita não modelada. Entretanto, tais sub-redes apresentam características bem distintas no que se refere aos vazamentos, sendo que eles ocorrem principalmente na sub-rede não modelada.

Dessa maneira, MARTÍNEZ, CONEJOS e VERCHER (1999) consideram que o parâmetro $q_{1, i}$ para a sub-rede modelada pode ser expresso como

$$
q_{1, i}=\frac{1}{2} \sum_{j \in J_{i}} q_{1, i j}
$$

sendo $J_{i}$ todos os nós conectados ao nó $i$ e $q_{1, i j}$ calculado segundo a equação proposta por GERMANOPOULOS E JOWITT (1989), na forma:

$$
q_{1, i j}=c_{1}^{s} L_{i j}\left(p_{i j}^{a v}\right)^{1,18}
$$

sendo $q_{1, i j}$ a vazão de água perdida (vazamento) entre os nós $i$ e $j, c_{1}^{s}$ é a constante global que depende das características particulares da rede $s, L_{i j}$ é o comprimento do tubo entre os nós $i$ e $j$ e $p_{i j}^{a v}$ é a pressão média do tubo obtida através da média das pressões entre os nós $i$ e $j$, assim;

$$
p_{i j}^{a v}=\frac{\left(p_{i}+p_{j}\right)}{2}=\frac{\left(H_{i}-z_{i}+H_{j}-z_{j}\right)}{2}
$$


sendo $p_{i}$ a pressão no nó $i, H_{i}$ a carga hidráulica no nó $i$ e $z_{i}$ a cota geométrica do nó $i$.

Para a rede não-modelada, MARTÍNEZ, CONEJOS e VERCHER (1999) expressam o vazamento através da equação;

$$
q_{2, i}(k)=c_{2}^{s}\left[\sum_{k=1}^{T} Q_{c, i}(k)\right] p_{i}^{\beta}(k)
$$

Experimentos realizados por GOODWIN (1980) em cidades com consumos noturnos baixos ou quase nulos, afirmam que o expoente $\beta$ tem valores acima de 1,18. $c_{2}^{s}$ é o novo coeficiente global a ser determinado para todo o setor não-modelado, $T$ é o número total de intervalos no período simulado considerado. Então o consumo total no nó $i$ será:

$$
Q_{c, i}(k)=Q_{d, i}(k)+q_{1, i}(k)+q_{2, i}(k)
$$

Com base em algumas considerações próprias, o modelo de MARTÍNEZ, CONEJOS e VERCHER (1999) considera que a influência da pressão sobre a demanda será:

$$
Q_{d, i}(k)=C_{i}(k)\left(p_{i}(k)-p_{m, i}(k)\right)^{\gamma}
$$

sendo $p_{m, i}$ a pressão mínima requerida pelo no $i$ para fornecer a vazão requisitada (usualmente 0 a $10 \mathrm{~m}$ ), o expoente ? terá o valor 0,5 em descargas para a atmosfera, porém, nem todos os tipos de consumo podem ser associados com descargas para a atmosfera. Muitos deles são regulados por volume (máquinas de lavar, banheiras, etc) e outros são regulados por tempo (chuveiro, torneiras, etc.). A partir desse conceito, os autores avaliaram em um uso doméstico comum para a cidade de Valência, Espanha que o valor ajustado do expoente ? seria 0,21. Finalmente, os autores consideram que o coeficiente $C_{i}(k)$ será diferente para cada nó em um intervalo de tempo, já que $p_{i}(k)$ e $Q_{d, i}(k)$ são conhecidos através das considerações anteriores.

ARAUJO, RAMOS e COELHO (2006) apresentam um modelo de apoio à decisão para quantificação, localização e ajuste de abertura de válvulas de controle em uma rede de abastecimento, com o objetivo principal de minimizar pressão e, consequentemente, os níveis de vazamento. O modelo EPANET é usado para análise hidráulica da rede e dois modelos operacionais são desenvolvidos com base no método de otimização de algoritmo genético para controle de pressão e, conseqüentemente, redução de vazamento, uma vez que o vazamento é função dependente da pressão. $\mathrm{O}$ trabalho destaca duas fases principais. 
A primeira fase consiste na otimização do número e identificação de possíveis localizações de válvulas de controle em sistemas de distribuição de água. A consideração de pseudo válvulas, em cada tubo, é obtida pela simulação de uma rugosidade adicional de maneira a minimizar as pressões nos nós do sistema, através da seguinte função objetivo:

$$
\left.f\left(p_{i}, n v\right)\right|_{t=1} ^{T}=\frac{n v_{t}}{\left.\left\{\sum_{i=1}^{N}\left[\left(P_{c a l, i, t}-P_{\min }\right) / P_{\text {min }}\right]^{2} \times n v_{t}+n v_{t}\right\}^{2}\right|_{t=1} ^{T}}
$$

sendo $T$ o número total de intervalos de simulação ( 24 intervalos de 1 hora); $N$ o número de nós; $P_{c a l, i, t}$ a pressão calculada no nó $i$ para a hora $t ; P_{\text {min }}$ a mínima pressão, préestabelecida pelo usuário, para qualquer nó da rede e $n ?_{t}$ o número de válvulas calculadas para o instante $t$ sendo, portanto, um condicionamento do problema formulado para ter menor número de válvulas.

Os trechos a serem dotados de válvulas são então identificados com base nos resultados da otimização, correspondendo aos trechos com maior incidência de rugosidades aumentadas (durante o período de simulação entendido).

A segunda fase da otimização tem o propósito de estabelecer o ajuste para diferentes tipos de válvulas através do coeficiente de perda de carga para válvulas estranguladoras de controle (TCV) ou pressões mínimas para válvulas reguladoras de pressão (VRP), para informar ao gerente o mais adequado número e localizações de válvulas necessárias econômica e tecnicamente viáveis ou simplesmente otimizar o ajuste de abertura de válvulas existentes. Neste caso, a primeira fase é opcional. A formulação matemática para resolução desse outro problema de otimização é baseado na seguinte função objetivo:

$$
\left.f\left(p_{i}\right)\right|_{t=1} ^{T}=\frac{1}{\left.\sum_{i=1}^{N}\left[\left(P_{c a l, i, t}-P_{\min }\right) / P_{\min }\right]^{2}\right|_{t=1} ^{T}}
$$

ARAUJO, RAMOS e COELHO (2006) concluem que o modelo permitiu uma otimização do número e localização de válvulas de controle, tanto quanto seus respectivos ajustes de aberturas, para uma efetiva otimização dos níveis de vazamentos uma vez que vazamentos são modelados como um orifício de função dependente da pressão. A metodologia tem a capacidade de encontrar uma solução que satisfez completamente o gerenciamento de pressões extremas sem introdução de restrições significantes para a eficiência e performance da rede de distribuição. Uma eficiente 
estratégia de controle e minimização de pressão é usada como uma boa ferramenta operacional para redução de vazamentos em sistemas de distribuição de água. Cenários com diferentes números e localizações de válvulas de controle são analisados. A distribuição de pressão e vazamento ao longo do sistema, tão bem como a operação de estado de cada válvula instalada permite comparar possíveis soluções e estimar a média de vazamento obtido. Foi verificado que a seleção do melhor número e localização de possíveis válvulas dependentes da topologia e características do sistema que somente é obtido por análises de sensibilidade computacional. Nem sempre o maior número de válvulas fornece a melhor solução.

\subsubsection{A PROBLEMÁtICA DA LOCALIZAÇÃO DOS PONTOS DE MONITORAMENTO}

Com a tendência de se garantir uma parametrização do modelo com dados mais próximos da realidade, questionou-se a precisão na coleta de dados através da instrumentação de campo que ainda não oferecia um confiável princípio de funcionamento. Com o passar do tempo, os fabricantes de equipamentos chegaram a resultados, no mínimo, razoáveis quanto à precisão na aquisição dessas informações. Assim, pode-se dizer que o ferramental para dar tratamento aos problemas de reprodução do comportamento hidráulico das redes evoluiu bastante nos últimos anos.

Outro fator relevante para a geração de bons resultados de calibração de um sistema de abastecimento de água é a escolha dos pontos de coleta de dados no sistema, tendo em vista que é inviável monitorar as variáveis de estado (pressão e vazão) em todos os nós e trechos da rede. Assim, a literatura reporta muitas pesquisas desenvolvidas no sentido de estabelecer a rede de monitoramento ótima para aquisição de tais dados.

MEIER e BARKDOLL (2000) descrevem que se a localização dos pontos de monitoramento de vazão não forem bons, os dados coletados podem gerar informações insuficientes para garantir uma calibração precisa, deixando para o modelador a escolha entre uma nova coleta de dados (gastos adicionais) ou usar um modelo menos preciso. Os autores aplicaram o algoritmo genético para um modelo de rede de uma pequena cidade de Ohio, EUA, que resultou excelente rendimento. Os resultados obtidos foram validados por comparação com aqueles gerados por enumeração completa. 
Este assunto também é abordado no trabalho de VITKOVSKÝ, SIMPSON e LAMBERT (2003). Eles comentam que a qualidade da detecção e quantificação do vazamento e a calibração dos coeficientes de atrito em redes de abastecimento através do método de transiente inverso são dependentes da qualidade e localização dos pontos de medição dos dados. Os autores apresentam uma aproximação na configuração e quantificação dos pontos de medição direcionados à produção de resultados ótimos. Entre as conclusões do trabalho, VITKOVSKÝ, SIMPSON e LAMBERT (2003) mostram que existe uma correlação entre o número de pontos de medição e o registro de dados medido e que maiores comprimentos de registro e poucos pontos de medidas podem produzir resultados igualmente bons, quando utilizados menores durações de registro e muitos pontos de coleta.

KAPELAN, SAVIC e WALTERS (2005) apresentam uma metodologia que tem como objetivo principal encontrar os pontos ótimos de localização dos loggers de pressão na rede usados para coletar dados para a calibração de um modelo de sistema de distribuição de água. Os autores usam dois modelos baseados em algoritmos genéticos, um para objetivo único (SOGA) e um multiobjetivo (MOGA). O resultado mostra muitas vantagens e uma desvantagem do modelo MOGA quando comparado ao SOGA.

É interessante notar que, apesar de muitos estudos já realizados sobre o tema, não existe um consenso em torno de um método de determinação da rede de monitoramento ótima. 


\section{MATERIAIS E MÉTODOS}

São descritos neste capítulo os materiais empregados, bem como os modelos de calibração e simulação hidráulica utilizados, além da descrição das etapas do trabalho e dos sistemas reais que constituíram objetos de estudo.

\subsection{MATERIAIS}

O presente trabalho utilizou o laboratório de simulação computacional com instrumentação disponível (computadores e impressoras). Um notebook composto por microprocessador Pentium M 1,6 GHz, com 512 MB de memória RAM e sistema operacional Windows XP, foi disponibilizado pela SABESP. O software supervisório iFIX, utilizado pela SABESP no controle operacional da cidade de Guariba, foi também disponibilizado pela empresa. Softwares como compilador de linguagem de programação $C++$ Builder 5, simulador hidráulico EPANET 2 (ROSSMAN, 2000) desenvolvido pela "U.S. Environmental Protection Agency" - EPA e de domínio público, biblioteca GAlib C++ (WALL, 1996) do Departamento de Engenharia Mecânica do "Massachussetts Institute of Technology" - MIT, de distribuição livre, pacote Microsoft Office 2003 e AutoCAD 2004, foram amplamente utilizados para as simulações computacionais além da redação da dissertação.

Para as medições de campo, foram utilizados medidores de vazão eletromagnéticos (Figura 4.1.a), um medidor de nível ultrasônico (Figura 4.1.c), um medidor de pressão hidrostático (Figura 4.1.f), 35 DataLoggers como equipamentos de coleta de dados de pressão (Figura 4.1.f), um calibrador de sinais eletrônicos de tensão e corrente e um manômetro padrão de 0-100 $\mathrm{mH}_{2} \mathrm{O}$ (Figura 4.1.f). Válvula reguladora de pressão (Figura 4.1.b), registros de gaveta (Figura 4.1.d) e inversor de freqüência (Figura 4.1.e) fizeram parte dos equipamentos usados para alterações das situações de comportamento da rede de distribuição de água dos municípios de Guariba e Itirapuã. 


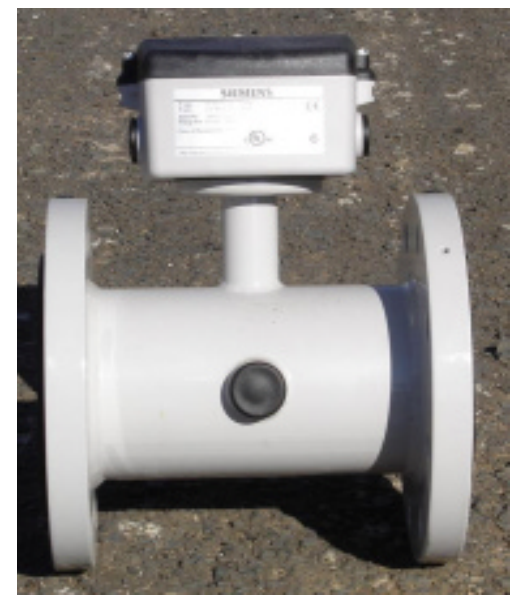

(a)

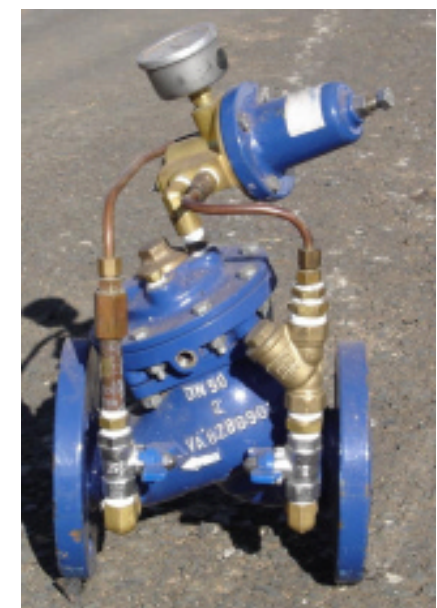

(b)
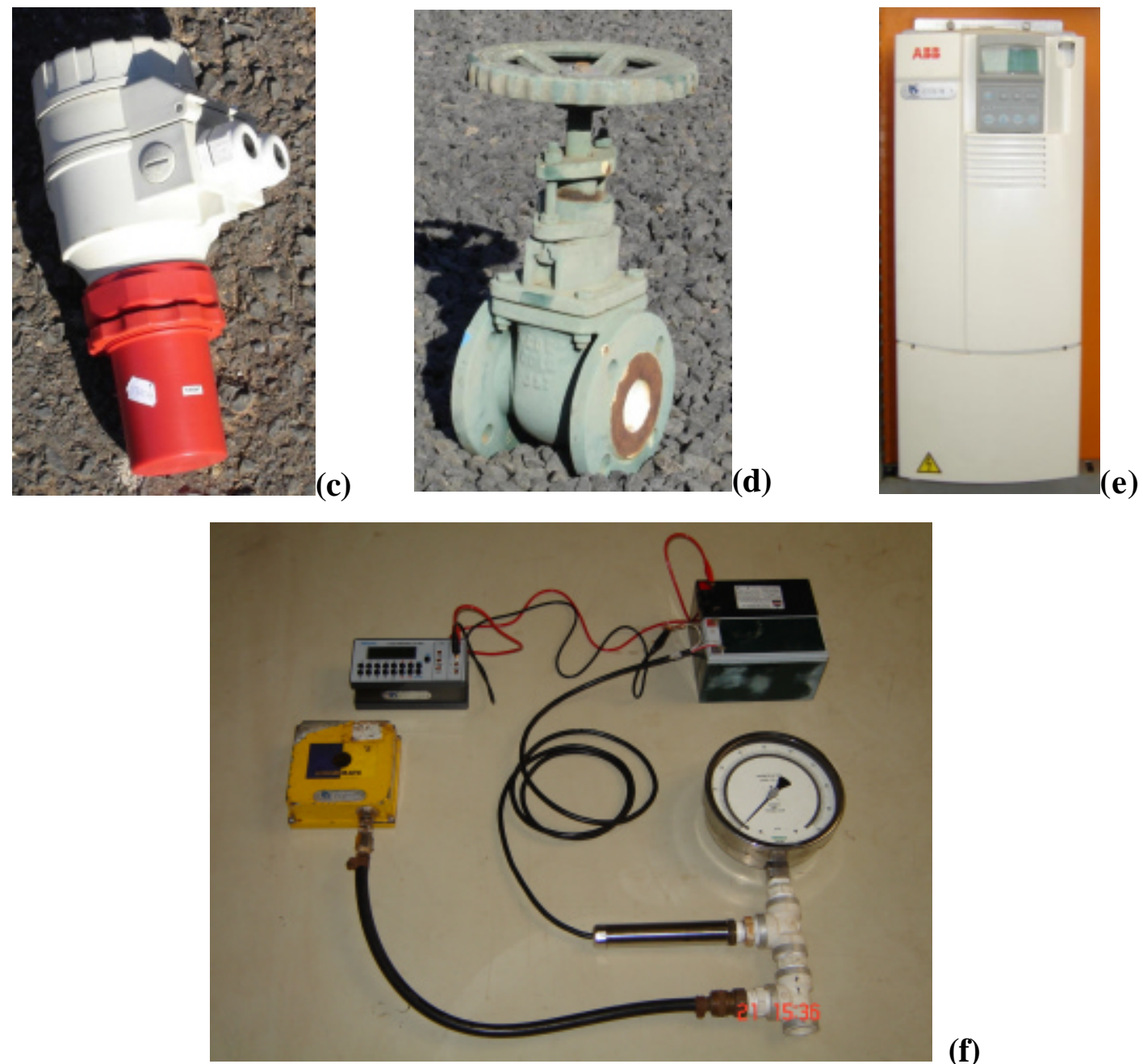

(f)

Figura 4.1 - Equipamentos usados na coleta de dados de campo e na alteração do comportamento das redes hidráulicas de Guariba e Itirapuã: (a)Medidor de vazão eletromagnético, (b)Válvula reguladora de pressão-VRP, (c)Medidor de nível ultrasônico, (d)Registro de gaveta, (e)Inversor de freqüência, (f) Calibrador de sinais eletrônicos de tensão e corrente, datalogger e um manômetro padrão de 0-100 $\mathbf{m H}_{2} \mathrm{O}$ 


\subsection{MÉTODOS}

\subsubsection{DESCRIÇÃO DO MODELO INVERSO DE SOARES (2003)}

Considera-se que a metodologia sugerida por SOARES (2003) seja adequada para dar tratamento ao problema de calibração, utilizando o código computacional construído por ele. SOARES (2003) baseia-se na minimização dos desvios entre os parâmetros (pressão e vazão) não reais observados em uma rede hipotética e aqueles obtidos pela rotina computacional produzida utilizando-se o simulador hidráulico EPANET como modo de avaliação auxiliar. No presente trabalho, o mesmo modelo de SOARES (2003) foi utilizado, no entanto, os parâmetros usados na calibração e a rede de abastecimento de água são reais. Com modificações nas rotinas do software de SOARES (2003), o modelo de JOWITT foi inserido e uma nova tentativa de calibração foi realizada. Os padrões de vazão, pressão e nível do reservatório, utilizados como arquivos de entrada do modelo, foram compostos por observações em alguns nós do setor eleito como mais crítico (Zona Média) da cidade de Guariba e para alguns nós da zona de pressão única da cidade de Itirapuã através de instrumentação de campo.

Além de vazões e pressões, o modelo também considerou como dados de entrada os comprimentos, diâmetros e rugosidade absoluta das tubulações, cota topográfica e demandas médias nos nós, os setores de rugosidade, coeficientes (?) e expoentes do modelo de vazamento $(\beta)$.

Foram consideradas como variáveis de decisão no modelo, as rugosidades absolutas (e), os parâmetros do modelo pressão x vazamento, coeficiente (?) e expoente $(\beta)$ para tubulações ou setores de tubulações. Este trabalho seguiu o mesmo procedimento usado por SOARES (2003), porém, ao invés dos parâmetros observados (pressão e vazão) serem valores extraídos via simulação hidráulica através de uma rede hipotética, foram utilizados valores reais extraídos de instrumentação de campo instalada em uma rede de abastecimento de água existente.

SOARES (2003) utilizou duas funções objetivo em seu trabalho, com fins comparativos. A primeira função objetivo baseia-se no somatório dos quadrados das diferenças de valores computados e simulados de pressões e vazões divididos pelo somatório do quadrado da média dos valores observados: 


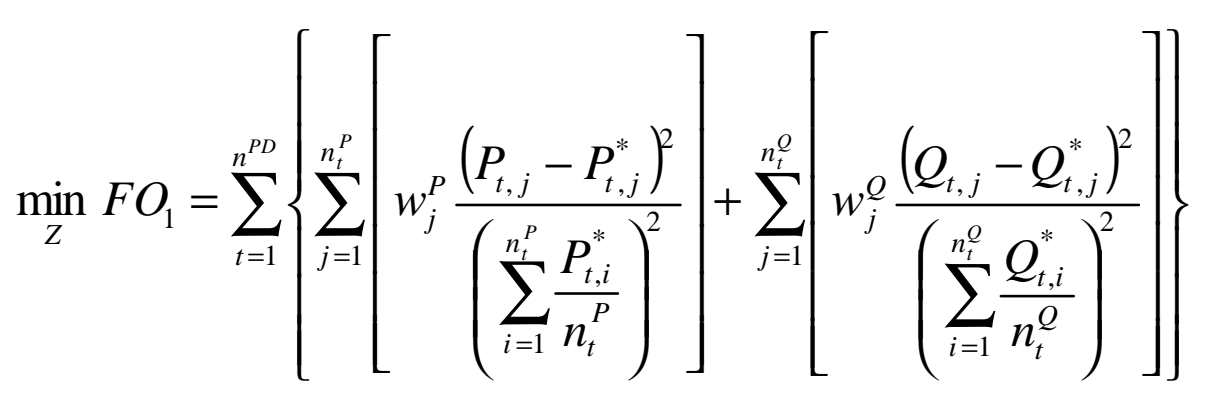

sendo $n^{P D}$ é o número de padrões de demanda observados $n^{P}$ é o número de padrões de demanda em que há observações de pressões, $n^{Q}$ é o número de padrões de demanda em que há observações de vazões, $w^{P}$ e $w^{Q}$ são pesos atribuídos às observações de pressões e vazões, respectivamente, $P$ são as pressões simuladas, $P^{*}$ as pressões observadas, $Q$ as vazões simuladas, $Q^{*}$ as vazões observadas e $Z$ o conjunto de variáveis de decisão do problema, dado por:

$$
Z=Z_{1}=\left(\varepsilon_{1}, \ldots, \varepsilon_{n_{\varepsilon}}, D_{1}, \ldots, D_{n_{D}}, d_{1}, \ldots, d_{n_{d}}, z_{1}, \ldots, z_{n_{z}}, \theta_{1}, \ldots, \theta_{n_{\theta}}, \beta_{1}, \ldots, \beta_{n_{\beta}}\right)
$$

sendo $n_{e}$ e $n_{D}$ são o número de tubulações ou setores de tubulações com rugosidades absolutas e diâmetros homogêneos, respectivamente, $n_{d}$ e $n_{z}$ o número de nós ou setores com demandas e cotas topográficas homogêneas, respectivamente, e $n_{\text {? }}$ e $n_{\beta}$ o número de tubulações ou setores com coeficiente e expoente de vazamento homogêneos.

Para o caso de determinação de registros em tubulações da rede, o conjunto de variáveis de decisão toma a seguinte forma:

$$
Z=\left(Z_{1}, I D_{1}, \Delta H_{1}, I D_{2}, \Delta H_{2}, \ldots, I D_{n_{T}}, \Delta H_{n_{T}}\right)
$$

sendo $I D$ é a identificação da tubulação que contêm registro, número inteiro arbitrado pelo autor da modelação, ?H é a respectiva perda de carga localizada devido à presença de registro, estimada pelo comprimento equivalente ou acréscimo da rugosidade absoluta, e $n_{T}$ é o número de registros que se estima estarem presentes na rede. Para este trabalho, considerou-se o número de registros presentes na rede como o obtido através do cadastro eletrônico da rede do setor e posterior visita in loco para confirmação da quantidade e disposição dos mesmos nas redes de abastecimento de água de Guariba e de Itirapuã.

A outra função objetivo baseia-se no quadrado da diferença de valores computados e simulados de pressões e vazões para os diversos padrões de demanda observados.

$$
\min _{Z} F O_{2}=\sum_{t=1}^{n^{P D}}\left\{\sum_{j=1}^{n_{t}^{P}}\left[\left(P_{t, j}-P_{t, j}^{*}\right)^{2}\right]+\sum_{j=1}^{n_{t}^{Q}}\left[\left(Q_{t, j}-Q_{t, j}^{*}\right)^{2}\right]\right\}
$$


SOARES (2003) argumenta que muitos erros no processo de calibração podem ter origem na coleta de dados de campo que alimentam o modelo (erros de medidores ou má localização dos pontos escolhidos) e que uma das maneiras de se diminuir essas imprecisões no modelo é a aplicação de pesos na função objetivo.

Uma metodologia para a adoção de pesos na função objetivo é apresentada por REDDY,SHIDHARAN e RAO (1996) investigando a influência dos diferentes tipos de pesos para pressão e vazão. Um erro padrão (tipo fixo) baseado na média dos valores observados é adotado para medidas de pressão. Porém, para as medidas de vazão, o erro se baseia na variância e na magnitude dos valores observados adotando-se a porcentagem de cada valor.

No trabalho de SOARES (2003), a adoção de pesos é feita mase da tentativa, adotando-se pesos fixos para cada conjunto de medidas de tipos diferentes, sendo um peso para o conjunto de medidas de pressão e outro peso para o conjunto de medidas de vazão, com análise dos desvios gerados. No presente trabalho, será utilizado o mesmo método de adoção de pesos usado por SOARES (2003).

\subsubsection{MODELO DE SIMULAÇÃO HIDRÁULICA}

Segundo ROSSMAN (2000), o Método Hequações da continuidade e da conservação da energia, e a relação entre a perda de carga e a vazão, que caracterizam as condições de equilíbrio hidráulico da rede num dado instante. TODINI e PILATI ${ }^{*}$ (1987 apud ROSSMAN, 2000, p. 183) optaram por designar o Método H como "Método Gradiente". ROSSMAN (2000) salienta que a única diferença entre os dois métodos é o modo como as vazões nos tubos são atualizadas após ter encontrado uma nova solução de pressões nos nós durante o processo iterativo. Por se tratar de um método mais simples, o simulador hidráulico EPANET utiliza o método proposto por Todini e Pilati para obter os valores de vazão e pressão na rede. Este método está descrito a seguir:

Considerando uma rede com $N$ nós e $N F$ nós com carga hidráulica fixa, a relação perda de carga x vazão em uma tubulação entre os nós $i$ e $j$ pode ser representada pela seguinte expressão:

\footnotetext{
* TODINI, E., PILATI, S. (1987). A gradient method for the analysis of pipe network. International Conference on Computer Applications for Water Supply and Distribution. UK. Leicester Polytechnic apud ROSSMAN, L. A. (2000). EPANET 2 users manual. Cincinnati, Ohio. U.S. Environmental Protection Agency. P. 183.
} 


$$
H_{i}-H_{j}=h_{i j}=r Q_{i j}^{n}+m Q_{i j}^{2}
$$

sendo $H$ a carga hidráulica no nó, $h$ a perda de carga total, $r$ o termo de perda de carga que depende da formulação utilizada, $Q$ a vazão na tubulação, $n$ o expoente da formulação perda de carga x vazão e $m$ o coeficiente de perda de carga localizada.

A conservação de massa nos nós é especificada pela expressão:

$$
\sum_{j \in J_{i}} Q_{i j}-C_{i}=0 \quad \text { para } i=1, \ldots, N
$$

em que $C$ é o consumo no nó $i$ e $J_{i}$ são todos os nós conectados ao nó $i$. Assim, conhecendo a carga hidráulica nos $N F$ nós, obtém-se os valores de pressão e vazão na rede que satisfaçam as eqs. (4.5) e (4.6).

Arbitrada uma solução inicial para as vazões nas tubulações, novas cargas hidráulicas nos nós são obtidas em cada iteração do Método Gradiente, resolvendo o seguinte sistema linear:

$$
\text { A. } \mathrm{H}=\mathrm{F}
$$

em que A é a matriz Jacobiana $(N x N), \mathrm{H}$ o vetor de incógnitas em termos das cargas hidráulicas e F o vetor de balanço de massa mais um fator de correção da vazão.

Os elementos da diagonal da matriz Jacobiana são dados por:

$$
A_{i i}=\sum_{j \in J_{i}} x_{i j}
$$

enquanto os elementos não nulos fora da diagonal são dados por:

$$
A_{i j}=-x_{i j}
$$

em que $x_{i j}$ é o inverso da derivada da perda de carga total na tubulação entre os nós $i$ e $j$, dado por:

$$
x_{i j}=\frac{1}{n . r .\left|Q_{i j}\right|^{n-1}+2 . m \cdot\left|Q_{i j}\right|}
$$

$\mathrm{O}$ vetor $\mathrm{F}$ é composto pela parcela do balanço de massa no nó adicionada um fator de correção da vazão, como:

$$
F_{i}=\left(\sum_{j \in J_{i}} Q_{i j}-C_{i}\right)+\sum_{j \in J_{i}} y_{i j}+\sum_{f \in J_{f}} x_{i f} \cdot H_{f}
$$

sendo o último termo aplicável a qualquer tubulação ligando o nó $i$ a um nó $f$ de carga hidráulica constante, $J_{f}$ o conjunto de nós com carga hidráulica constante ligados ao nó $i$, e $y$ o fator de correção da vazão, dado pela seguinte expressão: 


$$
y_{i j}=x_{i j}\left(r\left|Q_{i j}\right|^{n}+m\left|Q_{i j}\right|^{2}\right) \operatorname{sgn}\left(Q_{i j}\right)
$$

em que $\operatorname{sgn}(\mathrm{x})$ é 1 se $\mathrm{x}>0$ e -1 caso contrário.

Após terem sido calculadas as cargas hidráulicas nos nós, os novos valores das vazões nas tubulações são obtidos de acordo com a seguinte expressão:

$$
Q_{i j}=Q_{i j}-\left\lfloor y_{i j}-x_{i j}\left(H_{i}-H_{j}\right)\right\rfloor
$$

Se a soma de todas as variações de vazão (em valor absoluto) relativa à vazão total em todas as tubulações for superior à tolerância especificada, as eqs. (4.7) e (4.13) são resolvidas novamente.

SOARES (2003) utiliza o simulador hidráulico EPANET como um módulo auxiliar na avaliação hidráulica da rede de distribuição de água que considera vazamentos e demandas dirigidas pela pressão. O autor ainda comenta a dificuldade de se avaliar a parcela da vazão abastecida total que corresponde aos vazamentos, sendo necessária uma suposição quanto à composição da vazão abastecida. Assim, admitiu-se que a vazão total abastecida (TS) possa ser subdividida em demanda total efetivamente abastecida $(T D)$ e vazamentos $(V)$, embora, haja na prática, a possibilidade de usos não autorizados da água. O balanço de massa correspondente passa ser escrito como:

$$
T S=T D+V
$$

A partir da suposição de que a distribuição espacial da demanda total seja conhecida e obedeça a um mesmo padrão de variação temporal, refletido no fator multiplicador $(F T)$ da demanda total de referência $\left(T S^{*}\right)$, geralmente estabelecida com base nos consumos mensais, a demanda potencial total (TDP) pode ser expressa como:

$$
T D P=F T . T S^{*}
$$

Assim, a demanda potencial total corresponde à demanda efetivamente abastecida total mais aquela parcela que deixa de ser atendida (PNA), devido às limitações impostas pelas variações das pressões (modelo pressão x demanda):

$$
T D=T D P-P N A
$$

Substituindo-se as equações (4.15) e (4.16) em (4.14), tem-se:

$$
T S=F T . T S^{*}-P N A+V
$$

Dessa maneira, o fator $(F T)$ pode ser obtido a partir dos valores estimados iniciais para PNA e $V$ como:

$$
F T=\frac{T S+P N A-V}{T S^{*}}
$$

sendo $P N A=\left(F T . T S^{*}-T D\right)_{\text {inicial }} ;$ para $V_{\text {inicial }}$. 
Assim, o novo fator multiplicador $\left(F T_{2}\right)$ no procedimento iterativo será:

$$
F T_{2}=\frac{T S+F T_{1} \cdot T S^{*}-T D_{1}-V_{1}}{T S^{*}}
$$

sendo $F T_{1}, T D_{1}$ e $V_{1}$ os valores na estimativa anterior para o fator multiplicador, a demanda total efetivamente abastecida e o vazamento total, respectivamente.

SOARES (2003) propõe a avaliação do desempenho dos modelos de vazamento e demanda dependentes da pressão de FUJIWARA e LI (1998), TUCCIARELLI, CRIMINISI e TERMINI (1999) e TABESH e KARIMZADEH (2000), integrando-os ao simulador hidráulico EPANET, sem intervenção direta sobre o código existente, por meio do procedimento iterativo descrito na Figura 4.2. Assim, uma rotina computacional de cálculo foi codificada em linguagem $C++$ para a realização dos cálculos seguindo o mesmo fluxograma.

O autor avalia as perdas por vazamento por meio da formulação proposta por TUCCIARELLI, CRIMINISI e TERMINI (1999) dada pela eq. (3.15), em que se considera que nas tubulações que compõem cada zona há valores constantes de vazamento por área de superfície de tubo. Para avaliação das demandas nos nós, são utilizadas as metodologias propostas por FUJIWARA e LI (1998), TUCCIARELLI, CRIMINISI e TERMINI (1999) e TABESH e KARIMZADEH (2000), descritas na Tabela 3.1.

O início do processo representado na Figura 4.2 é o conhecimento prévio da vazão abastecida total (TS) e do consumo potencial no espaço para certa condição operacional do dia, que inclui a demanda total efetivamente abastecida aos consumidores $(T D)$ e a quantidade total das perdas por vazamentos $(V)$. O conhecimento da vazão total abastecida pode ser feito através do controle das vazões que saem dos reservatórios. Além da vazão total abastecida, também são dados de entrada no modelo a vazão de abastecimento de referência $\left(T S^{*}\right)$, geralmente determinada com base no consumo médio mensal, as rugosidades absolutas $e$ e coeficientes de perdas por vazamento ? para cada tubulação ou zona, o expoente de perda $\beta$ para cada nó ou zona, a formulação para variação das demandas com a pressão, além das características da rede, como diâmetros e comprimentos das tubulações, níveis dos reservatórios, topografia e componentes hidráulicos. 


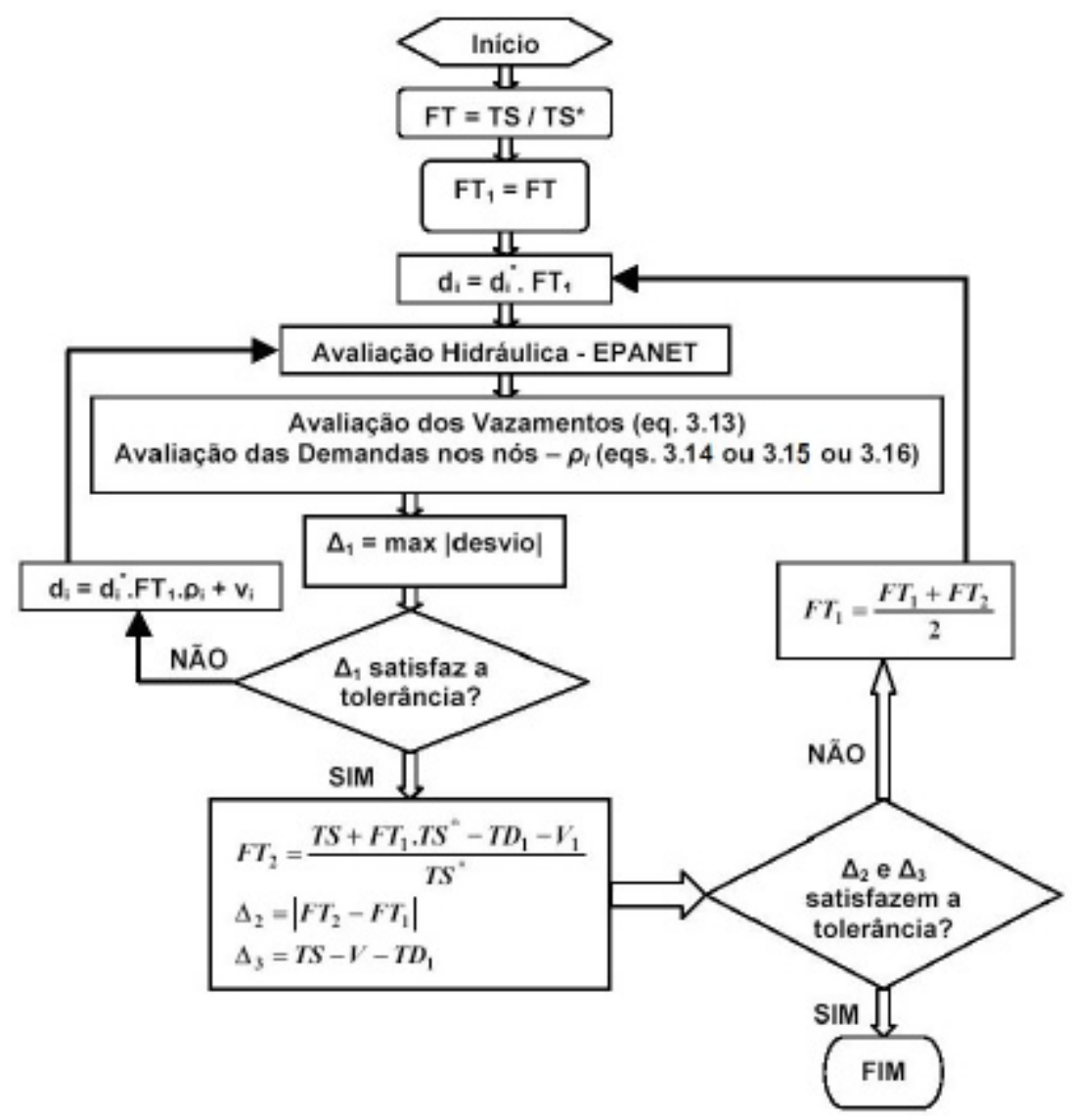

Figura 4.2 - Fluxograma do processo iterativo proposto para avaliação hidráulica e determinação do fator de consumo para cada padrão (cenário) de demanda. SOARES (2003)

$?_{1}$ é máximo desvio entre as pressões anteriores e presentes calculadas para cada nó.

$$
\begin{aligned}
& T S^{*}=\sum_{i \in N} d_{i}^{*} \\
& T D=F T_{1} \sum_{i \in N} d_{i}^{*} \cdot \rho_{i} \\
& V=\sum_{i \in N} v_{i}
\end{aligned}
$$

$N$ = número de nós.

SOARES (2003) implementou uma rotina computacional em linguagem $C++$, utilizando o simulador hidráulico EPANET como módulo auxiliar no processo iterativo proposto e a biblioteca GAlib $C++$ para desenvolvimento dos Algoritmos Genéticos, além da implementação do método Simplex (NELDEReMEAD, 1965) para uso em conjunto com os AGs (método híbrido). A partir daí, estudos sobre a calibração em termos das rugosidades absolutas, diâmetros, demandas, cotas topográficas e parâmetros 
do modelo de vazamentos, além da identificação de registros na rede de distribuição de água foram possíveis.

O código computacional de SOARES (2003) prevê a utilização de três arquivos de entrada que foram criados segundo as características das redes de abastecimento de água de Guariba e Itirapuã.

O arquivo 1 (field2.in) é composto por dados observados de pressão, vazão abastecida, carga hidráulica na entrada do setor (nível do reservatório), com as respectivas identificações de localização da medida (nó e tubulação), e vazão abastecida para cada tipo de medida (pressão ou vazão).

O arquivo 2 (ga1.in) contém os parâmetros estabelecidos dos AGs, como tipo (geracional elitista ou Steady-State), seleção (Ordenamento, Roda da Roleta, Torneio, Uniforme, Amostragem Determinística e Stochastic Remainder Sampling - SRS), número de cromossomos a serem trocados (no caso do AG Steady-State), recombinação (Uniforme, Um Ponto, Dois Pontos, Aritmética e $B L X-a$ ), probabilidades de recombinação e mutação, tamanho da população, número de gerações e semente aleatória. Também fornece a setorização da rede de distribuição de água em relação às rugosidades absolutas e parâmetros de vazamento (coeficiente e expoente), diâmetros, cotas topográficas, demandas e a localização de um determinado número de registros, além dos limites mínimo e máximo para cada variável de decisão. E como última opção, o modelo pressão x demanda a ser usado (FUJIWARA e LI, 1998; TUCCIARELLI, CRIMINISI e TERMINI, 1999 e TABESH e KARIMZADEH, 2000).

$\mathrm{O}$ arquivo 3 (tucciarelli.inp) é o arquivo de entrada gerado pelo simulador hidráulico EPANET, contendo os dados da rede, como demandas e cotas topográficas dos nós, nível do reservatório, comprimentos, diâmetros e rugosidades das tubulações, válvulas, além de opções quanto ao uso de equações de perda de carga ( DarcyWeisbach, Hazen-Williams ou Chezy-Manning), unidades, tolerância e outros. Para a construção do arquivo 3, estimaram-se rugosidades para as tubulações de acordo com os materiais que as compõem tendo como referência PORTO (2000).

O processo de calibração com a utilização dos AGs como método de busca está demonstrado na Figura 4.3 e a integração do modelo de otimização ao processo de calibração, empregando o modelo híbrido (AGs e Método Nelder-Mead) é apresentada na Figura 4.4. 


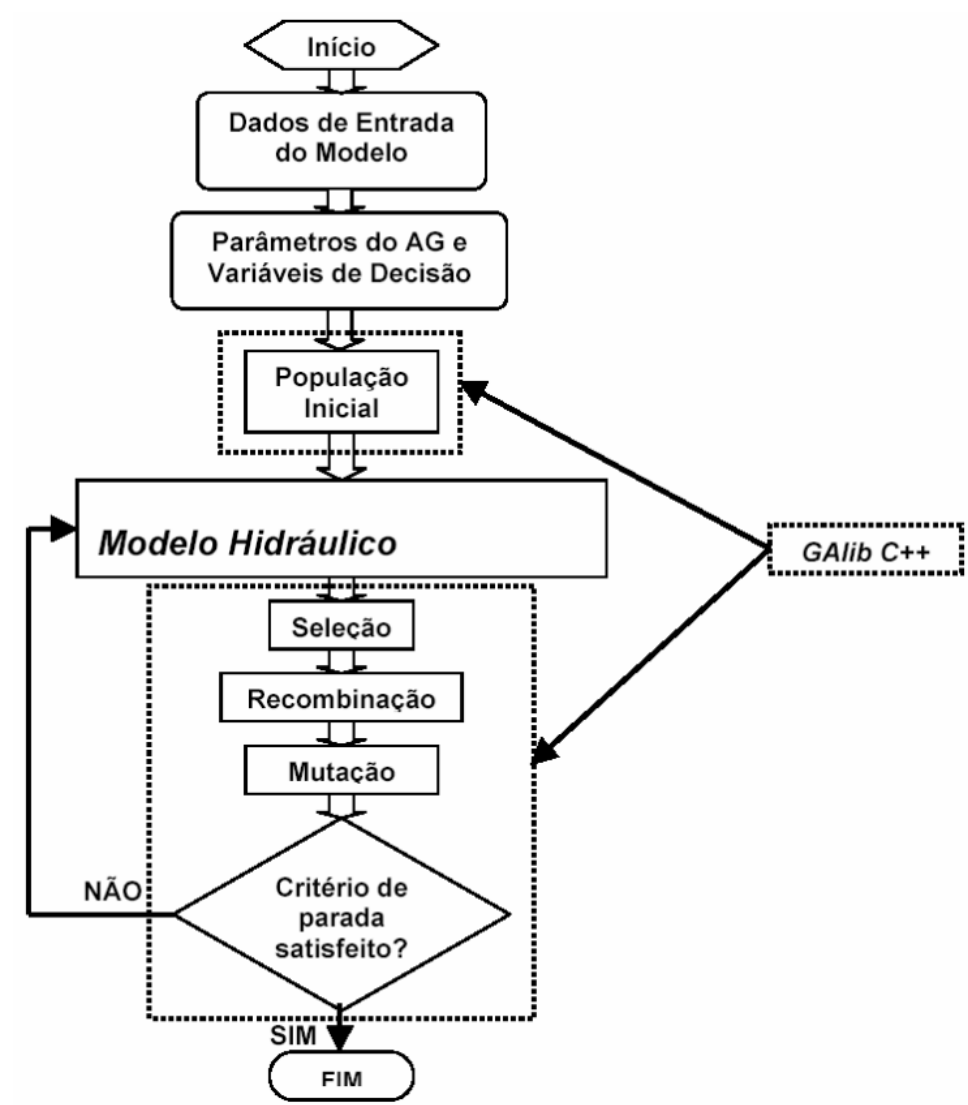

Figura 4.3 - Fluxograma do processo de calibração com os AGs. SOARES (2003)

O código computacional de SOARES (2003) ainda prevê critérios de convergência. Para os Algoritmos Genéticos, o critério de parada adotado foi o número de gerações. Este critério foi adotado por facilitar a utilização da biblioteca GAlib $C++$, visto que outro critério demandaria um esforço computacional maior, devido à incompatibilidade da biblioteca com outras formas de convergência.

No caso do método híbrido, uma tolerância foi adotada para a verificação da convergência do Método Simplex, e comparada com a eq. (3.12). 


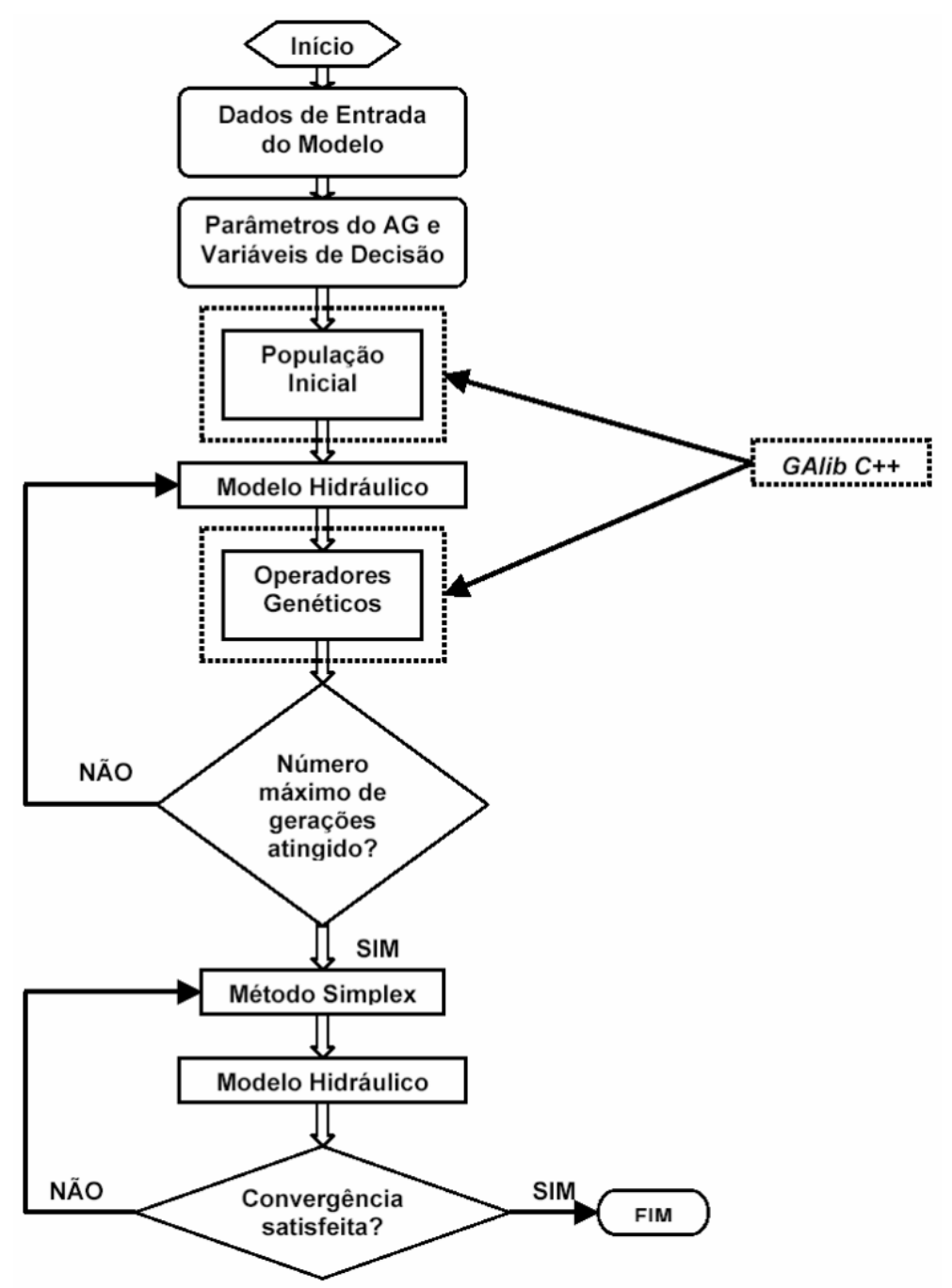

Figura 4.4 - Fluxograma do processo de calibração com o modelo híbrido. SOARES (2003)

\subsubsection{ANÁLISE DA CALIBRAÇÃO}

WATER RESEARCH CENTRE (1989) apresenta critérios para comparação entre os valores observados em campo e aqueles obtidos via simulação. Para os valores de pressão, o critério deve se basear no erro absoluto, dado pela diferença entre o valor simulado e o observado, e não deve exceder uma das seguintes faixas:

$$
\begin{aligned}
& > \pm 0,5 \mathrm{~m} \text { para } 85 \% \text { das medidas de pressão; } \\
& > \pm 0,75 \mathrm{~m} \text { para } 95 \% \text { das medidas de pressão; } \\
& > \pm 2 \mathrm{~m} \text { para } 100 \% \text { das medidas de pressão. }
\end{aligned}
$$

Neste trabalho, a análise do desempenho da calibração será feita com base nestes critérios. 


\subsection{ETAPAS DO TRABALHO}

O desenvolvimento do presente projeto de pesquisa consistiu das seguintes etapas;

Escolha do sistema a ser estudado;

Levantamento dos dados existentes;

Monitoramento de pressões e vazões na entrada dos setores;

Análise detalhada (Calibração) do setor mais crítico identificado;

Diagnóstico dos problemas a partir da análise dos resultados;

Conforme será visto mais adiante, o primeiro setor escolhido para análise mostrou-se inadequado, exigindo que outro sistema fosse analisado. Assim, o trabalho desenvolvido foi subdividido em duas partes. A primeira compreendeu o estudo realizado sobre o sistema de distribuição de água de Guariba, que convenientemente apresenta vazamentos expressivos, merecendo ser investigado. A segunda etapa do trabalho visou o sistema de abastecimento de água de Itirapuã que apresentava características distintas do primeiro. Tratava-se de um município de dimensões reduzidas, abastecido por um único reservatório, características essas que lhe conferem a propriedade de um setor de rede de abastecimento isolado.

\subsection{OBJETOS DE ESTUDO}

\subsubsection{PRIMEIRO SISTEMA ESTUDADO}

A escolha do primeiro sistema a ser estudado foi realizada em parceria com o setor de Desenvolvimento Operacional (RGO) da Unidade de Negócio Pardo e Grande da Companhia de Saneamento Básico do Estado de São Paulo (SABESP) situado em Franca-SP de qual o aluno é funcionário. A partir de reunião realizada no dia 13 de janeiro de 2005, na SABESP, definiu-se, entre os municípios que são atendidos por esta unidade de negócio da empresa, que a cidade de Guariba, por apresentar índice de perda excessivo (da ordem de $40 \%$ do total abastecido), deveria ser alvo do presente estudo. A rede apresentava problemas de vazamentos, levando a crer que um modelo incluindo vazamentos é de especial interesse. 


\subsubsection{CARACTERÍSTICAS GERAIS DA CIDADE DE GUARIBA}

A cidade de Guariba tem como coordenadas geográficas $21^{\circ} 24^{\prime} 00^{\prime \prime}$ de latitude sul e $48^{\circ} 14^{\prime} 00^{\prime}$ de longitude W. Gr. e como principais acessos rodoviários a via Anhanguera (SP-330); a via Washington Luis (SP-310); a via Brigadeiro Faria Lima (SP-326) e a Rodovia José Corona. A cidade situa-se na $7^{\mathrm{a}}$ zona hidrográfica do Estado de São Paulo e pertence à Bacia do Rio Mogi Guaçú, de classe 2 quanto ao índice de qualidade das águas, tendo uma pluviometria média que oscila entre $1100 \mathrm{~mm}$ e $1700 \mathrm{~mm}$, sendo a maior precipitação anual entre os meses de janeiro e fevereiro e a menor entre os meses de abril e setembro e estiagem ocorrendo entre setembro e novembro. A cidade está situado em área de clima úmido tropical sem estação seca, símbolo de Koeppen Aw, com temperatura média do mês mais quente de $22^{\circ} \mathrm{C}$ e do mês mais frio de $18^{\circ} \mathrm{C}$. Está assentada sobre a formação Bauru, onde existe uma camada de basalto que se inicia na profundidade de $20 \mathrm{~m}$, terminando na profundidade de $300 \mathrm{~m}$. As altitudes da cidade variam, atualmente, entre as cotas $570 \mathrm{~m}$ e $650 \mathrm{~m}$, podendo-se considerar como cota média o valor de $620 \mathrm{~m}$. A parte mais acidentada fica a Este, onde se situam os bairros de Vila Progresso e Vila Corona. O restante da cidade apresenta topografia levemente ondulada.

\subsubsection{DESCRIÇÃO DO SISTEMA DA CIDADE DE GUARIBA}

Guariba possui aproximadamente $96,3 \mathrm{Km}$ de rede de distribuição de água potável em quatro zonas de pressão; Zona Alta I, Zona Alta II (Amorim), Zona Média e Zona Baixa, composta por tubos de cinco tipos de materiais; PVC, DEFoFo, FoFo, CA (Cimento Amianto) e FoGo (Ferro Galvanizado). Os diâmetros dos tubos variam entre $400 \mathrm{~mm}, 300 \mathrm{~mm}, 200 \mathrm{~mm}, 150 \mathrm{~mm}, 100 \mathrm{~mm}, 75 \mathrm{~mm}, 60 \mathrm{~mm}, 50 \mathrm{~mm}$ e $37 \mathrm{~mm}$. O abastecimento da cidade é feito por dois poços principais P1 e P2, com vazão total de $250 \mathrm{~m}^{3} / \mathrm{h}$ (medidos através de medidores eletromagnéticos de vazão) armazenados em reservatórios de grandes volumes distribuídos da seguinte forma: R1 com capacidade de $800 \mathrm{~m}^{3}$ com duas saídas de recalque, sendo uma para o abastecimento do reservatório principal R5 e outra para o abastecimento do reservatório de aço Amorim. A capacidade do reservatório R5 é de $2000 \mathrm{~m}^{3}$ e possui duas saídas de distribuição responsável pelo abastecimento das Zonas de pressão Média, Baixa e Alta I, sendo que esta última tem o sistema de abastecimento pressurizado por bombas hidráulicas. A capacidade do reservatório de aço Amorim é de $100 \mathrm{~m}^{3}$ com apenas uma saída de distribuição 
responsável pelo abastecimento da Zona Alta II (Amorim). A cidade possui ainda medidores eletromagnéticos de vazão localizados em todas as saídas de distribuição de água para a cidade e fornecem, através de sua soma, o valor macromedido de vazão da cidade. Além disso, a cidade conta com cerca de 8400 ligações de água para uma população de 35000 habitantes aproximadamente.

$\mathrm{O}$ anexo A apresenta o sistema de distribuição de água para abastecimento da cidade de Guariba além de detalhes das tubulações de maiores diâmetros de cada setor.

\subsubsection{SEGUNDO SISTEMA ESTUDADO}

Devido aos resultados encontrados no estudo de simulação e calibração da cidade de Guariba não representarem adequadamente o estado atual da rede, um novo estudo foi proposto em outra cidade de concessão da SABESP. Uma nova reunião com o setor de Desenvolvimento Operacional (RGO) da SABESP em Franca aconteceu no dia 24 de julho de 2006, onde se decidiu pela cidade de Itirapuã como escolha do segundo sistema a ser estudado.

As dimensões reduzidas da cidade diminuindo razoavelmente o risco de falhas no cadastro existente, baixa densidade populacional facilitando o cálculo dos consumos nodais, e a cidade apresentar apenas uma zona de abastecimento alimentada por um único reservatório elevado foram as principais características que tenderam Itirapuã como a escolha da cidade, uma vez que as características citadas garantiriam reduzidas visitas à cidade para que o estudo fosse completado antes do término do prazo de entrega da dissertação.

\subsubsection{CARACTERÍSTICAS GERAIS DA CIDADE DE ITIRAPUÃ}

A cidade integra a micro-região do Planalto de Franca na região nordeste de São Paulo e ocupa uma área de $154 \mathrm{Km}^{2}$, limitando-se ao norte e oeste com a cidade de Patrocínio Paulista, a leste com Capetinga (MG) e ao sul com São Tomas de Aquino (MG). A sua sede tem por coordenadas geográficas $20^{\circ} 28^{\prime} 00^{\prime \prime}$ de latitude sul e $47^{\circ}$ 13'00" de longitude W. Gr., e uma altitude de 865 m (IBGE RN no 73 K). a cidade dista da capital $448 \mathrm{Km}$, rumo noroeste tendo como acessos principais as rodovias SP-330, SP-334 e SP-345.

Itirapuã encontra-se no alto de uma elevação entre os córregos Capanema e São Francisco. Está inserida na Unidade de Gerenciamento de Recursos Hídricos - UGRHI 
08, a Bacia Hidrográfica do Sapucaí Mirim/Grande, na sub-bacia 1, denominada Alto do Sapucaí, cuja geomorfologia é constituída por Cuestas Basálticas e Planalto Ocidental.

O clima da região é muito úmido sub-tropical com estiagem no inverno. O período das chuvas estende-se de fins de novembro a fevereiro, em que a precipitação total média anual está compreendida entre 1.500 e $1.600 \mathrm{~mm}$. Quanto a temperatura, a média das mínimas é de $16^{\circ} \mathrm{C}$ e a média das máximas, de $26^{\circ} \mathrm{C}$.

Situada a aproximadamente $1 \mathrm{Km}$ da encosta direita do vale do ribeirão Capanema, Itirapuã apresenta uma topografia suave, com declividade de 2 a $6 \%$ para o lado do ribeirão. O ponto mais alto da cidade está na cota $870 \mathrm{~m}$ e o mais baixo na cota 785 m (R.T.P. Água Itirapuã - 1976).

\subsubsection{DESCRIÇÃO DO SISTEMA DA CIDADE DE ITIRAPUÃ}

Itirapuã possui apenas uma zona de pressão ou setor de abastecimento com aproximadamente $17,408 \mathrm{Km}$ de rede de distribuição de água potável, composta essencialmente por tubos de PVC e CA (Cimento Amianto). Os diâmetros dos tubos variam entre $150 \mathrm{~mm}, 100 \mathrm{~mm}, 75 \mathrm{~mm}$ e $50 \mathrm{~mm}$. O abastecimento da cidade é feito por três poços tubulares; PPS01, PPS03 e PPS04 com capacidade de vazão total de $60 \mathrm{~m} / \mathrm{h}$ (medidos através de medidores eletromagnéticos de vazão) capaz de atender integralmente a demanda máxima da cidade. A água captada pelos poços é recalcada para o reservatório apoiado RA01 com capacidade de $100 \mathrm{~m}^{3}$ funcionando atualmente como caixa de mistura para a dosagem de produtos químicos utilizados na desinfecção da água. Por meio de duas bombas centrífugas horizontais, a água tratada no RA01 é recalcada para o reservatório elevado T01 de capacidade $250 \mathrm{~m}^{3}$ que, por sua vez, é responsável pelo abastecimento total da cidade.

A cidade possui um medidor eletromagnético de vazão localizado na saída de distribuição do reservatório elevado T01 fornecendo o valor macromedido de vazão de demanda da cidade. Além disso, a cidade conta com cerca de 1.471 ligações de água para uma população de 4.700 habitantes aproximadamente.

$\mathrm{O}$ anexo B apresenta o sistema de distribuição de água para abastecimento da cidade de Itirapuã além de detalhes das tubulações de maiores diâmetros de cada setor. 


\subsubsection{LEVANTAMENTO DOS DADOS EXISTENTES}

Foram realizadas visitas aos municípios de Guariba e Itirapuã, visando adquirir cadastros eletrônicos das redes de abastecimento, com informações específicas sobre os sistemas tais como: diâmetros, comprimentos e material dos tubos segundo Tabela 4.1 para a cidade de Guariba e Tabela 4.2 para a cidade de Itirapuã, localização de singularidades como curvas, reduções, registros, etc., delimitação das zonas de pressão para o caso da cidade de Guariba uma vez que a cidade de Itirapuã tem apenas uma zona de pressão, arruamento com os respectivos nomes, rotas de leituras dos hidrômetros (percurso utilizado pelos leituristas), posição espacial dos reservatórios de abastecimento e curvas de nível. Observa-se que para o sistema de Guariba a atualização do cadastro, no que se refere às características e posições dos componentes da rede, é feita através das informações das ordens de serviço (OS) executadas diariamente e das expansões de redes realizadas para abastecer novos loteamentos ou ruas que ainda não recebiam abastecimento de água. Esse procedimento não é realizado na cidade de Itirapuã por não haver um funcionário habilitado a executar tal procedimento.

Tabela 4.1. Comprimento da rede de abastecimento de água em relação à zona de pressão e o material que a compõe para a cidade de Guariba

\begin{tabular}{|l|r|r|r|}
\hline \multicolumn{1}{|c|}{ MATERIAL } & ZONA ALTA $(\mathbf{m})$ & ZONA MÉDIA (m) & ZONA BAIXA (m) \\
\hline PVC & 38753.74 & 14672.4 & 7588.52 \\
\hline DEFoFo & 193.6 & 2428.2 & 1115.89 \\
\hline FoFo & 4109.01 & 7498.99 & 949.87 \\
\hline CA & 79.82 & & 486.26 \\
\hline FoGo & & 473.84 & 10140.54 \\
\hline Compr. Total & 43136.17 & 25073.43 & \\
\hline Compr. total da rede & 78350.14 & &
\end{tabular}

Tabela 4.2. Comprimento da rede de abastecimento de água em relação ao material que a compõe para a cidade de Itirapuã

\begin{tabular}{|l|c|r|}
\hline \multicolumn{1}{|c|}{ MATERIAL } & DIÂMETRO $(\mathbf{m m})$ & ZONA ÚNICA $(\mathbf{m})$ \\
\hline CA & 75 & 514 \\
\hline CA & 50 & 7116 \\
\hline PVC & 100 & 548 \\
\hline PVC & 75 & 710 \\
\hline PVC & 50 & 8520 \\
\hline Compr. total da rede & & 17408 \\
\hline
\end{tabular}


Arquivos eletrônicos de micromedição por ligação foram obtidos junto ao setor comercial. Observa-se que, para efeito da avaliação da distribuição espacial da demanda, os dados da micromedição devem ser totalizados por quadra e transferidos aos nós da rede.

Para o cálculo das demandas nodais de referência, o software de gerenciamento de consumo (Hidrocontrol) e o cadastro de ligações de água usados pelo departamento comercial da SABESP foram disponibilizados. O Hidrocontrol, ilustrado na Figura 4.5, foi capaz de fornecer dados como grupo, setor, rota, quadra, endereço e consumo mensal e semestral em $\mathrm{m}^{3}$ de cada ligação de água da cidade.

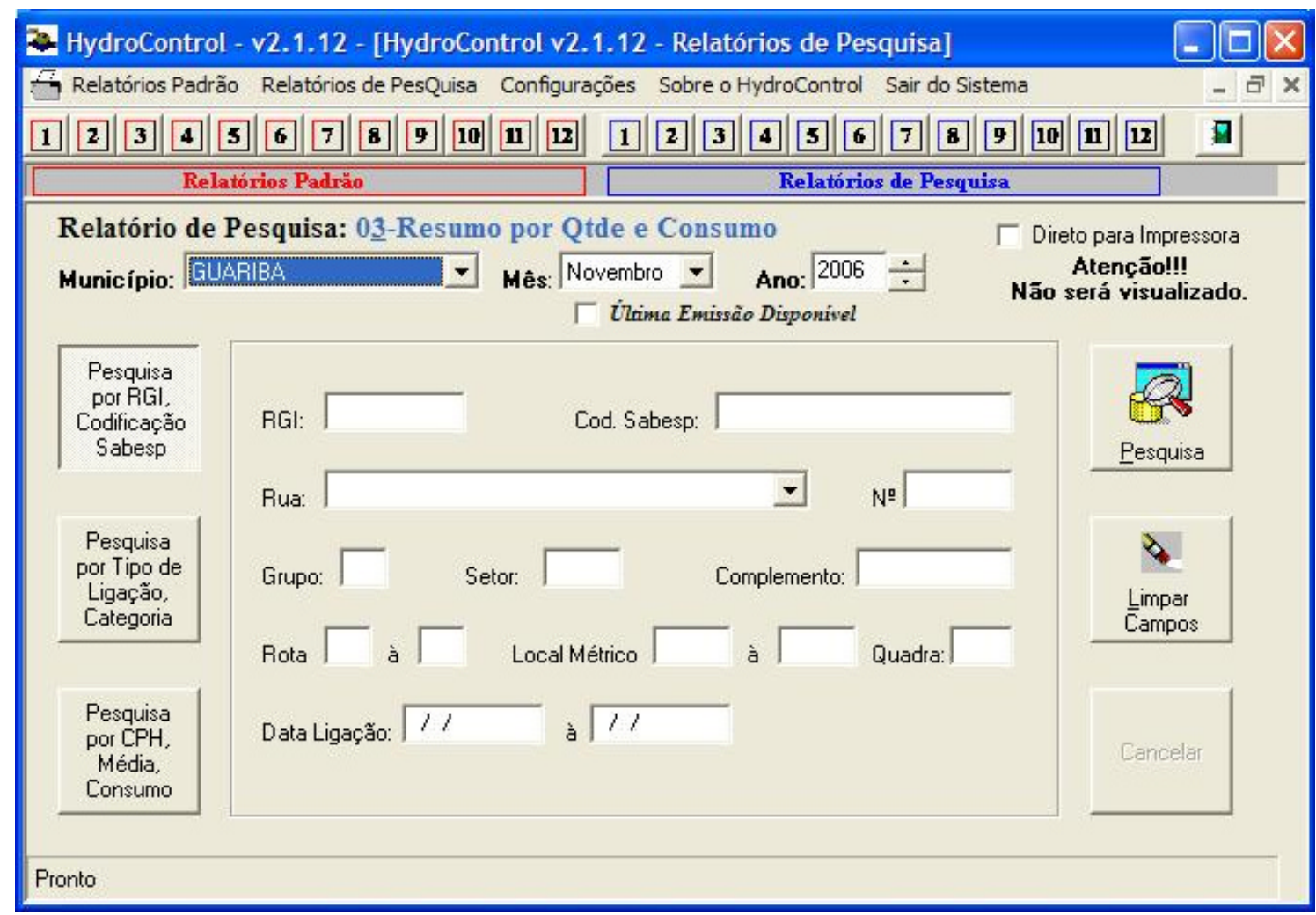

Figura 4.5 - Tela principal de geração de relatórios de pesquisa do software HydroControl

O procedimento de cálculo do consumo nodal foi o seguinte; através de uma tabela fornecida pelos leituristas da cidade de Guariba, identificaram-se os grupos que faziam parte do setor Zona Média. A partir daí, consultava-se, através do software Hidrocontrol, a média semestral do consumo de cada quadra dos grupos. Assim era possível a aquisição dos dados de consumo de apenas um dos lados (de numeração par ou ímpar) das quatro ruas que compõem cada quadra. Para se obter o consumo entre as esquinas de uma mesma rua era necessária a consulta do consumo das quadras adjacentes correspondentes às residências de números pares e números ímpares de uma 
mesma rua. Assim, a soma dos dois valores correspondia ao consumo total entre as esquinas daquela rua. Com a média semestral do consumo de todas as ruas que correspondiam ao setor Zona Média, o consumo obtido entre duas esquinas de uma mesma rua era dividido por dois e cada esquina recebia uma parte deste valor, de maneira que cada nó acumulasse esses valores médios relativos às ruas que convergem para ele. A Figura 4.6 ilustra a posição das quadras e a eq.(4.23) exemplifica como o cálculo do consumo nodal foi feito.

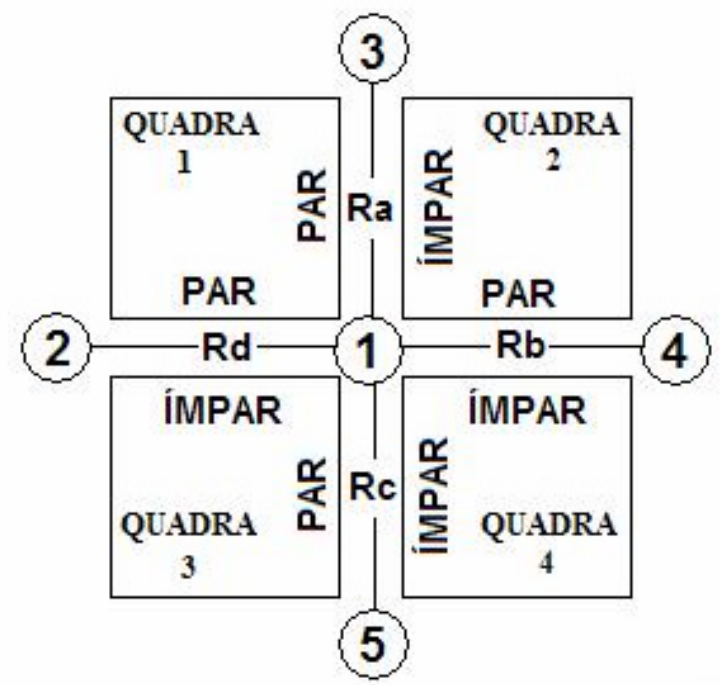

Figura 4.6 - Exemplo de disposição das quadras e posição das numerações residenciais

$$
C_{n_{1}}=\left(\frac{C_{R a_{p a r}}+C_{R a_{i m p a r}}}{2}\right)+\left(\frac{C_{R b_{p a r}}+C_{R b_{\text {impar }}}}{2}\right)+\left(\frac{C_{R c_{p a r}}+C_{R c_{\text {impar }}}}{2}\right)+\left(\frac{C_{R d_{p a r}}+C_{R d_{\text {impar }}}}{2}\right)
$$

Sendo $C_{R a_{p a r}}, C_{R b_{p a r}}, C_{R c_{p a r}}$ e $C_{R d_{p a r}}$ a soma das médias semestrais dos consumos das residências situadas do lado par das ruas $a, b, c$ e $d$ respectivamente; $C_{R a_{\text {impar }}}, C_{R b_{\text {impar }}}$, $C_{R c_{\text {impar }}}$ e $C_{R d_{\text {impar }}}$ a soma das médias semestrais dos consumos das residências situadas do lado ímpar das ruas $a, b, c$ e $d$ respectivamente e $C_{n_{1}}$ o consumo semestral referente ao nó 1 .

Alguns consumos foram corrigidos posteriormente devido a cadastros residenciais que não condiziam com a realidade. Isto ocorreu em algumas residências localizadas em esquinas com cadastro endereçado a uma rua, no entanto o ramal que a abastecia estava conectado a rede de outra rua. O último passo para a determinação do 
consumo nodal foi converter o volume semestral médio de cada nó de $\mathrm{m}^{3}$ para $\mathrm{L} / \mathrm{s}$ considerando um mês padrão como tendo 30 dias, ou seja, $1 \mathrm{~m}^{3} / \mathrm{mês}=3,858.10^{-4} \mathrm{~L} / \mathrm{s}$. Assim, o consumo nodal resulta da multiplicação de $3,858.10^{-4} \mathrm{~L} / \mathrm{s}$ pelo volume semestral médio de cada nó. A mesma metodologia foi usada para a aquisição dos consumos nodais da rede de abastecimento da cidade de Itirapuã.

Como os município de Guariba e Itirapuã são monitorados por sistema de telemetria e por um sistema de supervisão (software iFIX), dispõe-se de um banco de dados com informações de níveis de reservatórios, pressões de recalque das bombas, vazões de entrada e saída de reservatórios e vazões mínimas noturnas, além de horários de funcionamento das bombas. As Figuras 4.7 e 4.8 ilustram as telas de monitoramento e operação desenvolvidas por meio do software supervisório iFix para os municípios de Guariba e Itirapuã respectivamente.

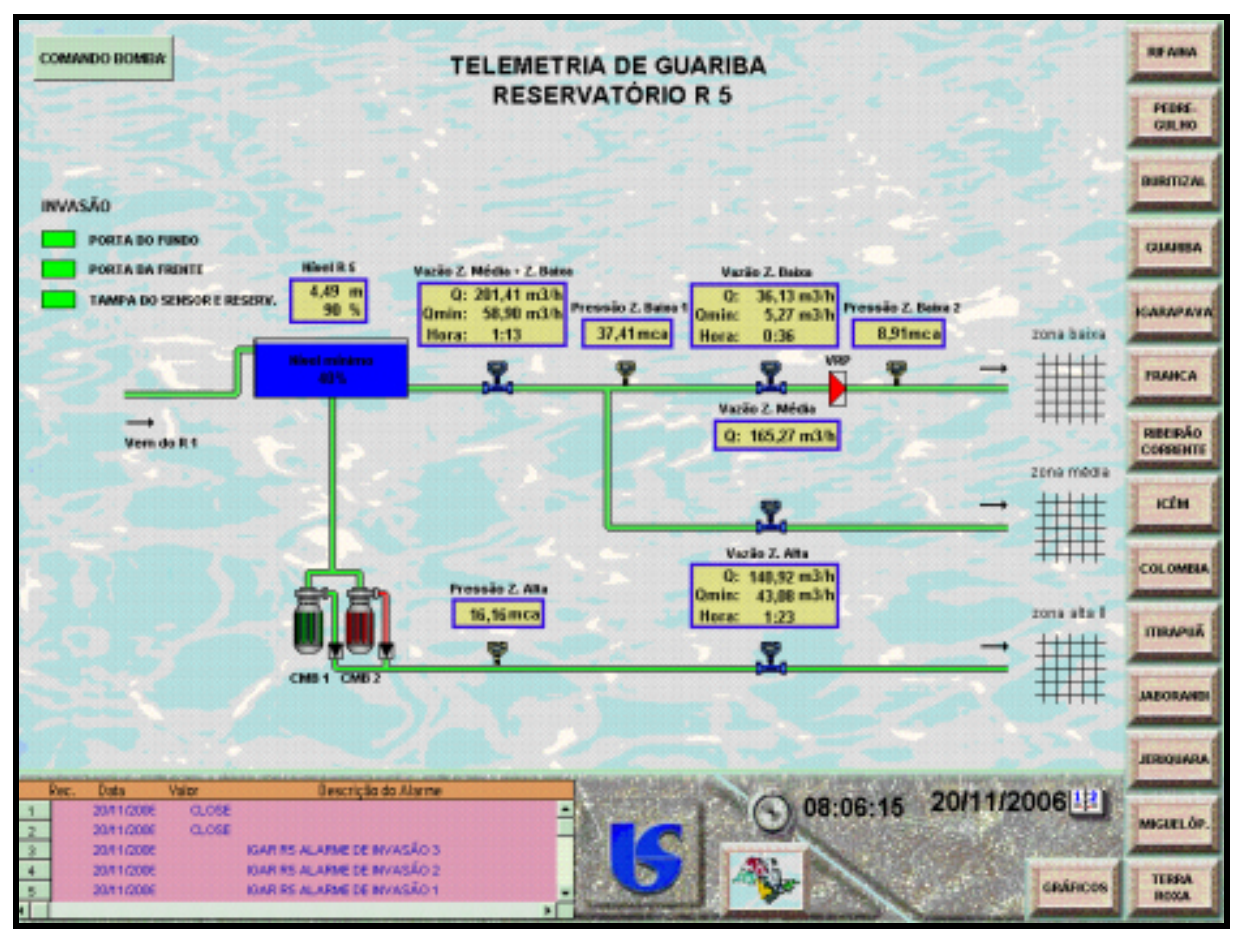

Figura 4.7 - Tela de operação e monitoramento do sistema de Guariba 


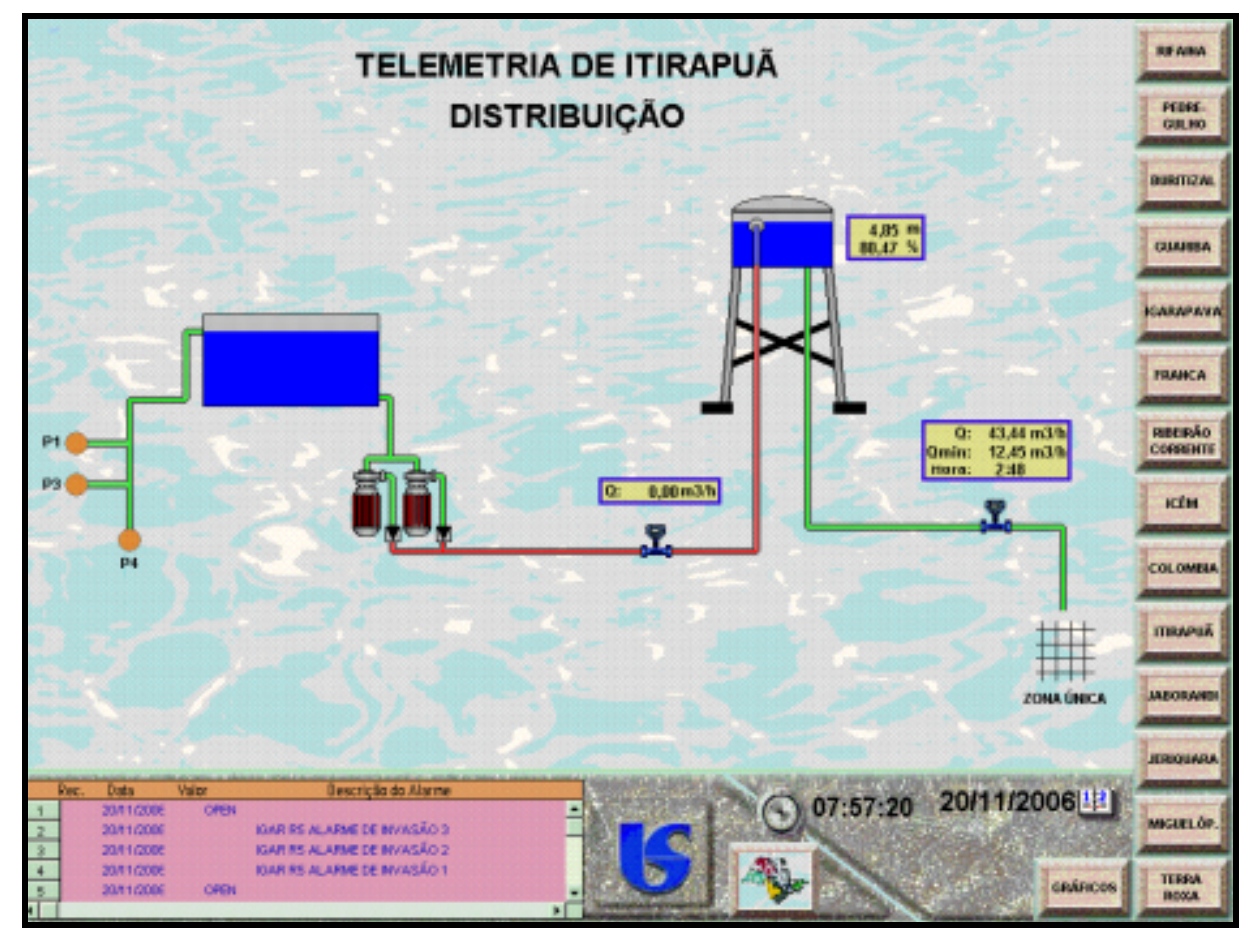

Figura 4.8 - Tela de operação e monitoramento do sistema de Itirapuã 


\section{RESULTADOS E DISCUSSÕES}

\subsection{DELIMITAÇÕES DAS ZONAS DE PRESSÃO PARA A CIDADE DE GUARIBA}

Durante o primeiro semestre de 2005, foram realizadas medições de pressão em pontos específicos da rede de abastecimento da cidade de Guariba com o intuito de garantir as delimitações dos setores da mesma. O método usado nestas coletas de dados foi o seguinte: através do cadastro eletrônico da rede identificavam-se os pontos de interligação entre os setores da rede (zonas de pressão) e in loco garantia-se que os registros de controle de cada ligação estavam fechados. A seguir, instalavam-se medidores de pressão (Dataloggers) em cavaletes residênciais, com a aprovação prévia dos inquilinos, que se encontravam nas divisas das zonas de pressão, asim, se a interligação localizava-se entre as zonas de pressão média e baixa, por exemplo, um Datalogger era instalado na residência da zona média imediatamente antes da divisa do setor e outro Datalogger era instalado na residência da zona baixa imediatamente antes da divisa do setor. A coleta destes dados era feita simultaneamente em um período aproximado de três dias. Ao final do período, os Dataloggers eram retirados das residências e seus arquivos de dados descarregados em um computador. Os gráficos resultantes dos dados coletados dos Datalogger eram então comparados com vistas à identificação de pontos das divisas dos setores da rede que apresentassem interligação, usando o seguinte critério: se os gráficos de dois pontos pertencentes ao mesmo ponto da divisa de setores, porém em zonas de pressão supostamente distintas, apresentassem curvas de pressões muito parecidas, considerava-se que havia interligação entre os setores e que o registro de controle dessa divisa estava aberto; caso contrário considerava-se que não existia interligação entre estes dois setores neste ponto. Nesta etapa foram encontradas três interligações entre os setores, sendo duas entre as zonas de pressão Média e Alta II (Amorim) e uma entre as zonas de pressão Média e Alta I e dois pontos de vazamentos "invisíveis" (não aparentes) na divisa entre os setores Zona Média e Zona Alta I. Os vazamentos eram de grande magnitude e aconteciam devido ao 
rompimento de dois CAPs de 2" localizados em pontas de rede. O setor de manutenção foi acionado, e os vazamentos foram corrigidos imediatamente.

É importante lembrar que esta etapa do trabalho tinha o objetivo de garantir as delimitações dos setores a partir do cadastro eletrônico fornecido pela cidade. Portanto, a possibilidade da existência de interligações "invisíveis" (sem cadastro), clandestinas entre os setores ou vazamentos em pontas de rede próximos as divisas de setores ainda não pode ser descartada.

O estudo para delimitações das zonas de pressão da rede de abastecimento de água não foi realizada ma cidade de Itirapuã pelo motivo já mencionado anteriormente de que esta cidade possui apenas um setor de abastecimento. A cidade não apresenta outras fontes de alimentação de água que não o reservatório elevado da SABESP.

\subsubsection{MONITORAMENTO DE PRESSÕES E VAZÕES NA ENTRADA DOS SETORES DA CIDADE DE GUARIBA}

A atual companhia de abastecimento de água da cidade de Guariba possui medidores eletromagnéticos de vazão registrando continuamente dados que possibilitam a avaliação das vazões distribuídas na entrada de cada um dos setores da rede.

De acordo com o esquema da Figura 5.1, o sistema em estudo possui medidores eletromagnéticos de vazão responsáveis pela totalização do consumo dos seguintes setores; Zona Alta I abastecida diretamente pelo reservatório R5, Zona Alta II (Amorim) localizada na saída do reservatório R1 (RAP); Zona Baixa que é abastecida diretamente pelo reservatório R5 e a Zona Média que não possui um medidor eletromagnético instalado diretamente na entrada do setor, no entanto, seu consumo é obtido pela diferença entre o consumo total dos setores Zona Média + Zona Baixa, uma vez que existe apenas uma saída para abastecer os dois setores, e o consumo do setor Zona Baixa como ilustra o esquema da Figura 5.1. 


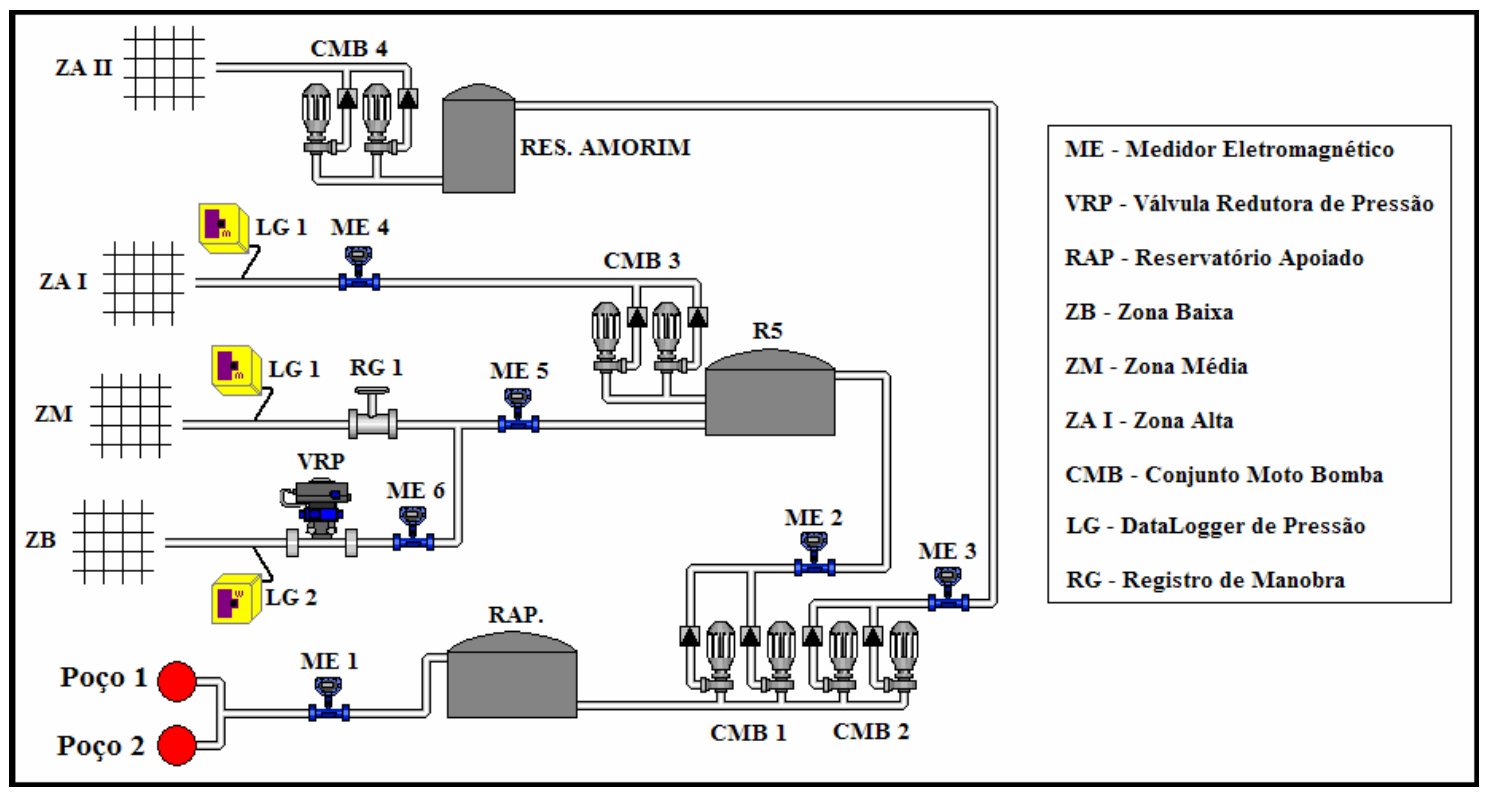

Figura 5.1. Esquema de posicionamento dos medidores eletromagnéticos eDataloggers de pressão na rede de distribuição de água da cidade de Guariba

Apesar do sistema de telemetria da cidade também registrar o nível de grande parte dos reservatórios, não o registra as pressões nos pontos de entrada dos setores da rede. Assim, o monitoramento desses dados foi feito com o suporte de instrumentos de campo tais como Dataloggers de pressão localizados de maneira conveniente no esqueleto da rede e, depois, internamente ao setor eleito para análise detalhada.

A partir do monitoramento de pressões feito pelos Dataloggers e vazões coletadas através do sistema supervisório na entrada dos setores, realizado entre os dias 29 de outubro e 1 de novembro de 2005, foi possível construir as curvas pressão x vazão dos setores ZA I, ZM e ZB. O setor ZA II não será contemplado neste estudo por se tratar de um sistema relativamente novo e abastecer diversos consumidores especiais (Distrito industrial). Além disso, os testes noturnos de geofonamento realizados nesse setor pela equipe da SABESP mostram uma incidência muito baixa de vazamentos no mesmo e as reclamações por parte dos consumidores deste setor são praticamente nulas. A Figura 5.2 apresenta as curvas de vazão e pressão construídas a partir de dados coletados na entrada do setor Zona Baixa. A curva de vazão mostra um comportamento característico de setores residenciais abastecidos por gravidade, ou seja, consumo elevado em períodos diurnos e consumo reduzido em períodos noturnos. No caso da pressão, a utilização de uma VRP na entrada do setor gera uma curva de pressão praticamente constante em $40 \mathrm{mH}_{2} \mathrm{O} . \quad \mathrm{O}$ salto de $40 \mathrm{mH}_{2} \mathrm{O}$ para $45 \mathrm{mH}_{2} \mathrm{O}$ aproximadamente às $19 \mathrm{~h} 00 \mathrm{~min}$ do dia 28 ocorreu devido à manobra da VRP pelos 
funcionários da SABESP com o intuito de melhorar o abastecimento nos pontos desfavoráveis do setor. A Figura 5.3 apresenta a curva de dispersão pressão x vazão para o mesmo setor Zona Baixa. O gráfico ilustra duas nuvens de pontos separadas por um espaço vazio, que caracteriza dois patamares de pressão, um anterior a manobra da VRP (com pressões em torno de $40 \mathrm{mH}_{2} \mathrm{O}$ ) e outro posterior (com pressões em torno.de $\left.45 \mathrm{mH}_{2} \mathrm{O}\right)$.

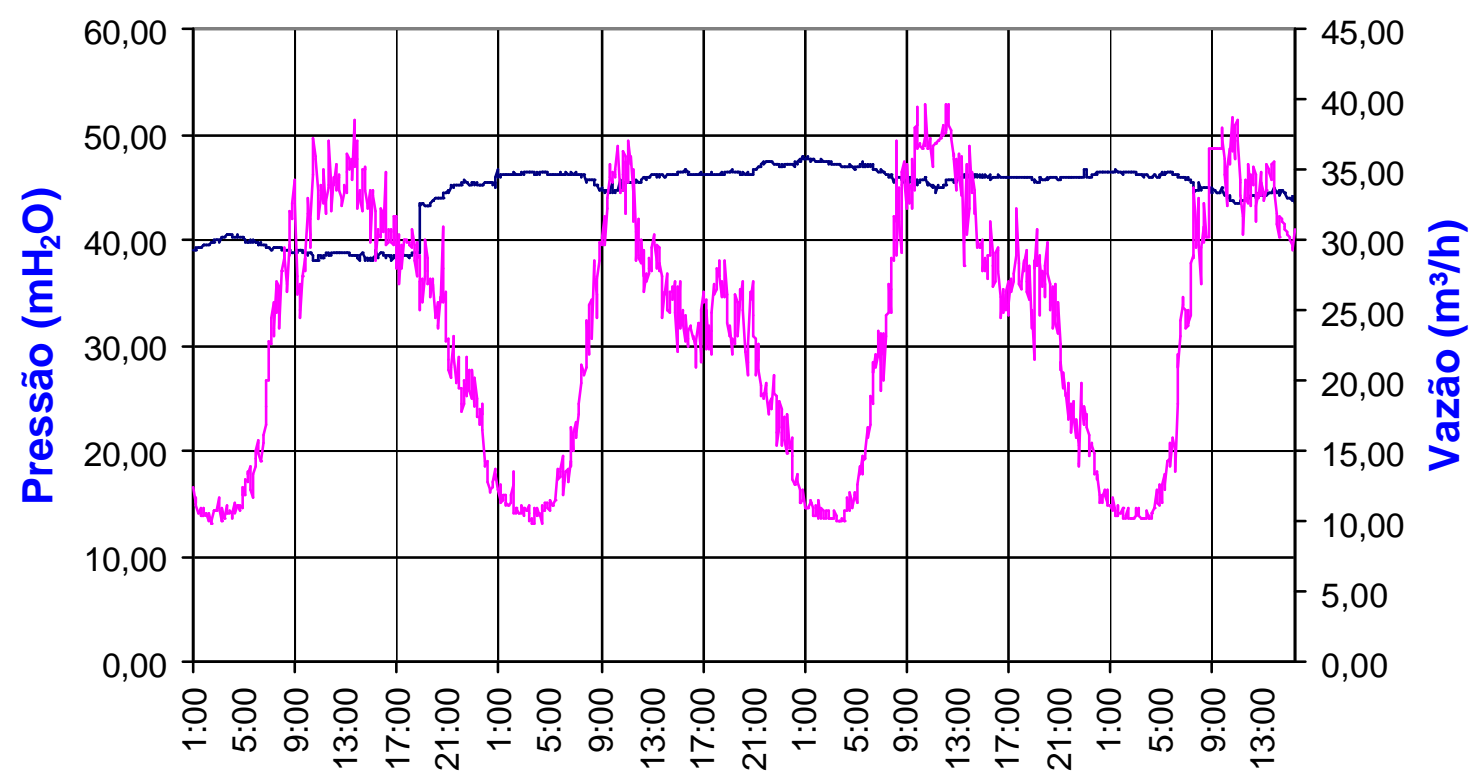

Horas entre os dias 28/11/05 e 01/12/05

一Pressão - Vazão

Figura 5.2. Comportamento da vazão e pressão na entrada do setor Zona Baixa coletados a montante da VRP

A Figura 5.4 apresenta o comportamento da vazão e da pressão na entrada do setor Zona Média. Como a distribuição de água para este setor se dá por gravidade, as curvas de consumo de vazão e pressão são características para setores residenciais abastecidos por gravidade, ou seja, consumo elevado e pressões reduzidas em períodos diurnos e consumo reduzido e pressões elevadas em períodos noturnos. A Figura 5.5 apresenta o gráfico de dispersão vazão x pressão para o mesmo período analisado anteriormente no setor Zona Média. 


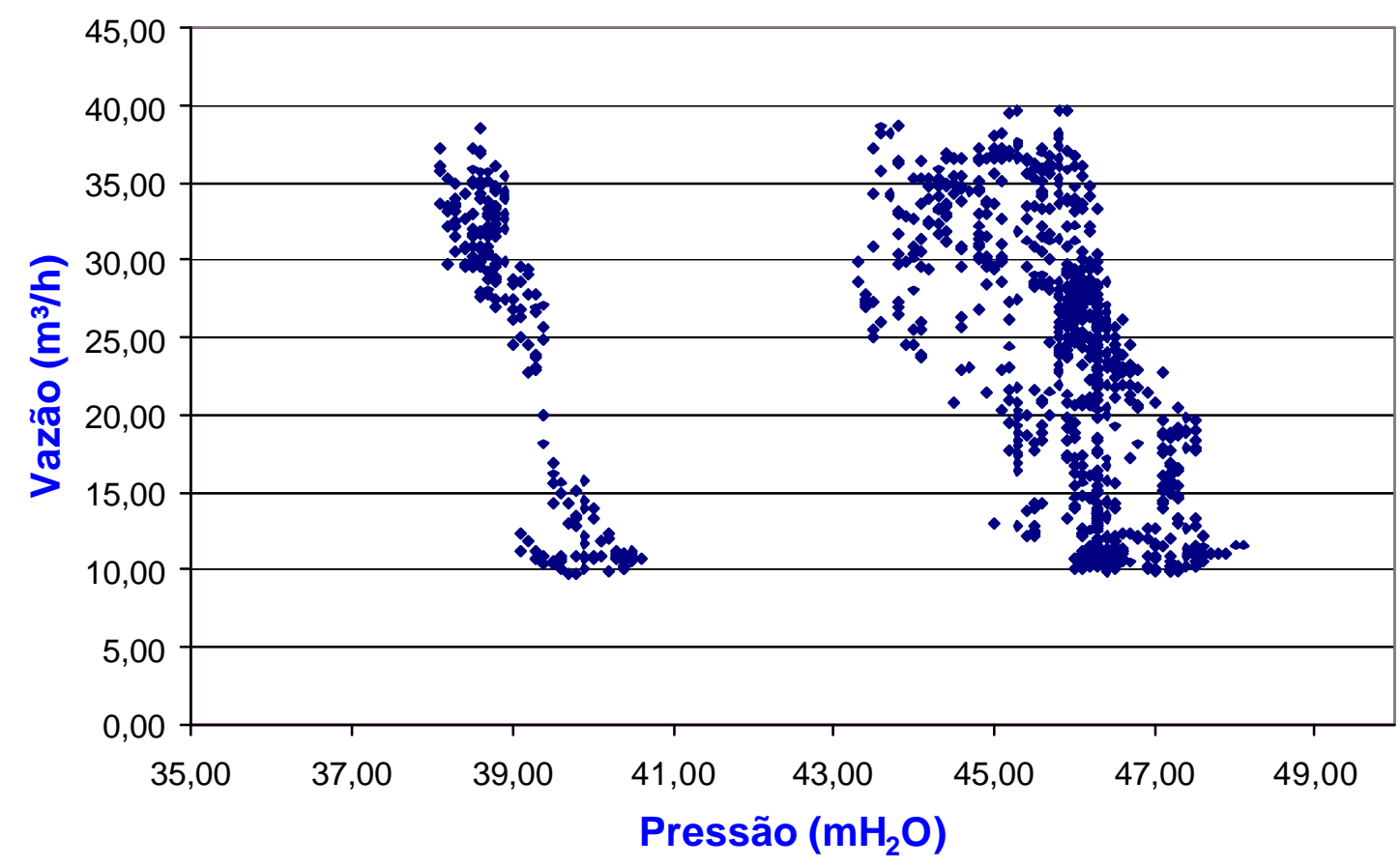

Figura 5.3 - Dispersão vazão x pressão na entrada do setor Zona Baixa coletados a montante da VRP

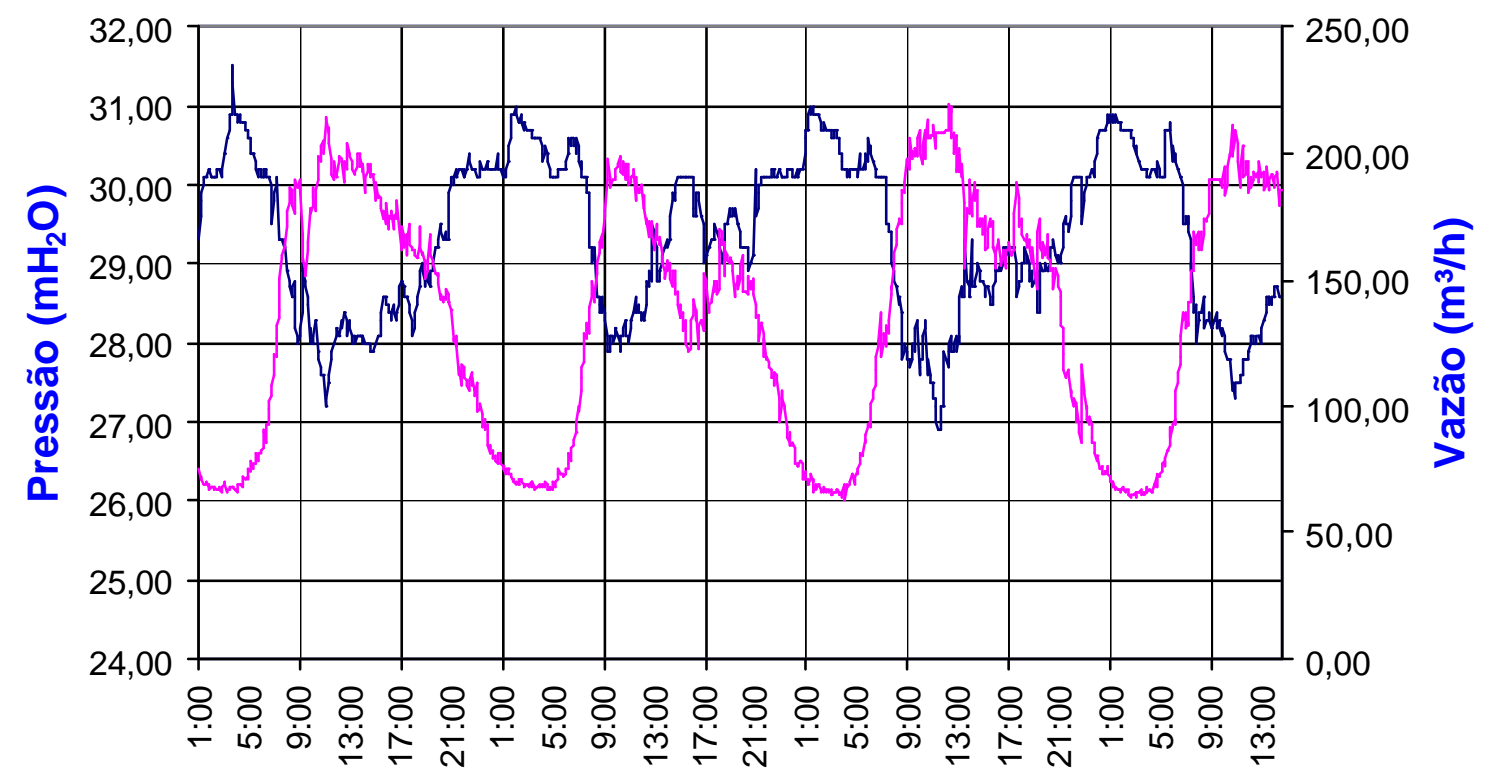

Horas entre os dias 28/10/05 e 01/11/05

\section{- Pressão - Vazão}

Figura 5.4 - Comportamento da vazão e pressão na entrada do setor Zona Média 


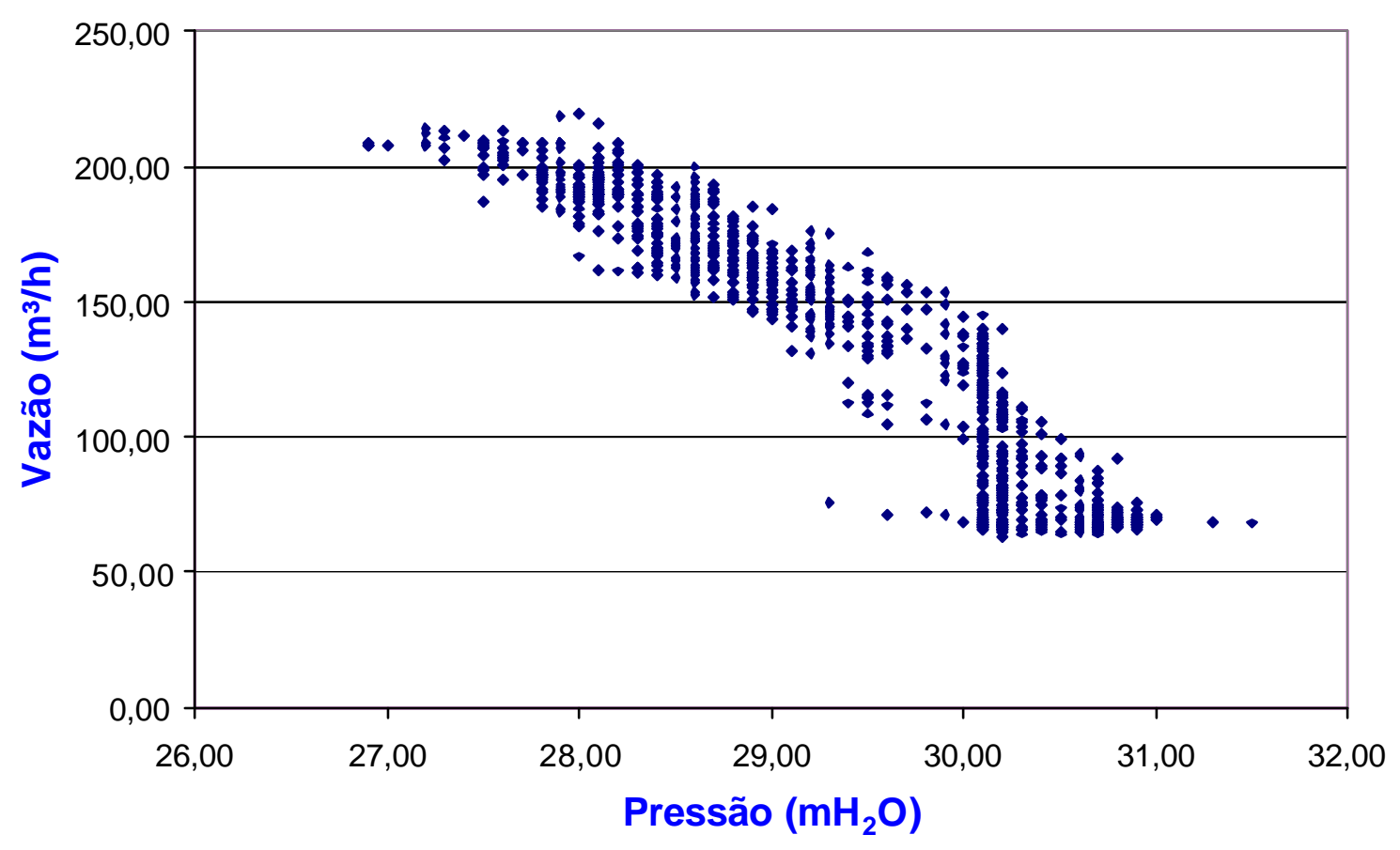

Figura 5.5 - Dispersão vazão x pressão na entrada do setor Zona Média

A Figura 5.6 ilustra o comportamento da vazão e da pressão para o setor Zona Alta I de Guariba. O setor é pressurizado por duas bombas que são controladas por um inversor de freqüência. Assim, a pressão do setor se mantém praticamente estável independentemente do consumo, ao passo que o consumo se caracteriza por valores elevados durante o dia e reduzidos durante a madrugada. O gráfico da Figura 5.7 reflete este comportamento exibindo uma pequena variação da pressão em relação à enorme variação da vazão no setor. 


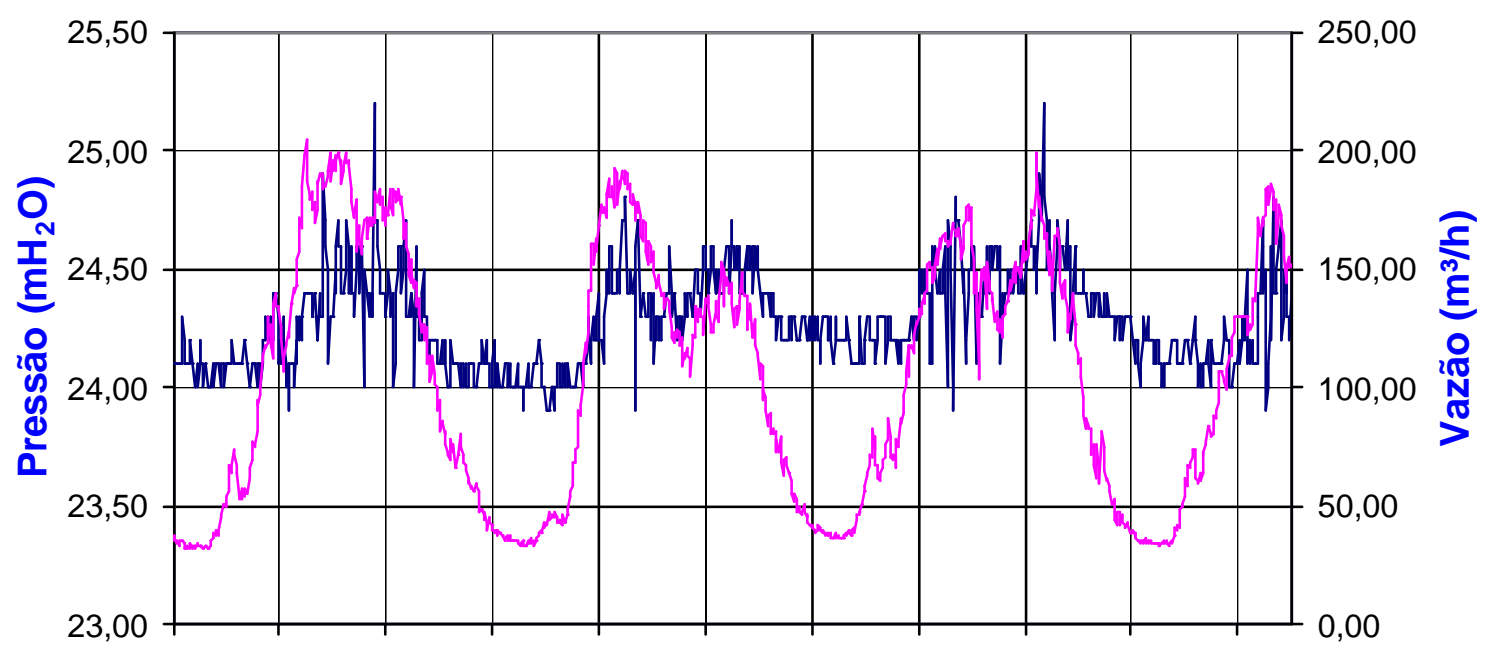

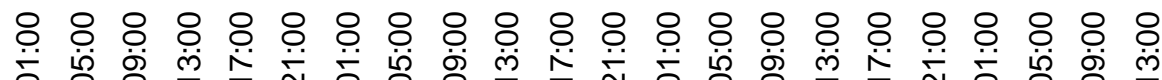
Horas entre os dias 28/10/05 e 01/11/05

- Pressão - Vazão

Figura 5.6 - Comportamento da vazão e pressão na entrada do setor Zona Alta I

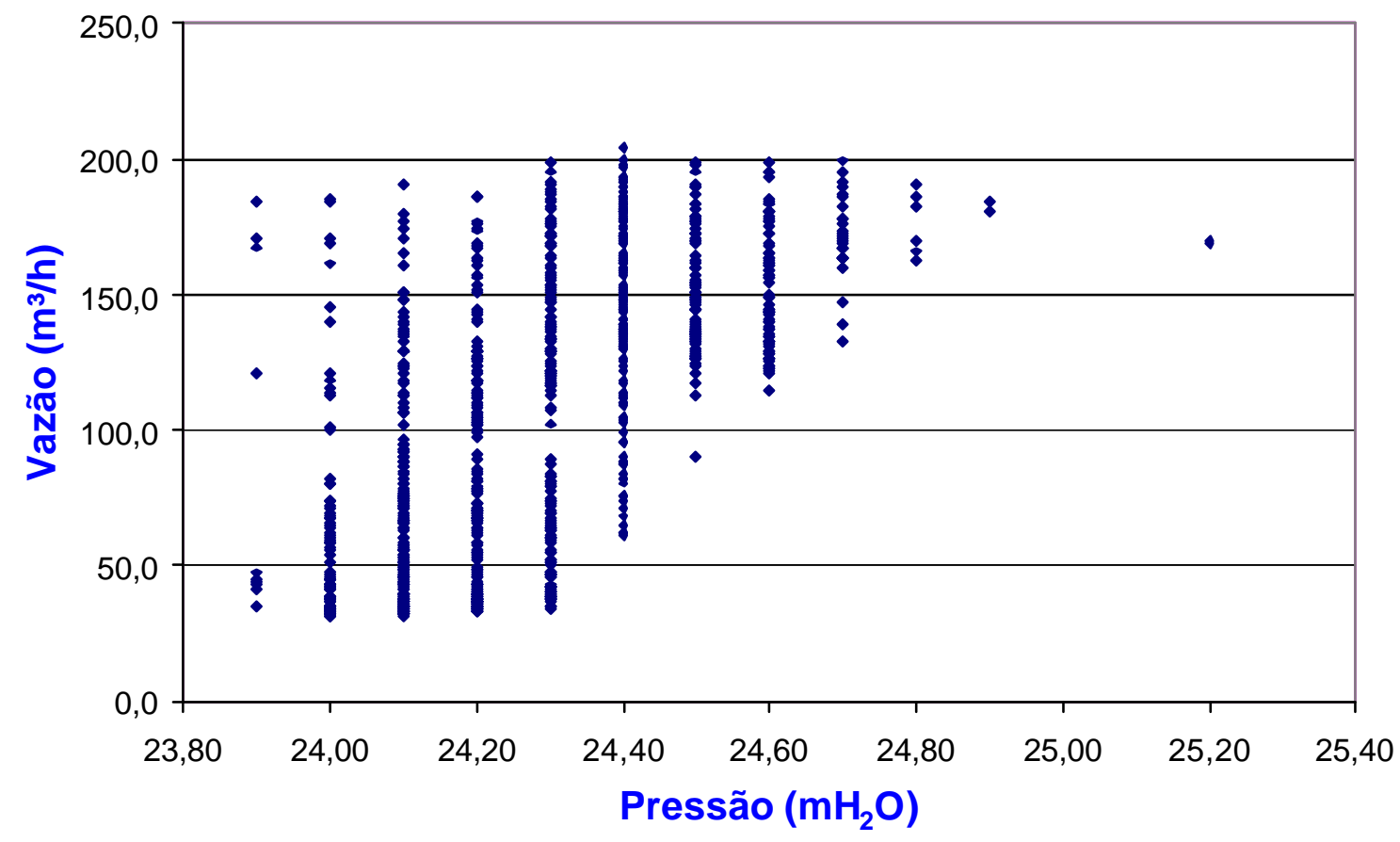

Figura 5.7 - Dispersão vazão x pressão na entrada do setor Zona Alta I 


\subsubsection{MONITORAMENTO DE PRESSÕES E VAZÕES NA ENTRADA DO SETOR DA CIDADE DE ITIRAPUÃ}

Da mesma maneira que para a cidade de Guariba, Itirapuã possui um medidor eletromagnético de vazão, localizado na entrada do setor de abastecimento, que registra segundo a segundo o valor total da demanda da cidade. A Figura 5.8 apresenta, de maneira sucinta, o croqui do sistema de abastecimento completo da cidade juntamente com a posição que o medidor de vazão e o transmissor de pressão foram instalados.

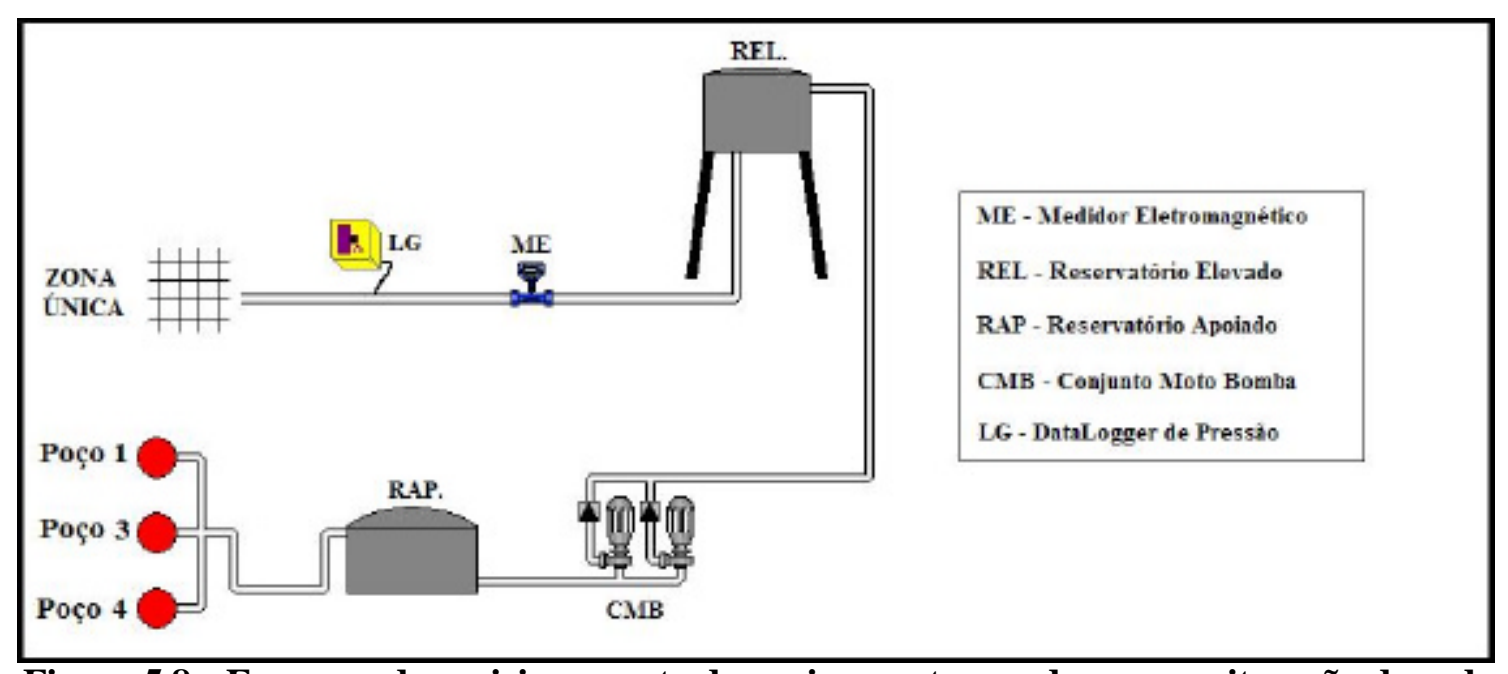

Figura 5.8 - Esquema de posicionamento de equipamentos usados na monitoração da rede de distribuição de água da cidade de Itirapuã

Como a cidade de Itirapuã não possui um equipamento residente na entrada do setor responsável pelo registro contínuo da pressão da rede, faz-se necessário o monitoramento com Datalogger de pressão repetindo o processo realizado para a cidade de Guariba. O monitoramento da pressão por meio do Datalogger e a vazão coletada por meio do sistema supervisório na entrada do setor foram realizados entre os dias $23 \mathrm{e}$ 30 de agosto de 2006, possibilitando a construção da curva pressão x vazão que descreve o comportamento destas variáveis para a cidade. A Figura 5.9 apresenta as curvas de pressão e vazão em função do tempo. A curva de vazão mostra um comportamento característico de setores residenciais abastecidos por gravidade. A pequena variação na curva de pressão da entrada do setor ocorreu devido à rede da cidade de Itirapuã ter sido sobre dimensionada. A Figura 5.10 apresenta a curva de dispersão pressão x vazão para o setor de Itirapuã. Nota-se uma concentração grande da nuvem de pontos entre $16 \mathrm{mH}_{2} \mathrm{O}$ e $18 \mathrm{mH}_{2} \mathrm{O}$ comentada anteriormente. 


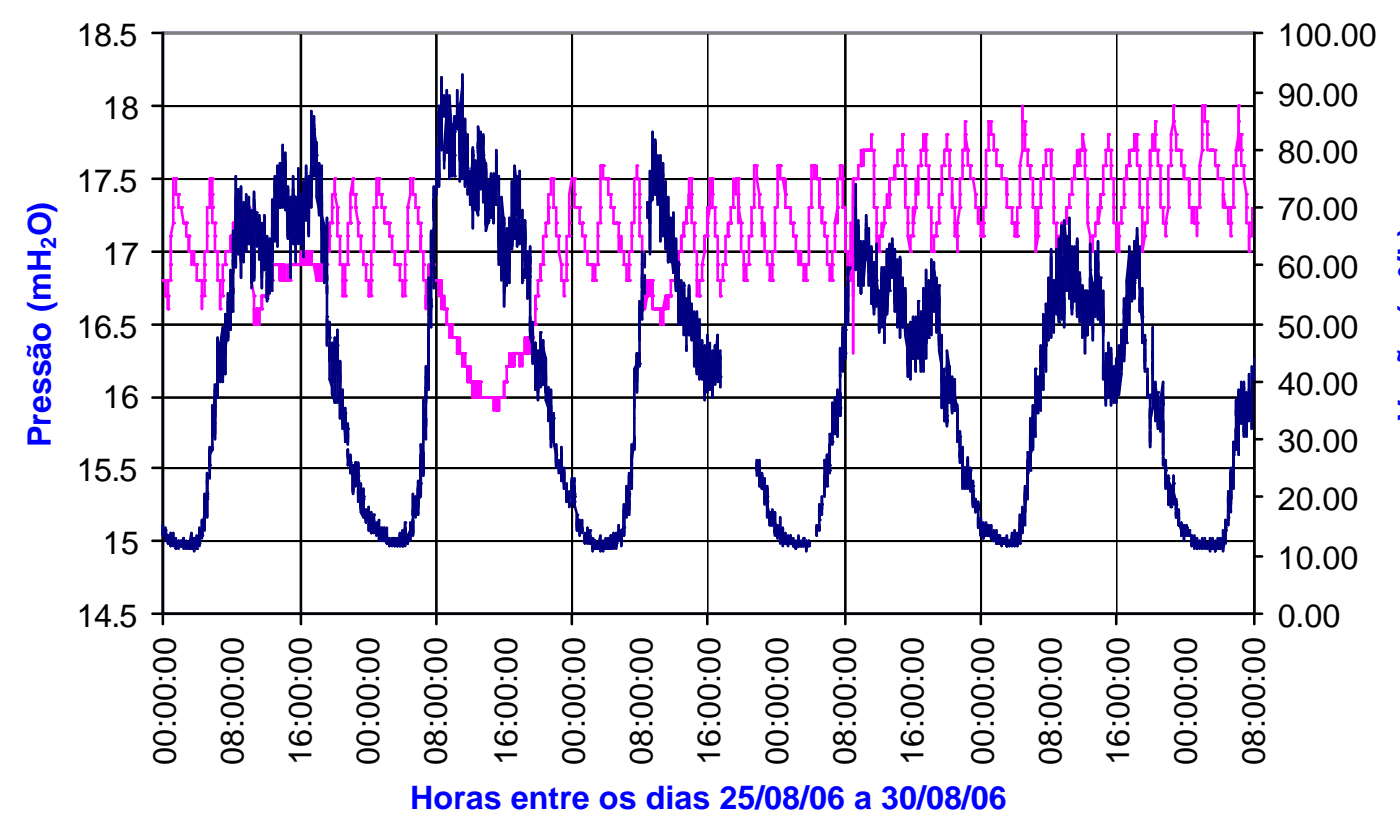

Figura 5.9 - Comportamento da vazão e pressão na entrada do setor de abastecimento de Itirapuã

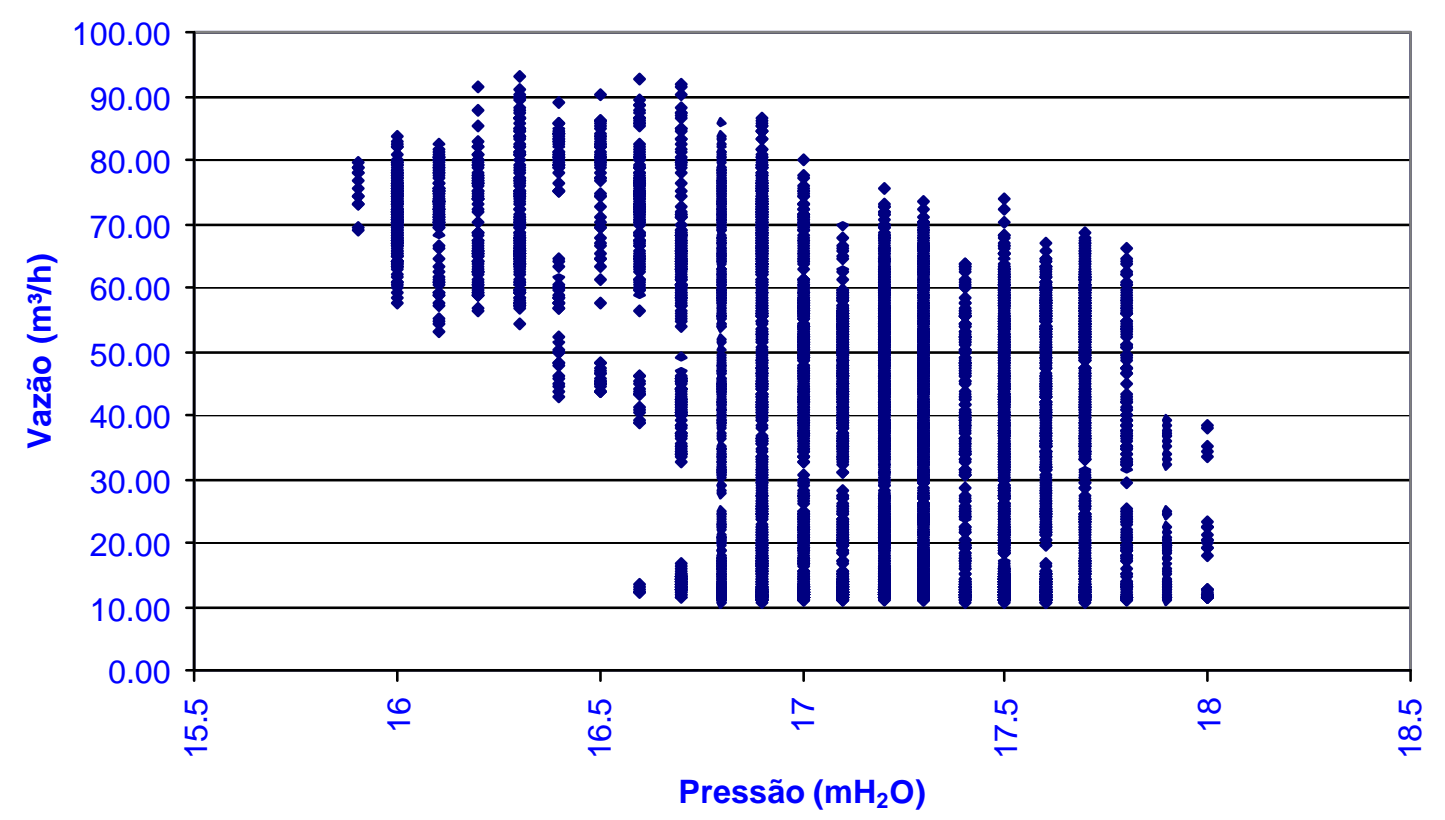

- Vazão

Figura 5.10 - Dispersão vazão x pressão na entrada do setor de abastecimento de Itirapuã

\subsection{TESTES NOTURNOS DE VAZAMENTOS}

Entre os dias 29 de outubro de 2005 e 11 de janeiro de 2006, foram realizadas medições noturnas de pressões e vazões na entrada de cada setor do sistema de Guariba (ZB, ZM e ZA I), com o objetivo de identificar a maior incidência de perda de água de 
abastecimento levando-se em consideração o tamanho do setor, ou seja, quantificar o vazamento por metro linear de tubo que compõe a rede de cada setor. Para a realização dessa etapa do trabalho foram necessárias 13 visitas noturnas à cidade. A partir da análise de localização dos pontos de coleta de dados (entrada dos setores), uma nova caixa de inspeção foi construída sobre a rede de entrada do setor ZM, conforme Figura 5.11, para que a coleta de dados relativa a este setor pudesse ser feita.

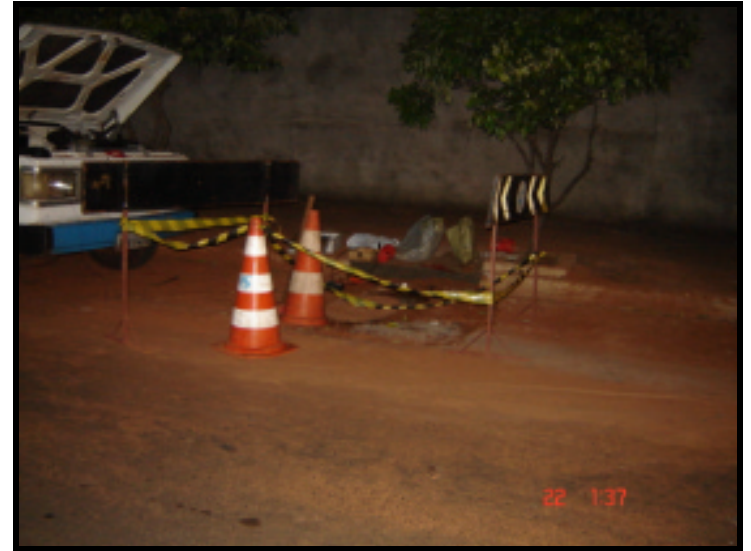

a)

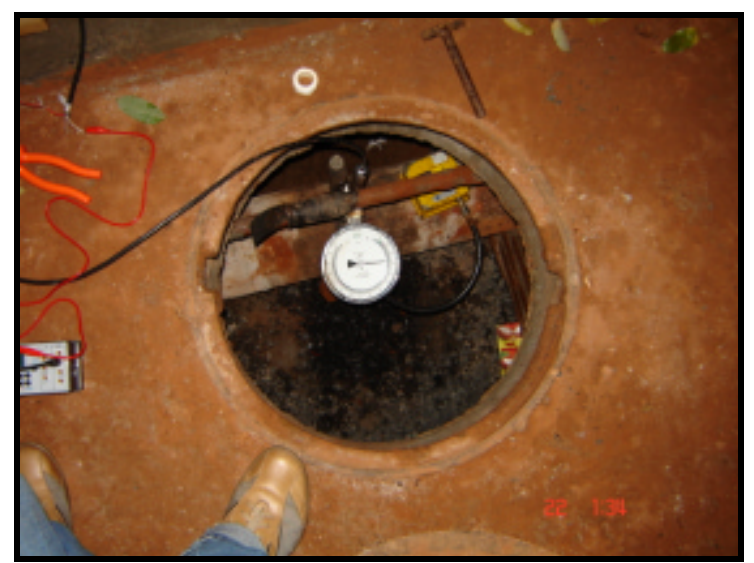

c)

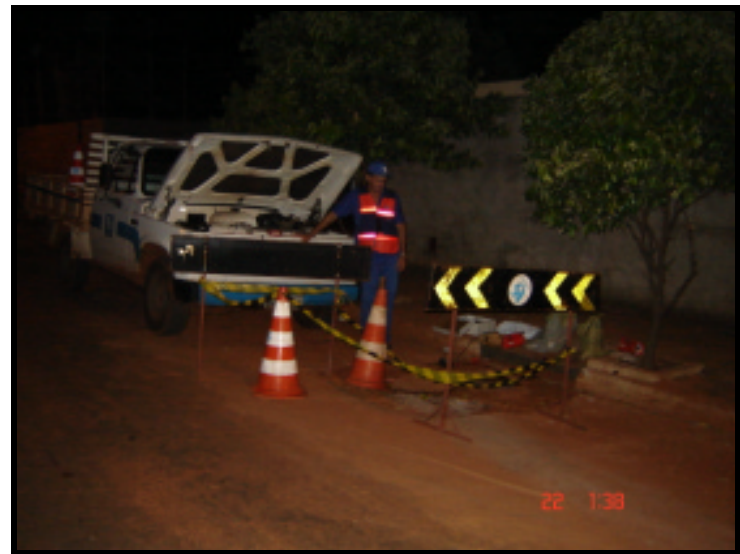

b)

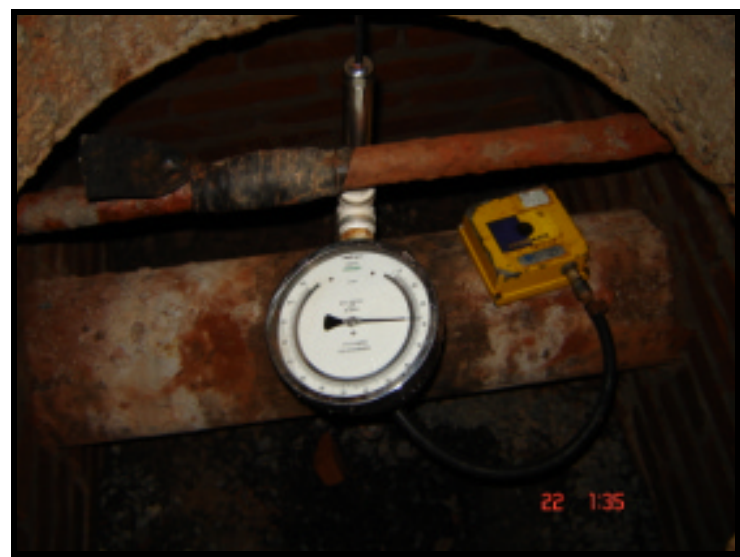

d)

Figura 5.11 - Fotos da caixa de inspeção construída na entrada do setor ZM

O procedimento do teste consistia em regular manualmente a pressão de entrada do setor em três patamares diferentes no horário em que o consumo do setor fosse mínimo (madrugada), supostamente devido exclusivamente a vazamentos. Com o auxílio do centro de controle operacional de Franca (CCO), constatou-se que os testes deveriam ser realizados entre as 2:00h e 4:00h da manhã, pois o consumo dos setores se mostrou mínimo e razoavelmente estável durante esse período.

A regulagem da pressão na entrada da Zona Baixa foi feita através de uma VRP localizada aproximadamente 100 metros a jusante do medidor ME6 (Figura 5.1). O 
medidor de pressão LG2 (Figura 5.1) foi adaptado diretamente à jusante do corpo da VRP juntamente com um manômetro padrão de 0-100 $\mathrm{mH}_{2} \mathrm{O}$ aferido em mesa de calibração por funcionário habilitado da SABESP. A Figura 5.12 apresenta o comportamento da pressão e da vazão na Zona Baixa para o monitoramento do dia 08/01/2006.

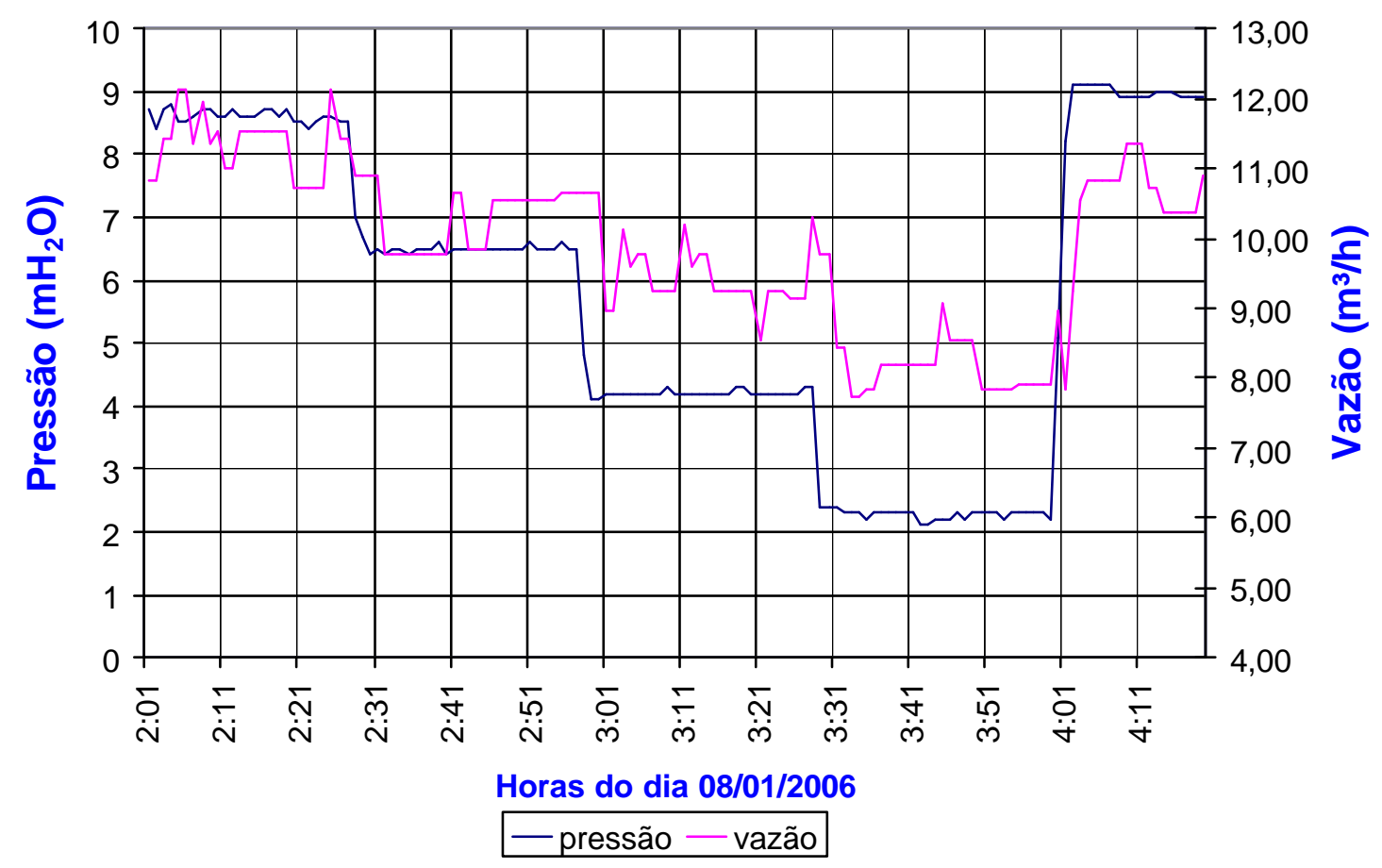

Figura 5.12 - Registro de pressão e vazão na entrada do setor Zona Baixa à jusante da válvula reguladora de pressão

Na Zona Média, a regulagem da pressão foi feita através de um registro localizado a jusante do ME5, como ilustra a Figura 5.1. Devido à dificuldade da monitoração da regulagem da pressão pelo manômetro padrão, optou-se por utilizar um sistema eletrônico de monitoração composto por um transmissor de pressão de 0-200 mca com sinal de saída de corrente de 4 a 20mA, um calibrador eletrônico para visualizar o sinal de corrente; e para alimentar o sistema com $24 \mathrm{Vcc}$, duas baterias de 12 Vcc foram ligadas em série sendo uma delas a bateria da viatura da SABESP e a outra uma bateria de moto $(12 \mathrm{Vcc})$. O esquema de ligação do sistema eletrônico de monitoração e a foto dos equipamentos interligados estão ilustrados nas Figuras 5.13 e 4.1 respectivamente. 


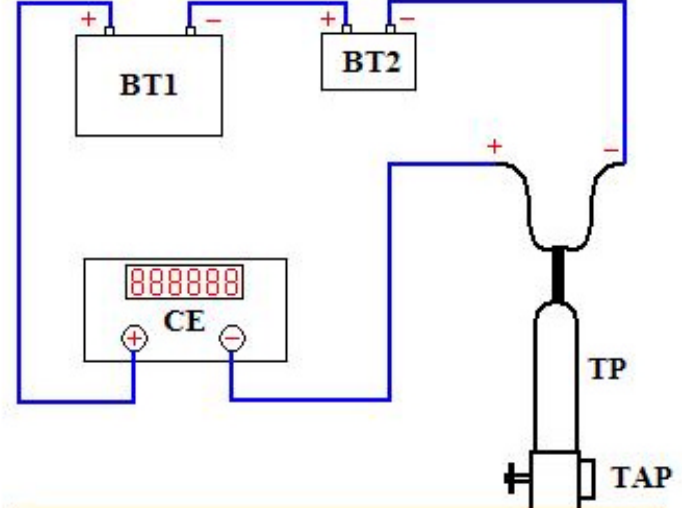

REDE DE ABASTECIMENTO
BT1 - BATERIA 1 (Viatura SABESP)

BT2 - BATERIA 2 (Moto)

CE - CALIBRADOR ELETRÔNICO

TP - TRANSMIISSOR DE PRESSÃO

Figura 5.13 - Esquema de ligação elétrica do sistema de monitoramento de pressão eletrônico

A Figura 5.14 apresenta o comportamento da pressão e da vazão para a Zona Média durante o monitoramento do dia 11/01/2006.

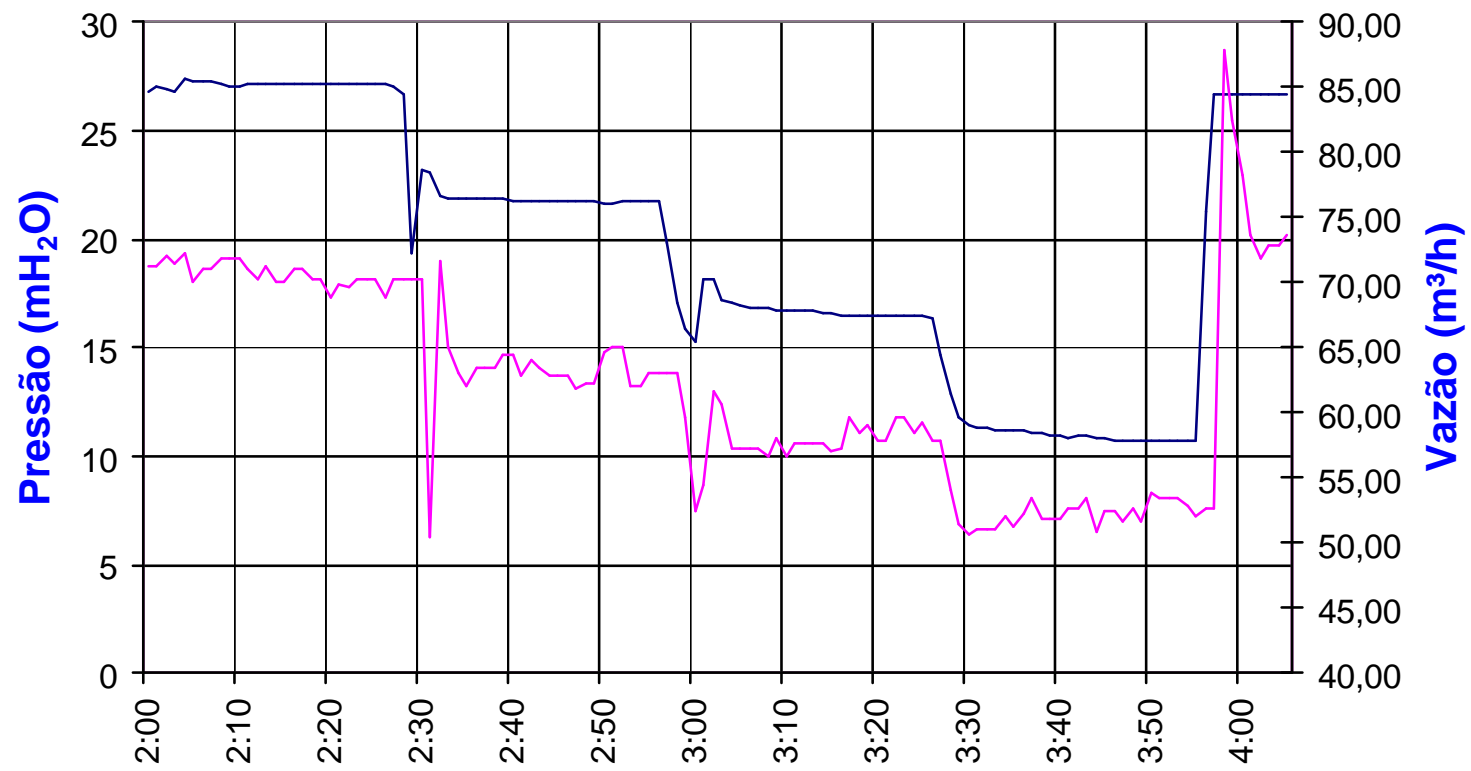

Horas do dia 11/01/06

$$
\text { - Pressão - Vazão }
$$

Figura 5.14 - Registro de pressão e vazão na entrada da rede do setor Zona Média

A Figura 5.15 apresenta o comportamento da pressão e da vazão para a Zona Média durante o monitoramento realizado dia 08/01/2006. 


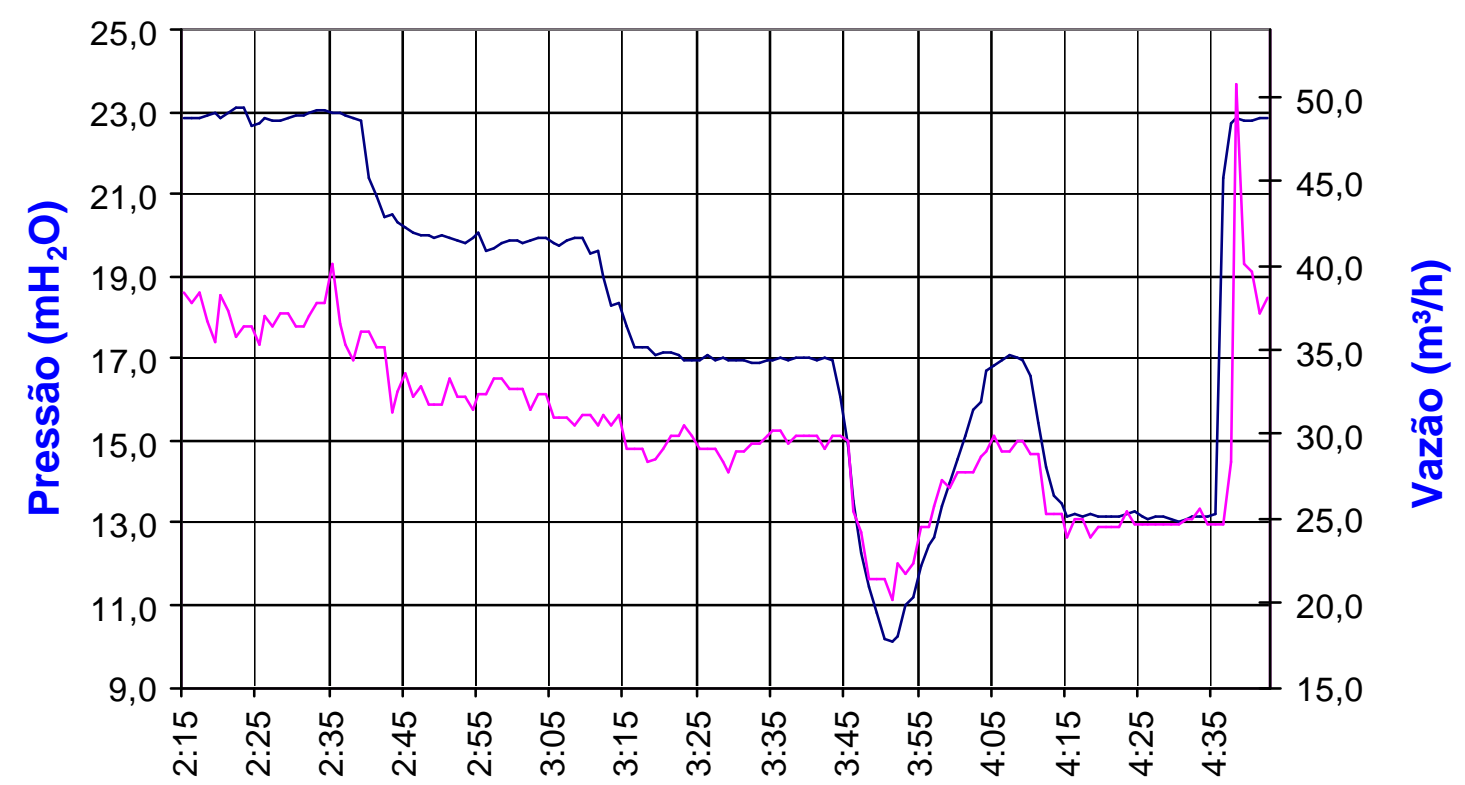

Horas do dia 08/01/2006

- pressão - vazão

Figura 5.15 - Registro de pressão e vazão na entrada do setor Zona Alta I

As Tabelas 5.1, 5.2 e 5.3 apresentam os valores médios registrados durante os referidos testes, os quais foram utilizados para construir as curvas das Figuras 5.16 e 5.17 .

Tabela 5.1 - Valores representativos de vazões e pressões do setor Zona Baixa durante os testes noturnos de vazamento

\begin{tabular}{|c|c|c|c|}
\hline \multirow{2}{*}{$\begin{array}{c}\text { Condição } \\
\text { (aproximada) }\end{array}$} & \multicolumn{3}{|c|}{ ZONA BAIXA } \\
\cline { 2 - 4 } & Vazão $\left(\mathbf{m}^{\mathbf{3}} / \mathbf{h}\right)$ & Pressão (mca) & Período \\
\hline Inicial $^{*}$ & 11,34 & 8,6 & entre 2:01h e 2:27h \\
\hline 3/4 da pressão inicial & 10,26 & 6,5 & entre 2:30h e 2:57h \\
\hline $1 / 2$ da pressão inicial & 9,39 & 4,21 & entre 3:00h e 3:27h \\
\hline $1 / 4$ da pressão inicial & 8,17 & 2,27 & entre 3:30h e 3:59h \\
\hline
\end{tabular}

* válvula redutora de pressão totalmente aberta

Tabela 5.2 - Valores representativos de vazões e pressões do setor Zona Média durante os testes noturnos de vazamento

\begin{tabular}{|c|c|c|c|}
\hline $\begin{array}{c}\text { Condição } \\
\text { (aproximada) }\end{array}$ & \multicolumn{3}{|c|}{ ZONA MÉDIA } \\
\cline { 2 - 4 } & Vazão $\left(\mathbf{m}^{\mathbf{3}} / \mathbf{h}\right)$ & Pressão (mca) & Período \\
\hline Inicial $^{*}$ & 70,63 & 26,75 & entre 2:00h e 2:30h \\
\hline 3/4 da pressão inicial & 63,28 & 21,51 & entre 2:33h e 2:58h \\
\hline 1/2 da pressão inicial & 57,93 & 16,56 & entre 3:04h e 3:27h \\
\hline 1/4 da pressão inicial & 52,27 & 10,91 & entre 3:31h e 3:55h \\
\hline
\end{tabular}

registro totalmente aberto 
Tabela 5.3 - Valores representativos de vazões e pressões do setor Zona Alta durante os testes noturnos de vazamento

\begin{tabular}{|c|c|c|c|}
\hline \multirow{2}{*}{$\begin{array}{c}\text { Condição } \\
\text { (aproximada) }\end{array}$} & \multicolumn{3}{|c|}{ ZONA ALTA } \\
\cline { 2 - 4 } & Vazão $\left(\mathbf{m}^{\mathbf{3} / \mathbf{h})}\right.$ & Pressão (mca) & Período \\
\hline Inicial $^{*}$ & 36,82 & 22,84 & entre $2: 15 \mathrm{~h}$ e $2: 40 \mathrm{~h}$ \\
\hline $4 / 5$ da pressão inicial & 32,1 & 19,87 & entre $2: 47 \mathrm{~h}$ e 3:09h \\
\hline 3/5 da pressão inicial & 29,42 & 17,06 & entre 3:15h e 3:43h \\
\hline $1 / 2$ da pressão inicial & 24,7 & 13,16 & entre $4: 15 \mathrm{~h}$ e $4: 35 \mathrm{~h}$ \\
\hline
\end{tabular}

"inversor trabalhando em rotação normal (padrão)

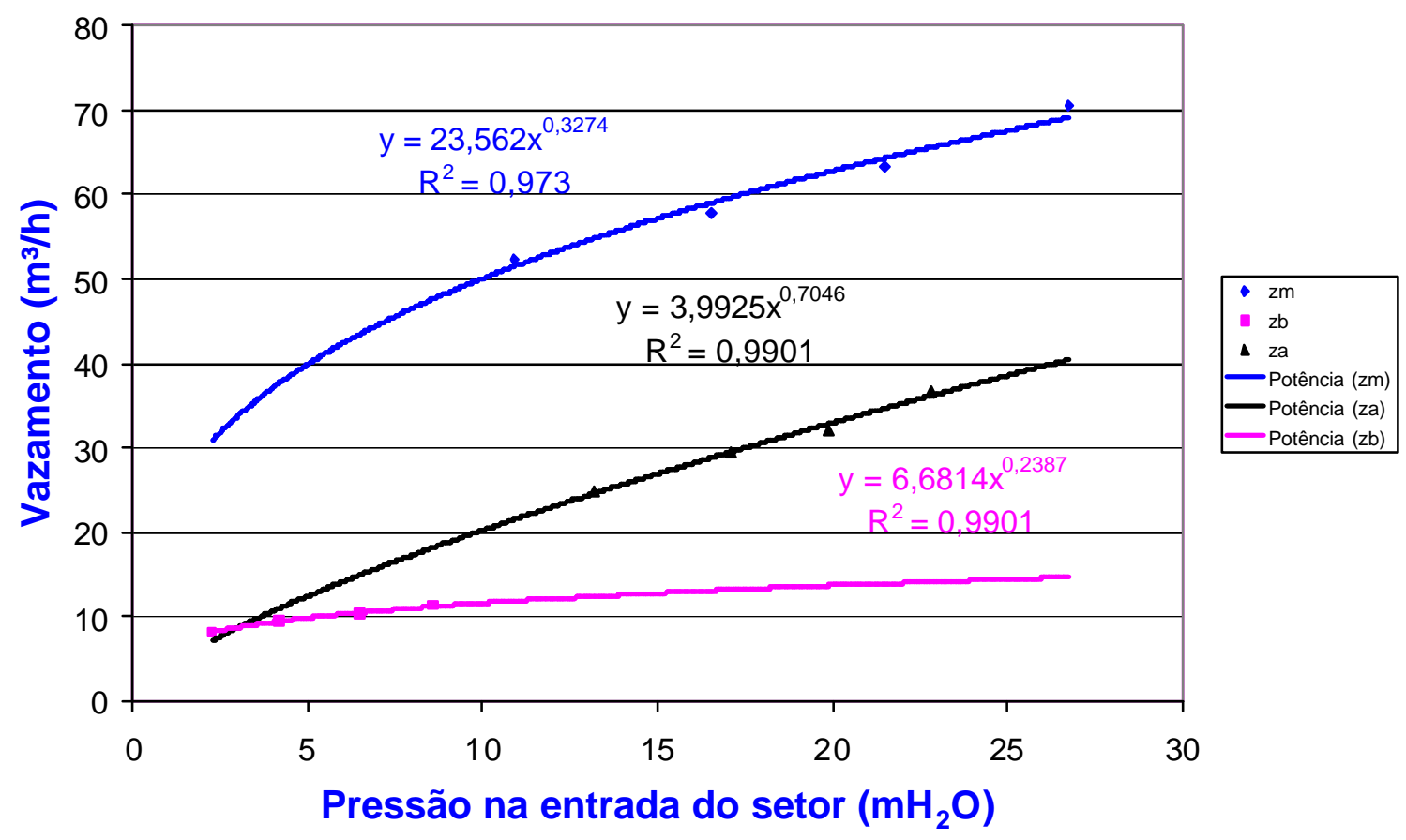

Figura 5.16 - Registro de pressão e vazão na entrada do setor Zona Alta I 


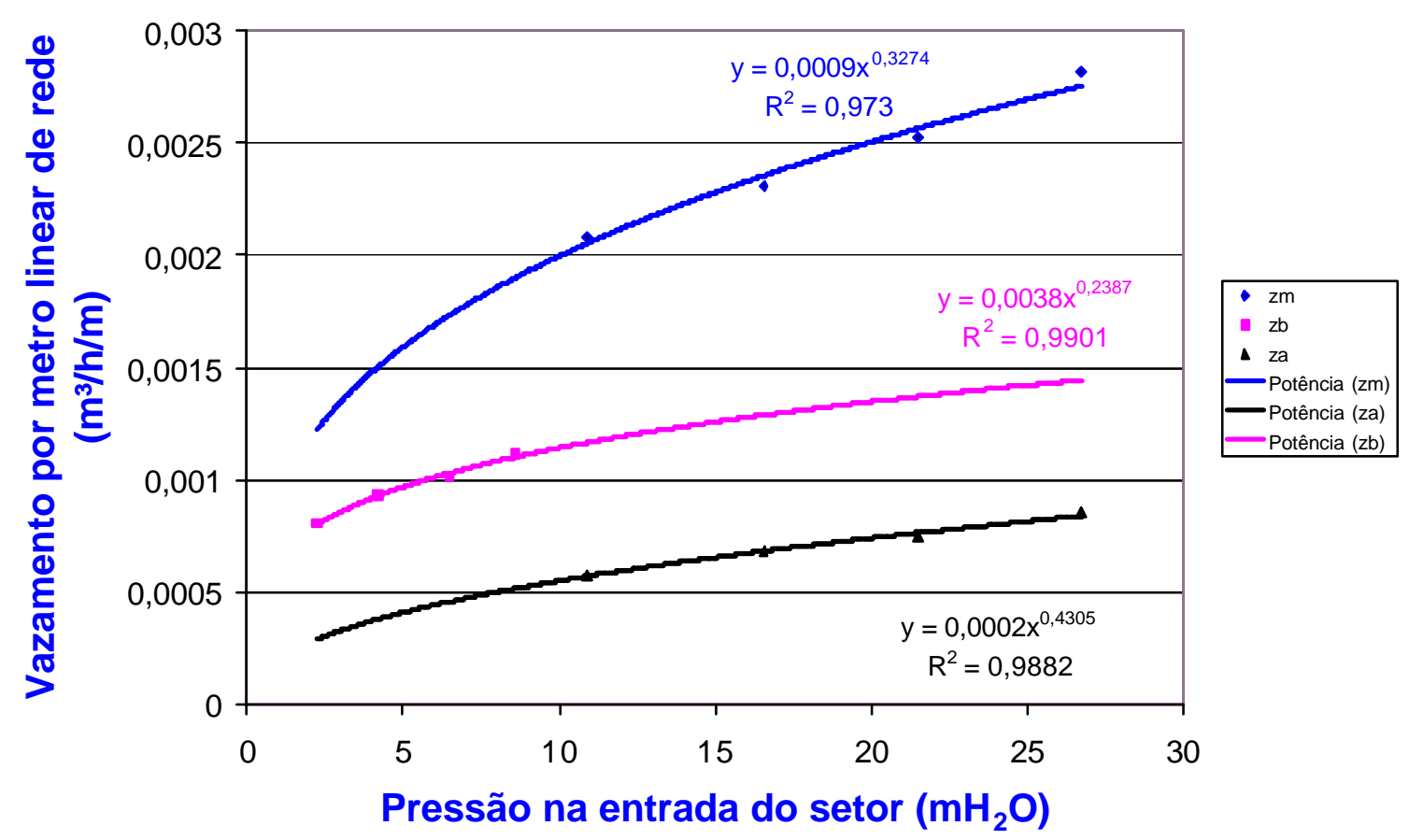

Figura 5.17 - Registro de pressão e vazão na entrada do setor Zona Alta I

A Figura 5.17 é esclarecedora por permitir que as zonas média, baixa e alta sejam ordenadas em ordem decrescente do vazamento médio por metro linear de extensão de rede, sugerindo maior nível de vazamento. Assim, o setor Zona Média foi identificado como o que apresenta maior vazamento para o mesmo nível de pressão na entrada. Portanto, o estudo de calibração focou a Zona Média, com vistas à determinação do modelo que melhor descreva o seu comportamento em termos das vazões e pressões ao longo das horas do dia.

O teste noturno de vazamento não foi realizado m cidade de Itirapuã devido ao fato do mesmo apresentar apenas um setor de abastecimento. Assim, não se fazia necessário estimar o vazamento médio por metro linear de extensão de rede, uma vez que esse procedimento realizado em Guariba tinha o intuito de determinar o setor a ser estudado. Para Itirapuã, o procedimento de calibração foi adotado diretamente.

\subsection{ANÁLISE DETALHADA (CALIBRAÇÃO) DOS MODELOS}

Uma vez identificado o setor mais crítico da cidade de Guariba em termos da vazão noturna, da qual grande parte é atribuída a vazamentos, realizou-se uma análise mais detalhada do mesmo. Essa fase do trabalho compreendeu:

Construção do sistema hidráulico a tratar; 
Levantamento de dados simultâneos de vazão abastecida e pressões em diversos pontos da rede;

Análise dos dados levantados em campo;

Tentativa de calibração, usando o software desenvolvido por SOARES (2003).

Vale lembrar que os mesmos passos citados acima foram usados para se chegar a calibração do modelo do sistema de Itirapuã. Assim, os tópicos seguintes descreverão a realização dos referidos passos para a cidade de Guariba e Itirapuã simultâneamente.

\subsubsection{CONSTRUÇÃO DO SISTEMA HIDRÁULICO A TRATAR}

Para a simulação da rede de abastecimento de água de Guariba foi necessária construção do sistema em arquivo eletrônico O simulador hidráulico EPANET foi usado para este fim. Para tanto, o cadastro de dados da rede fornecido pela concessionária da cidade (SABESP) foi utilizado. Foram retirados deste cadastro os diâmetros, comprimentos e tipo de material dos tubos e a localização de alguns registros de bloqueio. Estimaram-se rugosidades para as tubulações de acordo com os materiais que as compõem tendo como referência PORTO (2000), conforme indicações da Tabela 5.4.

Tabela 5.4 - Rugosidades adotadas para os diversos tipos de materiais de tubulações

\begin{tabular}{|l|c|c|}
\hline \multicolumn{1}{|c|}{ MATERIAL } & $\begin{array}{c}\text { FAIXA DE RUGOSIDADE } \\
\text { CARACTERÍSTICA (Porto, 1998) }\end{array}$ & $\begin{array}{c}\text { VALOR } \\
\text { ADOTADO }\end{array}$ \\
\hline PVC & 0,0015 a 0,010 & 0.0015 \\
\hline Ferro Fundido (velho) & 3 a 5 & 3.5 \\
\hline Ferro Galvanizado & não apresenta & 0.025 \\
\hline DeFoFo & 0,0015 a 0,010 & 0.005 \\
\hline Cimento Amianto (CA) & 0,025 & 0.025 \\
\hline
\end{tabular}

No presente trabalho, o número de registros presentes na rede foi obtido através do cadastro eletrônico da rede do setor e posterior visita in loco para confirmação da quantidade e disposição dos mesmos nas redes de abastecimento de água de Guariba e de Itirapuã. No entanto, observou-se uma incerteza por parte dos funcionários da SABESP em relação a existência ou não de válvulas em algumas ruas antigas do setor Zona Média de Guariba por se tratar de redes sem cadastro herdadas da gestão municipal de distribuição de água e que até o presente momento não necessitaram de manutenção enquanto da gestão da SABESP na cidade.

As cotas topográficas dos nós (final ou cruzamento de ruas) foram levantadas por um funcionário da SABESP, durante os meses março e abril de 2006, habilitado em topografia que utilizou o teodolito como instrumento de medição. 
Para o cálculo das demandas nodais de referência, a metodologia descrita no item 4.4.3 foi adotada.

A Figura 5.18 ilustra o resultado final do arquivo digital desenvolvido no simulador hidráulico EPANET.

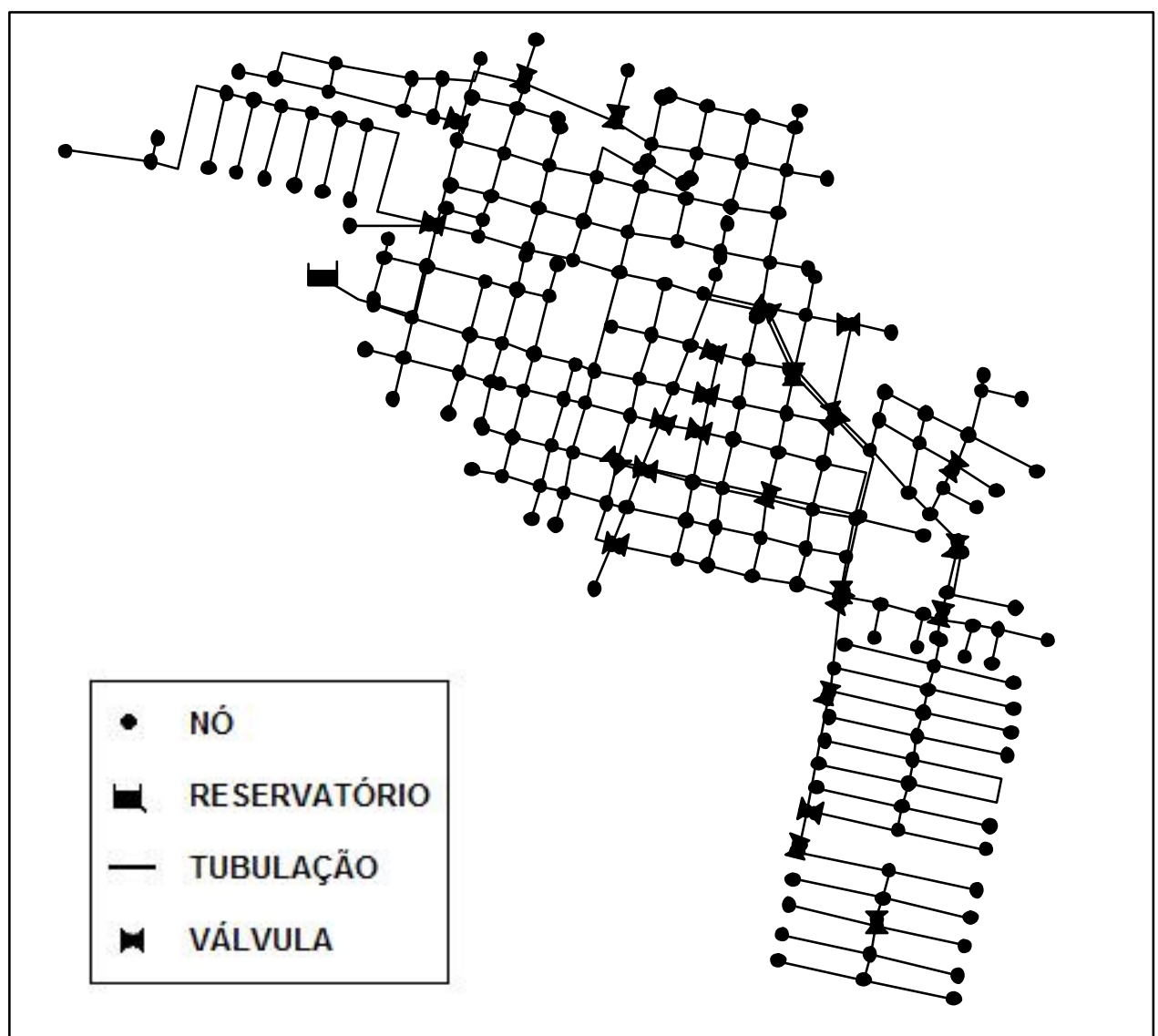

Figura 5.18 - Setor ZM do Sistema de abastecimento da cidade de Guariba no modo gráfico do simulador EPANET

O procedimento para construção da rede de abastecimento da cidade de Itirapuã foi o mesmo adotado para o de Guariba, no entanto, as cotas topográficas de cada nó do sistema foram retiradas de cadastros da SABESP. Verificourse, porém, a necessidade do deslocamento de topógrafos da empresa para a cidade com o intuito de confirmar algumas cotas incoerentes e encontrar algumas outras que o cadastro original não contemplava. A Figura 5.19 ilustra a rede de abastecimento de Itirapuã construída no modo gráfico do simulador hidráulico EPANET. 


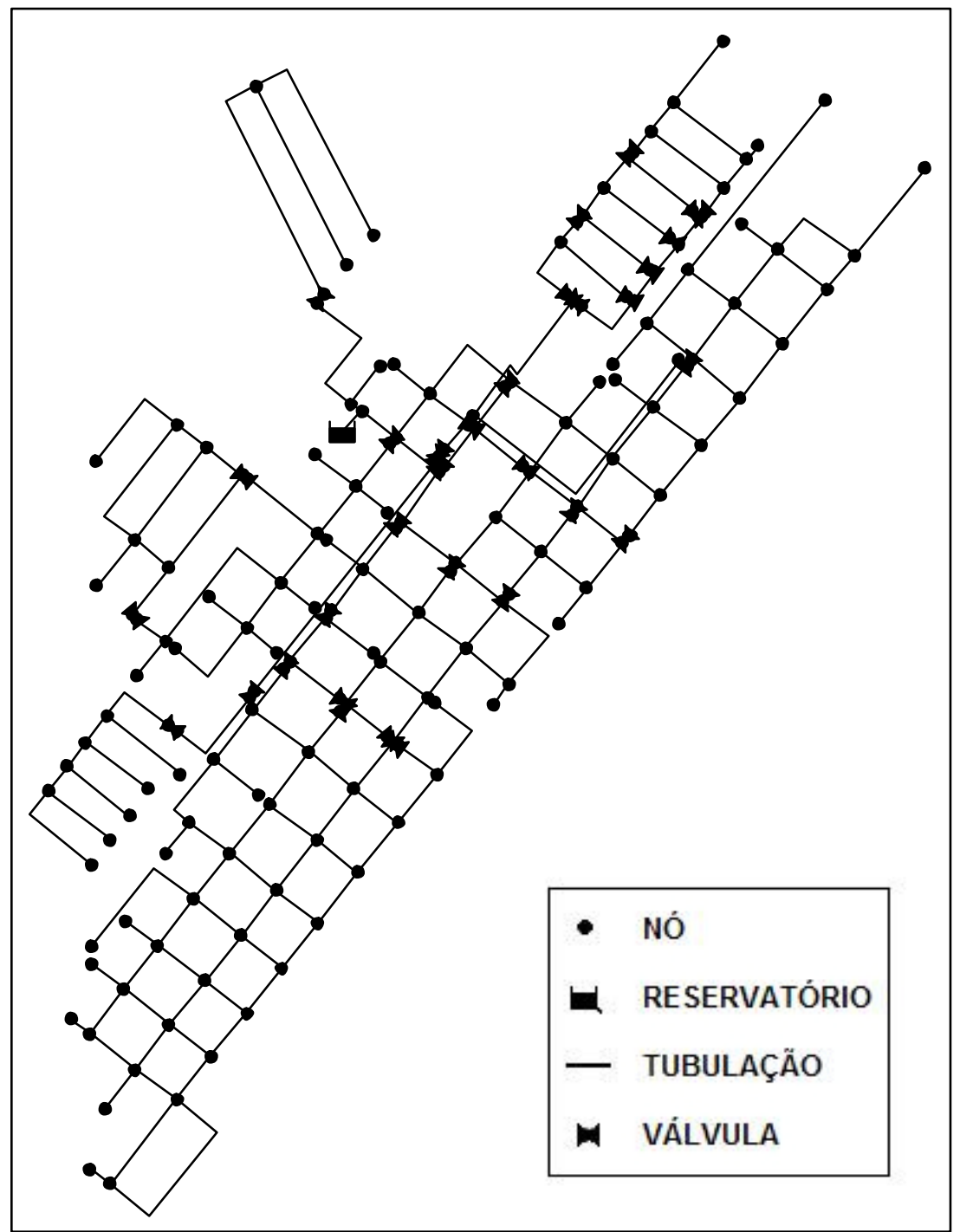

Figura 5.19 - Sistema de abastecimento da cidade de Itirapuã no modo gráfico do simulador EPANET

\subsubsection{PROBLEMAS ENCONTRADOS}

Já se comentou que alguns registros precisaram ser fechados para que o setor pudesse ser considerado isolado. Mesmo assim, sabe-se que as válvulas de gaveta instaladas a mais tempo não proporcionam total bloqueio a passagem da água, da mesma forma que a abertura total dessas válvulas dificilmente pode ser garantida.

Inicialmente vislumbrou-se considerar os trechos dotados de válvula como sendo trechos de rugosidade elevada, no caso da presença desses dispositivos fechados, e de rugosidade ligeiramente superior a do conduto, no caso de existir uma válvula aberta. Entretanto, tais rugosidades precisariam ser determinadas pelo calibrador e os testes com o EPANET mostraram-se infrutíferos provavelmente devido às estimativas de rugosidades feitas. 
Tentou-se também uma simulação no EPANET em que se considerava o sistema com pontas secas nas posições em que as válvulas encontravam-se fechadas, e como tubulações normais as tubulações dotadas de válvulas abertas. Os resultados mostraramse incoerentes levantando dúvidas em relação ao cadastro da rede.

\subsubsection{LEVANTAMENTO DE CAMPO}

\section{GUARIBA}

Visando a calibração do modelo da cidade de Guariba, informações dinâmicas do sistema foram coletadas para a construção dos seis padrões operacionais usados neste trabalho compostos por dados simultâneos de carga hidráulica na entrada do sistema, vazão abastecida e pressões em pontos pré-determinados da rede.

Os valores de nível do reservatório R5 e da vazão na entrada do setor ZM, para os horários de cada padrão de entrada, foram retirados do banco de dados histórico do sistema supervisório do CCO de Franca.

A vazão abastecida foi obtida pela diferença dos valores da vazão total de abastecimento dos setores Zona Média + Zona Baixa e.da vazão de abastecimento exclusivo para o setor Zona Baixa.

Por falta de informação, a carga hidráulica na entrada do setor foi avaliada com base em informações de nível do reservatório R5, vazão no trecho e estimativa da rugosidade dessa linha de $1 \mathrm{~km}$ de extensão, usando a fórmula de Hazen-Williams.

Para as pressões de campo foram usados 35 Dataloggers fornecidos pela SABESP. A instalação, coleta de dados e desinstalação desses coletores de pressão foi realizada no mês de março do ano 2006 sendo a instalação nos cavaletes de hidrômetros residenciais durante os dias 15, 16 e 17, coleta dos dados entre os dias 17 e 22 e a desinstalação durante os dias 22, 23 e 24. Os pontos para a instalação dos equipamentos foram escolhidos obedecendo aos seguintes critérios:

- em regiões com grande concentração de registros, uma vez que o estado (aberto ou fechado) desses componentes causa grande variação hidráulica no sistema;

- em regiões onde o comprimento das tubulações apresentasse maiores valores;

-em regiões que historicamente apresentavam quantidades elevadas de vazamentos aparentes. 
- em residências (cavaletes residenciais) que se localizavam o mais próximo possível das esquinas das quadras (nós do sistema), mediante a aceitação dos moradores em colaborar.

Para que os dados pudessem ser utilizados em análises hidráulicas de regime permanente, foram escolhidos seis padrões de funcionamento do sistema, compreendendo pressões nodais, vazão de abastecimento e carga hidráulica na entrada do setor. Esses seis padrões foram construídos a partir de valores médios observados para intervalos de tempo em que a variação das variáveis de estado podia ser considerada pequena.

A Tabela 5.5 apresenta os dias e os horários dos padrões usados neste trabalho enquanto as Tabela 5.6 e 5.7 fornecem todos os valores que compõem cada um dos seis padrões usados. Observa-se que dos 35 pontos de coleta, apenas 25 foram considerados satisfatórios pelas seguintes razões; dois equipamentos apresentaram defeito enquanto da coleta dos dados, verificou-se que alguns moradores retiraram os medidores dos pontos em que foram instalados (cavaletes) enquanto a coleta acontecia por acreditarem que poderiam estar sendo lesados com o estudo, alguns equipamentos apresentaram leituras de valores negativos (tais equipamentos não são aptos a realizar medidas de pressões negativas).

A Figura 5.20 destaca em vermelho os dados empregados para a construção dos seis padrões em função das magnitudes da vazão de entrada do setor.

Tabela 5.5 - Dias e horários das medidas usadas como padrões na calibração da cidade de Guariba

\begin{tabular}{|c|c|c|}
\hline PADRÃO & DIA & HORÁRIO \\
\hline $\mathbf{1}$ & $19 / 3 / 2006$ & $6: 45-7: 00$ \\
\hline $\mathbf{2}$ & $20 / 3 / 2006$ & $2: 15-2: 45$ \\
\hline $\mathbf{3}$ & $20 / 3 / 2006$ & $6: 45-7: 00$ \\
\hline $\mathbf{4}$ & $20 / 3 / 2006$ & $9: 00-9: 30$ \\
\hline $\mathbf{5}$ & $20 / 3 / 2006$ & $15: 15-15: 45$ \\
\hline $\mathbf{6}$ & $20 / 3 / 2006$ & $22: 30-22: 45$ \\
\hline
\end{tabular}


Tabela 5.6 - Valores do nível e carga hidráulica do reservatório; e vazão de entrada observadas no sistema de Guariba

\begin{tabular}{|l|c|c|c|c|c|c|}
\hline \multicolumn{1}{|c|}{ Descrição } & Padrão 1 & Padrão 2 & Padrão 3 & Padrão 4 & Padrão 5 & Padrão 6 \\
\hline Nv. R5 (m) & 4,62 & 4,29 & 3,97 & 4,36 & 3,87 & 2,62 \\
\hline Nv. + cota (m) & 652,05 & 652,01 & 650,88 & 650,12 & 650,81 & 650,10 \\
\hline Vaz. ZM (L/s) & 21,73 & 12,77 & 32,43 & 50,51 & 33,03 & 21,06 \\
\hline
\end{tabular}

Tabela 5.7 - Pressões dinâmicas observadas no sistema de Guariba

\begin{tabular}{|c|c|c|c|c|c|c|}
\hline $\begin{array}{c}\text { Descrição } \\
\text { (nó) }\end{array}$ & $\begin{array}{c}\text { Padrão } 1 \\
\left(\mathrm{mH}_{2} \mathrm{O}\right)\end{array}$ & \begin{tabular}{|c|} 
Padrão 2 \\
$\left(\mathrm{mH}_{2} \mathrm{O}\right)$ \\
\end{tabular} & $\begin{array}{c}\text { Padrão } 3 \\
\left(\mathrm{mH}_{2} \mathrm{O}\right)\end{array}$ & $\begin{array}{c}\text { Padrão } 4 \\
\left(\mathrm{mH}_{2} \mathrm{O}\right) \\
\end{array}$ & \begin{tabular}{|c|} 
Padrão 5 \\
$\left(\mathrm{mH}_{2} \mathrm{O}\right)$ \\
\end{tabular} & $\begin{array}{c}\text { Padrão } 6 \\
\left(\mathrm{mH}_{2} \mathrm{O}\right)\end{array}$ \\
\hline 8 & 28.58 & 31.33 & 24.88 & 15.44 & 24.71 & 28.00 \\
\hline 11 & 33.63 & 36.27 & 29.73 & 20.34 & 29.66 & 32.98 \\
\hline 13 & 26.05 & 28.61 & 22.23 & 13.34 & 21.50 & 25.05 \\
\hline 31 & 27.40 & 29.81 & 23.05 & 14.41 & 23.10 & 26.45 \\
\hline 38 & 43.85 & 46.09 & 38.53 & 28.46 & 39.51 & 42.78 \\
\hline 46 & 40.43 & 44.49 & 34.05 & 20.64 & 34.86 & 40.28 \\
\hline 75 & Ião medido & 50.93 & não medido & não medido & não medido & não medido \\
\hline 79 & 50.78 & 54.38 & 41.85 & 25.71 & 42.50 & 50.00 \\
\hline 97 & 23.95 & 25.67 & 18.90 & 11.23 & 19.89 & 22.65 \\
\hline 99 & 27.40 & 30.67 & 17.23 & 18.50 & 25.87 & 27.95 \\
\hline 102 & 22.90 & 24.03 & 19.48 & 14.09 & 19.61 & 21.48 \\
\hline 112 & 40.93 & 42.90 & 35.03 & 25.73 & 35.13 & 39.36 \\
\hline 114 & 36.15 & 37.97 & 30.95 & 21.71 & 31.93 & 34.75 \\
\hline 119 & 41.23 & 42.44 & 37.88 & 31.87 & 38.11 & 39.75 \\
\hline 132 & 45.06 & 46.04 & 41.74 & 33.24 & 41.45 & 43.14 \\
\hline 153 & 35.53 & 36.21 & 32.88 & 27.51 & 33.29 & 34.15 \\
\hline 154 & 33.09 & 33.02 & 30.14 & 26.11 & 29.96 & 31.08 \\
\hline 169 & 26.68 & 26.99 & 24.22 & 19.81 & 24.29 & 25.19 \\
\hline 178 & 23.19 & 23.72 & 21.14 & 17.87 & 20.99 & 21.67 \\
\hline 193 & 50.78 & 50.55 & 48.50 & 45.08 & 45.96 & 48.31 \\
\hline 195 & 25.81 & 27.16 & 23.94 & 20.70 & 22.72 & não medido \\
\hline 198 & 32.45 & 33.10 & 29.85 & 26.81 & 30.16 & 31.10 \\
\hline 203 & 25.25 & 25.67 & 22.95 & 19.96 & 23.50 & 23.80 \\
\hline 208 & 28.23 & 28.90 & 26.37 & 23.52 & 26.13 & 27.13 \\
\hline 211 & 29.11 & 29.72 & 27.74 & 25.45 & 27.50 & 27.93 \\
\hline
\end{tabular}




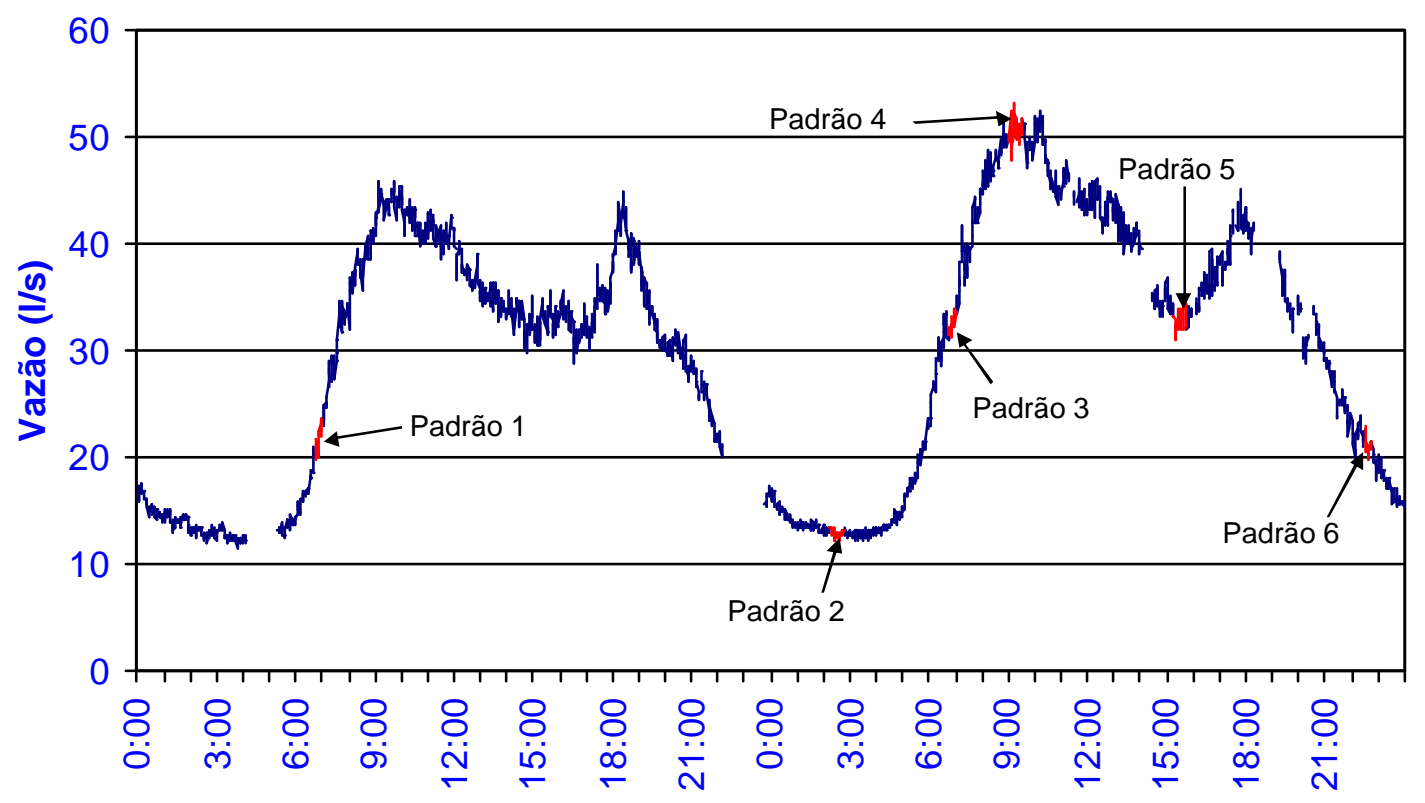

Horas dias 19 e 20/03/06

Figura 5.20 - Localização dos padrões de vazão em função do tempo para a cidade de Guariba

\section{ITIRAPŨ̃}

Quatro padrões operacionais foram criados para a simulação e calibração do sistema de Itirapuã a partir dos dados coletados simultaneamente de carga hidráulica na entrada do sistema, demanda de vazão abastecida total e pressões em pontos da rede.

Os valores de nível do reservatório elevado bem como a vazão na entrada do setor, respeitando os horários dos padrões usados, também foram retirados do banco de dados histórico do sistema supervisório do CCO de Franca.

A coleta das medidas de pressões intrasetoriais de Itirapuã contou com 26 Dataloggers fornecidos pela SABESP dos quais apenas 19 foram efetivamente instalados. 5 Dataloggers não puderam ser usados porque as casas escolhidas para a instalação não ofereciam segurança (muros e portões) suficiente para a permanência dos equipamentos uma vez que a instalação dos equipamentos é feita no hidrômetro da residência além da cidade não apresentar caixas de visitas localizadas nos cruzamentos da rede de abastecimento (nó). Outros 8 Dataloggers não apresentaram resultados satisfatórios de medida. Assim, apenas 13 coletas, realizadas entre os dias 23 e 30 de agosto de 2006, foram usadas. A escolha dos pontos para a instalação dos equipamentos em Itirapuã seguiu os mesmos critérios adotados para Guariba. 
Para a geração dos padrões usados na calibração do modelo de Itirapuã, valores médios observados em pequenos intervalos de tempo foram separados para cada ponto de medição. No entanto, os valores de pressão resultantes para os pontos de medição não caracterizam a pressão exata do nó pelo desnível geométrico dos cavaletes em relação ao cruzamento das ruas. No intuito de minimizar este erro, as pressões observadas foram deslocadas para os nós da seguinte forma: as cotas topográficas do hidrômetro e do cruzamento da rede foram utilizadas para compensar o valor da pressão medida. Assim, caso o hidrômetro estivesse instalado em uma cota superior ao do cruzamento, a diferença em metros entre a cota topográfica do hidrômetro e do cruzamento seria somada ao valor da pressão medida no hidrômetro. Caso contrário, este valor seria subtraído da pressão medida no hidrômetro. A Tabela 5.8 apresenta os dias e os horários dos padrões usados na calibração de Itirapuã, enquanto as Tabela 5.9 e 5.10 fornecem os valores que compõem os mesmos. É importante mencionar que os valores das pressões apresentadas na Tabela 5.10 já sofreram o ajuste para correção do desnível da medida em cavalete. A Figura 5.21 destaca em vermelho os dados empregados para a construção dos padrões em função das magnitudes da vazão de entrada do setor.

Tabela 5.8 - Dias e horários das medidas usadas como padrões na calibração da cidade de Itirapuã

\begin{tabular}{|c|c|c|}
\hline PADRÃO & DIA & HORÁRIO \\
\hline $\mathbf{1}$ & $30 / 08 / 06$ & $1: 30-2: 00$ \\
\hline $\mathbf{2}$ & $29 / 08 / 06$ & $8: 34-8: 59$ \\
\hline $\mathbf{3}$ & $26 / 08 / 06$ & $13: 58-14: 28$ \\
\hline $\mathbf{4}$ & $29 / 08 / 06$ & $20: 55-21: 10$ \\
\hline
\end{tabular}

Tabela 5.9 - Valores do nívele carga hidráulica do reservatório; e vazão de entrada observadas no sistema de Itirapuã

\begin{tabular}{|l|c|c|c|c|}
\hline \multicolumn{1}{|c|}{ Descrição } & Padrão 1 & Padrão 2 & Padrão 3 & Padrão 4 \\
\hline Nv (m) & 4.45 & 4.22 & 3.38 & 4.44 \\
\hline Nv + cota (m) $)^{\star \star}$ & 890.62 & 890.36 & 889.07 & 890.61 \\
\hline Vaz. ZM (L/s) & 3.27 & 15.39 & 19.74 & 9.29 \\
\hline
\end{tabular}

NIVEL do RESERVATORIO ELEVADO

** NÍVEL DO RESERVATÓRIO ELEVADO SOMADO A COTA TOPOGRÁFICA DO PONTO 
Tabela 5.10 - Pressões dinâmicas observadas no sistema de Itirapuã

\begin{tabular}{|c|c|c|c|c|}
\hline $\begin{array}{c}\text { Descrição } \\
\text { (nó) }\end{array}$ & $\begin{array}{c}\text { Padrão 1 } \\
\left(\mathbf{m H}_{\mathbf{2}} \mathbf{\mathbf { O }}\right)\end{array}$ & $\begin{array}{c}\text { Padrão 2 } \\
\left(\mathbf{m H}_{\mathbf{2}} \mathbf{\mathbf { O }}\right)\end{array}$ & $\begin{array}{c}\text { Padrão 3 } \\
\left(\mathbf{m H}_{\mathbf{2}} \mathbf{\mathbf { O }}\right)\end{array}$ & $\begin{array}{c}\text { Padrão 4 } \\
\left(\mathbf{m ~}_{\mathbf{2}} \mathbf{\mathbf { O }}\right)\end{array}$ \\
\hline 112 & 32.86 & 29.99 & 26.48 & 31.88 \\
\hline 15 & 32.38 & 29.55 & 25.80 & 31.08 \\
\hline 168 & 19.08 & 18.82 & 17.53 & 19.06 \\
\hline 80 & 27.87 & 26.96 & 25.92 & 27.68 \\
\hline 149 & 25.99 & 25.13 & 23.49 & 25.60 \\
\hline 89 & 41.92 & 39.21 & 35.96 & 40.94 \\
\hline 30 & 33.79 & 31.71 & 26.68 & 32.73 \\
\hline 34 & 24.61 & 23.62 & 22.30 & 24.14 \\
\hline 122 & 34.21 & 32.70 & 31.42 & 33.79 \\
\hline 148 & 24.39 & 23.26 & 21.17 & 23.74 \\
\hline 17 & 46.02 & 43.15 & 39.09 & 44.84 \\
\hline 75 & 20.02 & 19.41 & 18.19 & 19.06 \\
\hline 134 & 30.18 & 28.50 & 25.58 & 29.77 \\
\hline
\end{tabular}

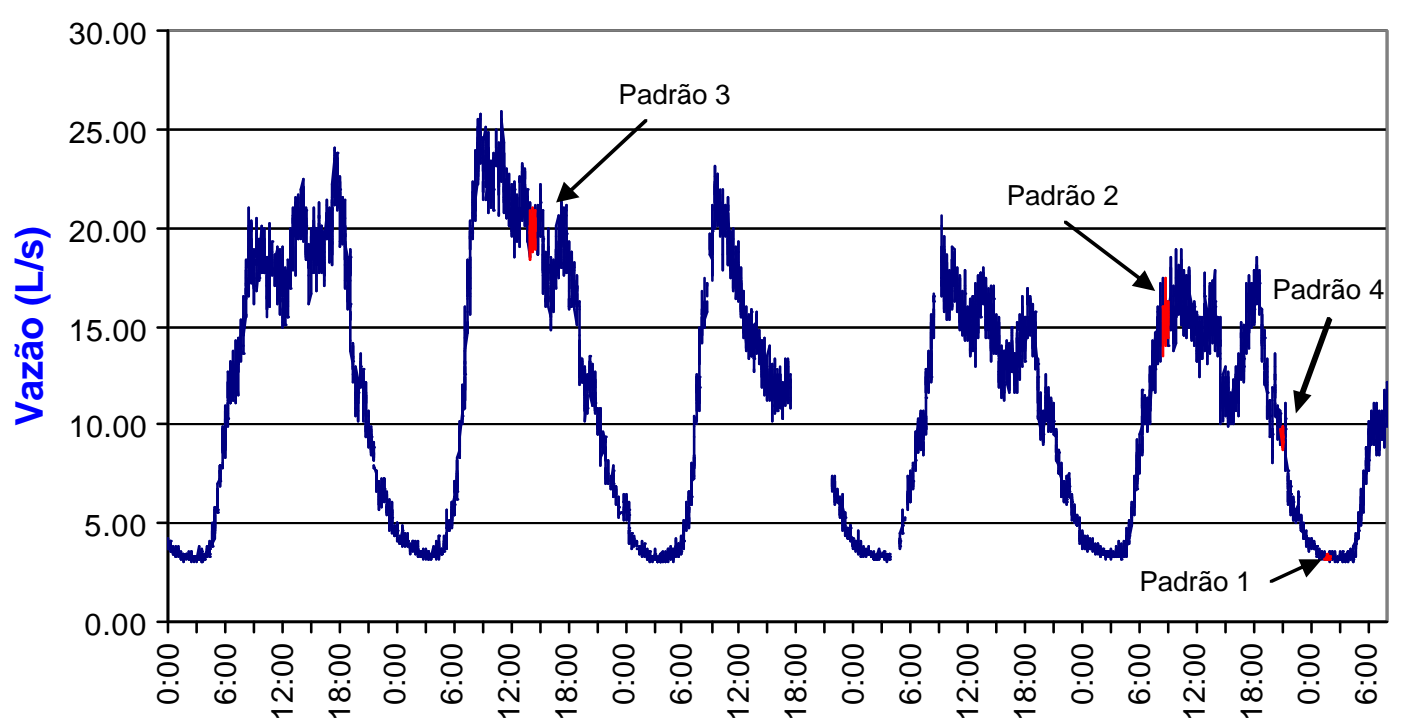

Horas entre os dias 25 e 30/08/06

Figura 5.21 - Localização dos padrões de vazão em função do tempo para a cidade de Itirapuã

\subsubsection{VERIFICAÇÃO DA CONSISTÊNCIA DOS DADOS DE CAMPO}

Foram realizadas algumas análises de verificação da consistência dos dados de campo coletados. Compararam-se as respectivas pressões estáticas e dinâmicas dos nós de observação de pressão para os seis padrões operacionais escolhidos para Guariba. A Tabela 5.11 apresenta os valores das pressões estáticas para os nós em estudo, em que os valores em vermelho indicam pressões estáticas de valores ligeiramente inferiores aos respectivos valores de pressões dinâmicas (observadas). 
Comparando-se as Tabelas 5.7 e 5.11, observa-se que os valores de pressões estáticas inferiores aos respectivos valores de pressões dinâmicas podem ser explicados. Foram tomadas as cotas topográficas relativas a localização dos Dataloggers como coincidentes com nós da rede (esquinas), enquanto que as pressões dinâmicas fram medidas em pontos deslocados alguns metros dos nós da rede pelo fato de tratarem-se de cavaletes residenciais. Assim, em alguns casos, o deslocamento do ponto de medida pode ter implicado num pequeno erro devido à diferença da cota topográfica entre o ponto medido e o respectivo nó da rede. Além disso, as cotas topográficas usadas são correspondentes à topografia do terreno (asfalto) e não da rede de abastecimento propriamente dita, gerando outro erro nos valores topográficos. Para a correção deste último, adotou-se a profundidade padrão utilizado pela SABESP para instalação de redes de água que é de 1,5 metros. Assim, às cotas correspondentes aos pontos de medida (cavaletes residenciais) sofreram um acréscimo de 1,5 metros.

Tabela 5.11 - Pressões estáticas nos nós monitorados no setor ZM da cidade de Guariba

\begin{tabular}{|c|c|c|c|c|c|c|}
\hline $\begin{array}{c}\text { Descrição } \\
\text { (nó) }\end{array}$ & $\begin{array}{c}\text { Padrão 1 } \\
\left(\mathbf{m H}_{\mathbf{2}} \mathbf{\mathbf { }}\right)\end{array}$ & $\begin{array}{c}\text { Padrão 2 } \\
\left(\mathbf{m H}_{\mathbf{2}} \mathbf{\mathbf { O }}\right)\end{array}$ & $\begin{array}{c}\text { Padrão 3 } \\
\left(\mathbf{m H}_{\mathbf{2}} \mathbf{\mathbf { O }}\right)\end{array}$ & $\begin{array}{c}\text { Padrão 4 } \\
\left(\mathbf{m H}_{\mathbf{2}} \mathbf{\mathbf { }}\right)\end{array}$ & $\begin{array}{c}\text { Padrão 5 } \\
\left(\mathbf{m H}_{\mathbf{2}} \mathbf{\mathbf { O }}\right)\end{array}$ & $\begin{array}{c}\text { Padrão 6 } \\
\left(\mathbf{m H}_{\mathbf{2}} \mathbf{\mathbf { }}\right)\end{array}$ \\
\hline $\mathbf{8}$ & 47,28 & 47,24 & 46,11 & 45,35 & 46,04 & 45,33 \\
\hline $\mathbf{1 1}$ & 36,16 & 36,12 & 34,98 & 34,23 & 34,91 & 34,2 \\
\hline $\mathbf{1 3}$ & 36,18 & 36,14 & 35,01 & 34,26 & 34,94 & 34,23 \\
\hline $\mathbf{3 1}$ & 30,57 & 30,53 & 29,39 & 28,64 & 29,32 & 28,61 \\
\hline $\mathbf{3 8}$ & 46,15 & 46,11 & 44,97 & 44,22 & 44,9 & 44,19 \\
\hline $\mathbf{4 6}$ & 51,25 & 51,21 & 50,07 & 49,32 & 50 & 49,29 \\
\hline $\mathbf{7 5}$ & 51,34 & 51,3 & 50,17 & 49,41 & 50,1 & 49,39 \\
\hline $\mathbf{7 9}$ & 59,91 & 59,87 & 58,73 & 57,98 & 58,67 & 57,95 \\
\hline $\mathbf{9 7}$ & 28,69 & 28,65 & 27,51 & 26,76 & 27,45 & 26,73 \\
\hline $\mathbf{9 9}$ & 33,15 & 33,11 & 31,98 & 31,23 & 31,91 & 31,2 \\
\hline $\mathbf{1 0 2}$ & 25,39 & 25,35 & 24,21 & 23,46 & 24,14 & 23,43 \\
\hline $\mathbf{1 1 2}$ & 47,28 & 47,24 & 46,11 & 45,35 & 46,04 & 45,33 \\
\hline $\mathbf{1 1 4}$ & 39,6 & 39,56 & 38,42 & 37,67 & 38,35 & 37,64 \\
\hline $\mathbf{1 1 9}$ & 41,45 & 41,41 & 40,28 & 39,52 & 40,21 & 39,5 \\
\hline $\mathbf{1 3 2}$ & 48,44 & 48,4 & 47,27 & 46,52 & 47,2 & 46,49 \\
\hline $\mathbf{1 5 3}$ & 38,58 & 38,54 & 37,4 & 36,65 & 37,33 & 36,62 \\
\hline $\mathbf{1 5 4}$ & 35,19 & 35,15 & 34,01 & 33,26 & 33,94 & 33,23 \\
\hline $\mathbf{1 6 9}$ & 30,88 & 30,84 & 29,7 & 28,95 & 29,63 & 28,92 \\
\hline $\mathbf{1 7 8}$ & 24,78 & 24,74 & 23,61 & 22,85 & 23,54 & 22,83 \\
\hline $\mathbf{1 9 3}$ & 53,72 & 53,68 & 52,54 & 51,79 & 52,47 & 51,76 \\
\hline $\mathbf{1 9 5}$ & 25,7 & 25,66 & 24,53 & 23,78 & 24,46 & 23,75 \\
\hline $\mathbf{1 9 8}$ & 36,57 & 36,53 & 35,39 & 34,64 & 35,32 & 34,61 \\
\hline $\mathbf{2 0 3}$ & 27 & 26,96 & 25,82 & 25,07 & 25,75 & 25,04 \\
\hline $\mathbf{2 0 8}$ & 35,26 & 35,22 & 34,09 & 33,33 & 34,02 & 33,31 \\
\hline $\mathbf{2 1 1}$ & 30,87 & 30,83 & 29,7 & 28,95 & 29,63 & 28,92 \\
\hline
\end{tabular}


A Tabela 5.12 traz os valores de pressões estáticas dos nós calculadas a partir dos pontos escolhidos para medição na cidade de Itirapuã. Neste município, a comparação entre as pressões estáticas e dinâmicas dos pontos de coleta não demonstrou incoerências. A razão é que durante os dias 13 e 14 de novembro de 2006, uma nova visita foi realizada m cidade visando à confirmação das cotas topográficas dos pontos em questão e de alguns outros intermediários a estes. Diferentemente da cidade de Guariba, as cotas dos pontos de medição de pressões usadas para Itirapuã não foram as medidas nas esquinas das quadras, e sim nos cavaletes residenciais, representando exatamente a cota que os Dataloggers foram instalados. O trabalho topográfico foi feito por funcionários treinados da SABESP.

Tabela 5.12 - Pressões estáticas nos nós monitorados na cidade de Itirapuã

\begin{tabular}{|c|c|c|c|c|}
\hline $\begin{array}{c}\text { Descrição } \\
\text { (nó) }\end{array}$ & $\begin{array}{c}\text { Padrão 1 } \\
\left(\mathbf{m H}_{\mathbf{2}} \mathbf{\mathbf { O }}\right)\end{array}$ & $\begin{array}{c}\text { Padrão 2 } \\
\left(\mathbf{m H}_{\mathbf{2}} \mathbf{O}\right)\end{array}$ & $\begin{array}{c}\text { Padrão 3 } \\
\left(\mathbf{m H}_{\mathbf{2}} \mathbf{O}\right)\end{array}$ & $\begin{array}{c}\text { Padrão 4 } \\
\left(\mathbf{m ~}_{\mathbf{2}} \mathbf{O}\right)\end{array}$ \\
\hline $\mathbf{1 1 2}$ & 37.09 & 36.83 & 35.54 & 37.08 \\
\hline $\mathbf{1 5}$ & 33.61 & 33.35 & 32.06 & 33.60 \\
\hline $\mathbf{1 6 8}$ & 19.08 & 18.82 & 17.53 & 19.06 \\
\hline $\mathbf{8 0}$ & 28.19 & 27.93 & 26.64 & 28.17 \\
\hline $\mathbf{1 4 9}$ & 26.42 & 26.16 & 24.87 & 26.41 \\
\hline $\mathbf{8 9}$ & 42.82 & 42.56 & 41.27 & 42.80 \\
\hline $\mathbf{3 0}$ & 36.84 & 36.58 & 35.30 & 36.83 \\
\hline $\mathbf{3 4}$ & 25.47 & 25.21 & 23.92 & 25.45 \\
\hline $\mathbf{1 2 2}$ & 35.49 & 35.23 & 33.95 & 35.48 \\
\hline $\mathbf{1 4 8}$ & 25.48 & 25.22 & 23.93 & 25.46 \\
\hline $\mathbf{1 7}$ & 47.21 & 46.95 & 45.67 & 47.20 \\
\hline $\mathbf{7 5}$ & 21.62 & 21.36 & 20.07 & 21.61 \\
\hline $\mathbf{1 3 4}$ & 33.03 & 32.77 & 31.48 & 33.02 \\
\hline
\end{tabular}

Para melhor compreender o comportamento do plano piezométrico, foram traçadas ainda as curvas de nível do setor Zona Média de Guariba e da cidade completo de Itirapuã demonstradas no Apêndice A. Também estão demonstradas as curvas de resposta em termos das pressões estáticas e dinâmicas observadas em Guariba e Itirapuã. Tais curvas são apresentadas nos Apêndices F e G, sugerindo que o plano de pressões dinâmicas segue o respectivo plano de pressões estáticas em ambos os casos.

\subsection{CALIBRAÇÃO}

O procedimento de calibração realizado para os municípios de Guariba e Itirapuã, considerou diferentes padrões de consumo, baseados em horários que caracterizavam nítidas mudanças de demanda. Para o setor Zona Média da cidade de Guariba, seis padrões de consumo, representados na Tabela 5.7, foram criados. A cidade de Itirapuã 
considerou quatro padrões de consumo representados na Tabela 5.10. Para ambos os municípios, dados de vazão total abastecida e nível do reservatório foram também observados, respeitando os horários de cada padrão. Isso pode ser observado nas Tabelas 5.6 e 5.9 para Guariba e Itirapuã respectivamente.

Para todo o procedimento de calibração realizado neste trabalho, faixas mínimas e máximas, fixadas diferentemente para cada município, foram consideradas para os dados da rugosidade absoluta e os parâmetros do modelo de vazamento. Vale lembrar que o presente trabalho obteve um valor de calibração da rugosidade absoluta e do expoente de perda para cada um dos setores representados na Tabela 5.13 e discriminados na coluna "Setor" das tabelas apresentadas nos Apêndices B e C. Estes setores são divididos segundo o material da tubulação que os compõem. Para o coeficiente de perda, apenas um valor de calibração foi gerado para cada rede independente da quantidade de setores que ela possua. As Tabelas 5.14, 5.15 e 5.16 apresentam, respectivamente, os limites dos valores das rugosidades absolutas, dos coeficientes de perda, dos expoentes de perda e das demandas de referência usados na calibração das redes dos municípios de Guariba e Itirapuã.

Tabela 5.13 - Divisão dos setores segundo o material que o compõem

\begin{tabular}{|c|c|c|c|c|c|}
\hline \multicolumn{4}{|c|}{ Guariba } & \multicolumn{2}{c|}{ Itirapuã } \\
\hline Setor 1 & Setor 2 & Setor 3 & Setor 4 & Setor 1 & Setor 2 \\
\hline PVC & DeFoFo & $\begin{array}{c}\text { Ferro } \\
\text { Galvanizado }\end{array}$ & Ferro Fundido & PVC & $\begin{array}{c}\text { Cimento } \\
\text { Amianto }\end{array}$ \\
\hline
\end{tabular}

Tabela 5.14 - Limites de rugosidade absoluta para os municípios de Guariba e Itirapuã

\begin{tabular}{|c|c|c|c|c|c|c|c|c|c|c|c|}
\hline \multicolumn{12}{|c|}{ Rugosidade Absoluta (mm) } \\
\hline \multicolumn{8}{|c|}{ Guariba } & \multicolumn{4}{|c|}{ Itirapuã } \\
\hline \multicolumn{2}{|c|}{$\begin{array}{c}\mathbf{e}_{\mathbf{1}} \\
\text { Limite }\end{array}$} & \multicolumn{2}{|c|}{$\begin{array}{c}\mathbf{e}_{\mathbf{2}} \\
\text { Limite }\end{array}$} & \multicolumn{2}{|c|}{$\begin{array}{c}\mathbf{e}_{\mathbf{3}} \\
\text { Limite }\end{array}$} & \multicolumn{2}{|c|}{$\begin{array}{c}\mathbf{e}_{\mathbf{4}} \\
\text { Limite }\end{array}$} & \multicolumn{2}{|c|}{$\begin{array}{c}\mathbf{e}_{\mathbf{1}} \\
\text { Limite } \\
\end{array}$} & \multicolumn{2}{|c|}{$\begin{array}{c}\mathbf{e}_{\mathbf{2}} \\
\text { Limite }\end{array}$} \\
\hline mín & máx & mín & máx & mín & máx & mín & máx & mín & máx & mín & máx \\
\hline 0,001 & 3,5 & 0,001 & 3,5 & 0,001 & 3,5 & 0,001 & 3,5 & 0,001 & 0,002 & 0,02 & 0,03 \\
\hline
\end{tabular}

Tabela 5.15 - Limites do coeficiente de perda para os municípios de Guariba e Itirapuã

\begin{tabular}{|c|c|c|c|c|c|c|c|c|c|c|c|}
\hline \multicolumn{12}{|c|}{ Coeficiente de Perda $(\mathrm{L} / \mathrm{s})$} \\
\hline \multicolumn{8}{|c|}{ Guariba } & \multicolumn{4}{|c|}{ Itirapuã } \\
\hline \multicolumn{2}{|c|}{$\begin{array}{c}?_{1} \\
\text { Limite } \\
\end{array}$} & \multicolumn{2}{|c|}{$\begin{array}{c}?_{2} \\
\text { Limite }\end{array}$} & \multicolumn{2}{|c|}{$\begin{array}{c}?_{3} \\
\text { Limite }\end{array}$} & \multicolumn{2}{|c|}{$\begin{array}{c}\boldsymbol{?}_{\mathbf{4}} \\
\text { Limite }\end{array}$} & \multicolumn{2}{|c|}{$\begin{array}{c}?_{1} \\
\text { Limite }\end{array}$} & \multicolumn{2}{|c|}{$\begin{array}{c}?_{2} \\
\text { Limite }\end{array}$} \\
\hline mín & máx & mín & máx & mín & máx & mín & máx & mín & máx & mín & máx \\
\hline$\overline{0,00}$ & 0,001 & 0,00 & 0,001 & 0,00 & 0,001 & 0,00 & 0,001 & 0,00001 & 0,0001 & 0,00001 & 0,0001 \\
\hline
\end{tabular}


Tabela 5.16 - Expoente de perda e demanda total para os municípios de Guariba e Itirapuã

\begin{tabular}{|c|c|c|c|c|c|}
\hline \multicolumn{4}{|c|}{ Expoente de Perda $\boldsymbol{\beta}$} & \multicolumn{2}{c|}{ Demanda Total (L/s) } \\
\hline \multicolumn{2}{|c|}{$\begin{array}{c}\text { Guariba } \\
\text { Limite }\end{array}$} & \multicolumn{2}{c|}{$\begin{array}{c}\text { Itirapuã } \\
\text { Limite }\end{array}$} & Guariba & Itirapuã \\
\cline { 1 - 3 } mín & máx & mín & máx & \multirow{2}{*}{18,63} & \multirow{2}{*}{7,05} \\
\hline 0,5 & 1,15 & 0,5 & 1,18 & & \\
\hline
\end{tabular}

\subsubsection{RESULTADOS DA CALIBRAÇÃO DA REDE DE GUARIBA}

Na calibração da rede de abastecimento de água da cidade de Guariba, apesar do calibrador ter atingido convergência, apenas o padrão 2 apresentou resultados. Este é o padrão que representa o comportamento das pressões nos nós monitorados para o horário de menor magnitude de vazão abastecida.

Os valores indicados na Tabela 5.17 são adotados para os parâmetros do AG nas simulações do modelo da rede de Guariba, seguindo os valores recomendados por SOARES (2003) que apresenta resultados de simulações baseados em diversas parametrizações dos AGs.

Tabela 5.17 - Parametros dos AGs para as simulações da rede de Guariba

\begin{tabular}{|l|c|}
\cline { 2 - 2 } \multicolumn{1}{c|}{} & \multicolumn{1}{c|}{ AG } \\
\hline População de soluções & Geracional Elitista \\
\hline Recombinação & aritmética \\
\hline Probabilidade de recombinação & 0.70 \\
\hline Seleção & SRS \\
\hline Mutação & gaussiana \\
\hline Probabilidade de mutação & 0.01 \\
\hline Taxa de elitismo & 0.30 \\
\hline Número de gerações & 100 \\
\hline Semente aleatória & 1200 \\
\hline
\end{tabular}

A Tabela 5.18 apresenta uma comparação entre as pressões observadas e as pressões resultantes da calibração para o padrão 2 usando apenas os Algoritmos Genéticos e posteriormente, o Método Híbrido (AG + Nelder-Mead,).

A Tabela 5.19 fornece os resultados calibrados para os parâmetros rugosidade, $\beta$ e ? do padrão 2 seguindo os limites máximos e mínimos apresentados nas Tabelas 5.14, 5.15 e 5.16 . 
Tabela 5.18 - Resultado da calibração das pressões do sistema com o modelo de SOARES (2003) para o padrão 2 da rede de Guariba

\begin{tabular}{|c|c|c|c|}
\hline \multirow{2}{*}{ Nós } & \multicolumn{3}{|c|}{ Pressões $\mathbf{( m H}_{\mathbf{2}} \mathbf{O}$ ) } \\
\cline { 2 - 4 } & \multirow{2}{*}{ Observadas } & Simuladas (Método Híbrido) \\
\cline { 2 - 4 } & & 32.497 & $\begin{array}{c}\text { Nelder \& Mead } \\
\mathbf{1 9 6 5 )}\end{array}$ \\
\hline $\mathbf{8}$ & 31.33 & 32.711 & 32.565 \\
\hline $\mathbf{1 1}$ & 36.27 & 32.743 & 32.779 \\
\hline $\mathbf{1 3}$ & 28.61 & 27.279 & 32.811 \\
\hline $\mathbf{3 1}$ & 29.81 & 43.109 & 27.345 \\
\hline $\mathbf{3 8}$ & 46.09 & 47.595 & 43.179 \\
\hline $\mathbf{4 6}$ & 44.49 & 47.436 & 47.694 \\
\hline $\mathbf{7 5}$ & 50.93 & 55.994 & 47.551 \\
\hline $\mathbf{7 9}$ & 54.38 & 25.829 & 56.110 \\
\hline $\mathbf{9 7}$ & 25.67 & 30.697 & 25.895 \\
\hline $\mathbf{9 9}$ & 30.67 & 22.862 & 30.753 \\
\hline $\mathbf{1 0 2}$ & 24.03 & 44.403 & 22.918 \\
\hline $\mathbf{1 1 2}$ & 42.90 & 36.734 & 44.470 \\
\hline $\mathbf{1 1 4}$ & 37.97 & 39.055 & 36.801 \\
\hline $\mathbf{1 1 9}$ & 42.44 & 46.077 & 39.112 \\
\hline $\mathbf{1 3 2}$ & 46.04 & 37.820 & 46.135 \\
\hline $\mathbf{1 5 3}$ & 36.21 & 34.425 & 37.808 \\
\hline $\mathbf{1 5 4}$ & 33.02 & 29.492 & 34.414 \\
\hline $\mathbf{1 6 9}$ & 26.99 & 24.397 & 29.520 \\
\hline $\mathbf{1 7 8}$ & 23.72 & 53.394 & 24.401 \\
\hline $\mathbf{1 9 3}$ & 50.55 & 25.231 & 25.388 \\
\hline $\mathbf{1 9 5}$ & 27.16 & 36.106 & 36.106 \\
\hline $\mathbf{1 9 8}$ & 33.10 & & \\
\hline & & & \\
\hline
\end{tabular}

Tabela 5.19 - Resultados obtidos em termos dos valores dos parâmetros calibrados

\begin{tabular}{|c|c|c|}
\hline \multirow[b]{2}{*}{ Parâmetro } & \multicolumn{2}{|c|}{ Resultados } \\
\hline & AG & $\begin{array}{c}\text { Híbrido AG } \\
\text { Nelder-Mead }\end{array}$ \\
\hline$e_{1}(\mathrm{~mm})$ & 0.272232 & 0.253302 \\
\hline$e_{2}(\mathrm{~mm})$ & 0.407421 & 0.426447 \\
\hline$e_{3}(\mathrm{~mm})$ & 0.309607 & 0.00634565 \\
\hline$e_{4}(\mathrm{~mm})$ & 0.001 & 0.00135795 \\
\hline$e_{5}(\mathrm{~mm})$ & 0.458677 & 0.602656 \\
\hline$?_{1}(\mathrm{x} 10 \mathrm{e}-7)$ & 0.0000 & 0.0000 \\
\hline$?_{2}(\mathrm{x} 10 \mathrm{e}-7)$ & 0.000093661 & 0.000138988 \\
\hline$?_{3}(\mathrm{x} 10 \mathrm{e}-7)$ & 0.000623737 & 0.000620013 \\
\hline$?_{4}(\mathrm{x} 10 \mathrm{e}-7)$ & 0.000706958 & 0.000812859 \\
\hline$?_{5}(\mathrm{x} 10 \mathrm{e}-7)$ & 0.000587213 & 0.000558129 \\
\hline B & 0.586192 & 0.886954 \\
\hline
\end{tabular}

Para os padrões 1, 3, 4, 5 e 6, a calibração da rede não foi possível já que, durante o processo, pressões negativas em alguns nós com cotas topográficas mais elevadas (desfavoráveis) eram geradas. 
Suspeitando que o calibrador incluindo vazamentos pudesse apresentar problemas, optou-se por realizar alguns testes com a rede do setor Zona Média usando o simulador hidráulico EPANET. Dois níveis foram utilizados para o reservatório de abastecimento do setor, como se pode observar na Tabela 5.20. Para que vazões maiores fossem admitidas, o valor do fator de cons umo foi alterado durante as simulações com o intuito de obterem-se valores de consumo do sistema próximos aos valores de vazões dos padrões de vazões observados. A pressão resultante foi observada apenas no nó 1 por se tratar do ponto mais desfavorável do setor em termos de abastecimento, ou seja, o nó 1 seria o primeiro ponto a apresentar desabastecimento se o registro de entrada do setor fosse fechado. A Figura 5.22 apresenta a localização do nó 1 na rede de distribuição de água de Guariba, e a Tabela AP.2 lista todos os nós com suas respectivas cotas topográficas também para a cidade de Guariba. A Tabela 5.20 traz as vazões e as pressões resultantes da simulação realizada com os valores das rugosidades das tubulações iguais aos valores adotados na rede construída no EPANET bem como os valores do fator de consumo usados para o mesmo.

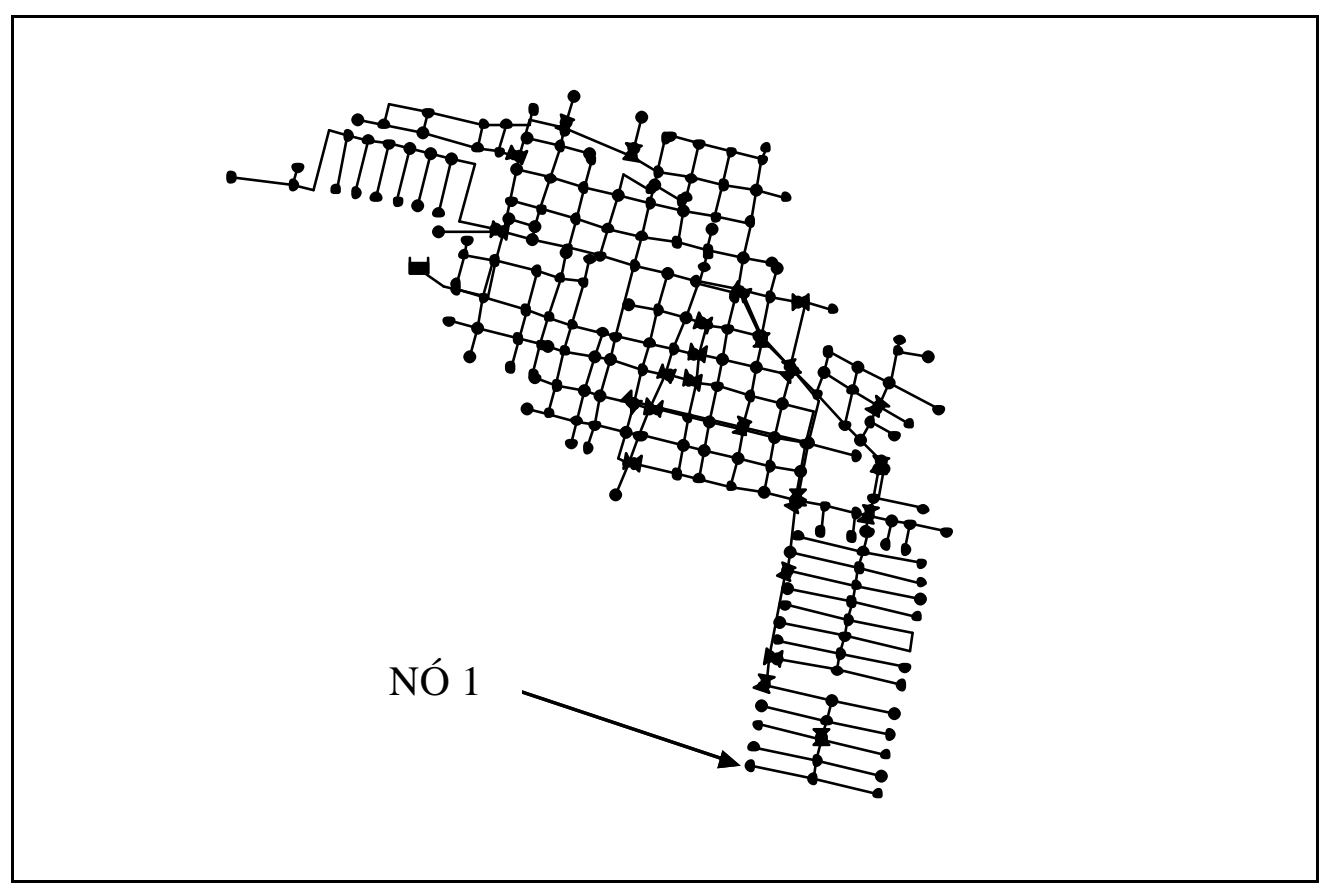

Figura 5.22 - Localização do nó na rede de distribuição de água da cidade de Guariba 
Tabela 5.20 - Resultados da simulação no EPANET com rugosidades médias dos tubos

\begin{tabular}{|c|c|c|c|c|}
\hline $\begin{array}{c}\text { Nível + cota res. } \\
(\mathbf{m})\end{array}$ & Fator de Consumo & $\begin{array}{c}\text { Erro } \\
\text { Conv. }\end{array}$ & $\begin{array}{c}\text { Vazão Entrada } \\
(\mathbf{L} / \mathbf{s})\end{array}$ & $\begin{array}{c}\text { Press. nó 1 } \\
\left(\mathbf{m H}_{\mathbf{2}} \mathbf{O}\right)\end{array}$ \\
\hline 650.62 & 1.0 & 0.001 & 18.63 & 8.16 \\
\hline 650.62 & 1.5 & 0.001 & 27.94 & -9.63 \\
\hline 652.00 & 1.0 & 0.001 & 18.63 & 9.54 \\
\hline 652.00 & 1.5 & 0.001 & 27.94 & -8.25 \\
\hline
\end{tabular}

Avaliando-se que as rugosidades imputadas aos tubos pudessem constituir razão para as perdas de carga elevadas e conseqüentes valores negativos para as pressões simuladas da Tabela 5.20, os testes foram repetidos, conforme indicações da Tabela 5.21, considerando os valores mínimos reportados na literatura para as rugosidades dos tubos para os diversos materiais.

Tabela 5.21 - Resultados da simulação no EPANET com rugosidades mínimas dos tubos

\begin{tabular}{|c|c|c|c|c|}
\hline $\begin{array}{c}\text { Nível + cota res. } \\
(\mathbf{m})\end{array}$ & Fator de Consumo & $\begin{array}{c}\text { Erro } \\
\text { Conv. }\end{array}$ & $\begin{array}{c}\text { Vazão Entrada } \\
\mathbf{( \mathbf { L } / \mathbf { s } )}\end{array}$ & $\begin{array}{c}\text { Press. nó 1 } \\
\left(\mathbf{m} \mathbf{H}_{\mathbf{2}} \mathbf{0}\right)\end{array}$ \\
\hline 650.62 & 1.0 & 0.001 & 18.63 & 14.16 \\
\hline 650.62 & 1.5 & 0.001 & 27.94 & 3.84 \\
\hline 652.00 & 1.0 & 0.001 & 18.63 & 15.54 \\
\hline 652.00 & 1.5 & 0.001 & 27.94 & 5.22 \\
\hline
\end{tabular}

\subsubsection{RESULTADOS DA CALIBRAÇÃO DA REDE DE ITIRAPUÃ}

São apresentados a seguir os resultados obtidos pela calibração que visou identificar as rugosidades absolutas e parâmetros do modelo pressão x vazamento (coeficiente ? e expoente $\beta$ ) para a rede da cidade de Itirapuã, ilustrada pela Figura 5.19. Considerando dois tipos de AGs (Geracional Elitista e Steady-State) e a função objetivo FO1 definida pela eq. (4.1), alguns parâmetros dos AGs foram testados, com o intuito de identificar aqueles que produzem melhores resultados para a calibração. Assim, os tópicos seguintes do trabalho são dedicados à análise de sensibilidade dos parâmetros dos AGs.

Vale lembrar que, o arquivo ag1.in, responsável pela parametrização dos AGs e divisão da rede em áreas de valores homogêneos para a rugosidade e parâmetros do modelo de vazamento, permite, para o caso do AG tipo Steady-State, a escolha do número de soluções a serem substituídas de uma geração para outra após a aplicação dos operadores recombinação e mutação. Neste trabalho optou-se pela substituição de quatro indivíduos por apresentar melhores resultados em testes preliminares. Este número não foi alterado durante as simulações levando-se em consideração a 
recomendação de SOARES (2003) que alerta a descaracterização do tipo de AG que a alteração do número de indivíduos traria.

\subsubsection{TAMANHO DA POPULAÇÃO DE SOLUÇÕES}

Na Tabela 5.22 estão descritos, de maneira sucinta, os valores dos parametros dos Algoritmos Genéticos usados nas simulações para a rede de Itirapuã variando-se o tamanho da população de soluções.

Tabela 5.22 - Parâmetros adotados para os testes de tamanho da população

\begin{tabular}{|l|c|c|}
\cline { 2 - 3 } \multicolumn{1}{c|}{} & \multicolumn{2}{c|}{ Tipos de Ags } \\
\cline { 2 - 3 } \multicolumn{1}{c|}{} & Geracional elitista & Steady-State \\
\hline Recombinação & aritmética & aritmética \\
\hline Probabilidade de recombinação & 0.70 & 0.70 \\
\hline Seleção & SRS & SRS \\
\hline Mutação & gaussiana & gaussiana \\
\hline Probabilidade de mutação & 0.01 & 0.01 \\
\hline Taxa de elitismo & 0.30 & 0.30 \\
\hline Número de gerações & 100 & 100 \\
\hline Semente aleatória & 1 & 1 \\
\hline
\end{tabular}

São realizadas quatro simulações para cada tipo de AG, variando-se a população de soluções segundo indicações da Tabela 5.22. Os valores obtidos para a função objetivo conforme apresentados na Tabela 5.23 não revelam diferenças consideráveis para os dois tipos de AGs e diversos tamanhos da população, da mesma maneira que a hibridização não se demonstrou efetiva em reduzir tais valores.

Tabela 5.23 - Valores da função objetivo para diversas simulação

\begin{tabular}{|c|c|c|c|c|c|}
\hline \multirow{2}{*}{ Simulação } & \multirow{2}{*}{ População } & \multicolumn{5}{|c|}{ Resultado Função Objetivo } \\
\cline { 3 - 6 } & & $\begin{array}{c}\text { AG } \\
\text { Ger. Elit. }\end{array}$ & Híbrido & $\begin{array}{c}\text { AG } \\
\text { Steady-State }\end{array}$ & Híbrido \\
\hline 1 & 20 & 0.375066 & 0.375093 & 0.375277 & 0.375023 \\
\hline 2 & 30 & 0.374942 & 0.374995 & 0.375007 & 0.375059 \\
\hline 3 & 40 & 0.375070 & 0.375081 & 0.375259 & 0.374992 \\
\hline 4 & 50 & 0.375521 & 0.374952 & 0.375108 & 0.375127 \\
\hline
\end{tabular}

Os resultados correspondentes em termos das pressões, vazões e valores calibrados das variáveis de decisão, são apresentados nas Figuras de 5.23 a 5.32, e nas Tabelas 5.29 a 5.35 para as diferentes populações de soluções. Tais figuras possibilitam que as pressões e vazões observadas sejam comparadas aos respectivos valores simulados com os parâmetros determinados pela calibração. Se, para as vazões, diferenças mínimas foram obtidas, desvios superiores àqueles recomendados pelo 
WATER RESEARCH CENTRE (1989) foram observados para as pressões de alguns nós e todos os padrões de consumo analisados, indistintamente. Nas Tabelas 5.24 a 5.34 os desvios que ultrapassaram as recomendações do WATER RESEARCH CENTRE (1989) estão apresentados na cor vermelho. Observa-se que desvios superiores aos referidos valores estavam previstos pelo fato de terem sido desconsiderados os efeitos do consumo sobre as pressões coletadas nos hidrômetros residenciais. Entretanto, não se contavam com diferenças da ordem de 6 metros obtidas para alguns nós relativos ao padrão de consumo máximo (padrão 3 - 19,74 L/s).

Tabela 5.24 - Desvios entre pressões simuladas e observadas para o padrão 1 (AG Geracional Elitista)

\begin{tabular}{|r|r|r|r|r|r|r|r|r|r|}
\hline nó & \multicolumn{1}{c|}{ Obs. } & \multicolumn{1}{c|}{ Sim. 1 } & $\begin{array}{l}\text { Erro } \\
\text { Abs. }\end{array}$ & Sim. 2 & $\begin{array}{l}\text { Erro } \\
\text { Abs. }\end{array}$ & Sim. 3 & $\begin{array}{l}\text { Erro } \\
\text { Abs. }\end{array}$ & Sim. 4 & $\begin{array}{c}\text { Erro } \\
\text { Abs. }\end{array}$ \\
\hline 112 & 32.86 & 36.8331 & 3.9731 & 36.833 & 3.973 & 36.8331 & 3.9731 & 36.833 & 3.973 \\
\hline 15 & 32.38 & 33.438 & 1.058 & 33.4379 & 1.0579 & 33.4381 & 1.0581 & 33.438 & 1.058 \\
\hline 168 & 19.08 & 18.9453 & -0.1347 & 18.9453 & -0.1347 & 18.9453 & -0.1347 & 18.9453 & -0.1347 \\
\hline 80 & 27.87 & 28.064 & 0.194 & 28.064 & 0.194 & 28.0641 & 0.1941 & 28.064 & 0.194 \\
\hline 149 & 25.99 & 25.5617 & -0.4283 & 25.5621 & -0.4279 & 25.562 & -0.428 & 25.5621 & -0.4279 \\
\hline 89 & 41.92 & 42.2502 & 0.3302 & 42.2501 & 0.3301 & 42.2502 & 0.3302 & 42.2501 & 0.3301 \\
\hline 30 & 33.79 & 36.5749 & 2.7849 & 36.5749 & 2.7849 & 36.575 & 2.785 & 36.5749 & 2.7849 \\
\hline 34 & 24.61 & 25.4081 & 0.7981 & 25.4081 & 0.7981 & 25.4081 & 0.7981 & 25.4081 & 0.7981 \\
\hline 122 & 34.21 & 34.831 & 0.621 & 34.831 & 0.621 & 34.831 & 0.621 & 34.831 & 0.621 \\
\hline 148 & 24.39 & 24.7925 & 0.4025 & 24.7929 & 0.4029 & 24.7928 & 0.4028 & 24.7929 & 0.4029 \\
\hline 17 & 45.62 & 47.0397 & 1.4197 & 47.0396 & 1.4196 & 47.0398 & 1.4198 & 47.0397 & 1.4197 \\
\hline 75 & 20.02 & 19.5473 & -0.4727 & 19.5473 & -0.4727 & 19.5473 & -0.4727 & 19.5473 & -0.4727 \\
\hline 134 & 30.18 & 32.9403 & 2.7603 & 32.9402 & 2.7602 & 32.9403 & 2.7603 & 32.9403 & 2.7603 \\
\hline
\end{tabular}

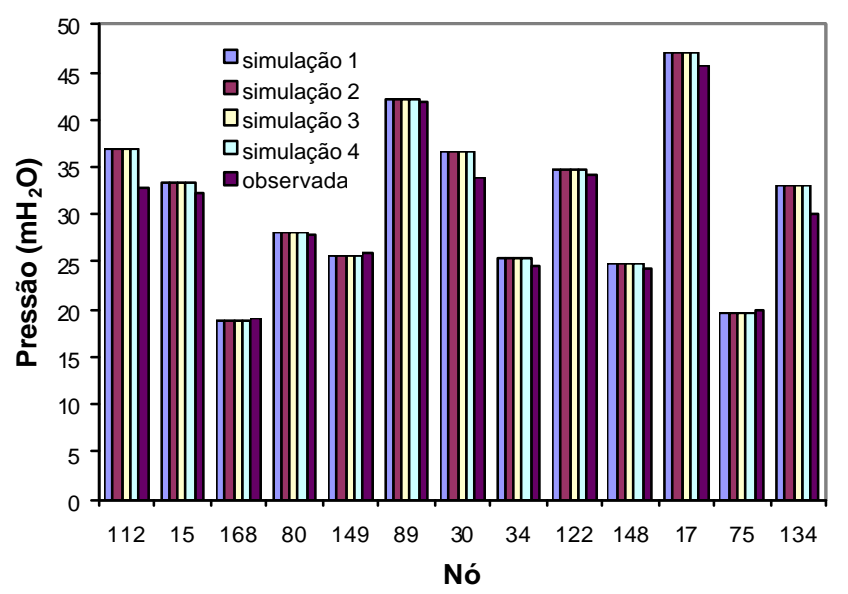

Figura 5.23 - Pressões simuladas e observadas para o padrão 1 (AG Geracional Elitista) 
Tabela 5.25 - Desvios entre pressões simuladas e observadas para o padrão 2 (AG Geracional Elitista)

\begin{tabular}{|c|r|r|r|r|r|r|r|r|r|}
\hline nó & \multicolumn{1}{c|}{ Obs. } & Sim. 1 & \multicolumn{1}{c}{$\begin{array}{l}\text { Erro } \\
\text { Abs. }\end{array}$} & Sim. 2 & $\begin{array}{l}\text { Erro } \\
\text { Abs. }\end{array}$ & Sim. 3 & $\begin{array}{l}\text { Erro } \\
\text { Abs. }\end{array}$ & Sim. 4 & \multicolumn{1}{c|}{$\begin{array}{l}\text { Erro } \\
\text { Abs. }\end{array}$} \\
\hline 112 & 29.99 & 32.8677 & 2.8777 & 32.8664 & 2.8764 & 32.8667 & 2.8767 & 32.8654 & 2.8754 \\
\hline 15 & 29.55 & 30.6281 & 1.0781 & 30.6267 & 1.0767 & 30.6273 & 1.0773 & 30.6259 & 1.0759 \\
\hline 168 & 18.82 & 18.371 & -0.449 & 18.3711 & -0.4489 & 18.371 & -0.449 & 18.371 & -0.449 \\
\hline 80 & 26.96 & 25.9801 & -0.9799 & 25.9793 & -0.9807 & 25.9796 & -0.9804 & 25.9785 & -0.9815 \\
\hline 149 & 25.13 & 20.9292 & -4.2008 & 20.9295 & -4.2005 & 20.9293 & -4.2007 & 20.9293 & -4.2007 \\
\hline 89 & 39.21 & 39.3083 & 0.0983 & 39.3074 & 0.0974 & 39.3074 & 0.0974 & 39.3065 & 0.0965 \\
\hline 30 & 31.71 & 34.4965 & 2.7865 & 34.4955 & 2.7855 & 34.4959 & 2.7859 & 34.4949 & 2.7849 \\
\hline 34 & 23.62 & 24.2731 & 0.6531 & 24.273 & 0.653 & 24.273 & 0.653 & 24.2726 & 0.6526 \\
\hline 122 & 32.7 & 32.5138 & -0.1862 & 32.5137 & -0.1863 & 32.5136 & -0.1864 & 32.5135 & -0.1865 \\
\hline 148 & 23.26 & 20.1718 & -3.0882 & 20.1721 & -3.0879 & 20.1719 & -3.0881 & 20.1719 & -3.0881 \\
\hline 17 & 42.75 & 44.2315 & 1.4815 & 44.2301 & 1.4801 & 44.2306 & 1.4806 & 44.2292 & 1.4792 \\
\hline 75 & 19.41 & 18.2288 & -1.1812 & 18.2286 & -1.1814 & 18.2288 & -1.1812 & 18.2284 & -1.1816 \\
\hline 134 & 28.5 & 31.3743 & 2.8743 & 31.3742 & 2.8742 & 31.3743 & 2.8743 & 31.3741 & 2.8741 \\
\hline
\end{tabular}

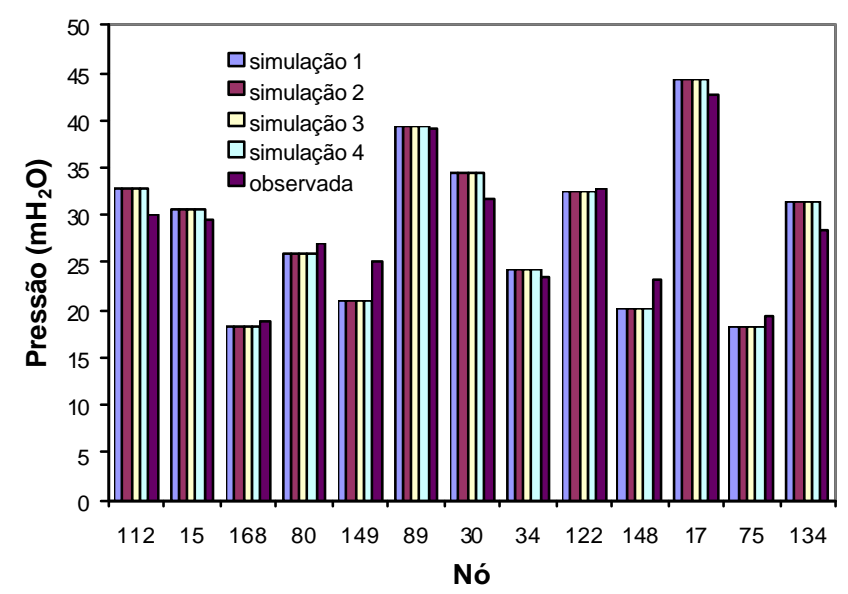

Figura 5.24 - Pressões simuladas e observadas para o padrão 2 (AG Geracional Elitista)

Tabela 5.26 - Desvios entre pressões simuladas e observadas para o padrão 3 (AG Geracional Elitista)

\begin{tabular}{|c|r|r|r|r|r|r|r|r|r|}
\hline nó & \multicolumn{1}{|c|}{ Obs. } & Sim. 1 & $\begin{array}{c}\text { Erro } \\
\text { Abs. }\end{array}$ & Sim. 2 & $\begin{array}{l}\text { Erro } \\
\text { Abs. }\end{array}$ & Sim. 3 & $\begin{array}{l}\text { Erro } \\
\text { Abs. }\end{array}$ & Sim. 4 & $\begin{array}{l}\text { Erro } \\
\text { Abs. }\end{array}$ \\
\hline 112 & 26.48 & 29.3072 & 2.8272 & 29.3047 & 2.8247 & 29.3056 & 2.8256 & 29.3034 & 2.8234 \\
\hline 15 & 25.8 & 27.756 & 1.956 & 27.7532 & 1.9532 & 27.7545 & 1.9545 & 27.7515 & 1.9515 \\
\hline 168 & 17.53 & 16.8693 & -0.6607 & 16.8693 & -0.6607 & 16.8693 & -0.6607 & 16.8694 & -0.6606 \\
\hline 80 & 25.92 & 23.5403 & -2.3797 & 23.5385 & -2.3815 & 23.5392 & -2.3808 & 23.5375 & -2.3825 \\
\hline 149 & 23.49 & 17.006 & -6.484 & 17.0058 & -6.4842 & 17.0045 & -6.4855 & 17.0051 & -6.4849 \\
\hline 89 & 35.96 & 36.3579 & 0.3979 & 36.356 & 0.396 & 36.3565 & 0.3965 & 36.3549 & 0.3949 \\
\hline 30 & 26.68 & 32.0666 & 5.3866 & 32.0648 & 5.3848 & 32.0654 & 5.3854 & 32.0637 & 5.3837 \\
\hline 34 & 22.3 & 22.4274 & 0.1274 & 22.4268 & 0.1268 & 22.427 & 0.127 & 22.4264 & 0.1264 \\
\hline 122 & 31.42 & 29.9687 & -1.4513 & 29.9685 & -1.4515 & 29.9683 & -1.4517 & 29.9683 & -1.4517 \\
\hline 148 & 21.17 & 16.2554 & -4.9146 & 16.2552 & -4.9148 & 16.2538 & -4.9162 & 16.2544 & -4.9156 \\
\hline 17 & 38.69 & 41.3602 & 2.6702 & 41.3574 & 2.6674 & 41.3587 & 2.6687 & 41.3557 & 2.6657 \\
\hline 75 & 18.19 & 16.2728 & -1.9172 & 16.2722 & -1.9178 & 16.2725 & -1.9175 & 16.2717 & -1.9183 \\
\hline 134 & 25.58 & 29.2752 & 3.6952 & 29.2749 & 3.6949 & 29.275 & 3.695 & 29.2744 & 3.6944 \\
\hline
\end{tabular}




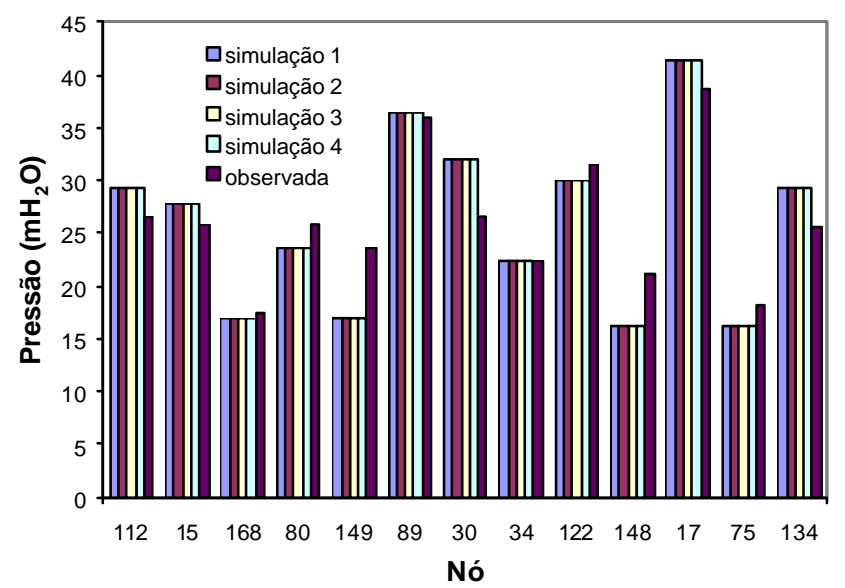

Figura 5.25 - Pressões simuladas e observadas para o padrão 3 (AG Geracional Elitista)

Tabela 5.27 - Desvios entre pressões simuladas e observadas para o padrão 4 (AG Geracional Elitista)

\begin{tabular}{|c|r|r|r|r|r|r|r|r|r|}
\hline nó & Obs. & Sim. 1 & $\begin{array}{l}\text { Erro } \\
\text { Abs. }\end{array}$ & Sim. 2 & $\begin{array}{l}\text { Erro } \\
\text { Abs. }\end{array}$ & Sim. 3 & $\begin{array}{l}\text { Erro } \\
\text { Abs. }\end{array}$ & Sim. 4 & $\begin{array}{l}\text { Erro } \\
\text { Abs. }\end{array}$ \\
\hline 112 & 31.88 & 35.4837 & 3.6037 & 35.4831 & 3.6031 & 35.4833 & 3.6033 & 35.4829 & 3.6029 \\
\hline 15 & 32.91 & 32.5147 & -0.3953 & 32.514 & -0.396 & 32.5144 & -0.3956 & 32.514 & -0.396 \\
\hline 168 & 17.53 & 18.8302 & 1.3002 & 18.8302 & 1.3002 & 18.8302 & 1.3002 & 18.8302 & 1.3002 \\
\hline 80 & 27.68 & 27.4096 & -0.2704 & 27.4092 & -0.2708 & 27.4094 & -0.2706 & 27.4091 & -0.2709 \\
\hline 149 & 26.6 & 23.9725 & -2.6275 & 23.9715 & -2.6285 & 23.9724 & -2.6276 & 23.9724 & -2.6276 \\
\hline 89 & 41.88 & 41.2815 & -0.5985 & 41.281 & -0.599 & 41.2812 & -0.5988 & 41.2808 & -0.5992 \\
\hline 30 & 32.73 & 35.9195 & 3.1895 & 35.919 & 3.189 & 35.9192 & 3.1892 & 35.9189 & 3.1889 \\
\hline 34 & 23.38 & 25.0905 & 1.7105 & 25.0903 & 1.7103 & 25.0904 & 1.7104 & 25.0903 & 1.7103 \\
\hline 122 & 33.79 & 34.0776 & 0.2876 & 34.0775 & 0.2875 & 34.0775 & 0.2875 & 34.0775 & 0.2875 \\
\hline 148 & 24.74 & 23.2071 & -1.5329 & 23.2061 & -1.5339 & 23.207 & -1.533 & 23.207 & -1.533 \\
\hline 17 & 42.83 & 46.1169 & 3.2869 & 46.1163 & 3.2863 & 46.1166 & 3.2866 & 46.1163 & 3.2863 \\
\hline 75 & 19.06 & 19.1631 & 0.1031 & 19.1628 & 0.1028 & 19.1631 & 0.1031 & 19.1629 & 0.1029 \\
\hline 134 & 30.63 & 32.4626 & 1.8326 & 32.4623 & 1.8323 & 32.4627 & 1.8327 & 32.4625 & 1.8325 \\
\hline
\end{tabular}

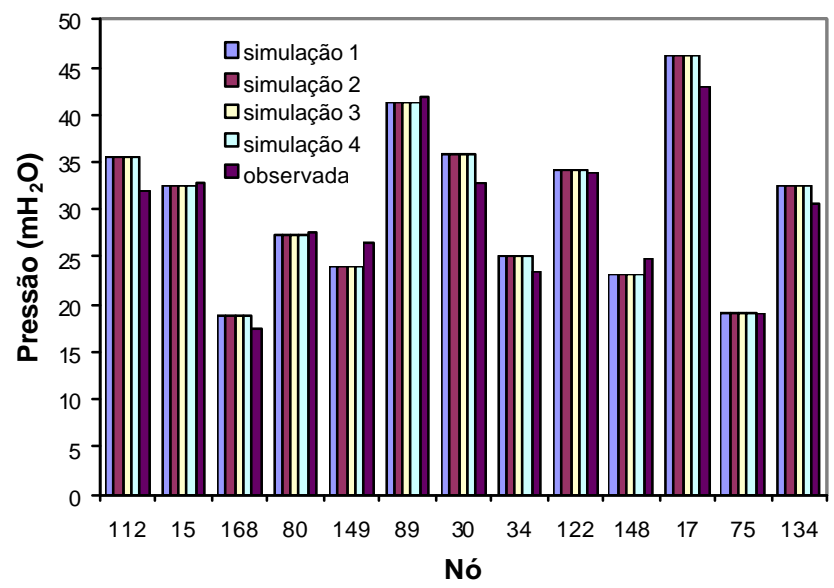

Figura 5.26 - Pressões simuladas e observadas para o padrão 4 (AG Geracional Elitista) 
Tabela 5.28 - Desvios entre vazões simuladas e observadas para os diversos padrões (AG Geracional Elitista)

\begin{tabular}{|c|r|c|c|c|c|c|c|c|c|}
\hline Padrão & Obs. & Sim. 1 & $\begin{array}{l}\text { Erro } \\
\text { Abs. }\end{array}$ & Sim. 2 & $\begin{array}{c}\text { Erro } \\
\text { Abs. }\end{array}$ & Sim. 3 & $\begin{array}{l}\text { Erro } \\
\text { Abs. }\end{array}$ & Sim. 4 & $\begin{array}{l}\text { Erro } \\
\text { Abs. }\end{array}$ \\
\hline 1 & 3.27 & 3.33028 & 0.06028 & 3.33086 & 0.06086 & 3.33061 & 0.06061 & 3.33111 & 0.06111 \\
\hline 2 & 15.39 & 15.3269 & -0.0631 & 15.3253 & -0.0647 & 15.3266 & -0.0634 & 15.3268 & -0.0632 \\
\hline 3 & 19.74 & 19.6918 & -0.0482 & 19.6916 & -0.0484 & 19.6931 & -0.0469 & 19.6915 & -0.0485 \\
\hline 4 & 9.29 & 9.22167 & -0.06833 & 9.22278 & -0.06722 & 9.22232 & -0.06768 & 9.2227 & -0.0673 \\
\hline
\end{tabular}

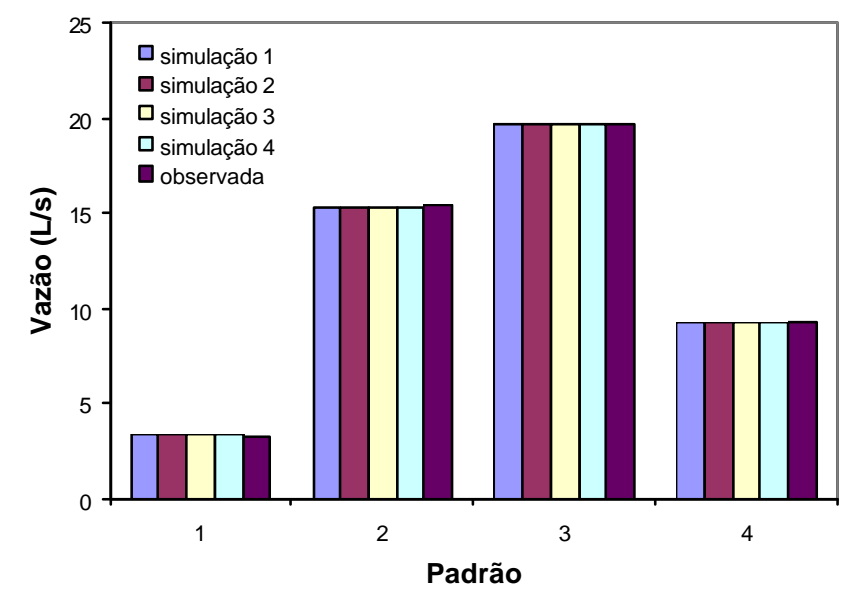

Figura 5.27 - Vazões simuladas e observadas para os diversos padrões (AG Geracional Elitista)

Tabela 5.29 - Valores das variáveis de decisão obtidos para simulações com AG geracional elitista

\begin{tabular}{|c|c|c|c|c|c|c|}
\hline \multirow{2}{*}{$\begin{array}{l}\text { Variável de } \\
\text { Decisão }\end{array}$} & \multicolumn{2}{|c|}{ Limite } & \multicolumn{4}{|c|}{$\begin{array}{l}\text { Simulações } \\
\text { Geracional Elitista + Nelder-Mead) }\end{array}$} \\
\hline & mín & máx & 1 & 2 & 3 & 4 \\
\hline$e_{1}$ & 0,001 & 0,002 & 0.001 & 0.001 & 0.00103 & 0.001025 \\
\hline$\theta_{2}$ &, 02 & 0,03 & 0.029487 & 0.029821 & 0.029611 & 0.029995 \\
\hline$?_{1}(\mathrm{x} 10 \mathrm{e}-7)$ & 0,00001 & 0,0001 & 5.97E-05 & $3.42 E-05$ & 4.66E-05 & $1.09 \mathrm{E}-05$ \\
\hline$?_{2}(\mathrm{x} 10 \mathrm{e}-7)$ & 0,00001 & 0,0001 & $8.27 \mathrm{E}-05$ & $1.38 \mathrm{E}-05$ & $8.97 \mathrm{E}-05$ & $8.22 \mathrm{E}-05$ \\
\hline$B$ & 0,5 & 1,18 & 1.1783 & 1.17436 & 0.750364 & 725 \\
\hline
\end{tabular}


Tabe la 5.30 - Desvios entre pressões simuladas e observadas para o padrão 1 (AG SteadyState )

\begin{tabular}{|c|c|r|r|r|r|r|r|r|r|}
\hline nó & Obs. & Sim. 1 & $\begin{array}{l}\text { Erro } \\
\text { Abs. }\end{array}$ & Sim. 2 & $\begin{array}{l}\text { Erro } \\
\text { Abs. }\end{array}$ & Sim. 3 & $\begin{array}{l}\text { Erro } \\
\text { Abs. }\end{array}$ & Sim. 4 & $\begin{array}{l}\text { Erro } \\
\text { Abs. }\end{array}$ \\
\hline 112 & 32.86 & 36.8331 & 3.9731 & 36.833 & 3.973 & 36.833 & 3.973 & 36.8331 & 3.9731 \\
\hline 15 & 32.38 & 33.4381 & 1.0581 & 33.438 & 1.058 & 33.438 & 1.058 & 33.438 & 1.058 \\
\hline 168 & 19.08 & 18.9453 & -0.1347 & 18.9453 & -0.1347 & 18.9453 & -0.1347 & 18.9453 & -0.1347 \\
\hline 80 & 27.87 & 28.0641 & 0.1941 & 28.064 & 0.194 & 28.064 & 0.194 & 28.064 & 0.194 \\
\hline 149 & 25.99 & 25.562 & -0.428 & 25.5619 & -0.4281 & 25.562 & -0.428 & 25.5619 & -0.4281 \\
\hline 89 & 41.92 & 42.2503 & 0.3303 & 42.2501 & 0.3301 & 42.2501 & 0.3301 & 42.2502 & 0.3302 \\
\hline 30 & 33.79 & 36.575 & 2.785 & 36.5749 & 2.7849 & 36.5749 & 2.7849 & 36.5749 & 2.7849 \\
\hline 34 & 24.61 & 25.4081 & 0.7981 & 25.4081 & 0.7981 & 25.4081 & 0.7981 & 25.4081 & 0.7981 \\
\hline 122 & 34.21 & 34.831 & 0.621 & 34.831 & 0.621 & 34.831 & 0.621 & 34.831 & 0.621 \\
\hline 148 & 24.39 & 24.7928 & 0.4028 & 24.7927 & 0.4027 & 24.7929 & 0.4029 & 24.7928 & 0.4028 \\
\hline 17 & 45.62 & 47.0398 & 1.4198 & 47.0397 & 1.4197 & 47.0396 & 1.4196 & 47.0396 & 1.4196 \\
\hline 75 & 20.02 & 19.5473 & -0.4727 & 19.5473 & -0.4727 & 19.5473 & -0.4727 & 19.5473 & -0.4727 \\
\hline 134 & 30.18 & 32.9402 & 2.7602 & 32.9403 & 2.7603 & 32.9402 & 2.7602 & 32.9403 & 2.7603 \\
\hline
\end{tabular}

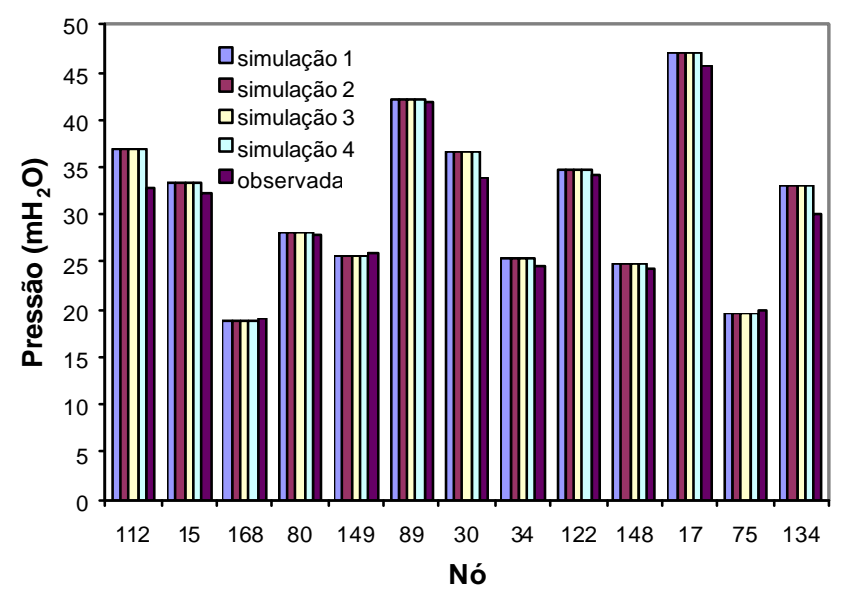

Figura 5.28 - Pressões simuladas e observadas para o padrão 1 (AG Steady-State)

Tabela 5.31 - Desvios entre pressões simuladas e observadas para o padrão 2 (AG SteadyState )

\begin{tabular}{|c|r|r|r|r|r|r|r|r|r|}
\hline nó & \multicolumn{1}{c|}{ Obs. } & Sim. 1 & $\begin{array}{l}\text { Erro } \\
\text { Abs. }\end{array}$ & Sim. 2 & $\begin{array}{l}\text { Erro } \\
\text { Abs. }\end{array}$ & Sim. 3 & $\begin{array}{l}\text { Erro } \\
\text { Abs. }\end{array}$ & Sim. 4 & $\begin{array}{l}\text { Erro } \\
\text { Abs. }\end{array}$ \\
\hline 112 & 29.99 & 32.8658 & 2.8758 & 32.8664 & 2.8764 & 32.8659 & 2.8759 & 32.8678 & 2.8778 \\
\hline 15 & 29.55 & 30.6265 & 1.0765 & 30.627 & 1.077 & 30.6267 & 1.0767 & 30.628 & 1.078 \\
\hline 168 & 18.82 & 18.371 & -0.449 & 18.371 & -0.449 & 18.3711 & -0.4489 & 18.3711 & -0.4489 \\
\hline 80 & 26.96 & 25.9788 & -0.9812 & 25.9792 & -0.9808 & 25.9789 & -0.9811 & 25.9803 & -0.9797 \\
\hline 149 & 25.13 & 20.9277 & -4.2023 & 20.9278 & -4.2022 & 20.9295 & -4.2005 & 20.9293 & -4.2007 \\
\hline 89 & 39.21 & 39.3067 & 0.0967 & 39.3073 & 0.0973 & 39.3069 & 0.0969 & 39.3084 & 0.0984 \\
\hline 30 & 31.71 & 34.4952 & 2.7852 & 34.4957 & 2.7857 & 34.4955 & 2.7855 & 34.4965 & 2.7865 \\
\hline 34 & 23.62 & 24.2727 & 0.6527 & 24.2729 & 0.6529 & 24.2729 & 0.6529 & 24.2732 & 0.6532 \\
\hline 122 & 32.7 & 32.5134 & -0.1866 & 32.5136 & -0.1864 & 32.5136 & -0.1864 & 32.5137 & -0.1863 \\
\hline 148 & 23.26 & 20.1703 & -3.0897 & 20.1705 & -3.0895 & 20.1721 & -3.0879 & 20.1719 & -3.0881 \\
\hline 17 & 42.75 & 44.2299 & 1.4799 & 44.2304 & 1.4804 & 44.2301 & 1.4801 & 44.2314 & 1.4814 \\
\hline 75 & 19.41 & 18.2285 & -1.1815 & 18.2287 & -1.1813 & 18.2285 & -1.1815 & 18.2289 & -1.1811 \\
\hline 134 & 28.5 & 31.3741 & 2.8741 & 31.3744 & 2.8744 & 31.3742 & 2.8742 & 31.3744 & 2.8744 \\
\hline
\end{tabular}




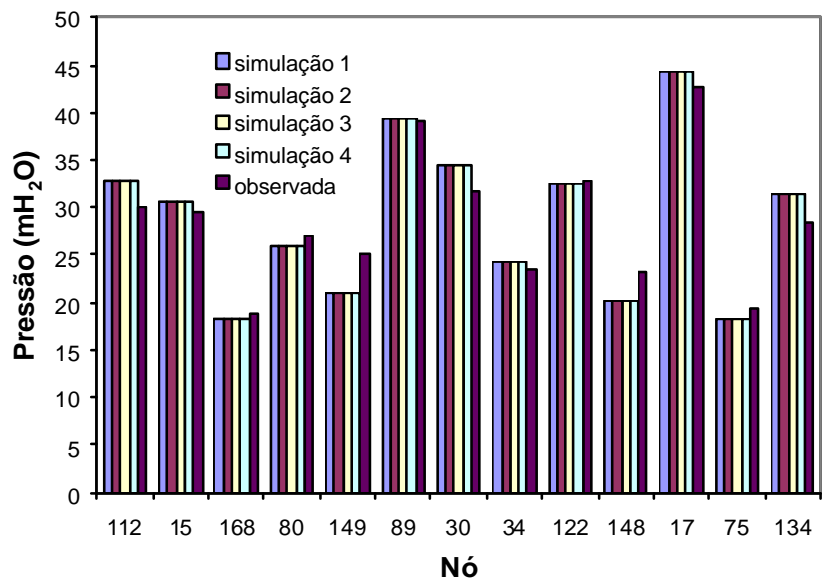

Figura 5.29 - Pressões simuladas e observadas para o padrão 2 (AG Steady-State)

Tabela 5.32 - Desvios entre pressões simuladas e observadas para o padrão 3 (AG SteadyState)

\begin{tabular}{|c|r|c|c|r|r|l|l|l|l|}
\hline nó & \multicolumn{1}{c|}{ Obs. } & Sim. 1 & $\begin{array}{l}\text { Erro } \\
\text { Abs. }\end{array}$ & Sim. 2 & $\begin{array}{l}\text { Erro } \\
\text { Abs. }\end{array}$ & Sim. 3 & $\begin{array}{l}\text { Erro } \\
\text { Abs. }\end{array}$ & Sim. 4 & $\begin{array}{l}\text { Erro } \\
\text { Abs. }\end{array}$ \\
\hline 112 & 26.48 & 29.3045 & 2.8245 & 29.3051 & 2.8251 & 29.3044 & 2.8244 & 29.3075 & 2.8275 \\
\hline 15 & 25.8 & 27.7531 & 1.9531 & 27.7536 & 1.9536 & 27.7524 & 1.9524 & 27.7562 & 1.9562 \\
\hline 168 & 17.53 & 16.8693 & -0.6607 & 16.8693 & -0.6607 & 16.8694 & -0.6606 & 16.8694 & -0.6606 \\
\hline 80 & 25.92 & 23.5385 & -2.3815 & 23.5387 & -2.3813 & 23.5382 & -2.3818 & 23.5406 & -2.3794 \\
\hline 149 & 23.49 & 17.0053 & -6.4847 & 17.005 & -6.485 & 17.0054 & -6.4846 & 17.0053 & -6.4847 \\
\hline 89 & 35.96 & 36.3559 & 0.3959 & 36.3562 & 0.3962 & 36.3557 & 0.3957 & 36.3583 & 0.3983 \\
\hline 30 & 26.68 & 32.0647 & 5.3847 & 32.065 & 5.385 & 32.0643 & 5.3843 & 32.0669 & 5.3869 \\
\hline 34 & 22.3 & 22.4267 & 0.1267 & 22.4268 & 0.1268 & 22.4266 & 0.1266 & 22.4275 & 0.1275 \\
\hline 122 & 31.42 & 29.9681 & -1.4519 & 29.9685 & -1.4515 & 29.9685 & -1.4515 & 29.9685 & -1.4515 \\
\hline 148 & 21.17 & 16.2546 & -4.9154 & 16.2543 & -4.9157 & 16.2547 & -4.9153 & 16.2546 & -4.9154 \\
\hline 17 & 38.69 & 41.3573 & 2.6673 & 41.3578 & 2.6678 & 41.3566 & 2.6666 & 41.3604 & 2.6704 \\
\hline 75 & 18.19 & 16.2721 & -1.9179 & 16.2723 & -1.9177 & 16.2719 & -1.9181 & 16.2726 & -1.9174 \\
\hline 134 & 25.58 & 29.2748 & 3.6948 & 29.275 & 3.695 & 29.2745 & 3.6945 & 29.2748 & 3.6948 \\
\hline
\end{tabular}

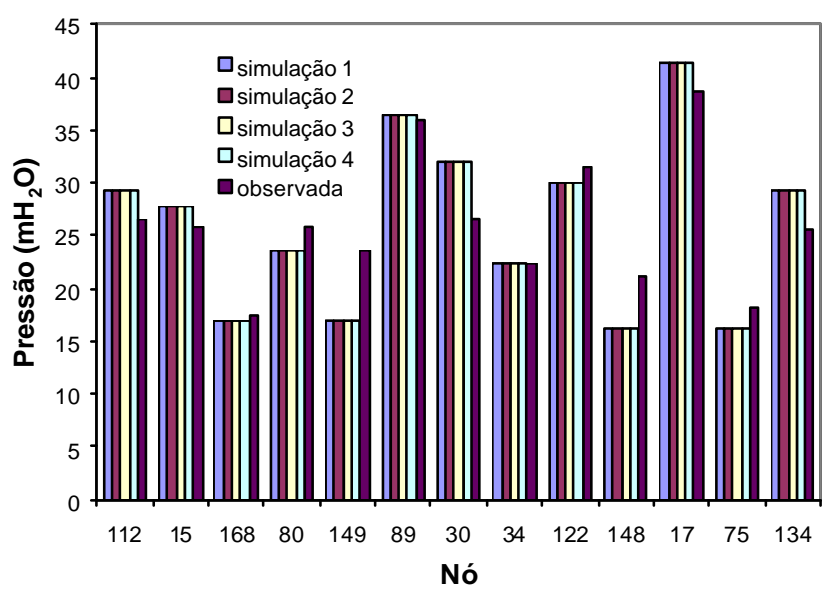

Figura 5.30 - Pressões simuladas e observadas para o padrão 3 (AG Steady-State) 
Tabela 5.33 - Desvios entre pressões simuladas e observadas para o padrão 4 (AG SteadyState )

\begin{tabular}{|c|r|r|r|r|r|r|r|r|r|}
\hline nó & Obs. & Sim. 1 & $\begin{array}{l}\text { Erro } \\
\text { Abs. }\end{array}$ & Sim. 2 & \multicolumn{1}{c|}{$\begin{array}{l}\text { Erro } \\
\text { Abs. }\end{array}$} & Sim. 3 & $\begin{array}{l}\text { Erro } \\
\text { Abs. }\end{array}$ & Sim. 4 & \multicolumn{1}{c|}{$\begin{array}{l}\text { Erro } \\
\text { Abs. }\end{array}$} \\
\hline 112 & 31.88 & 35.4831 & 3.6031 & 35.4832 & 3.6032 & 35.483 & 3.603 & 35.4838 & 3.6038 \\
\hline 15 & 32.91 & 32.5144 & -0.3956 & 32.5143 & -0.3957 & 32.5141 & -0.3959 & 32.5149 & -0.3951 \\
\hline 168 & 17.53 & 18.8302 & 1.3002 & 18.8302 & 1.3002 & 18.8302 & 1.3002 & 18.8302 & 1.3002 \\
\hline 80 & 27.68 & 27.4093 & -0.2707 & 27.4092 & -0.2708 & 27.4092 & -0.2708 & 27.4098 & -0.2702 \\
\hline 149 & 26.6 & 23.9726 & -2.6274 & 23.9728 & -2.6272 & 23.9716 & -2.6284 & 23.9725 & -2.6275 \\
\hline 89 & 41.88 & 41.281 & -0.599 & 41.2811 & -0.5989 & 41.281 & -0.599 & 41.2816 & -0.5984 \\
\hline 30 & 32.73 & 35.9191 & 3.1891 & 35.9191 & 3.1891 & 35.9189 & 3.1889 & 35.9195 & 3.1895 \\
\hline 34 & 23.38 & 25.0904 & 1.7104 & 25.0904 & 1.7104 & 25.0903 & 1.7103 & 25.0906 & 1.7106 \\
\hline 122 & 33.79 & 34.0775 & 0.2875 & 34.0775 & 0.2875 & 34.0775 & 0.2875 & 34.0775 & 0.2875 \\
\hline 148 & 24.74 & 23.2072 & -1.5328 & 23.2074 & -1.5326 & 23.2062 & -1.5338 & 23.2071 & -1.5329 \\
\hline 17 & 42.83 & 46.1166 & 3.2866 & 46.1165 & 3.2865 & 46.1163 & 3.2863 & 46.1171 & 3.2871 \\
\hline 75 & 19.06 & 19.1631 & 0.1031 & 19.163 & 0.103 & 19.163 & 0.103 & 19.1631 & 0.1031 \\
\hline 134 & 30.63 & 32.4628 & 1.8328 & 32.4626 & 1.8326 & 32.4626 & 1.8326 & 32.4627 & 1.8327 \\
\hline
\end{tabular}

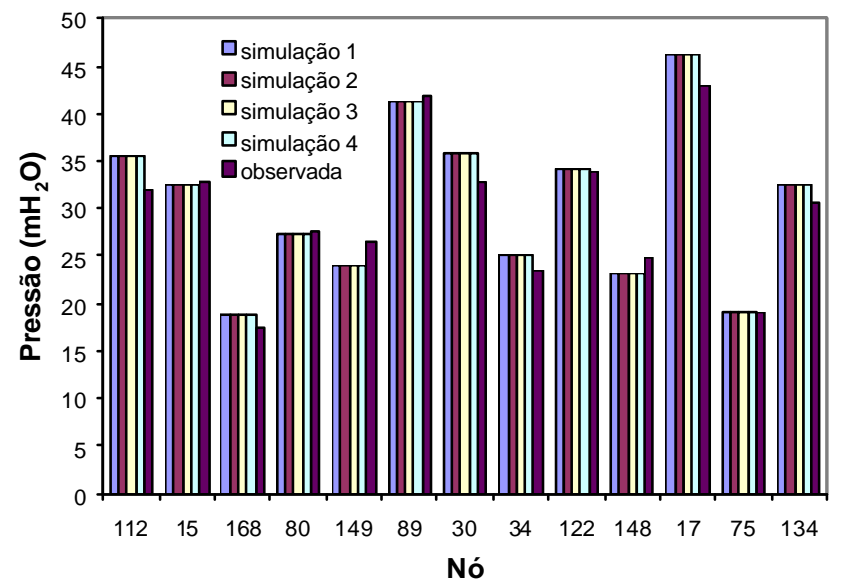

Figura 5.31 - Pressões simuladas e observadas para o padrão 4 (AG Steady-State)

Tabela 5.34 - Desvios entre vazões simuladas e observadas para os diversos padrões (AG Steady-State)

\begin{tabular}{|c|c|c|c|c|c|c|c|c|c|}
\hline Padrão & Obs. & Sim. 1 & $\begin{array}{c}\text { Erro } \\
\text { Abs. }\end{array}$ & Sim. 2 & $\begin{array}{c}\text { Erro } \\
\text { Abs. }\end{array}$ & Sim. 3 & $\begin{array}{c}\text { Erro } \\
\text { Abs. }\end{array}$ & Sim. 4 & $\begin{array}{c}\text { Erro } \\
\text { Abs. }\end{array}$ \\
\hline 1 & 3.27 & 3.32996 & 0.05996 & 3.33084 & 0.06084 & 3.33146 & 0.06146 & 3.33049 & 0.06049 \\
\hline 2 & 15.39 & 15.3271 & -0.0629 & 15.3266 & -0.0634 & 15.3261 & -0.0639 & 15.3263 & -0.0637 \\
\hline 3 & 19.74 & 19.6923 & -0.0477 & 19.6921 & -0.0479 & 19.6913 & -0.0487 & 19.6916 & -0.0484 \\
\hline 4 & 9.29 & 9.22166 & 0.06834 & 9.22267 & 0.06733 & 9.22257 & 0.06743 & 9.22156 & 0.06844 \\
\hline
\end{tabular}




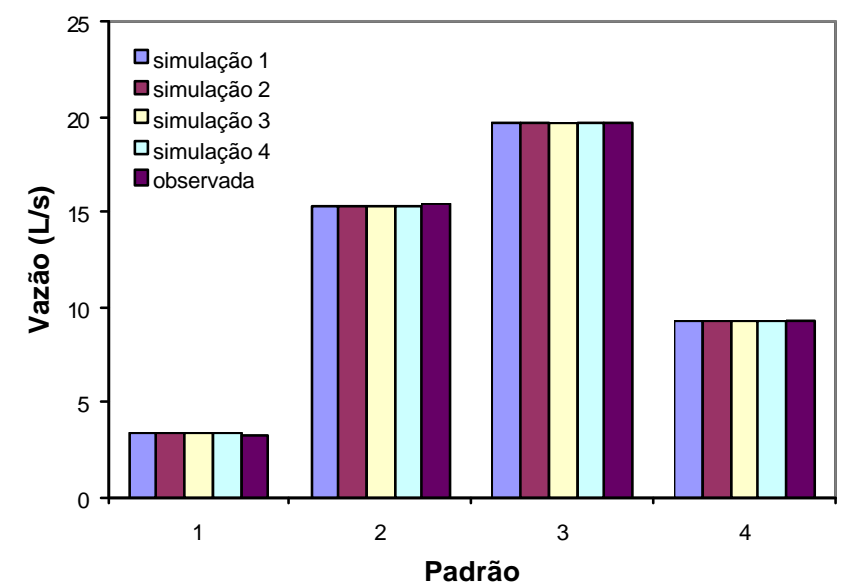

Figura 5.32 - Vazões simuladas e observadas para os diversos padrões (AG Steady-State)

Tabela 5.35 - Valores das variáveis de decisão obtidos para simulação com AG Steady State

\begin{tabular}{|c|c|c|c|c|c|c|}
\hline \multirow{2}{*}{$\begin{array}{l}\text { Variável de } \\
\text { Decisão }\end{array}$} & \multicolumn{2}{|c|}{ Limite } & \multicolumn{4}{|c|}{$\begin{array}{c}\text { Simulações } \\
\text { Steady State + Nelder-Mead) }\end{array}$} \\
\hline & mín & máx & 1 & 2 & 3 & 4 \\
\hline$e_{1}$ & 0,001 & 0,002 & 0.001048 & 0.001007 & 0.001009 & 0.001013 \\
\hline$e_{2}$ & 0,02 & 0,03 & 0.02981 & 0.029745 & 0.029882 & 0.029456 \\
\hline$?_{1}(\mathrm{x} 10 \mathrm{e}-7)$ & 0,00001 & 0,0001 & $1.42 \mathrm{E}-05$ & $1.77 \mathrm{E}-05$ & $6.84 \mathrm{E}-05$ & 7.15E-05 \\
\hline$?_{2}(x 10 \mathrm{e}-7)$ & 0,00001 & 0,0001 & 6.60E-05 & $1.90 \mathrm{E}-05$ & 5.93E-05 & $6.50 \mathrm{E}-05$ \\
\hline$B$ & 0,5 & 1,18 & 0.919577 & 0.838313 & 0.704827 & 0.778411 \\
\hline
\end{tabular}

\subsubsection{POPULAÇÃO DE SOLUÇÕES INICIAIS (DISTINTAS SEMENTES}

\section{ALEATÓRIAS)}

Na Tabela 5.36 está descrito, de maneira sucinta, os valores de parametrização dos Algoritmos Genéticos usados nas simulações para a rede de Itirapuã a partir de distintas populações iniciais de soluções.

As Tabelas 5.37 a 5.47 e as Figuras 5.33 a 5.40, possibilitam análises comparativas que só confirmam as conclusões obtidas anteriormente, indicando que os resultados obtidos a partir de populações distintas de soluções não apresentam diferenças significativas. Os desvios que ultrapassaram as recomendações do WATER RESEARCH CENTRE (1989) estão apresentados na cor vermelho nas Tabelas 5.38 a 5.46 . 
Tabela 5.36 - Parametrização dos AGs para as simulações alterando sementes aleatórias

\begin{tabular}{|l|c|c|}
\cline { 2 - 3 } \multicolumn{1}{c|}{} & \multicolumn{2}{c|}{ Tipos de Ags } \\
\cline { 2 - 3 } \multicolumn{1}{c|}{} & Geracional elitista & Steady-State \\
\hline Recombução de soluções & 40 & 40 \\
\hline Probabilidação & aritmética & aritmética \\
\hline Seleção & 0.70 & 0.70 \\
\hline Mutação & SRS & SRS \\
\hline Probabilidade de mutação & gaussiana & gaussiana \\
\hline Taxa de elitismo & 0.01 & 0.01 \\
\hline Número de gerações & 0.30 & 0.30 \\
\hline
\end{tabular}

Tabela 5.37 - Valores da função objetivo para variação da semente aleatória para as diversas simulações

\begin{tabular}{|c|c|c|c|c|c|}
\hline \multirow{2}{*}{ Simulação } & \multirow{2}{*}{$\begin{array}{c}\text { Semente } \\
\text { Aleatória }\end{array}$} & $\begin{array}{c}\text { AG } \\
\text { Ger. Elit. }\end{array}$ & Híbrido & $\begin{array}{c}\text { AG } \\
\text { Steady-State }\end{array}$ & Híbrido \\
\hline 1 & 1 & 0.375066 & 0.375093 & 0.375108 & 0.375127 \\
\hline 2 & 100 & 0.375062 & 0.375099 & 0.374994 & 0.374976 \\
\hline 3 & 200 & 0.375094 & 0.375102 & 0.374950 & 0.374980 \\
\hline 4 & 300 & 0.375118 & 0.375127 & 0.375012 & 0.375013 \\
\hline 5 & 400 & 0.374949 & 0.374947 & 0.374985 & 0.374978 \\
\hline 6 & 500 & 0.375102 & 0.374935 & 0.374950 & 0.374985 \\
\hline 7 & 600 & 0.374905 & 0.374933 & 0.375131 & 0.375116 \\
\hline 8 & 700 & 0.374982 & 0.374968 & 0.374928 & 0.374962 \\
\hline 9 & 800 & 0.375041 & 0.375059 & 0.375147 & 0.375085 \\
\hline 10 & 900 & 0.375101 & 0.374996 & 0.374938 & 0.374973 \\
\hline
\end{tabular}

Tabela 5.38 - Desvios entre pressões simuladas e observadas para o padrão 1 (AG Geracional Elitista)

\begin{tabular}{|c|c|c|c|c|c|c|c|c|c|c|c|c|c|}
\hline & & 5 & 8 & 0 & 49 & 9 & 0 & 4 & 22 & 48 & 17 & 75 & 134 \\
\hline ho & 9 & 24 & 1 & & 26 & & & 16 & 4 & 4 & 56 & 0 & 302 \\
\hline & 0 & 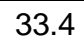 & 10.0 & 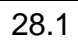 & 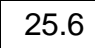 & & . & 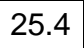 & 34.8 & 6.0 & 47 & & 32.9 \\
\hline & 97 & .06 & .13 & .19 & .43 & 33 & 2.78 & 0.8 & 0.62 & 0.4 & 1.42 & 47 & 2.76 \\
\hline & 8 & 33.4 & 9 & 1 & 56 & TL.V & 36.6 & 25.4 & 348 & 48 & 47 & 5 & 32.9 \\
\hline & .97 & 1.06 & 0.13 & 0.19 & -0.43 & 0.33 & 2.78 & 0.8 & 0.62 & 0.4 & 1.42 & 0.47 & 2.76 \\
\hline & 68 & 334 & 189 & 81 & 25 & 423 & 366 & 4 & 348 & 18 & 47 & 195 & 32.9 \\
\hline & 97 & 1.06 & .13 & 0.19 & 0.43 & 0.33 & 2.78 & 0.8 & 0.62 & 0.4 & .42 & 0.47 & 2.76 \\
\hline & 6.8 & 3. & 18 & 28.1 & 25.6 & 12 3 & 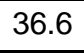 & 25.4 & 34.8 & $2+$. & 47 & (10.0 & 9 \\
\hline & 97 & 1.06 & .13 & 0.19 & 0.43 & 0.33 & 2.79 & 0.8 & 0.62 & 0.4 & 1.42 & 0.47 & 2.76 \\
\hline & 36.8 & 33.4 & 18.9 & 28.1 & 2 & 12 3 & 36.6 & 20.7 & 34.8 & $2 \pi .0$ & 7 & 195 & 329 \\
\hline & 97 & 1.06 & 0.13 & 0.19 & 0.43 & 0.33 & 2.78 & 0.8 & 0.62 & 0.4 & .42 & -0.47 & 2.76 \\
\hline & 68 & 334 & 189 & 281 & 25.6 & 12 3 & 366 & 54 & 348 & 48 & 47 & 10 & 32.9 \\
\hline & 97 & 1.06 & 0.13 & 0.19 & 0.43 & 0.33 & 2.78 & 0.8 & 0.62 & 0.4 & +2 & & 2.76 \\
\hline & 68 & 32 & 80 & 28.1 & 5 & 42.3 & 36.6 & 20.4 & 34 & 248 & 47 & 19 & 3 \\
\hline & 91 & 1.06 & .13 & 0.19 & 0.43 & 0.33 & 2.78 & 0.0 & 0.62 & 0.4 & .42 & -0.47 & 2.76 \\
\hline & 36.8 & 34 & 9 & 28.1 & 256 & 423 & 36 & 25.4 & 3 & 24.8 & 47 & 1 & 32.9 \\
\hline & .97 & 1.06 & -0.13 & 0.19 & -0.43 & 0.33 & 2.79 & 0.8 & 0.62 & 0.4 & 1.42 & -0.47 & 2.76 \\
\hline & 368 & 34 & 9 & 28.1 & 256 & 423 & 366 & 25.4 & 8 & 24.8 & 7 & 19.5 & 32.9 \\
\hline & .97 & 1.06 & -0.13 & 0.19 & -0.43 & 0.33 & 2.79 & 0.8 & 0.62 & 0.4 & 1.42 & -0.47 & 2.76 \\
\hline & 6.8 & 33 & 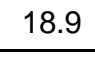 & 28.1 & 2 & 42 & 36.6 & 25 & 34.0 & 24.8 & 47 & 19.5 & 32.9 \\
\hline Erro ab & 97 & 1.06 & 0.13 & 0.19 & 0.43 & 0.33 & 2.78 & 0.8 & 0.62 & 0.4 & 1.42 & -0.47 & 2.76 \\
\hline
\end{tabular}




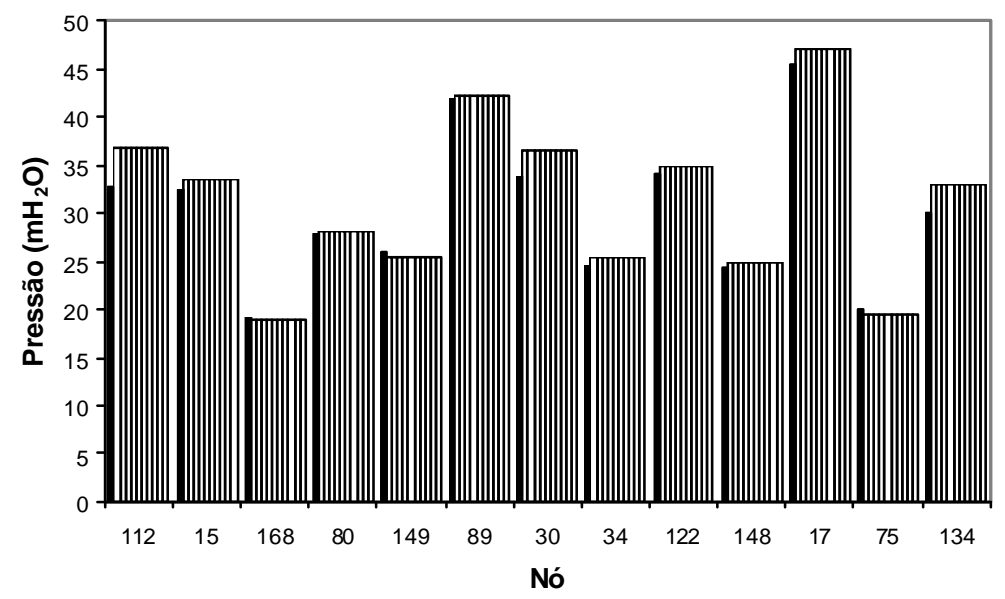

Figura 5.33 - Pressões simuladas e observadas para o padrão 1 (AG Geracional Elitista) para populações iniciais distintas de soluções

Tabela 5.39 - Desvios entre pressões simuladas e observadas para o padrão 2 (AG

Geracional Elitista) para populações iniciais distintas de soluções

\begin{tabular}{|c|c|c|c|c|c|c|c|c|c|c|c|c|c|}
\hline ó & 12 & 5 & 68 & 30 & 19 & 89 & 30 & 34 & 122 & 18 & 17 & 75 & 134 \\
\hline & 0 & & & 2 & 51 & & & & 32.7 & 3.3 & 2.8 & 19.4 & 28.5 \\
\hline & & .6 & 8.4 & 6 & 0.9 & 9.3 & & 3 & 32.5 & 0.2 & .2 & 8.2 & 1. \\
\hline & & 8 & 5 & 98 & 4. & 0. & & 65 & 0.19 & .05 & 48 & .18 & .87 \\
\hline & .9 & 0.6 & 3.4 & 26 & 20.9 & 9.4 & & 4.3 & 32.5 & 20.2 & t.2 & | 8.2 & 31.4 \\
\hline & 88 & 1.08 & -0.45 & .98 & -4.2 & 0.1 & 2.7 & 0.65 & -0.19 & 3.09 & 1.48 & 1.18 & 2.87 \\
\hline & 2.9 & 30.6 & 18.4 & 26 & 20.9 & 39.3 & & & 32.5 & 20.2 & 4.2 & 18.2 & 31.4 \\
\hline & 2.88 & 1.08 & -0.45 & .98 & $\begin{array}{l}-4.2 \\
\end{array}$ & 0.1 & 2.79 & 0.65 & -0.19 & -3.09 & 1.48 & -1.18 & 2.87 \\
\hline & 32.9 & 30.6 & 18.4 & 26 & 20.9 & 39.3 & 34 & 24. & 32.5 & 20.2 & 44.2 & 18. & 31.4 \\
\hline & 88 & .08 & .45 & .98 & -4.2 & & 270 & 0.65 & -0.19 & -3.0 & 1.48 & $1.1 \varepsilon$ & 2.8 \\
\hline & 32.9 & 30.6 & 18.4 & 26 & 20.9 & 39.3 & 34.5 & 24.3 & 32.5 & 20.2 & 44.2 & 18.2 & 31.4 \\
\hline & 2.88 & 1.08 & 0.45 & .98 & -4.2 & 0.1 & 2.7 & 0.65 & -0.19 & -3.09 & 1.48 & 1.18 & 2.8 \\
\hline & 32.9 & 30.6 & 18.4 & 26 & 20.9 & 39.3 & 34.5 & 24.3 & 32.5 & 20.2 & 44.2 & 18.2 & 31.4 \\
\hline & 2.88 & 1.08 & -0.45 & 0.98 & -4.2 & 0.1 & 2.79 & 0.65 & -0.19 & -3.09 & 1.48 & -1.18 & 2.87 \\
\hline & 32.9 & 30.6 & 18.4 & 26 & 20.9 & 39.3 & 34. & 24.3 & 32.5 & 20.2 & 44.2 & 18.2 & 31.4 \\
\hline & 2.88 & 1.08 & -0.45 & .98 & -4.2 & 0.1 & 2.79 & 0.65 & -0.19 & -3.09 & 1.48 & -1.18 & 2.87 \\
\hline & 32.9 & 30.6 & 18.4 & 26 & 20.9 & 39.3 & 34.5 & 24.3 & 32.5 & 20.2 & 44.2 & 18.2 & 31.4 \\
\hline & 2.88 & 1.08 & -0.45 & .98 & -4.2 & 0 & 2.7 & 0.65 & -0.19 & -3.09 & 1.48 & -1.18 & 2.87 \\
\hline & 32.9 & 30.6 & 18.4 & 26 & 20.9 & 39.3 & 34.5 & 24.3 & 32.5 & 20.2 & 44.2 & 18.2 & 31.4 \\
\hline & 2.88 & 1.08 & 0.45 & 0.98 & -4.2 & 0.1 & 2.7 & 0.65 & -0.19 & -3.09 & 1.48 & 1.18 & 2.87 \\
\hline & 32.9 & 30.6 & $1 \varepsilon$ & 26 & 20.9 & 9.3 & 34 & 24.3 & 32.5 & 20.2 & 44.2 & 18.2 & 31.4 \\
\hline rro abs. & 2.88 & 1.08 & -0.45 & -0.98 & -4.2 & 0.1 & 2.79 & 0.65 & -0.19 & -3.09 & 1.48 & -1.18 & 2.87 \\
\hline
\end{tabular}




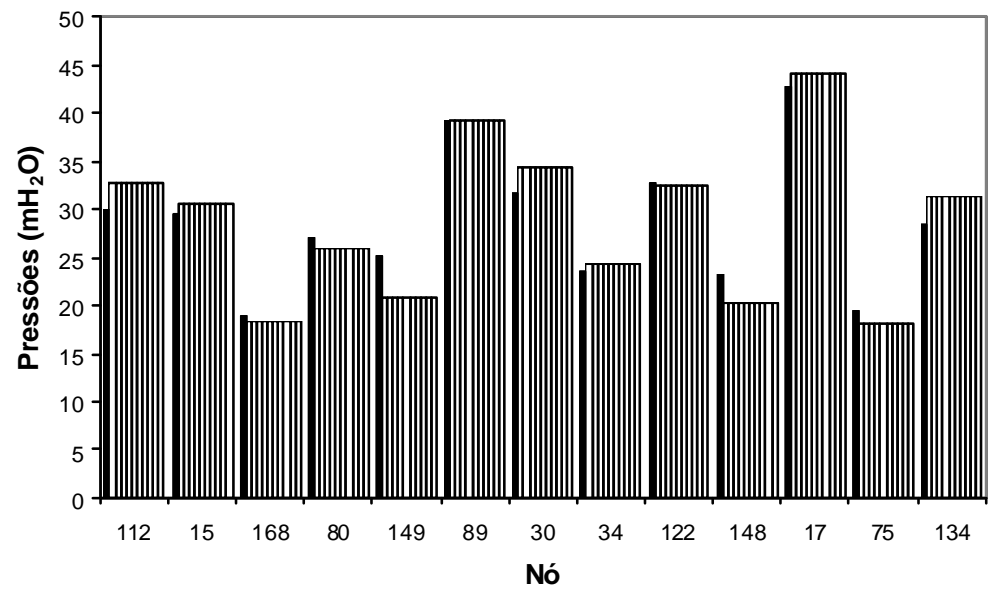

Figura 5.34 - Pressões simuladas e observadas para o padrão 2 (AG Geracional Elitista) para populações iniciais distintas de soluções

Tabela 5.40 - Desvios entre pressões simuladas e observadas para o padrão 3 (AG Geracional Elitista) para populações iniciais distintas de soluções

\begin{tabular}{|c|r|r|r|r|r|r|r|r|r|r|r|r|r|}
\hline Nó & $\mathbf{1 1 2}$ & $\mathbf{1 5}$ & $\mathbf{1 6 8}$ & $\mathbf{8 0}$ & $\mathbf{1 4 9}$ & $\mathbf{8 9}$ & $\mathbf{3 0}$ & $\mathbf{3 4}$ & $\mathbf{1 2 2}$ & $\mathbf{1 4 8}$ & $\mathbf{1 7}$ & \multicolumn{1}{c}{$\mathbf{7 5}$} & $\mathbf{1 3 4}$ \\
\hline obs. & $\mathbf{2 6 . 5}$ & $\mathbf{2 5 . 8}$ & 17.5 & $\mathbf{2 5 . 9}$ & $\mathbf{2 3 . 5}$ & $\mathbf{3 6}$ & $\mathbf{2 6 . 7}$ & 22.3 & 31.4 & 21.2 & 38.7 & 18.2 & 25.6 \\
\hline sim. 1 & 29.3 & 27.8 & 16.9 & 23.5 & 17 & 36.4 & 32.1 & 22.4 & 30 & 16.3 & 41.4 & 16.3 & 29.3 \\
\hline Erro abs. & 2.83 & 1.96 & -0.66 & -2.38 & -6.48 & 0.4 & 5.39 & 0.13 & -1.45 & -4.91 & 2.67 & -1.92 & 3.7 \\
\hline sim. 2 & 29.3 & 27.8 & 16.9 & 23.5 & 17 & 36.4 & 32.1 & 22.4 & 30 & 16.3 & 41.4 & 16.3 & 29.3 \\
\hline Erro abs. & 2.83 & 1.96 & -0.66 & -2.38 & -6.48 & 0.4 & 5.39 & 0.13 & -1.45 & -4.91 & 2.67 & -1.92 & 3.7 \\
\hline sim. 3 & 29.3 & 27.8 & 16.9 & 23.5 & 17 & 36.4 & 32.1 & 22.4 & 30 & 16.3 & 41.4 & 16.3 & 29.3 \\
\hline Erro abs. & 2.83 & 1.95 & -0.66 & -2.38 & -6.49 & 0.4 & 5.39 & 0.13 & -1.45 & -4.92 & 2.67 & -1.92 & 3.69 \\
\hline sim. 4 & 29.3 & 27.8 & 16.9 & 23.5 & 17 & 36.4 & 32.1 & 22.4 & 30 & 16.3 & 41.4 & 16.3 & 29.3 \\
\hline Erro abs. & 2.83 & 1.96 & -0.66 & -2.38 & -6.48 & 0.4 & 5.39 & 0.13 & -1.45 & -4.92 & 2.67 & -1.92 & 3.7 \\
\hline sim. 5 & 29.3 & 27.8 & 16.9 & 23.5 & 17 & 36.4 & 32.1 & 22.4 & 30 & 16.3 & 41.4 & 16.3 & 29.3 \\
\hline Erro abs. & 2.82 & 1.95 & -0.66 & -2.38 & -6.48 & 0.4 & 5.38 & 0.13 & -1.45 & -4.91 & 2.67 & -1.92 & 3.69 \\
\hline sim. 6 & 29.3 & 27.8 & 16.9 & 23.5 & 17 & 36.4 & 32.1 & 22.4 & 30 & 16.3 & 41.4 & 16.3 & 29.3 \\
\hline Erro abs. & 2.82 & 1.95 & -0.66 & -2.38 & -6.48 & 0.39 & 5.38 & 0.13 & -1.45 & -4.91 & 2.67 & -1.92 & 3.69 \\
\hline sim. 7 & 29.3 & 27.8 & 16.9 & 23.5 & 17 & 36.4 & 32.1 & 22.4 & 30 & 16.3 & 41.4 & 16.3 & 29.3 \\
\hline Erro abs. & 2.82 & 1.95 & -0.66 & -2.38 & -6.48 & 0.39 & 5.38 & 0.13 & -1.45 & -4.92 & 2.67 & -1.92 & 3.69 \\
\hline sim. 8 & 29.3 & 27.8 & 16.9 & 23.5 & 17 & 36.4 & 32.1 & 22.4 & 30 & 16.3 & 41.4 & 16.3 & 29.3 \\
\hline Erro abs. & 2.83 & 1.95 & -0.66 & -2.38 & -6.48 & 0.4 & 5.38 & 0.13 & -1.45 & -4.91 & 2.67 & -1.92 & 3.7 \\
\hline sim. 9 & 29.3 & 27.8 & 16.9 & 23.5 & 17 & 36.4 & 32.1 & 22.4 & 30 & 16.3 & 41.4 & 16.3 & 29.3 \\
\hline Erro abs. & 2.83 & 1.95 & -0.66 & -2.38 & -6.48 & 0.4 & 5.39 & 0.13 & -1.45 & -4.92 & 2.67 & -1.92 & 3.69 \\
\hline sim. 10 & 29.3 & 27.8 & 16.9 & 23.5 & 17 & 36.4 & 32.1 & 22.4 & 30 & 16.3 & 41.4 & 16.3 & 29.3 \\
\hline Erro abs. & 2.82 & 1.95 & -0.66 & -2.38 & -6.48 & 0.4 & 5.38 & 0.13 & -1.45 & -4.92 & 2.67 & -1.92 & 3.69 \\
\hline
\end{tabular}




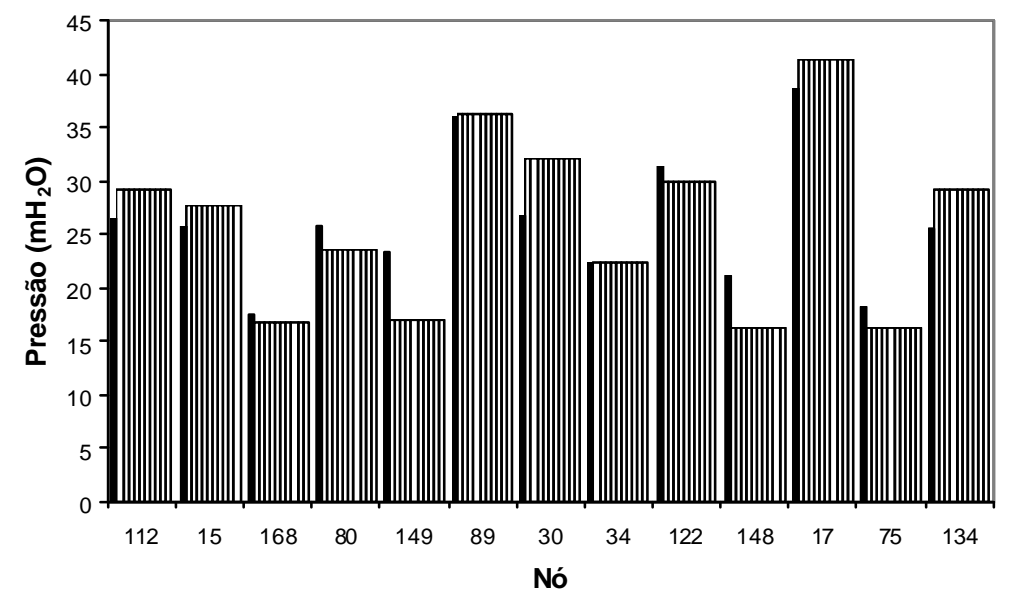

Figura 5.35 - Pressões simuladas e observadas para o padrão 3 (AG Geracional Elitista) para populações iniciais distintas de soluções

Tabela 5.41 - Desvios entre pressões simuladas e observadas para o padrão 4 (AG Geracional Elitista) para populações iniciais distintas de soluções

\begin{tabular}{|c|c|c|c|c|c|c|c|c|c|c|c|c|c|}
\hline Nó & 12 & 15 & 68 & 80 & 149 & 89 & 30 & 34 & 122 & 148 & 17 & 75 & 134 \\
\hline obs. & 1.9 & $\overline{32.9}$ & 17.5 & 27.7 & 26.6 & 41.9 & 32.7 & 23.4 & 33.8 & 24.7 & 42.8 & 19.1 & 30.6 \\
\hline $\operatorname{sim} .1$ & .5 & 32.5 & 18.8 & 27.4 & 24 & 41.3 & 35.9 & 5.1 & 4.1 & 23.2 & 6.1 & 19.2 & 3.5 \\
\hline rro & 3.6 & -0.4 & 1.3 & 0.27 & -2.63 & -0.6 & 3.19 & 1.71 & .29 & -1.53 & 3.29 & 0.1 & .83 \\
\hline m. 2 & 5.5 & 32.5 & 18.8 & 27.4 & 24 & 41.3 & 35.9 & 25.1 & 34.1 & 23.2 & 46.1 & 19.2 & 32.5 \\
\hline Erro abs & 3.6 & -0.4 & 1.3 & -0.27 & 2.63 & -0.6 & 3.19 & 1.71 & 0.29 & -1.53 & 3.29 & 0.1 & .83 \\
\hline sim. 3 & 35.5 & 32.5 & 18.8 & 27.4 & 24 & 41.3 & 35.9 & 25.1 & 34.1 & 23.2 & 46.1 & 19.2 & 2.5 \\
\hline Erro abs. & 3.6 & -0.4 & 1.3 & -0.27 & 2.63 & -0.6 & 3.19 & 1.71 & 0.29 & -1.53 & 3.29 & 0.1 & .83 \\
\hline $\operatorname{sim} .4$ & 35.5 & 32.5 & 18.8 & 27.4 & 24 & 41.3 & 35.9 & 25.1 & $\overline{34.1}$ & 23.2 & 46.1 & 19.2 & 32.5 \\
\hline Erro abs. & 3.6 & -0.4 & 1.3 & -0.27 & 2.63 & -0.6 & 3.19 & 1.71 & 0.29 & -1.53 & 3.29 & 0.1 & 1.83 \\
\hline $\operatorname{sim} .5$ & 35.5 & 32.5 & 18.8 & 27.4 & 24 & 41.3 & 35.9 & 25.1 & 34.1 & 23.2 & 46.1 & 19.2 & 32.5 \\
\hline Erro abs. & 3.6 & -0.4 & 1.3 & -0.27 & -2.63 & -0.6 & 3.19 & 1.71 & 0.29 & -1.53 & 3.29 & 0.1 & 1.83 \\
\hline $\operatorname{sim} .6$ & 35.5 & 32.5 & 18.8 & 27.4 & 24 & 41.3 & 35.9 & 25.1 & 34.1 & 23.2 & 46.1 & 19.2 & 32.5 \\
\hline Erro abs. & 3.6 & -0.4 & 1.3 & -0.27 & -2.63 & -0.6 & 3.19 & 1.71 & 0.29 & -1.53 & 3.29 & 0.1 & 1.83 \\
\hline & 35.5 & 32.5 & 18.8 & 27.4 & 24 & 41.3 & 35.9 & 25.1 & 34.1 & 23.2 & 46.1 & 19.2 & 32.5 \\
\hline Erro abs. & $\overline{3.6}$ & -0.4 & 1.3 & -0.27 & 2.63 & -0.6 & 3.19 & 1.71 & 0.29 & -1.53 & 3.29 & 0.1 & 1.83 \\
\hline $\operatorname{sim} .8$ & 35.5 & 32.5 & 18.8 & 27.4 & 24 & 41.3 & 35.9 & 25.1 & 34.1 & 23.2 & 46.1 & 19.2 & 32.5 \\
\hline Erro abs. & 3.6 & -0.4 & 1.3 & -0.27 & -2.63 & -0.6 & 3.19 & 1.71 & 0.29 & -1.53 & 3.29 & 0.1 & 1.83 \\
\hline $\operatorname{sim} .9$ & 35.5 & 32.5 & 18.8 & 27.4 & 24 & 41.3 & 35.9 & 25.1 & 34.1 & 23.2 & 46.1 & 19.2 & 32.5 \\
\hline Erro abs & 3.6 & -0.4 & 1.3 & -0.27 & 2.63 & -0.6 & 3.19 & 1.71 & 0.29 & -1.53 & 3.29 & 0.1 & 1.83 \\
\hline sim. 10 & 35.5 & 32.5 & 18.8 & 27.4 & 24 & 41.3 & 35.9 & 25.1 & 34.1 & 23.2 & 46.1 & 19.2 & 32.5 \\
\hline Erro abs. & 3.6 & -0.4 & 1.3 & -0.27 & .63 & -0.6 & 3.19 & 1.71 & 0.29 & -1.53 & 3.29 & 0.1 & 1.83 \\
\hline
\end{tabular}




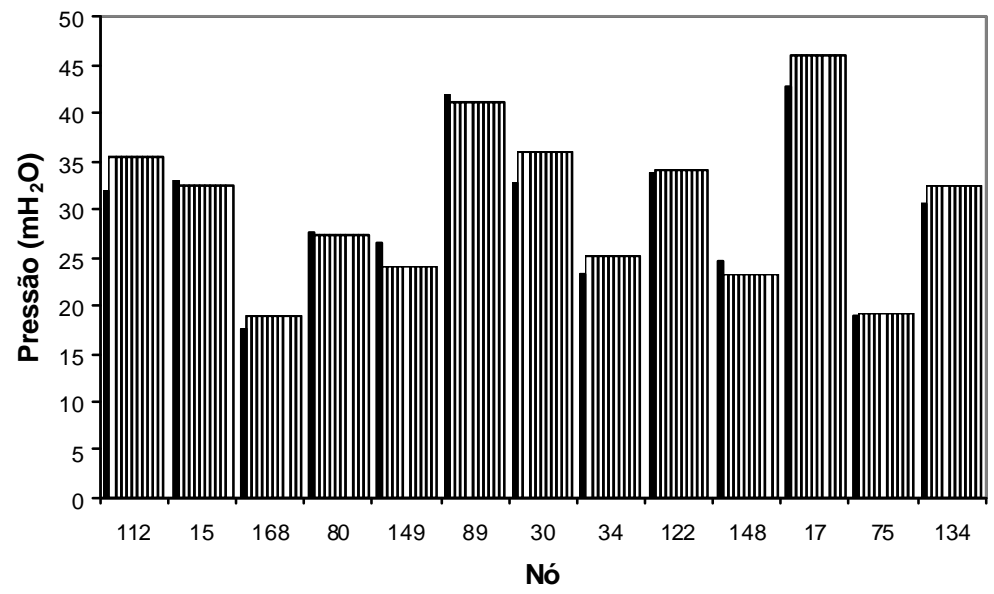

Figura 5.36 - Pressões simuladas e observadas para o padrão 4 (AG Geracional Elitista) para populações iniciais distintas de soluções

Tabela 5.42 - Resultados obtidos das variáveis de decisão usando AG híbrido (Geracional Elitista + Nelder-Mead)

\begin{tabular}{|c|c|c|c|c|c|c|}
\hline & \multicolumn{5}{|c|}{ AG Híbrido (Geracional Elitista + Nelder-Mead) } \\
\hline & & \multicolumn{5}{|c|}{ Variável de Decisão } \\
\hline & & $e_{1}$ & $e_{2}$ & $?_{1}(\mathrm{x} 10 \mathrm{e}-7)$ & $?_{2}(\mathrm{x} 10 \mathrm{e}-7)$ & B \\
\hline \multirow{10}{*}{ 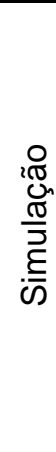 } & 1 & 0.001 & 0.029487 & $5.97 \mathrm{E}-05$ & $8.27 \mathrm{E}-05$ & 1.1783 \\
\hline & 2 & 0.001 & 0.029503 & $9.62 \mathrm{E}-05$ & $1.27 \mathrm{E}-05$ & 1 \\
\hline & 3 & 0.001045 & 0.02968 & $8.79 \mathrm{E}-05$ & $9.03 E-05$ & 1.02807 \\
\hline & 4 & 0.001016 & 0.029387 & 5.49E-05 & $1.12 \mathrm{E}-05$ & 0.765803 \\
\hline & 5 & 0.001 & 0.029866 & $2.76 \mathrm{E}-05$ & $9.85 \mathrm{E}-05$ & 1.17859 \\
\hline & 6 & 0.001009 & 0.03 & $1.11 \mathrm{E}-05$ & $1.09 \mathrm{E}-05$ & 0.53775 \\
\hline & 7 & 0.001001 & 0.029995 & $1.06 \mathrm{E}-05$ & $5.53 \mathrm{E}-05$ & 0.71422 \\
\hline & 8 & 0.001006 & 0.029792 & $1.27 \mathrm{E}-05$ & $1.12 \mathrm{E}-05$ & 0.529721 \\
\hline & 9 & 0.001003 & 0.029629 & $8.73 E-05$ & 1.07E-05 & 0.760654 \\
\hline & 10 & 0.00103 & 0.029797 & $1.37 \mathrm{E}-05$ & $6.10 \mathrm{E}-05$ & 0.83136 \\
\hline \multirow{2}{*}{ 蔦 } & mín & 0,001 & 0,02 & 0,00001 & 0,00001 & 0,5 \\
\hline & máx & 0,002 & 0,03 & 0,0001 & 0,0001 & 1,18 \\
\hline
\end{tabular}


Tabela 5.43 - Desvios entre pressões simuladas e observadas para o padrão 1 (AG SteadyState ) para populações iniciais distintas de soluções

\begin{tabular}{|c|c|c|c|c|c|c|c|c|c|c|c|c|c|}
\hline Nó & 12 & 15 & 168 & 80 & 149 & 89 & 30 & 34 & 122 & 148 & 17 & 75 & 134 \\
\hline obs. & 2.86 & 2.38 & 9.08 & 7.87 & 5.99 & 1.92 & 3.79 & 4.61 & 34.21 & 24.39 & 5.62 & 0.02 & 30.18 \\
\hline sim. 1 & 83 & 3.44 & .95 & .06 & .56 & 25 & .57 & .41 & 1.83 & 1.79 & 47.04 & 9.55 & 2.94 \\
\hline Erro & 973 & 1.058 & -0.13 & 194 & 0.43 & 0.33 & 2.785 & .798 & 0.621 & 0.403 & 1.42 & 0.47 & 2.76 \\
\hline s & 36.83 & 33.44 & 18.95 & 28.06 & 25.56 & 42.25 & 36.57 & 25.41 & 34.83 & 24.79 & 47.04 & 19.55 & 32.94 \\
\hline bs. & 973 & 1.058 & -0.13 & 0.194 & \begin{tabular}{l|l|}
-0.43 \\
\end{tabular} & 0.33 & 2.785 & 0.798 & 0.621 & 0.402 & 1.42 & -0.47 & 2.76 \\
\hline & 36.83 & 33.44 & 18.95 & 28.06 & 25.56 & 42.25 & 36.57 & 25.41 & 34.83 & 24.79 & 47.04 & 19.55 & 32.94 \\
\hline Erro & 3.973 & 1.058 & -0.13 & 0.194 & -0.43 & 0.33 & 2.785 & 0.798 & 0.621 & 0.403 & 1.42 & -0.47 & 2.76 \\
\hline 4 & 36.83 & 33.44 & 18.95 & 28.06 & 25.56 & 42.25 & 36.58 & 25.41 & 34.83 & 24.79 & 47.04 & 19.55 & 32.94 \\
\hline s. & 3.973 & 1.058 & -0.13 & 0.194 & -0.43 & 0.33 & 2.785 & 0.798 & 0.621 & 0.402 & 1.42 & -0.47 & 2.76 \\
\hline $\operatorname{sim} .5$ & 36.83 & 33.44 & 18.95 & 28.06 & 25.56 & 42.25 & 36.57 & 25.41 & 34.83 & 24.79 & 47.04 & 19.55 & 32.94 \\
\hline & 3.973 & 1.058 & -0.13 & 0.194 & \begin{tabular}{|c|}
-0.43 \\
\end{tabular} & 0.33 & 2.785 & 0.798 & 0.621 & 0.403 & 1.42 & -0.47 & 2.76 \\
\hline 1.6 & 36.83 & 33.44 & 18.95 & 28.06 & 25.56 & 42.25 & 36.57 & 25.41 & 34.83 & 24.79 & 47.04 & 19.55 & 32.94 \\
\hline Erro abs. & 3.973 & 1.058 & -0.13 & 0.194 & -0.43 & 0.33 & 2.785 & 0.798 & 0.621 & 0.403 & 1.42 & \begin{tabular}{l|l|}
-0.47 \\
\end{tabular} & 2.76 \\
\hline 1.7 & 36.83 & 33.44 & 18.95 & 28.06 & 25.56 & 42.25 & 36.58 & 25.41 & 34.83 & 24.79 & 47.04 & 19.55 & 32.94 \\
\hline Erro abs. & 3.973 & 1.058 & -0.13 & 0.194 & -0.43 & 0.33 & 2.785 & 0.798 & 0.621 & 0.403 & 1.42 & -0.47 & 2.76 \\
\hline sim. 8 & 36.83 & 33.44 & 3.95 & 28.06 & 25.56 & 2.25 & 36.58 & 25.41 & 34.83 & 24.79 & 47.04 & 19.55 & 32.94 \\
\hline rro abs. & 3.973 & 1.058 & -0.13 & 0.194 & $\begin{array}{l}-0.43 \\
\end{array}$ & 0.33 & 2.785 & 0.798 & 0.621 & 0.403 & 1.42 & $\begin{array}{l}-0.47 \\
\end{array}$ & 2.76 \\
\hline $\operatorname{sim} .9$ & 36.83 & 33.44 & 18.95 & 28.06 & 25.56 & 42.25 & 36.57 & 25.41 & 34.83 & 24.79 & 47.04 & 19.55 & 32.94 \\
\hline abs. & 3.973 & 1.058 & -0.13 & 0.194 & -0.43 & 0.33 & 2.785 & 0.798 & 0.621 & 0.403 & 1.42 & -0.47 & 2.76 \\
\hline sim. 10 & 36.83 & 33.44 & 18.95 & 28.06 & 25.56 & 42.25 & 36.58 & 25.41 & 34.83 & 24.79 & 47.04 & 19.55 & 32.94 \\
\hline bs. & 3.973 & 1.058 & -0.13 & 0.194 & $\begin{array}{l}-0.43 \\
\end{array}$ & 0.33 & 2.785 & 0.798 & 0.621 & 0.403 & 1.42 & \begin{tabular}{l|l|}
-0.47 \\
\end{tabular} & 2.76 \\
\hline
\end{tabular}

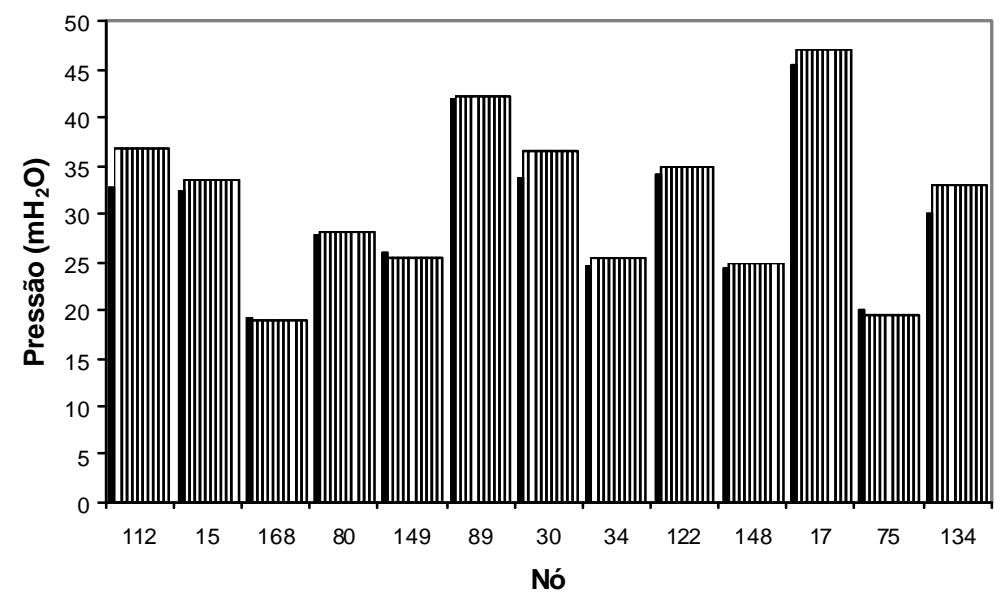

Figura 5.37 - Pressões simuladas e observadas para o padrão 1 (AG Steady-State) para populações iniciais distintas de soluções 
Tabela 5.44 - Desvios entre pressões simuladas e observadas para o padrão 2 (AG SteadyState ) para populações iniciais distintas de soluções

\begin{tabular}{|c|r|r|r|r|r|r|r|r|r|r|r|r|r|}
\hline Nó & $\mathbf{1 1 2}$ & $\mathbf{1 5}$ & \multicolumn{1}{|c|}{$\mathbf{1 6 8}$} & $\mathbf{8 0}$ & $\mathbf{1 4 9}$ & \multicolumn{1}{|c|}{$\mathbf{9}$} & $\mathbf{3 0}$ & $\mathbf{3 4}$ & $\mathbf{1 2 2}$ & $\mathbf{1 4 8}$ & $\mathbf{1 7}$ & $\mathbf{7 5}$ & $\mathbf{1 3 4}$ \\
\hline obs. & 30 & 29.6 & 18.8 & 27 & 25.1 & 39.2 & 31.7 & 23.6 & 32.7 & 23.3 & 42.8 & 19.4 & 28.5 \\
\hline sim. 1 & 32.9 & 30.6 & 18.4 & 26 & 20.9 & 39.3 & 34.5 & 24.3 & 32.5 & 20.2 & 44.2 & 18.2 & 31.4 \\
\hline Erro abs. & 2.88 & 1.08 & -0.45 & -0.98 & -4.2 & 0.1 & 2.79 & 0.65 & -0.19 & -3.09 & 1.48 & -1.18 & 2.87 \\
\hline sim. 2 & 32.9 & 30.6 & 18.4 & 26 & 20.9 & 39.3 & 34.5 & 24.3 & 32.5 & 20.2 & 44.2 & 18.2 & 31.4 \\
\hline Erro abs. & 2.88 & 1.08 & -0.45 & -0.98 & -4.2 & 0.1 & 2.79 & 0.65 & -0.19 & -3.09 & 1.48 & -1.18 & 2.87 \\
\hline sim. 3 & 32.9 & 30.6 & 18.4 & 26 & 20.9 & 39.3 & 34.5 & 24.3 & 32.5 & 20.2 & 44.2 & 18.2 & 31.4 \\
\hline Erro abs. & 2.88 & 1.08 & -0.45 & -0.98 & -4.2 & 0.1 & 2.79 & 0.65 & -0.19 & -3.09 & 1.48 & -1.18 & 2.87 \\
\hline sim. 4 & 32.9 & 30.6 & 18.4 & 26 & 20.9 & 39.3 & 34.5 & 24.3 & 32.5 & 20.2 & 44.2 & 18.2 & 31.4 \\
\hline Erro abs. & 2.88 & 1.08 & -0.45 & -0.98 & -4.2 & 0.1 & 2.79 & 0.65 & -0.19 & -3.09 & 1.48 & -1.18 & 2.87 \\
\hline sim. 5 & 32.9 & 30.6 & 18.4 & 26 & 20.9 & 39.3 & 34.5 & 24.3 & 32.5 & 20.2 & 44.2 & 18.2 & 31.4 \\
\hline Erro abs. & 2.88 & 1.08 & -0.45 & -0.98 & -4.2 & 0.1 & 2.79 & 0.65 & -0.19 & -3.09 & 1.48 & -1.18 & 2.87 \\
\hline sim. 6 & 32.9 & 30.6 & 18.4 & 26 & 20.9 & 39.3 & 34.5 & 24.3 & 32.5 & 20.2 & 44.2 & 18.2 & 31.4 \\
\hline Erro abs. & 2.88 & 1.08 & -0.45 & -0.98 & -4.2 & 0.1 & 2.79 & 0.65 & -0.19 & -3.09 & 1.48 & -1.18 & 2.87 \\
\hline sim. 7 & 32.9 & 30.6 & 18.4 & 26 & 20.9 & 39.3 & 34.5 & 24.3 & 32.5 & 20.2 & 44.2 & 18.2 & 31.4 \\
\hline Erro abs. & 2.88 & 1.08 & -0.45 & -0.98 & -4.2 & 0.1 & 2.79 & 0.65 & -0.19 & -3.09 & 1.48 & -1.18 & 2.87 \\
\hline sim. 8 & 32.9 & 30.6 & 18.4 & 26 & 20.9 & 39.3 & 34.5 & 24.3 & 32.5 & 20.2 & 44.2 & 18.2 & 31.4 \\
\hline Erro abs. & 2.88 & 1.08 & -0.45 & -0.98 & -4.2 & 0.1 & 2.79 & 0.65 & -0.19 & -3.09 & 1.48 & -1.18 & 2.87 \\
\hline sim. 9 & 32.9 & 30.6 & 18.4 & 26 & 20.9 & 39.3 & 34.5 & 24.3 & 32.5 & 20.2 & 44.2 & 18.2 & 31.4 \\
\hline Erro abs. & 2.88 & 1.08 & -0.45 & -0.98 & -4.2 & 0.1 & 2.79 & 0.65 & -0.19 & -3.09 & 1.48 & -1.18 & 2.87 \\
\hline sim. 10 & 32.9 & 30.6 & 18.4 & 26 & 20.9 & 39.3 & 34.5 & 24.3 & 32.5 & 20.2 & 44.2 & 18.2 & 31.4 \\
\hline Erro abs. & 2.88 & 1.08 & -0.45 & -0.98 & -4.2 & 0.1 & 2.79 & 0.65 & -0.19 & -3.09 & 1.48 & -1.18 & 2.87 \\
\hline
\end{tabular}

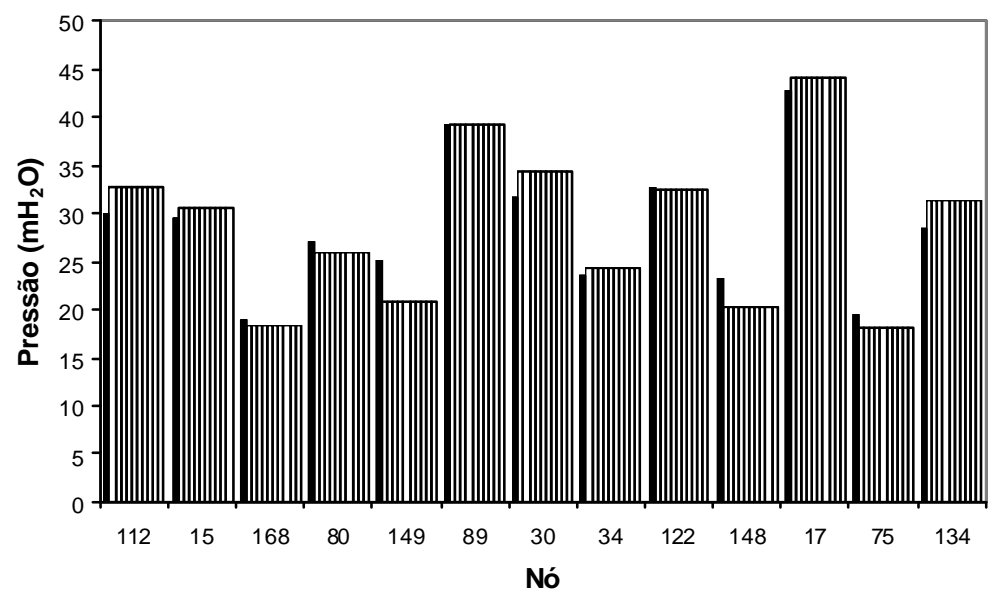

Figura 5.38 - Pressões simuladas e observadas para o padrão 2 (AG Steady-State) para populações iniciais distintas de soluções 
Tabela 5.45 - Desvios entre pressões simuladas e observadas para o padrão 3 (AG SteadyState ) para populações iniciais distintas de soluções

\begin{tabular}{|c|c|c|c|c|c|c|c|c|c|c|c|c|c|}
\hline & & 5 & 8 & 80 & 99 & 99 & & 34 & 2 & 8 & 7 & 75 & 34 \\
\hline & & & & & & & & & & & & & 56 \\
\hline & & & & & & & & & & & & & .3 \\
\hline & & 96 & .66 & 38 & 48 & 4 & & & .45 & .92 & & 1.92 & .69 \\
\hline & & .8 & 16.9 & 23.5 & 1 & 4 & & 22 & 30 & 3 & & 16.3 & 9.3 \\
\hline & & 95 & 06 & 2.38 & .48 & 4 & 38 & 0.13 & .45 & 4.92 & .67 & -1.92 & 3.69 \\
\hline & .3 & 27.8 & 16.9 & 23.5 & 17 & 4 & .1 & 22.4 & 30 & 16.3 & 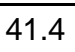 & 16.3 & 29.3 \\
\hline & & 95 & .66 & 38 & .49 & 4 & 38 & 0.13 & .45 & 2 & & 1.92 & 3.7 \\
\hline & .3 & 27.8 & 16.9 & 23.5 & 17 & 36.4 & 32.1 & 22.4 & 30 & 16.3 & 41.4 & 16.3 & 29.3 \\
\hline & 82 & 1.95 & .66 & -2.38 & .48 & 0.4 & .38 & 0.13 & .45 & 4.92 & 67 & -1.92 & 3.69 \\
\hline & 3 & 27.8 & 16.9 & 3.5 & 17 & 4 & 1 & 22 & & & & 16 & 9.3 \\
\hline & 82 & 1.95 & -0.66 & -2.38 & 48 & 0.4 & 5.38 & 0.13 & .45 & -4.92 & 2.67 & -1.92 & 3.69 \\
\hline & .3 & 27.8 & 16.9 & 3.5 & 17 & 6.4 & 32.1 & 22.4 & 30 & 16.3 & 41.4 & 16.3 & 29.3 \\
\hline & 82 & 1.95 & 0.66 & -2.38 & .48 & 0.4 & 5.38 & 0.13 & .45 & -4.92 & 2.67 & -1.92 & 3.69 \\
\hline & 9.3 & 27.8 & 16.9 & 23.5 & 17 & 36.4 & 32.1 & 22.4 & 30 & 16.3 & 41.4 & 16.3 & 29.3 \\
\hline & 83 & 1.96 & 0.66 & 2.38 & 49 & & 39 & 0.13 & .45 & 4.92 & .67 & -1.92 & 3.7 \\
\hline & 3 & 27.8 & 169 & 23.5 & 17 & 3.4 & 32.1 & 22.4 & 0 & 16.3 & 41.4 & 16.3 & 29.3 \\
\hline & 82 & 1.95 & 66 & .38 & 48 & 0.4 & 5.38 & 0.13 & .45 & -4.92 & 2.67 & -1.92 & 3.69 \\
\hline & 9.3 & 27.8 & 9 & 23.5 & 17 & 3.4 & 2.1 & 22.4 & 30 & 3 & 4 & 16.3 & 29.3 \\
\hline & 2.83 & 1.95 & 0.66 & \begin{tabular}{|l|}
-2.38 \\
\end{tabular} & 48 & 0.4 & 5.39 & 0.13 & .45 & -4.92 & 2.67 & -1.92 & 3.7 \\
\hline & 9.3 & 27.8 & 16.9 & 0 & 17 & 6.4 & 32.1 & 22.4 & 0 & 16.3 & 1.4 & 6.3 & 9.3 \\
\hline & .82 & 95 & \begin{tabular}{l|l|}
66 \\
\end{tabular} & 38 & & & 38 & .13 & 45 & .92 & 67 & .92 & $3.6 \mathrm{~s}$ \\
\hline
\end{tabular}

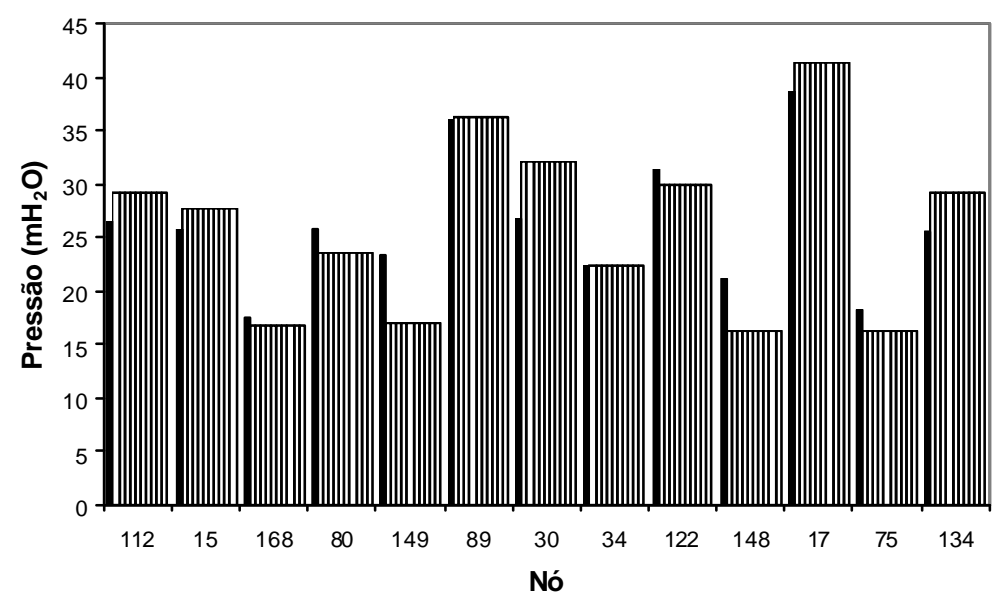

Figura 5.39 - Pressões simuladas e observadas para o padrão 3 (AG Steady-State) para populações iniciais distintas de soluções 
Tabela 5.46 - Desvios entre pressões simuladas e observadas para o padrão 4 (AG SteadyState ) para populações iniciais distintas de soluções

\begin{tabular}{|c|c|c|c|c|c|c|c|c|c|c|c|c|c|}
\hline Nó & 112 & 15 & 168 & 80 & 149 & 89 & 30 & 34 & 122 & 148 & 17 & 75 & 134 \\
\hline obs. & 31.9 & 32.9 & 17.5 & 27.7 & 26.6 & 41.9 & 32.7 & 23.4 & 33.8 & 24.7 & 42.8 & 19.1 & 30.6 \\
\hline sim. 1 & 35.5 & 32.5 & 18.8 & 27.4 & 24 & 41.3 & 35.9 & 25.1 & 34.1 & 23.2 & 46.1 & 19.2 & 32.5 \\
\hline Erro abs. & 3.6 & -0.4 & 1.3 & -0.27 & -2.63 & -0.6 & 3.19 & 1.71 & 0.29 & -1.53 & 3.29 & 0.1 & 1.83 \\
\hline sim. 2 & 35.5 & 32.5 & 18.8 & 27.4 & 24 & 41.3 & 35.9 & 25.1 & 34.1 & 23.2 & 46.1 & 19.2 & 32.5 \\
\hline Erro abs. & 3.6 & -0.4 & 1.3 & -0.27 & -2.63 & -0.6 & 3.19 & 1.71 & 0.29 & -1.53 & 3.29 & 0.1 & 1.83 \\
\hline $\operatorname{sim} .3$ & 35.5 & 32.5 & 18.8 & 27.4 & 24 & 41.3 & 35.9 & 25.1 & 34.1 & 23.2 & 46.1 & 19.2 & 32.5 \\
\hline Erro abs. & 3.6 & -0.4 & 1.3 & -0.27 & -2.63 & -0.6 & 3.19 & 1.71 & 0.29 & -1.53 & 3.29 & 0.1 & 1.83 \\
\hline & 35.5 & 32.5 & 18.8 & 27.4 & 24 & 41.3 & 35.9 & 25.1 & 34.1 & 23.2 & 46.1 & 19.2 & 32.5 \\
\hline Erro abs. & 3.6 & -0.4 & 1.3 & -0.27 & -2.63 & -0.6 & 3.19 & 1.71 & 0.29 & -1.53 & 3.29 & 0.1 & 1.83 \\
\hline $\operatorname{sim} .5$ & 35.5 & 32.5 & 18.8 & 27.4 & 24 & 41.3 & 35.9 & 25.1 & 34.1 & 23.2 & 46.1 & 19.2 & 32.5 \\
\hline Erro abs. & 3.6 & -0.4 & 1.3 & -0.27 & -2.63 & -0.6 & 3.19 & 1.71 & 0.29 & -1.53 & 3.29 & 0.1 & 1.83 \\
\hline $\operatorname{sim} .6$ & 35.5 & 32.5 & 18.8 & 27.4 & 24 & 41.3 & 35.9 & 25.1 & 34.1 & 23.2 & 46.1 & 19.2 & 32.5 \\
\hline Erro abs. & 3.6 & -0.4 & 1.3 & -0.27 & -2.63 & -0.6 & 3.19 & 1.71 & 0.29 & -1.53 & 3.29 & 0.1 & 1.83 \\
\hline $\operatorname{sim} .7$ & 35.5 & 32.5 & 18.8 & 27.4 & 24 & 41.3 & 35.9 & 25.1 & 34.1 & 23.2 & 46.1 & 19.2 & 32.5 \\
\hline Erro abs. & 3.6 & -0.4 & 1.3 & -0.27 & -2.63 & -0.6 & 3.19 & 1.71 & 0.29 & -1.53 & 3.29 & 0.1 & 1.83 \\
\hline $\operatorname{sim} .8$ & 35.5 & 32.5 & 18.8 & 27.4 & 24 & 41.3 & 35.9 & 25.1 & 34.1 & 23.2 & 46.1 & 19.2 & 32.5 \\
\hline Erro abs. & 3.6 & -0.4 & 1.3 & -0.27 & -2.63 & -0.6 & 3.19 & 1.71 & 0.29 & -1.53 & 3.29 & 0.1 & 1.83 \\
\hline $\operatorname{sim} .9$ & 35.5 & 32.5 & 18.8 & 27.4 & 24 & 41.3 & 35.9 & 25.1 & 34.1 & 23.2 & 46.1 & 19.2 & 32.5 \\
\hline Erro abs. & 3.6 & -0.4 & 1.3 & -0.27 & -2.63 & -0.6 & 3.19 & 1.71 & 0.29 & -1.53 & 3.29 & 0.1 & 1.83 \\
\hline sim. 10 & 35.5 & 32.5 & 18.8 & 27.4 & 24 & 41.3 & 35.9 & 25.1 & 34.1 & 23.2 & 46.1 & 19.2 & 32.5 \\
\hline Erro abs. & 3.6 & -0.4 & 1.3 & -0.27 & -2.63 & -0.6 & 3.19 & 1.71 & 0.29 & -1.53 & 3.29 & 0.1 & 1.83 \\
\hline
\end{tabular}

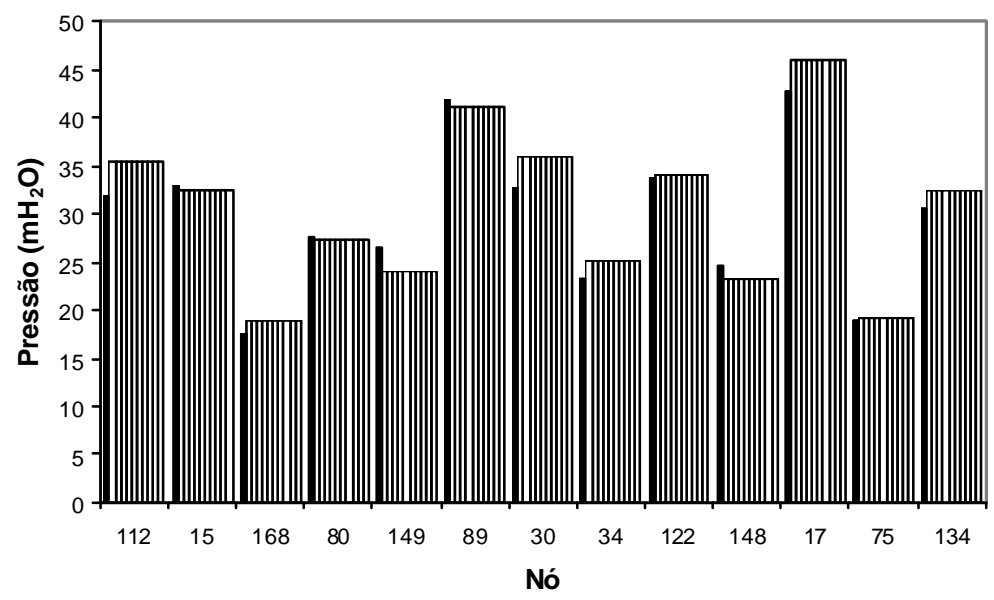

Figura 5.40 - Pressões simuladas e observadas para o padrão 4 (AG Steady-State) para populações iniciais distintas de soluções 
Tabela 5.47 - Resultados obtidos das variáveis de decisão usando AG híbrido (Steady State + Nelder-Mead)

\begin{tabular}{|c|c|c|c|c|c|c|}
\hline & \multicolumn{5}{|c|}{ AG Híbrido (Geracional Elitista + Nelder-Mead) } \\
\hline & & \multicolumn{5}{|c|}{ Variável de Decisão } \\
\hline & & $e_{1}$ & $e_{2}$ & $?_{1}(\mathrm{x} 10 \mathrm{e}-7)$ & $?_{2}(\mathrm{x} 10 \mathrm{e}-7)$ & B \\
\hline \multirow{10}{*}{ 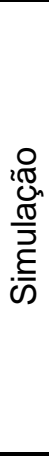 } & 1 & 0.001013 & 0.029456 & $7.15 \mathrm{E}-05$ & $6.50 \mathrm{E}-05$ & 0.778411 \\
\hline & 2 & 0.001014 & 0.029836 & 6.36E-05 & $1.53 \mathrm{E}-05$ & 0.939481 \\
\hline & 3 & 0.001009 & 0.029905 & $2.30 \mathrm{E}-05$ & 9.92E-05 & 0.638694 \\
\hline & 4 & 0.001003 & 0.029723 & $5.43 E-05$ & 7.95E-05 & 1.11633 \\
\hline & 5 & 0.001005 & 0.029799 & $5.40 \mathrm{E}-05$ & $2.47 \mathrm{E}-05$ & 0.784505 \\
\hline & 6 & 0.001 & 0.029875 & $6.26 \mathrm{E}-05$ & $8.38 \mathrm{E}-05$ & 0.77123 \\
\hline & 7 & 0.00103 & 0.029533 & $9.24 \mathrm{E}-05$ & 9.76E-05 & 0.840869 \\
\hline & 8 & 0.001002 & 0.029954 & $4.63 \mathrm{E}-05$ & $5.74 \mathrm{E}-05$ & 0.77354 \\
\hline & 9 & 0.001024 & 0.029595 & $4.11 \mathrm{E}-05$ & $4.87 \mathrm{E}-05$ & 0.822419 \\
\hline & 10 & 0.001 & 0.029912 & $6.90 \mathrm{E}-05$ & $1.80 \mathrm{E}-05$ & 0.931281 \\
\hline \multirow{2}{*}{ 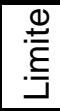 } & mín & 0,001 & 0,02 & 0,00001 & 0,00001 & 0,5 \\
\hline & máx & 0,002 & 0,03 & 0,0001 & 0,0001 & 1,18 \\
\hline
\end{tabular}

\subsubsection{PARÂMETRO? DO MODELO DE VAZAMENTOS}

Pode-se dizer que as simulações realizadas até então restringiram bastante a faixa de possíveis valores para o parâmetro ? do modelo de vazamentos. São reportadas em seguida quatro simulações realizadas ampliando gradativamente essa faixa a partir da simulação 2, conforme indicações da Tabela 5.48. Uma quinta simulação foi realizada ainda, ampliando o limite superior de $?_{l}$ e $?_{2}$ para 1,0, mas não foi verificada a convergência do modelo hidráulico nesse caso.

A Tabela 5.48 permite que se observe uma redução gradual do valor da função objetivo da simulação 1 para a 2 e da 2 para a 3, permanecendo constante de 3 para 4 . Foram identificados também os valores $0,01,0,034$ e 1,18 para $e_{1}, e_{1}$ e $\beta$, respectivamente, a partir da simulação 2. Embora o valor nulo não fosse esperado para $?_{1}$, ele sugere vazamento distribuído desprezível na área correspondente às tubulações de PVC, quando comparado com o vazamento da área relativa às tubulações de cimento amianto. É interessante notar ainda que o valor de $\beta$ para o expoente do modelo de vazamentos coincide com o valor adotado por diversos autores (MARTÍNEZ, CONEJOS E VERCHER (1999)).

Observa-se ainda que a redução do valor da função objetivo é pouco significativa, permitindo que as conclusões obtidas até agora sejam mantidas: os dados de entrada para o modelo de calibração precisam ser melhorados. 
Tabela 5.48 - Simulações variando o parâmetro ? do modelo de vazamentos

\begin{tabular}{|c|c|c|c|c|c|}
\hline \multirow{2}{*}{ SIMULAÇÕES } & \multirow{2}{*}{ VARIÁVEIS } & \multicolumn{2}{|c|}{ FAIXA ADMITIDA } & \multicolumn{2}{|c|}{ RESULTADOS OBTIDOS } \\
\hline & & Mín & Máx & AG & Híbrido \\
\hline \multirow{6}{*}{1} & $e_{1}$ & 0.01 & 0.02 & 0.01 & 0.010014 \\
\hline & $e_{2}$ & 0.02 & 0.035 & 0.034231 & 0.034399 \\
\hline & $?_{1}$ & 0.00001 & 0.0001 & $2.91 \mathrm{E}-05$ & $3.18 \mathrm{E}-05$ \\
\hline & $?_{2}$ & 0.00001 & 0.0001 & $7.88 \mathrm{E}-05$ & $8.00 \mathrm{E}-05$ \\
\hline & $\beta$ & 0.5 & 1.18 & 0.5 & 0.679268 \\
\hline & F.O. & & & 0.35664 & 0.356632 \\
\hline \multirow{6}{*}{2} & $e_{1}$ & 0.01 & 0.02 & 0.010031 & 0.010317 \\
\hline & $e_{2}$ & 0.02 & 0.035 & 0.034231 & 0.034117 \\
\hline & $?_{1}$ & 0.001 & 0.1 & 0.001 & 0.00122 \\
\hline & $?_{2}$ & 0.0001 & 0.1 & 0.095265 & 0.098071 \\
\hline & $\beta$ & 0.5 & 1.18 & 1.07088 & 1.17864 \\
\hline & F.O. & & & 0.343226 & 0.337103 \\
\hline \multirow{6}{*}{3} & $e_{1}$ & 0.01 & 0.02 & 0.01 & 0.010154 \\
\hline & $e_{2}$ & 0.02 & 0.035 & 0.034231 & 0.034438 \\
\hline & $?_{1}$ & 0 & 0.1 & $2.91 \mathrm{E}-05$ & 0 \\
\hline & $?_{2}$ & 0 & 0.1 & $7.88 \mathrm{E}-05$ & 0.099119 \\
\hline & $\bar{\beta}$ & 0.5 & 1.18 & 0.5 & 1.17819 \\
\hline & F.O. & & & & 0.3367 \\
\hline \multirow{6}{*}{4} & $e_{1}$ & 0.01 & 0.02 & 0.01 & 0.010154 \\
\hline & $e_{2}$ & 0.02 & 0.035 & 0.034231 & 0.034438 \\
\hline & $?_{1}$ & 0 & 0.2 & 0 & 0 \\
\hline & $?_{2}$ & 0 & 0.2 & 0.095261 & 0.099119 \\
\hline & $\bar{\beta}$ & 0.5 & 1.18 & 1.07088 & 1.17819 \\
\hline & F.O. & & & 0.33689 & 0.3367 \\
\hline
\end{tabular}

As Tabelas 5.49 a 5.51 apresentam os valores das variáveis de estado do sistema resultantes do ajuste do modelo pelos AGs e AGs - Nelder-Mead, onde os valores em negrito representam os desvios absolutos entre os valores de pressão simulados e observados superiores a $2 \mathrm{mH}_{2} \mathrm{O}$. Os valores para a simulação 4 foram omitidos porque coincidem com aqueles obtidos na simulação 3. Observa-se que, apesar da redução pouco significativa do valor da função objetivo da simulação 1 para as demais, o máximo desvio absoluto, relativo ao padrão 3 no nó 149 da rede, caiu de 6,12 m para $5,68 \mathrm{~m}$. 
Tabela 5.49 - Valores observados e simulados para pressões nodais e vazões abastecidas simulação 1 variando o parâmetro ? do modelo de vazamentos

\begin{tabular}{|c|c|c|c|c|c|c|}
\hline PADRÃO & NÓ & CAMPO & $\mathbf{A G}$ & $\begin{array}{c}\text { Desvio } \\
\text { Absoluto }\end{array}$ & $\begin{array}{c}\text { AG - } \\
\text { Nelder- } \\
\text { Mead }\end{array}$ & $\begin{array}{c}\text { Desvio } \\
\text { Absoluto }\end{array}$ \\
\hline \multirow{14}{*}{1} & 112 & 32.86 & 37 & 4.14 & 37 & 4.14 \\
\hline & 15 & 32.38 & 33.43 & 1.05 & 33.43 & 1.04 \\
\hline & 173 & 19.08 & 19.06 & -0.02 & 19.06 & -0.02 \\
\hline & 80 & 27.87 & 28.29 & 0.42 & 28.29 & 0.42 \\
\hline & 149 & 25.99 & 26.09 & 0.1 & 26.09 & 0.1 \\
\hline & 89 & 41.92 & 42.56 & 0.64 & 42.56 & 0.64 \\
\hline & 30 & 33.79 & 37.06 & 3.27 & 37.06 & 3.27 \\
\hline & 34 & 24.61 & 25.41 & 0.8 & 25.41 & 0.8 \\
\hline & 122 & 34.21 & 34.83 & 0.62 & 34.83 & 0.62 \\
\hline & 148 & 24.39 & 25.15 & 0.76 & 25.15 & 0.76 \\
\hline & 17 & 45.62 & 46.92 & 1.3 & 46.92 & 1.3 \\
\hline & 75 & 20.02 & 20.35 & 0.33 & 20.35 & 0.33 \\
\hline & 134 & 30.18 & 32.94 & 2.76 & 32.94 & 2.76 \\
\hline & $\mathbf{Q}(\mathrm{L} / \mathrm{s})$ & 3.27 & 3.33 & 0.06 & 3.33 & 0.06 \\
\hline \multirow{14}{*}{2} & 112 & 29.99 & 32.06 & 2.07 & 32.06 & 2.07 \\
\hline & 15 & 29.55 & 30.44 & 0.89 & 30.44 & 0.89 \\
\hline & 168 & 18.82 & 18.49 & -0.34 & 18.49 & -0.34 \\
\hline & 80 & 26.96 & 25.32 & -1.64 & 25.32 & -1.64 \\
\hline & 149 & 25.13 & 21.37 & -3.76 & 21.37 & -3.76 \\
\hline & 89 & 39.21 & 38.68 & -0.53 & 38.68 & -0.53 \\
\hline & 30 & 31.71 & 34.82 & 3.11 & 34.82 & 3.11 \\
\hline & 34 & 23.62 & 24.22 & 0.6 & 24.22 & 0.6 \\
\hline & 122 & 32.7 & 32.47 & -0.23 & 32.47 & -0.23 \\
\hline & 148 & 23.26 & 20.44 & -2.82 & 20.44 & -2.82 \\
\hline & 17 & 42.75 & 43.93 & 1.18 & 43.93 & 1.18 \\
\hline & 75 & 19.41 & 19.03 & -0.38 & 19.03 & -0.38 \\
\hline & 134 & 28.5 & 31.36 & 2.86 & 31.36 & 2.86 \\
\hline & $\bar{Q}(\mathbf{L} / \mathbf{s})$ & 15.39 & 15.33 & -0.06 & 15.33 & -0.06 \\
\hline \multirow{14}{*}{3} & 112 & 26.48 & 27.88 & 1.4 & 27.88 & 1.4 \\
\hline & 15 & 25.8 & 27.45 & 1.65 & 27.45 & 1.65 \\
\hline & 168 & 17.53 & 16.98 & -0.55 & 16.98 & -0.55 \\
\hline & 80 & 25.92 & 22.33 & -3.59 & 22.33 & -3.59 \\
\hline & 149 & 23.49 & 17.37 & -6.12 & 17.37 & -6.12 \\
\hline & 89 & 35.96 & 35.14 & -0.82 & 35.14 & -0.82 \\
\hline & 30 & 26.68 & 32.28 & 5.6 & 32.28 & 5.6 \\
\hline & 34 & 22.3 & 22.34 & 0.04 & 22.34 & 0.04 \\
\hline & 122 & 31.42 & 29.9 & -1.52 & 29.9 & -1.52 \\
\hline & 148 & 21.17 & 16.45 & -4.72 & 16.45 & -4.72 \\
\hline & 17 & 38.69 & 40.94 & 2.25 & 40.94 & 2.25 \\
\hline & 75 & 18.19 & 17.06 & -1.13 & 17.06 & -1.13 \\
\hline & 134 & 25.58 & 29.25 & 3.67 & 29.25 & 3.67 \\
\hline & $\bar{Q}(\mathbf{L} / \mathbf{s})$ & 19.74 & 19.69 & -0.05 & 19.69 & -0.05 \\
\hline \multirow{14}{*}{4} & 112 & 31.88 & 35.31 & 3.43 & 35.31 & 3.43 \\
\hline & 15 & 32.91 & 32.44 & -0.47 & 32.44 & -0.47 \\
\hline & 168 & 17.53 & 18.94 & 1.41 & 18.94 & 1.41 \\
\hline & 80 & 27.68 & 27.32 & -0.36 & 27.32 & -0.36 \\
\hline & 149 & 26.6 & 24.48 & -2.12 & 24.48 & -2.12 \\
\hline & 89 & 41.88 & 41.26 & -0.62 & 41.26 & -0.62 \\
\hline & 30 & 32.73 & 36.35 & 3.62 & 36.35 & 3.62 \\
\hline & 34 & 23.38 & 25.07 & 1.69 & 25.07 & 1.69 \\
\hline & 122 & 33.79 & 34.07 & 0.28 & 34.07 & 0.28 \\
\hline & 148 & 24.74 & 23.54 & -1.2 & 23.54 & -1.2 \\
\hline & 17 & 42.83 & 45.93 & 3.1 & 45.93 & 3.1 \\
\hline & 75 & 19.06 & 19.97 & 0.91 & 19.97 & 0.91 \\
\hline & 134 & 30.63 & 32.46 & 1.83 & 32.46 & 1.83 \\
\hline & $\mathbf{Q}(\mathbf{L} / \mathbf{s})$ & 9.29 & 9.22 & -0.07 & 9.22 & -0.07 \\
\hline
\end{tabular}


Tabela 5.50 - Valores observados e simulados para pressões nodais e vazões abastecidas simulação 2 variando o parâmetro ? do modelo de vazamentos

\begin{tabular}{|c|c|c|c|c|c|c|}
\hline PADRÃO & NÓ & CAMPO & $\mathbf{A G}$ & $\begin{array}{c}\text { Desvio } \\
\text { Absoluto }\end{array}$ & $\begin{array}{c}\text { AG - Nelder- } \\
\text { Mead }\end{array}$ & $\begin{array}{c}\text { Desvio } \\
\text { Absoluto }\end{array}$ \\
\hline \multirow{14}{*}{1} & 112 & 32.86 & 37.04 & 4.18 & 37.06 & 4.20 \\
\hline & 15 & 32.38 & 33.42 & 1.04 & 33.41 & 1.03 \\
\hline & 173 & 19.08 & 19.06 & -0.02 & 19.06 & -0.02 \\
\hline & 80 & 27.87 & 28.29 & 0.42 & 28.30 & 0.43 \\
\hline & 149 & 25.99 & 26.17 & 0.18 & 26.22 & 0.23 \\
\hline & 89 & 41.92 & 42.58 & 0.66 & 42.60 & 0.67 \\
\hline & 30 & 33.79 & 37.06 & 3.27 & 37.05 & 3.26 \\
\hline & 34 & 24.61 & 25.41 & 0.80 & 25.41 & 0.80 \\
\hline & 122 & 34.21 & 34.86 & 0.65 & 34.88 & 0.67 \\
\hline & 148 & 24.39 & 25.23 & 0.84 & 25.27 & 0.88 \\
\hline & 17 & 45.62 & 46.91 & 1.29 & 46.90 & 1.28 \\
\hline & 75 & 20.02 & 20.36 & 0.34 & 20.37 & 0.35 \\
\hline & 134 & 30.18 & 32.95 & 2.77 & 32.96 & 2.78 \\
\hline & $\mathrm{Q}(\mathrm{L} / \mathrm{s})$ & 3.27 & 3.34 & 0.07 & 3.31 & 0.04 \\
\hline \multirow{14}{*}{2} & 112 & 29.99 & 32.18 & 2.19 & 32.23 & 2.24 \\
\hline & 15 & 29.55 & 30.42 & 0.87 & 30.40 & 0.85 \\
\hline & 168 & 18.82 & 18.48 & -0.34 & 18.48 & -0.34 \\
\hline & 80 & 26.96 & 25.35 & -1.61 & 25.36 & -1.60 \\
\hline & 149 & 25.13 & 21.64 & -3.49 & 21.76 & -3.37 \\
\hline & 89 & 39.21 & 38.75 & -0.46 & 38.77 & -0.44 \\
\hline & 30 & 31.71 & 34.80 & 3.09 & 34.79 & 3.08 \\
\hline & 34 & 23.62 & 24.21 & 0.59 & 24.21 & 0.59 \\
\hline & 122 & 32.70 & 32.58 & -0.12 & 32.63 & -0.07 \\
\hline & 148 & 23.26 & 20.70 & -2.56 & 20.83 & -2.43 \\
\hline & 17 & 42.75 & 43.91 & 1.16 & 43.89 & 1.14 \\
\hline & 75 & 19.41 & 19.06 & -0.35 & 19.07 & -0.34 \\
\hline & 134 & 28.50 & 31.41 & 2.91 & 31.44 & 2.94 \\
\hline & $\mathrm{Q}(\mathrm{L} / \mathrm{s})$ & 15.39 & 15.33 & -0.06 & 15.33 & -0.06 \\
\hline \multirow{14}{*}{3} & 112 & 26.48 & 28.02 & 1.54 & 28.08 & 1.60 \\
\hline & 15 & 25.80 & 27.42 & 1.62 & 27.41 & 1.61 \\
\hline & 168 & 17.53 & 16.98 & -0.55 & 16.98 & -0.55 \\
\hline & 80 & 25.92 & 22.37 & -3.55 & 22.38 & -3.54 \\
\hline & 149 & 23.49 & 17.67 & -5.82 & 17.80 & -5.69 \\
\hline & 89 & 35.96 & 35.21 & -0.75 & 35.25 & -0.71 \\
\hline & 30 & 26.68 & 32.26 & 5.58 & 32.25 & 5.57 \\
\hline & 34 & 22.30 & 22.33 & 0.03 & 22.33 & 0.03 \\
\hline & 122 & 31.42 & 30.01 & -1.41 & 30.07 & -1.35 \\
\hline & 148 & 21.17 & 16.74 & -4.43 & 16.88 & -4.29 \\
\hline & 17 & 38.69 & 40.92 & 2.23 & 40.90 & 2.21 \\
\hline & 75 & 18.19 & 17.10 & -1.09 & 17.11 & -1.08 \\
\hline & 134 & 25.58 & 29.31 & 3.73 & 29.34 & 3.76 \\
\hline & $\mathrm{Q}(\mathrm{L} / \mathrm{s})$ & 19.74 & 19.69 & -0.05 & 19.69 & -0.05 \\
\hline \multirow{14}{*}{4} & 112 & 31.88 & 35.38 & 3.50 & 35.41 & 3.53 \\
\hline & 15 & 32.91 & 32.42 & -0.49 & 32.41 & -0.50 \\
\hline & 168 & 17.53 & 18.94 & 1.41 & 18.94 & 1.41 \\
\hline & 80 & 27.68 & 27.34 & -0.34 & 27.34 & -0.34 \\
\hline & 149 & 26.60 & 24.66 & -1.94 & 24.74 & -1.86 \\
\hline & 89 & 41.88 & 41.30 & -0.58 & 41.31 & -0.57 \\
\hline & 30 & 32.73 & 36.34 & 3.61 & 36.33 & 3.60 \\
\hline & 34 & 23.38 & 25.07 & 1.69 & 25.07 & 1.69 \\
\hline & 122 & 33.79 & 34.14 & 0.35 & 34.17 & 0.38 \\
\hline & 148 & 24.74 & 23.72 & -1.02 & 23.80 & -0.94 \\
\hline & 17 & 42.83 & 45.91 & 3.08 & 45.90 & 3.07 \\
\hline & 75 & 19.06 & 19.99 & 0.93 & 20.00 & 0.94 \\
\hline & 134 & 30.63 & 32.49 & 1.86 & 32.51 & 1.88 \\
\hline & $\mathrm{Q}(\mathrm{L} / \mathrm{s})$ & 9.29 & 9.24 & -0.05 & 9.25 & -0.04 \\
\hline
\end{tabular}


Tabela 5.51 - Valores observados e simulados para pressões nodais e vazões abastecidas simulação 3 variando o parâmetro ? do modelo de vazamentos

\begin{tabular}{|c|c|c|c|c|c|c|}
\hline PADRÃO & NÓ & CAMPO & $\mathbf{A G}$ & $\begin{array}{c}\text { Desvio } \\
\text { Absoluto }\end{array}$ & $\begin{array}{c}\text { AG - } \\
\text { Nelder- } \\
\text { Mead }\end{array}$ & $\begin{array}{c}\text { Desvio } \\
\text { Absoluto }\end{array}$ \\
\hline \multirow{14}{*}{1} & 112 & 32,86 & 37,04 & 4,18 & 37,06 & 4,20 \\
\hline & 15 & 32,38 & 33,42 & 1,04 & 33,41 & 1,03 \\
\hline & 173 & 19,08 & 19,06 & $-0,02$ & 19,06 & $-0,02$ \\
\hline & 80 & 27,87 & 28,29 & 0,42 & 28,30 & 0,43 \\
\hline & 149 & 25,99 & 26,17 & 0,18 & 26,22 & 0,23 \\
\hline & 89 & 41,92 & 42,58 & 0,66 & 42,60 & 0,68 \\
\hline & 30 & 33,79 & 37,06 & 3,27 & 37,05 & 3,26 \\
\hline & 34 & 24,61 & 25,41 & 0,80 & 25,41 & 0,80 \\
\hline & 122 & 34,21 & 34,86 & 0,65 & 34,88 & 0,67 \\
\hline & 148 & 24,39 & 25,23 & 0,84 & 25,27 & 0,88 \\
\hline & 17 & 45,62 & 46,91 & 1,29 & 46,90 & 1,28 \\
\hline & 75 & 20,02 & 20,36 & 0,34 & 20,37 & 0,35 \\
\hline & 134 & 30,18 & 32,95 & 2,77 & 32,96 & 2,78 \\
\hline & $\mathbf{Q}(\mathbf{L} / \mathbf{s})$ & 3,27 & 3,34 & 0,07 & 3,31 & 0,04 \\
\hline \multirow{14}{*}{2} & 112 & 29,99 & 32,18 & 2,19 & 32,23 & 2,24 \\
\hline & 15 & 29,55 & 30,42 & 0,86 & 30,40 & 0,85 \\
\hline & 168 & 18,82 & 18,48 & $-0,34$ & 18,48 & $-0,34$ \\
\hline & 80 & 26,96 & 25,35 & $-1,61$ & 25,36 & $-1,60$ \\
\hline & 149 & 25,13 & 21,64 & $-3,49$ & 21,76 & $-3,37$ \\
\hline & 89 & 39,21 & 38,74 & $-0,47$ & 38,77 & $-0,44$ \\
\hline & 30 & 31,71 & 34,80 & 3,09 & 34,79 & 3,08 \\
\hline & 34 & 23,62 & 24,21 & 0,59 & 24,21 & 0,59 \\
\hline & 122 & 32,70 & 32,58 & $-0,12$ & 32,63 & $-0,07$ \\
\hline & 148 & 23,26 & 20,71 & $-2,55$ & 20,83 & $-2,43$ \\
\hline & 17 & 42,75 & 43,91 & 1,16 & 43,89 & 1,14 \\
\hline & 75 & 19,41 & 19,06 & $-0,35$ & 19,07 & $-0,34$ \\
\hline & 134 & 28,50 & 31,41 & 2,91 & 31,44 & 2,94 \\
\hline & $\mathbf{Q}(\mathrm{L} / \mathrm{s})$ & 15,39 & 15,33 & $-0,06$ & 15,33 & $-0,06$ \\
\hline \multirow{14}{*}{3} & 112 & 26,48 & 28,02 & 1,54 & 28,08 & 1,60 \\
\hline & 15 & 25,80 & 27,42 & 1,62 & 27,40 & 1,60 \\
\hline & 168 & 17,53 & 16,98 & $-0,55$ & 16,98 & $-0,55$ \\
\hline & 80 & 25,92 & 22,37 & $-3,55$ & 22,38 & $-3,54$ \\
\hline & 149 & 23,49 & 17,67 & $-5,82$ & 17,81 & $-5,68$ \\
\hline & 89 & 35,96 & 35,21 & $-0,75$ & 35,24 & $-0,72$ \\
\hline & 30 & 26,68 & 32,26 & $\mathbf{5 , 5 8}$ & 32,25 & $\mathbf{5 , 5 7}$ \\
\hline & 34 & 22,30 & 22,33 & 0,03 & 22,33 & 0,03 \\
\hline & 122 & 31,42 & 30,01 & $-1,41$ & 30,07 & $-1,35$ \\
\hline & 148 & 21,17 & 16,74 & $-4,43$ & 16,88 & $-4,29$ \\
\hline & 17 & 38,69 & 40,92 & 2,23 & 40,90 & 2,21 \\
\hline & 75 & 18,19 & 17,10 & $-1,09$ & 17,11 & $-1,08$ \\
\hline & 134 & 25,58 & 29,31 & 3,73 & 29,34 & 3,76 \\
\hline & $\mathbf{Q}(\mathbf{L} / \mathbf{s})$ & 19,74 & 19,69 & $-0,05$ & 19,69 & $-0,05$ \\
\hline \multirow{14}{*}{4} & 112 & 31,88 & 35,38 & 3,50 & 35,41 & $\mathbf{3 , 5 3}$ \\
\hline & 15 & 32,91 & 32,42 & $-0,49$ & 32,41 & $-0,50$ \\
\hline & 168 & 17,53 & 18,94 & 1,41 & 18,94 & 1,41 \\
\hline & 80 & 27,68 & 27,34 & $-0,34$ & 27,34 & $-0,34$ \\
\hline & 149 & 26,60 & 24,66 & $-1,94$ & 24,75 & $-1,85$ \\
\hline & 89 & 41,88 & 41,30 & $-0,58$ & 41,31 & $-0,57$ \\
\hline & 30 & 32,73 & 36,34 & 3,61 & 36,33 & 3,60 \\
\hline & 34 & 23,38 & 25,07 & 1,69 & 25,06 & 1,68 \\
\hline & 122 & 33,79 & 34,14 & 0,35 & 34,17 & 0,38 \\
\hline & 148 & 24,74 & 23,72 & $-1,02$ & 23,81 & $-0,93$ \\
\hline & 17 & 42,83 & 45,91 & 3,08 & 45,90 & 3,07 \\
\hline & 75 & 19,06 & 19,99 & 0,93 & 20,00 & 0,94 \\
\hline & 134 & 30,63 & 32,49 & 1,86 & 32,51 & 1,88 \\
\hline & $\mathbf{Q}(\mathbf{L} / \mathbf{s})$ & 9,29 & 9,24 & $-0,05$ & 9,25 & $-0,04$ \\
\hline
\end{tabular}




\section{CONCLUSÕES E RECOMENDAÇÕES}

O presente trabalho de pesquisa visou o estudo de aplicação de um modelo especialmente construído para a calibração de sistemas, através do qual é possível identificar variáveis de campo tais como rugosidades, diâmetros, parâmetros do modelo de vazamentos, etc. O modelo empregado é abrangente o suficiente para incorporar vazamentos e demandas variáveis com a pressão. Através dele, foram realizados dois estudos de caso, para os quais resultados foram apresentados e objetivamente discutidos no item anterior.

Guariba foi a cidade escolhido inicialmente para o desenvolvimento do estudo por apresentar características específicas com relação aos elevados índices de vazamentos. Por meio de visitas constantes à cidade, foram possíveis aquisições de informações de naturezas cadastrais capazes de dar características concretas ao modelo da rede gerado por meio do simulador hidráulico EPANET. Os testes de campo e os resultados gerados para as simulações para este modelo direcionaram as seguintes conclusões:

1. Existe uma grande incerteza na setorização da cidade. Apesar das confirmações de setorização com base nos testes de pressão realizados nos limites dos setores de abastecimento, as delimitações apresentadas no cadastro de setores da cidade são incoerentes. As pressões negativas geradas para a simulação da rede de Guariba, podem ter sido causadas por interligações desconhecidas entre setores abastecidos, visto que interligações desta natureza podem representar um consumo elevado ou uma fonte de alimentação pontual para o setor;

2. O cadastro adquirido para a rede da cidade apresenta incertezas quanto aos diâmetros, comprimentos e materiais das tubulações; e localizações dos registros responsáveis pela setorização. Tendo em vista que a concessionária de água da cidade não realiza atualizações diárias no cadastro da rede, ou seja, eventuais manutenções na rede, consertos de vazamentos, troca do tipo de tubulação de ramal não são atualizadas 
cadastralmente. Para a caracterização do modelo da rede, corretas informações cadastrais dos materiais que a compõem são imprescindíveis;

3. O estado físico dos registros utilizados para setorização da rede é duvidoso. Visitas aos locais onde registros estão instalados comprovaram que os mesmos merecem manutenção ou substituição. Algumas companhias vêm adotando válvulas com sistema de vedação de borracha que tem a característica de apresentar uma maior vida útil. Simulações realizadas no EPANET, para diferentes níveis de fechamento dos registros, podem causar inversão do sentido da água na rede. Conclui-se imprescindível para a correta caracterização do modelo a real posição de fechamento de todos os registros instalados na rede.

Tendo em vista que os resultados apresentados para a cidade de Guariba não representaram adequadamente o estado atual da rede, um estudo para uma nova cidade foi proposto. A cidade de Itirapuã foi escolhido por apresentar uma rede de dimensões reduzidas com apenas um setor de abastecimento. A partir dos testes de campo e dos resultados gerados para as simulações para este modelo, podem-se concluir:

1. Apesar do comprimento reduzido da rede, o cadastro adquirido apresentou incertezas quanto aos diâmetros, comprimentos e materiais de algumas tubulações. De maneira semelhante à cidade de Guariba, a concessionária de água de Itirapuã não atualiza no cadastro eventuais manutenções na rede, consertos de vazamentos, troca do tipo de tubulação de ramal entre outros. As diferenças resultantes entre os padrões de consumo simulados e observados, para as simulações deste modelo, podem ter sido geradas a partir do cadastro não realístico utilizado para a construção do modelo da rede.

2. O real grau de fechamento dos registros usados na intrasetorização da cidade é desconhecido. Como a referida rede de abastecimento apresenta uma grande quantidade de registros para um comprimento de rede total considerado pequeno, as diversas combinações de estado dos registros (abertos ou fechados) podem causar influências significativas no comportamento do sistema. Assim, estas mudanças podem não ser observadas nos resultados já que as simulações realizadas partem do 
princípio de que os registros têm apenas dois graus de abertura (abertos ou fechados).

Diversas são as fontes de incerteza do processo de calibração desenvolvido, incluindo hipóteses necessárias, dados da rede, dados coletados em campo e procedimentos de rotina não observados, conforme se comenta a seguir:

1. Hipóteses:

a. Os consumos hídricos não-autorizados foram ignorados, o que equivale a admitir que sejam diretamente proporcionais aos consumos autorizados. Tal hipótese nem sempre é verdadeira e pode interferir nos resultados, caso uma parcela considerável de consumo na rede seja de natureza não autorizada.

b. Não há consumidores especiais, sendo o comportamento do consumo comum a todos os nós da rede, sem distinção entre residências, comércio, pequenas indústrias, etc.

2. No que diz respeito aos dados da rede propriamente dita, grande esforço foi empenhado no sentido de confirmar os dados cadastrais relativos a diâmetros, materiais, comprimentos, localização, características e status de funcionamento das válvulas existentes, mas a verificação de tais informações em loco não se mostrou viável na grande maioria das vezes. Pode-se dizer ainda que, em relação ao sistema de Itirapuã, cotas topográficas foram reavaliadas nos pontos de coleta dos dados de pressão e cruzamentos mais próximos, exibindo discrepâncias em relação a alguns pontos do cadastro original.

3. Os estudos aqui reportados tomaram por base dados de campo como:

a. Registros de vazões continuamente monitoradas por medidores eletromagnéticos, cuja calibração não foi verificada; e

b. Por falta de caixas de inspeção na rede, os dados de pressão foram mensurados em cavaletes residenciais, estando, portanto, sujeitos às interferências de consumo.

4. Alguns procedimentos de rotina anteriores a uma análise de calibração também não foram realizados, com vistas principalmente à determinação da distribuição espacial de demandas e vazamentos: 
a. Não foi realizada uma varredura para detecção e reparo de eventuais vazamentos localizados na rede; e

b. Não foi realizada uma amostragem de verificação das condições de leitura dos hidrômetros.

Algumas recomendações podem ser feitas no sentido de viabilizar estudos dessa natureza que possam produzir ferramental diretamente utilizável pelas concessionárias de água para abastecimento.

Todas as fontes de erro levantadas acima conduzem à necessidade de se estabelecer um setor piloto para estudos com vistas principalmente à criação da cultura da modelagem e da compreensão de suas necessidades. Essa estratégia envolveria a construção de caixas de inspeção em pontos chave da rede, a delimitação clara de setores de rede coincidentes com os de leitura, a implantação de uma sistemática rotineira de atualização de cadastros, com base em toda e qualquer intervenção realizada sobre a rede, a calibração periódica dos equipamentos de macro e micro-medição, o monitoramento constante dos consumos e pressões, caça a vazamentos e consumos não autorizados, etc. 


\section{ANEXO A - ILUSTRAÇÃO DA CIDADE E DOS} SETORES DE GUARIBA 


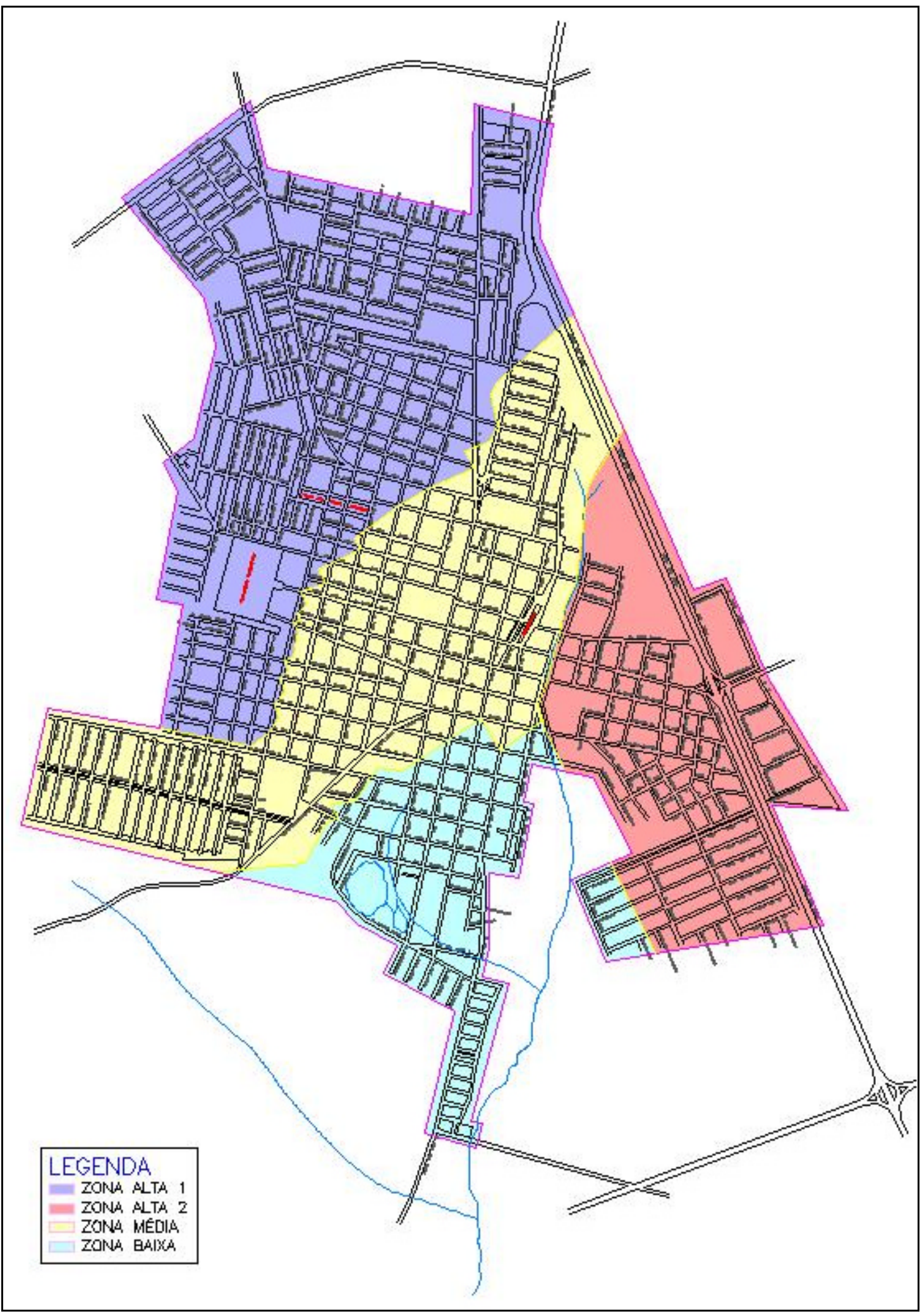

Figura An.1 - Planta da cidade de Guariba 


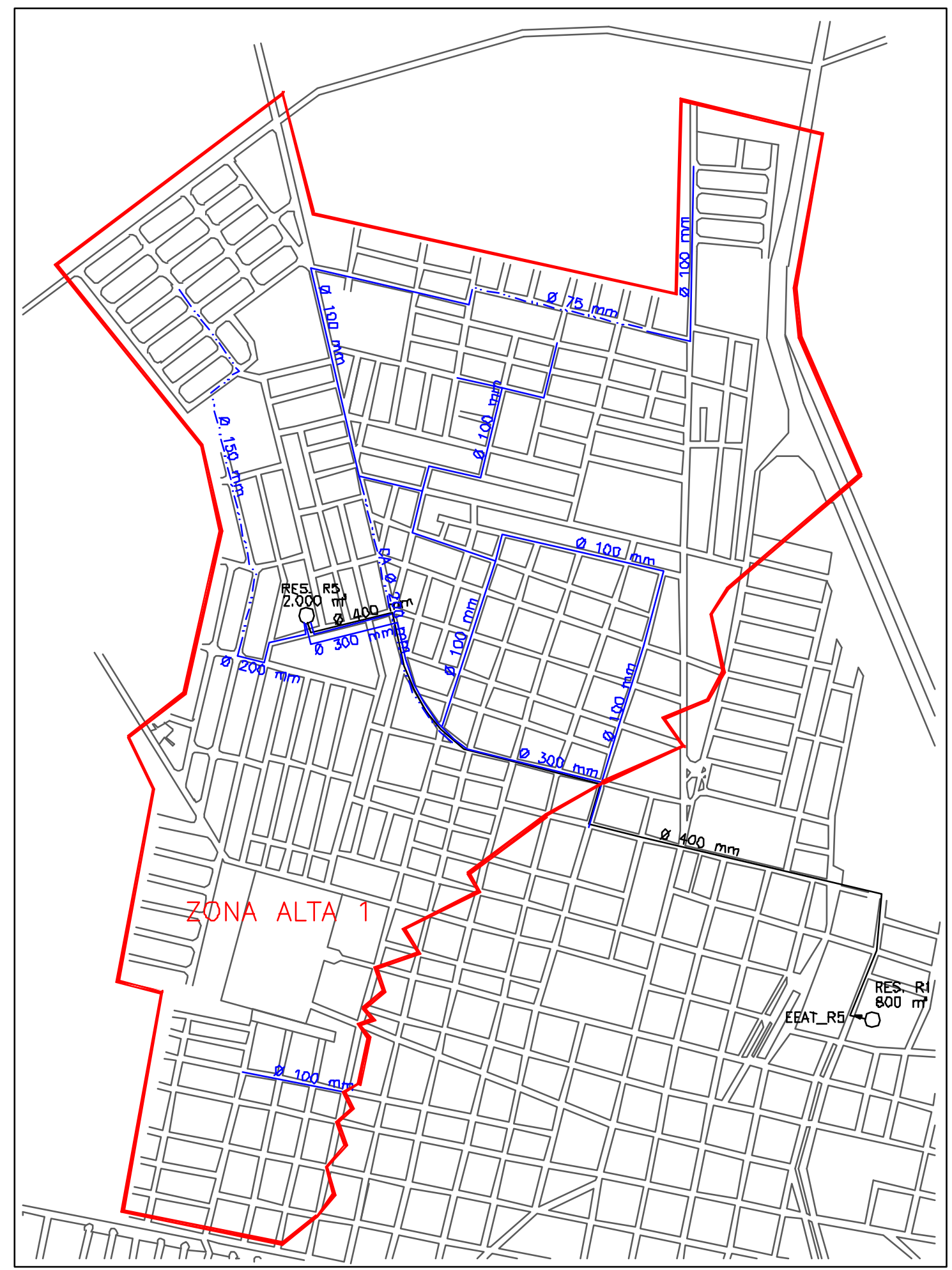

Figura An.2 - Planta do setor Zona Alta I 


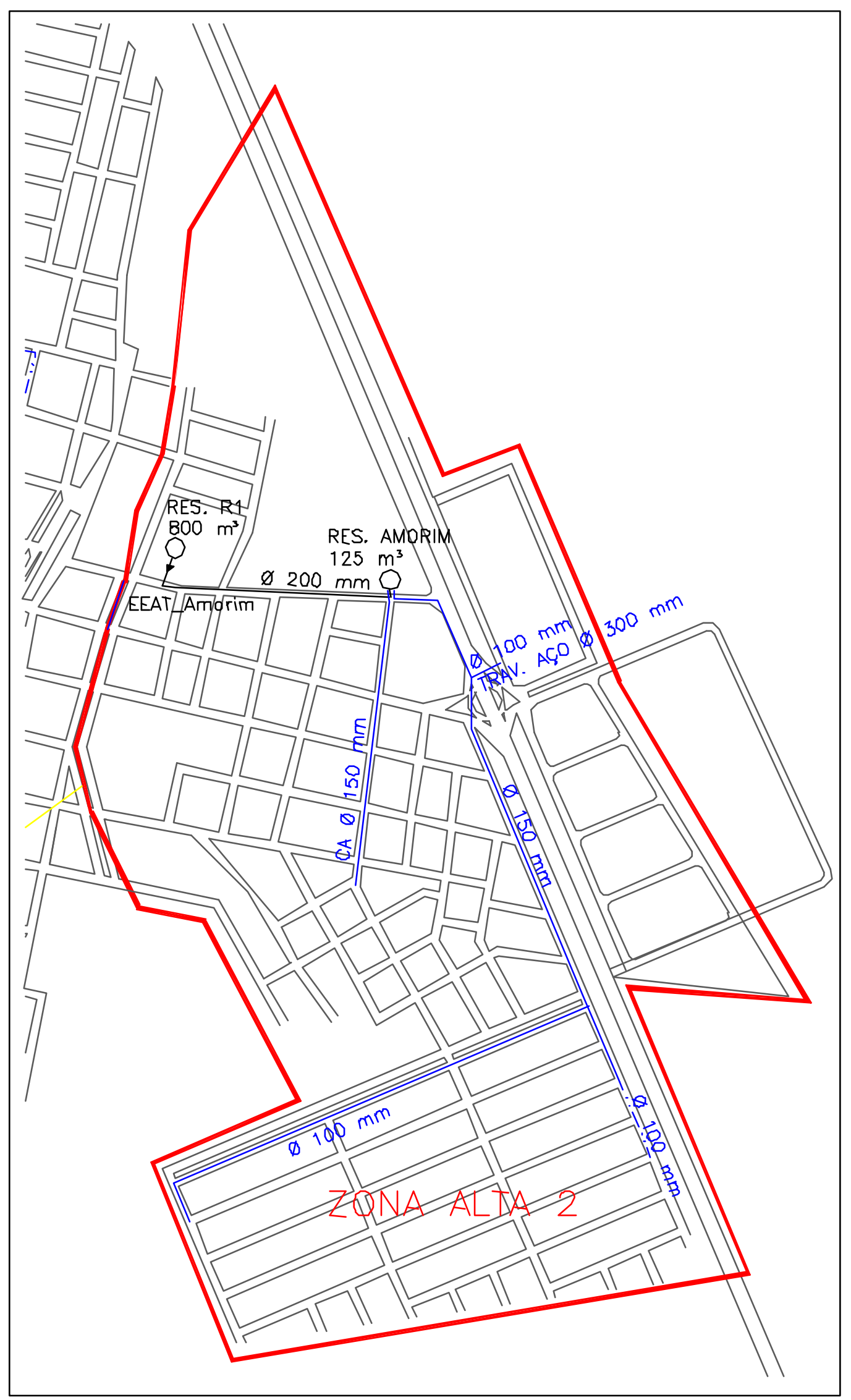

Figura An.3 - Planta do setor Zona Alta II 


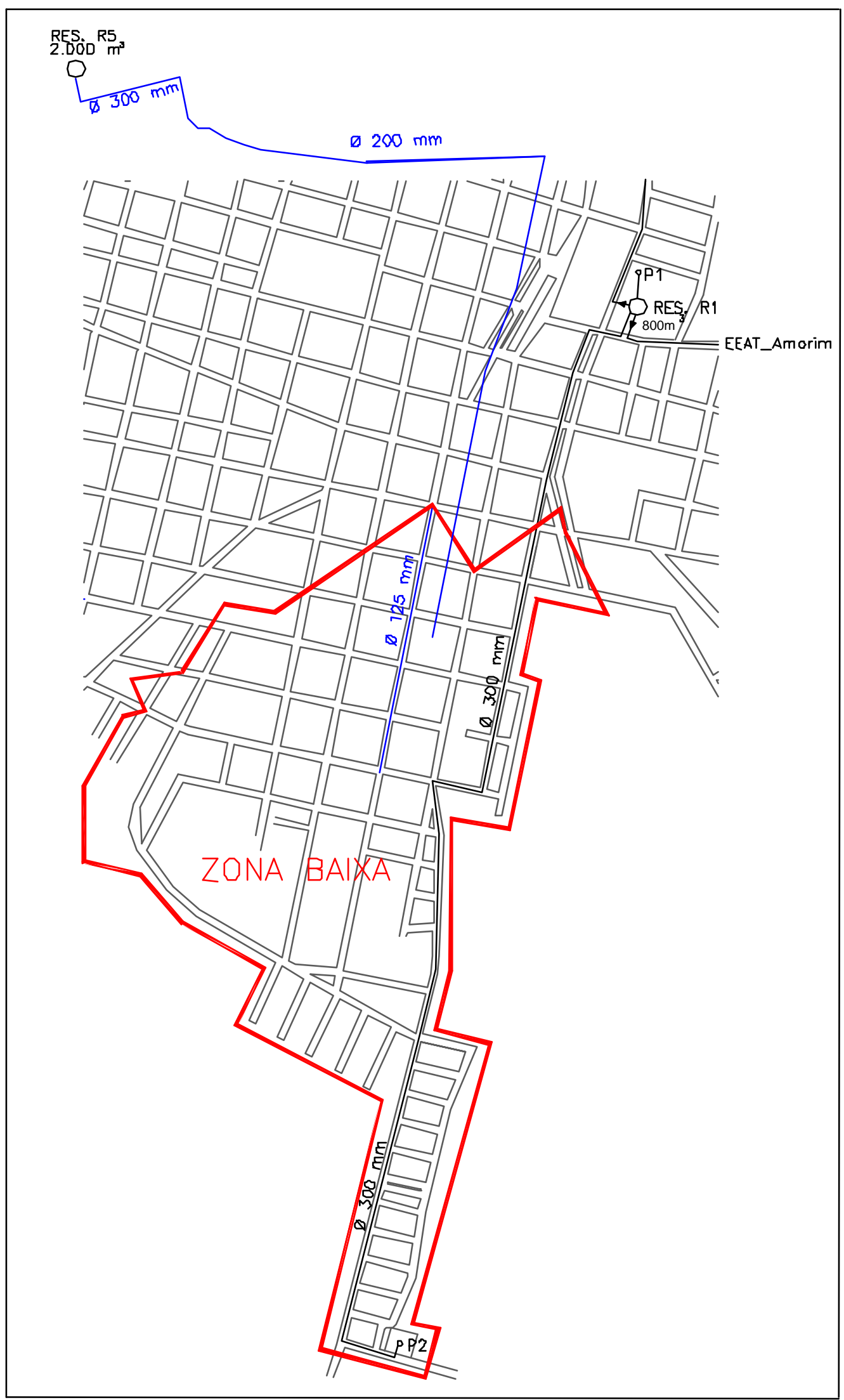

Figura An.4 - Planta do Setor Zona Baixa 


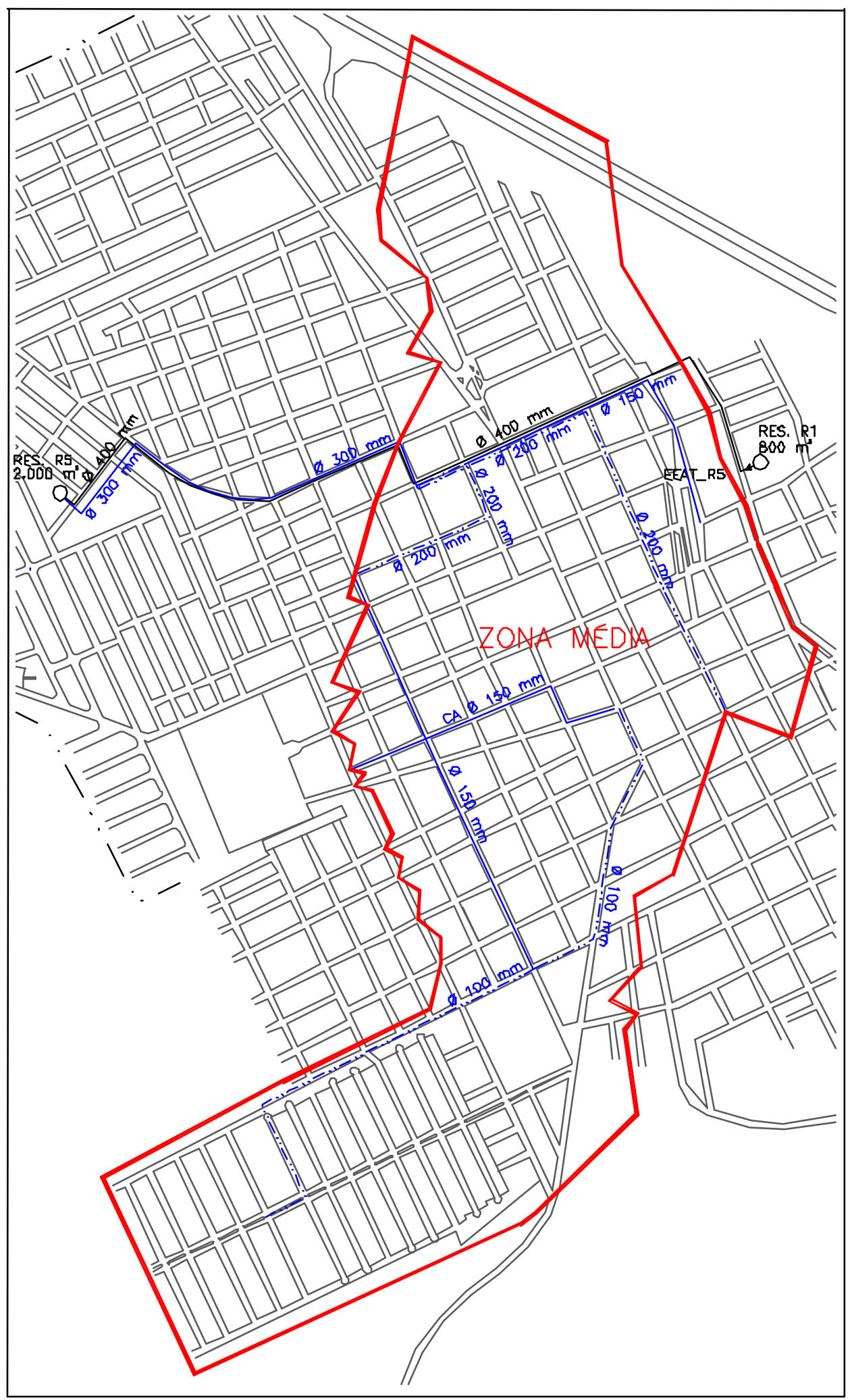

Figura An.5 - Planta do setor Zona Média 


\section{ANEXO B - ILUSTRAÇÃO DA CIDADE DE ITIRAPUÃ}




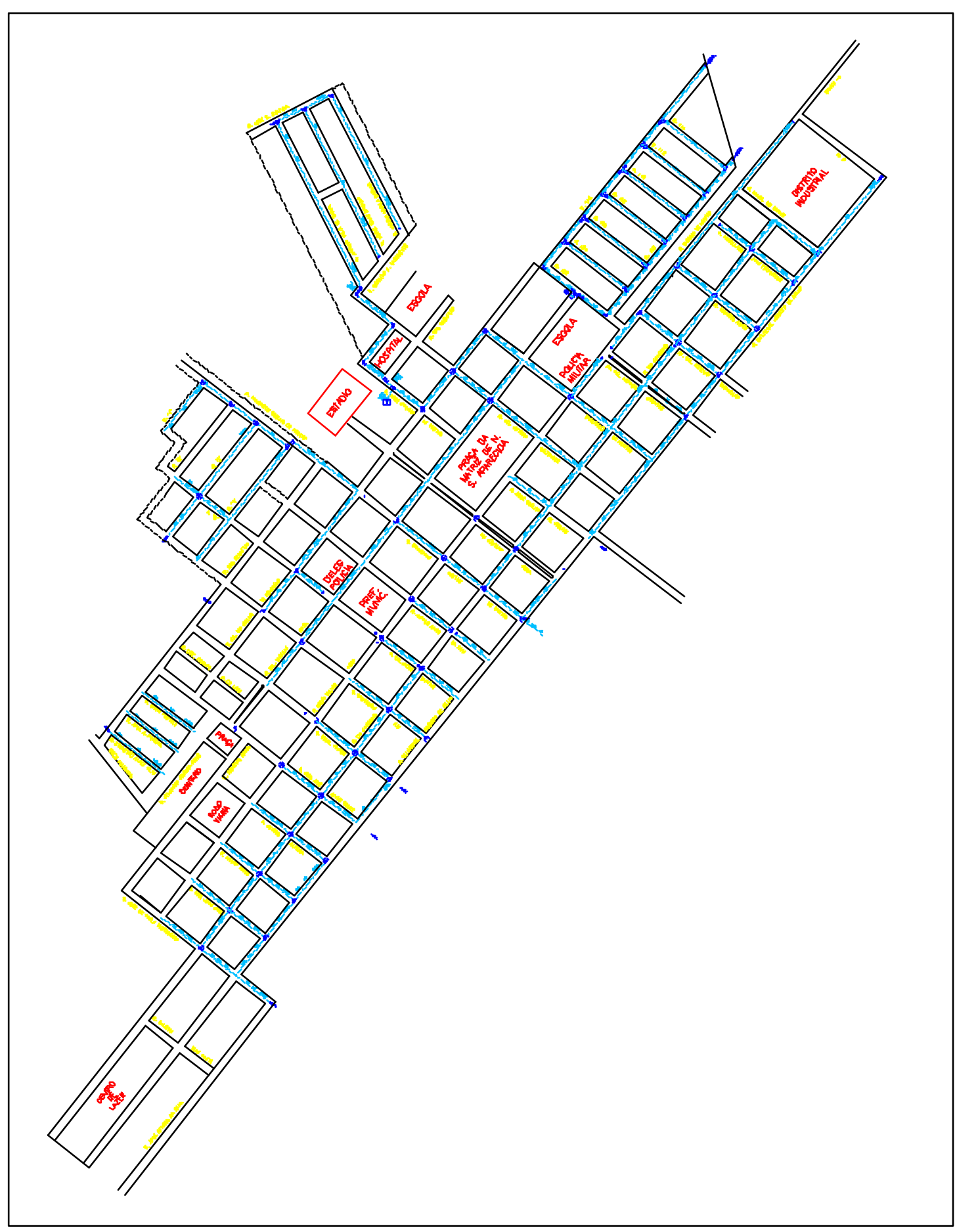

Figura An.6 - Planta da cidade Itirapuã 


\section{REFERÊNCIAS}

ALMANDOZ, J.; CABRERA, E. (2005). Leakage Assessment through Water Distribution Network Simulation. Journal of Water Resources Planning and Management, nov-dec, p. 458-466.

ARAUJO, L. S.; RAMOS H., COELHO S. T. (2006). Pressure Control for Leakage Minimisation in Water Distribution System Management. Water Resources Management, v. 20, p. 133-149.

BASCIÀ, A.; TUCCIARELLI, T. (2003). Simultaneous Zonation and Calibration of Pipe Network Parameters. Journal of Hydraulic Engineering. v. 129, n. 5, p. 394-403, May.

BHAVE, P. R. (1988). Calibrating Water Distribution Network Models. Journal of Environmental Engineering, v. 114, n. 1, p. 120-136, February.

BOULOS, P. F.; WOOD, D. J. (1990). Explicit Calculation of Pipe Network Parameters. Journal of Hydraulic Engineering, v. 116, n.11, p. 1329-1344, November.

BUCHBERGER, S. G.; NADIMPALLI, G. (2004). Leak Estimation in Water Distribution Systems by Statistical Analysis of Flow Readings. Journal of Water Resources Planning and Management, v. 130, n. 4, p 321-329.

DIXON, L. C. W. (1972). Nonlinear Optimisation. The English Universities Press, London.

FUJIWARA, O.; LI, J. (1998). Reliability Analysis of Water Distribution Networks in Consideration of Equity, Redistribution, and Pressure-Dependent Demand. Water Resources Research, v. 34, n. 7, p. 1843-1850, July. 
GERMANOPOULOS, G.; JOWITT, P. W. (1989). Leakage Redution by Excess Pressure Minimization in a Water Supply Network. Proc. Inst. of Civ. Engr., pt. 2, n. 87, p. 195-214, June.

GOLDBERG, D. E. (1989). Genetic Algorithms in Search, Otimization, and Machine Learning Addison-Wesley, Reading, Massachusetts, USA.

GRECO, M.; GIUDICE, G. D. (1999). New Approach to Water Distribution Network Calibration Journal of Hydraulic Engineering, v.125 , n.8 , p. 849-854. August.

HOLNICKI-SZULC, J.; KOLAKOWSKI, P.; NASHER, N. (2005). Leakage Detection in Water Network. Journal of Intelligent Material Systems and Structures. .v.16, p. 207219, March.

JOWITT, P. W. (1995). Effects of Pipe Failures on Water Distribution Networks. In: CABRERA, E. (ed.); VELA, A. F. (ed.): Improving Efficiency and Reliability in Water Distribution Systems, p. 283-302.

KAPELAN, Z. S.; SAVIC, D. A.; WALTERS, G. A. (2004). A hybrid inverse transient model for eakage detection and rougouness calibration in pipe network. Journal of Hydraulic Research, v. 41, n. 5, p. 481-492, february.

KAPELAN, Z. S.; SAVIC, D. A.; WALTERS, G. A. (2005). Optimal Sampling Design Methodologies for Water Distribution Model Calibration. Journal of Hydraulic Engineering, p. 190-200, March.

LACERDA, E. G. M.; CARVALHO, A. C. P. L. F. (1999). Introdução aos Algoritmos Genéticos. In: GALVÃO, C. O. (org.); VALENÇA, M. J. S. (org.): Sistemas Inteligentes: aplicações a recursos hídricos e sistemas ambientais. Ed. Universidade/UFRGS/ABRH, Porto Alegre, p. 99-150. (Coleção ABRH de Recursos Hídricos; 7). 
MARTÍNEZ, F.; CONEJOS, P.; VERCHER, J. (1999). Developing an Integrated Model for Water Distribution System Considering Both Distributed Leakage and Pressure-Dependent Demands. Proceedings of the 26 $6^{\text {th }}$ ASCE Water Resources Planning and Management Division Conference. Tempe. Arizona. p. 1-14, Jul.

MEIER, R. W.; BARKDOLL, B. D. (2000). Sampling Design for Network Model Calibration Using Genetic Algorithmis. Journal of Water Resources Planning and Management, v. 126, n. 4, p 245-250.

MICHALEWICZ, Z. (1992). Genetic Algorithms + Data Structures = Evolutionary Programs. Springer, Germany.

NELDER, J. A.; MEAD, R. (1965). A Simplex Method for Function Minimization. The Computer Journal, v. 7, n. 4, p. 308-313.

ORMSBEE, L. E., WOOD, D. J. (1986). Hydraulic Design Algorithm for Pipe Network. Journal of Hydraulic Engineering, v. 112, n. 12, p. 1195-1207, December.

ORMSBEE, L. E.; LIMGIREDDY, S. (1997). Calibrating Hydraulic Network Models. Journal American Water Works Association, v. 89, n. 2, p. 42-50.

PORTO, R. M. (1998). Hidráulica Básica. 1ª ed., Edusp, São Carlos.

PRESCOTT, S. L.; ULANICKI, B. (2003). Dynamic Modeling of Pressure Reducing Valves. Journal of Hydraulic Engineering, p. 804-812. October.

REDDY, P. V. N.; SHIDHARAN, K.; RAO, P. V. (1996). WLS Method for Parameter Estimation in Water Distribution Network. Journal of Water Resource Planning and Management, v. 122, n. 3, p. 157-164, May/June.

REIS, L. F. R.; PORTO, R. M.; CHAUDHRY, F. H. (1997). Optimal Location of Control Valves in Pipe Network by Genetic Algorithm. Journal of Water Resources Planning and Management, v. 123, n. 6, p. 317-326, Nov/Dec. 
REIS, L. F. R.; CHAUDHRY, F. H. (1999). Hydraulic Characteristics of Pressure Reducing Valves for Maximum Reduction of Leakage in Water Supply Networks. In: Water Industry Systems: Modelling and Optimization Applications Vol I, p.259-267 _ University of Exeter, UK.

ROSSMAN, L. A. (2000). EPANET 2 users manual. U.S. Environmental Protection Agency, Cincinnati, Ohio.

SERETE S. A. ENGENHARIA. (1976). Relatório Técnico Preliminar do Sistema de Abastecimento de Água de Itirapuã. RTP-714-01-20-07-001.

SILVA, F. G. B. (2003). Estudos de Calibração de Redes de Distribuição de Água através de Algoritmos Genéticos. São Carlos. 234 p. Tese (Doutorado) - Escola de Engenharia de São Carlos, Universidade de São Paulo.

SOARES, A. K.; (2003). Calibração de Modelos de Redes de Distribuição de Água para Abastecimento Considerando Vazamentos e Demandas Dirigidas pela Pressão. São Carlos. 153 p. Dissertação (Mestrado) - Escola de Engenharia de São Carlos, Universidade de são Paulo.

SUBRAHMANYAM, M. B. (1989). An Extension of the Simplex Method to Constrained Nonlinear Optimization. Journal of Optimization Theory and Applications, v. 62 , n. 2, p. 311-319, Aug.

TABESH, M.; KARIMZADEH, A. (2000). Optimum Design of Reliable Distribution Systems Considering Pressure Dependency of Outflows. In: SAVIC, D. A. (ed.); WALTERS, G. A. (ed.): Water Network Modeling for Optimal Design and Management, p. 211-220, Sept.

TODINI, E. (1999).Using a Kalman Filter approach for Looped Water Distribution Network Calibration. In: Water Industry Systems: Modelling and Optimization Applications, Vol I, p. 327-336 - University of Exeter, UK. 
TSUTIYA, M. T. (2004). Abastecimento de Água. $1^{\text {a }}$ ed., Departamento de Engenharia Hidráulica e Sanitária da Escola Politécnica da Universidade de São Paulo. 643 p.

TUCCIARELLI, T.; CRIMINISI, A.; TERMINI, D. (1999). Leak Analysis in Pipeline Systems by Means of Optimal Valve Regulation. Journal of Hydraulic Engineering, v. 125, n. 3, p. 277-285, Mar.

ULANICKI, B.; BOUNDS, P. L. M.; RANCE, J. P.; REYNOLDS, L. (2000). Open and Closed Loop Pressure Control for Leakage Reduction. Urban Water, v. 2, p. 105-114, September.

VAIRAVAMOORTHY, K.; LUMBERS, J. (1998). Leakage Reduction in Water Distribution Systems: Optimal Valve Control. Journal of Hydraulic Engineering, v. 124, n. 11, p. 1146-1154, November.

VÍTKOVSKÝ, J. P.; SIMPSON, A. R.; LAMBERT, M. F. (2000). Leak Detection and Calibration Using Transient and Genetic Algorithms. Journal of Water Resources Planning and Management, v. 126, n. 4, p. 262-265, July/August.

VÍTKOVSKÝ, J. P.; SIMPSON, A. R.; LAMBERT, M. F. (2003). Leak Detection and Calibration Using Transient and Genetic Algorithms. Journal of Water Resources Planning and Management, v. 129, n. 6, p. 480-492, November.

WALSKY, T. M. (1983). Technique for Calibrating Network Models. Journal of Water Resources Planning and Management, v. 109, n. 4, p. 360-372, October.

WALSKY, T. M. (1986). Case Study: Pipe Network Model Calibration Issues. Journal of Water Resources Planning and Management, v. 112, n. 2, p. 238-249, April.

WU, Z. Y.; SIMPSON, A. R. (2001). Competent Genetic-Evolutionary Optimization of Water Distribution Systems. Journal of Computing in Civil Engineering, v. 15, n. 2, p. 89-101, April. 
XU, C.; GOULTER, I. C. (1999). Reliability-Based Optimal Design of Water Distribution Networks. Journal of Water Resources Planning and Management, v. 125, n. 6, p. 352-362, November/December

ZYL, J. E.; SAVIC, D. A.; WALTERS, G. A. (2004). Operational Optimization of Water Distribution Systems Using a Hybrid Genetic Algorithm. Journal of Water Resource Planning and Management, v. 130, n. 2, p. 160-170, March. 
APÊNDICE A - Curva de Nível e Representação

Gráfica 3D do Setor Zona Média de Guariba e

Itirapuã 


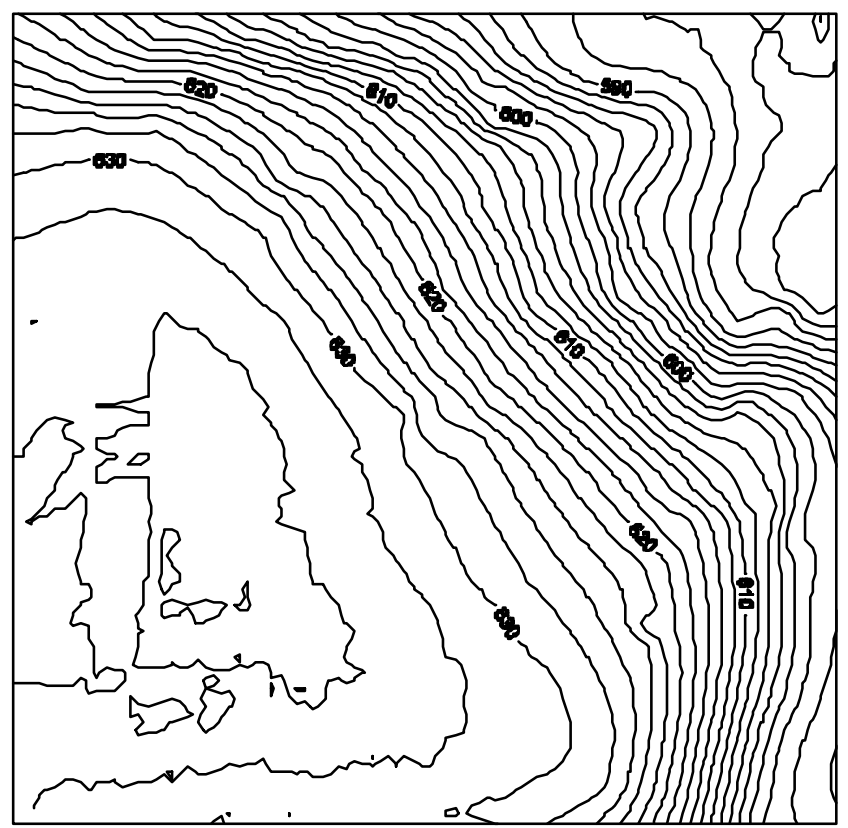

Ap.1 - Curvas de nível respectivas ao setor Zona Média de Guariba

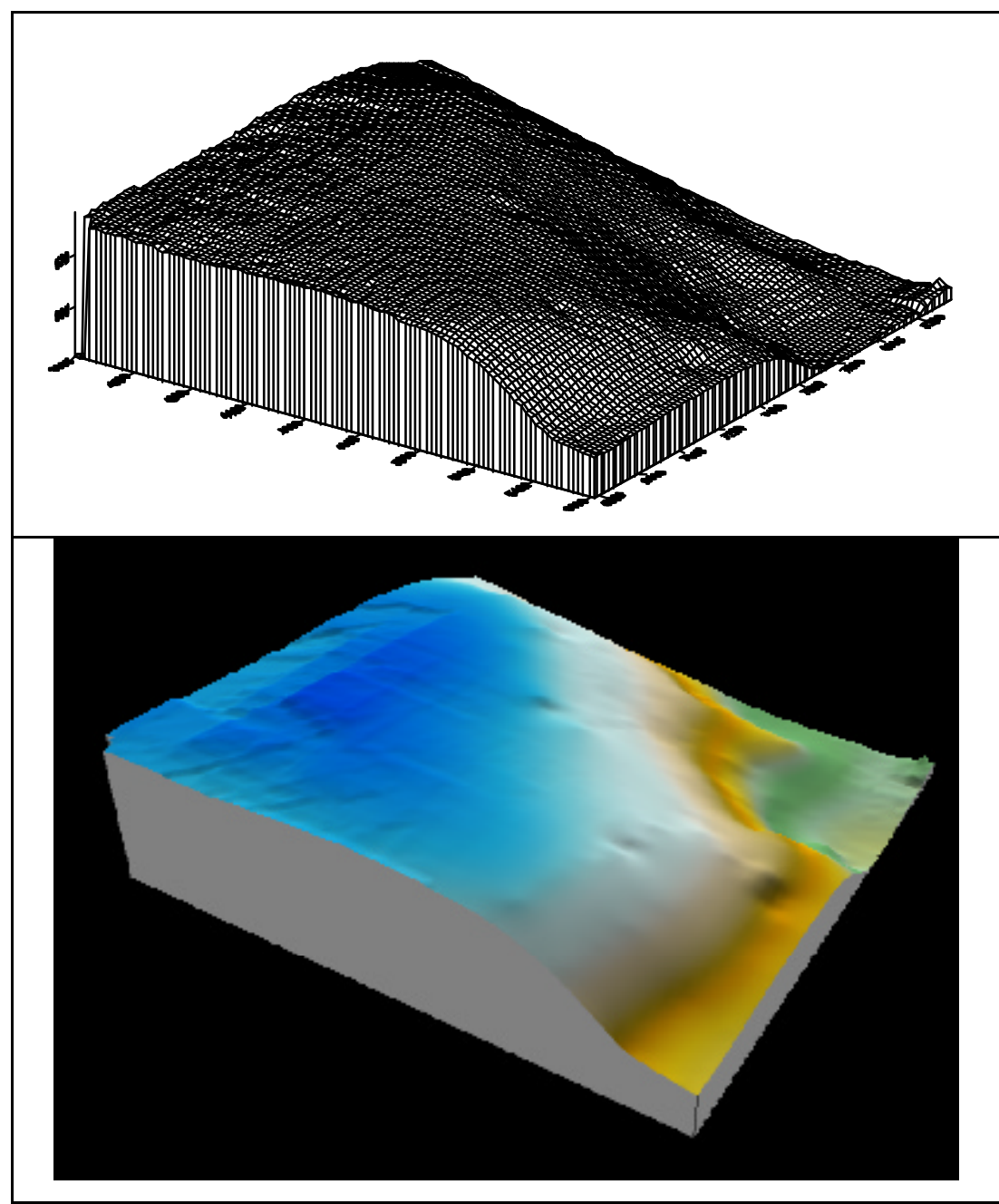

Ap.2 - Representação 3D da topografia do setor Zona Média de Guariba 


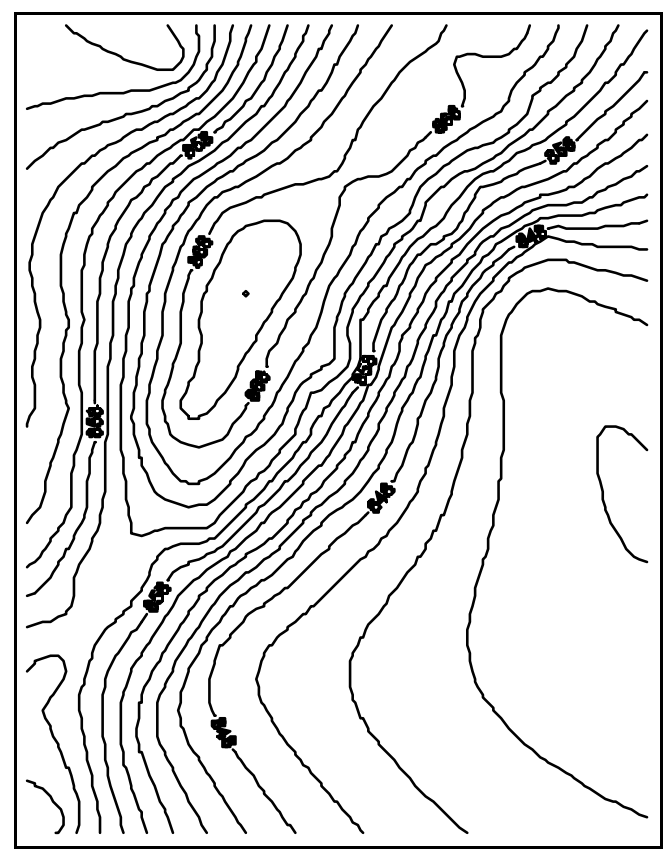

Ap.3 - Curvas de nível respectivas à cidade de Iitrapuã

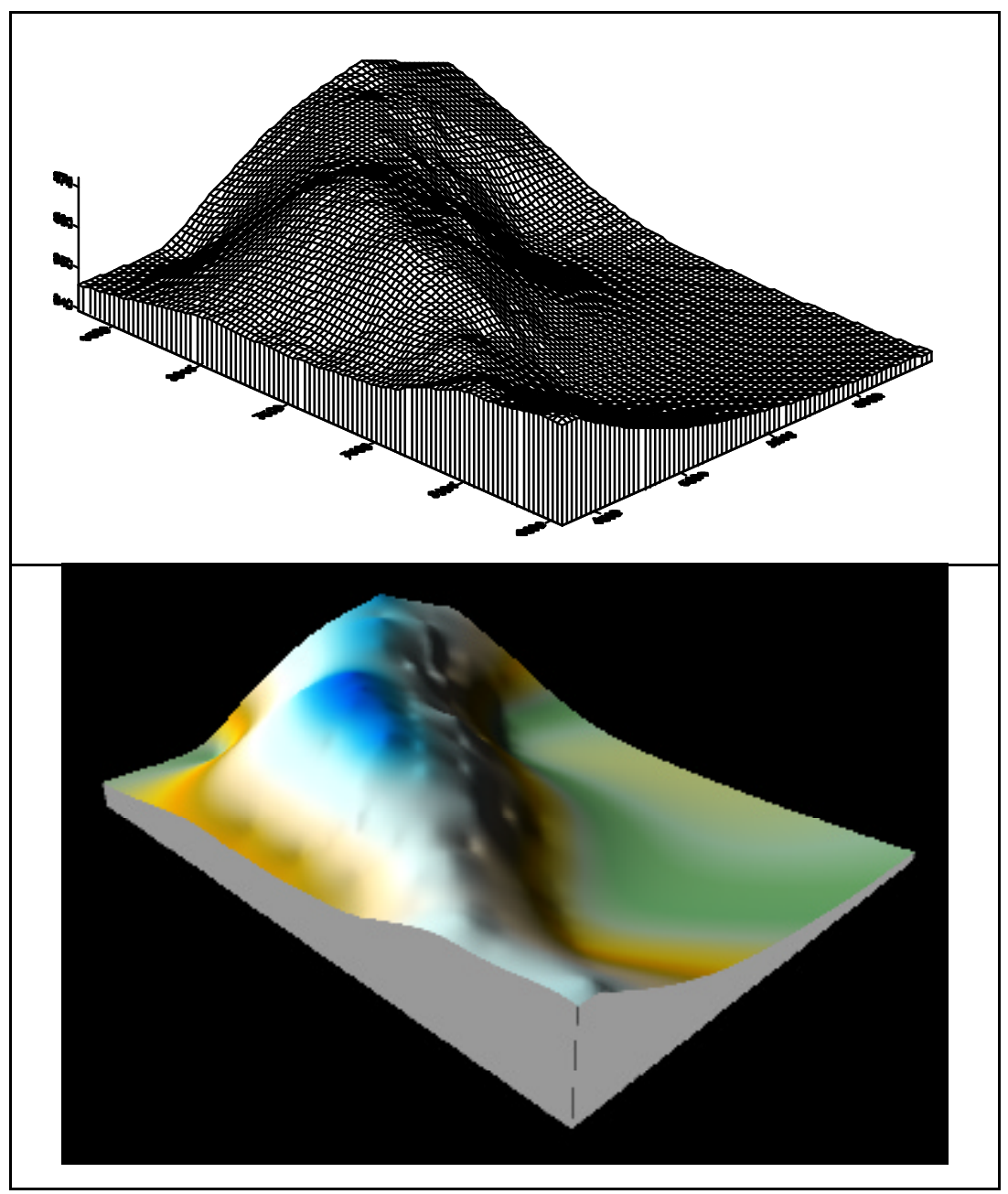

Figura Ap.4 - Representação 3D da topografia da cidade de Itirapuã 
APÊNDICE B - Informações da Setorização Rede de Abastecimento de Água da Cidade de Guariba 
Tabela Ap.1 - Características das tubulações da rede do setor Zona Média de Guariba

\begin{tabular}{|c|c|c|c|c|c|c|}
\hline Tubo & Nó Inicial & Nó Final & Comprimento $(\mathrm{m})$ & Diâmetro (mm) & $\begin{array}{c}\text { Rugosidade } \\
(\mathrm{mm})\end{array}$ & Setor \\
\hline 1 & 40 & 21 & 0.2 & 50 & 3.5 & 4 \\
\hline 2 & 39 & 15 & 0.2 & 100 & 3.5 & 4 \\
\hline 3 & 41 & 8 & 0.2 & 75 & 3.5 & 4 \\
\hline 4 & 59 & 61 & 0.2 & 50 & 3.5 & 4 \\
\hline 5 & 60 & 50 & 0.2 & 50 & 3.5 & 4 \\
\hline 6 & 64 & 65 & 0.2 & 100 & 3.5 & 4 \\
\hline 7 & 65 & 66 & 0.2 & 100 & 3.5 & 4 \\
\hline 8 & 83 & 74 & 0.2 & 50 & 3.5 & 4 \\
\hline 9 & 98 & 99 & 0.2 & 50 & 3.5 & 4 \\
\hline 10 & 101 & 102 & 0.2 & 50 & 3.5 & 4 \\
\hline 11 & 70 & 38 & 136.19 & 50 & 0.0015 & 1 \\
\hline 12 & 116 & 113 & 0.2 & 50 & 3.5 & 4 \\
\hline 13 & 270 & 170 & 87.64 & 75 & 3.5 & 4 \\
\hline 14 & 271 & 171 & 68.1 & 50 & 3.5 & 4 \\
\hline 15 & 39 & 21 & 81.89 & 100 & 0.0015 & 1 \\
\hline 16 & 127 & 125 & 0.2 & 50 & 3.5 & 4 \\
\hline 17 & 40 & 19 & 186 & 50 & 0.0015 & 1 \\
\hline 18 & 134 & 133 & 0.2 & 50 & 3.5 & 4 \\
\hline 19 & 167 & 168 & 0.2 & 150 & 3.5 & 4 \\
\hline 20 & 212 & 211 & 0.2 & 100 & 3.5 & 4 \\
\hline 21 & 222 & 223 & 0.2 & 60 & 3.5 & 4 \\
\hline 22 & 31 & 62 & 0.2 & 100 & 3.5 & 4 \\
\hline 23 & 247 & 194 & 0.2 & 75 & 3.5 & 4 \\
\hline 24 & 249 & 193 & 0.2 & 50 & 3.5 & 4 \\
\hline 25 & 193 & 278 & 0.2 & 75 & 3.5 & 4 \\
\hline 26 & 56 & 93 & 0.2 & 50 & 3.5 & 4 \\
\hline 27 & 162 & 140 & 0.2 & 75 & 3.5 & 4 \\
\hline 28 & 144 & 173 & 0.2 & 50 & 3.5 & 4 \\
\hline 29 & 255 & 144 & 0.2 & 50 & 3.5 & 4 \\
\hline 30 & 156 & 267 & 0.2 & 150 & 3.5 & 4 \\
\hline 31 & 163 & 269 & 0.2 & 50 & 3.5 & 4 \\
\hline 32 & 268 & 163 & 0.2 & 150 & 3.5 & 4 \\
\hline 33 & 175 & 271 & 0.2 & 50 & 3.5 & 4 \\
\hline 34 & 171 & 270 & 0.2 & 75 & 3.5 & 4 \\
\hline 35 & 265 & 272 & 0.2 & 50 & 3.5 & 4 \\
\hline 36 & 273 & 176 & 0.2 & 50 & 3.5 & 4 \\
\hline 37 & 274 & 211 & 0.2 & 50 & 3.5 & 4 \\
\hline 38 & 276 & 186 & 0.2 & 75 & 3.5 & 4 \\
\hline 39 & 275 & 186 & 0.2 & 75 & 3.5 & 4 \\
\hline 40 & 259 & 277 & 0.2 & 32 & 3.5 & 4 \\
\hline 41 & 279 & 229 & 0.2 & 150 & 3.5 & 4 \\
\hline 42 & 2 & 1 & 196 & 50 & 0.0015 & 1 \\
\hline 43 & 2 & 3 & 202 & 50 & 0.0015 & 1 \\
\hline 44 & 8 & 5 & 71 & 50 & 0.0015 & 1 \\
\hline 45 & 2 & 5 & 54 & 50 & 0.0015 & 1 \\
\hline 46 & 41 & 11 & 55.04 & 75 & 0.0015 & 1 \\
\hline 47 & 29 & 30 & 186 & 50 & 0.0015 & 1 \\
\hline 48 & 45 & 46 & 72.14 & 50 & 0.0015 & 1 \\
\hline 49 & 46 & 47 & 81.22 & 50 & 0.0015 & 1 \\
\hline
\end{tabular}




\begin{tabular}{|c|c|c|c|c|c|c|}
\hline Tubo & Nó Inicial & Nó Final & Comprimento (m) & Diâmetro $(\mathbf{m m})$ & $\begin{array}{c}\text { Rugosidade } \\
\text { (mm) }\end{array}$ & Setor \\
\hline 50 & 46 & 44 & 58 & 50 & 0.0015 & 1 \\
\hline 51 & 44 & 43 & 72.14 & 50 & 0.0015 & 1 \\
\hline 52 & 44 & 50 & 74 & 50 & 0.0015 & 1 \\
\hline 53 & 50 & 49 & 54 & 50 & 0.0015 & 1 \\
\hline 54 & 51 & 53 & 72.14 & 50 & 0.0015 & 1 \\
\hline 55 & 53 & 50 & 40 & 50 & 0.0015 & 1 \\
\hline 56 & 53 & 54 & 92 & 50 & 0.0015 & 1 \\
\hline 57 & 54 & 52 & 72.14 & 50 & 0.0015 & 1 \\
\hline 58 & 5 & 4 & 203 & 50 & 0.0015 & 1 \\
\hline 59 & 5 & 6 & 196 & 50 & 0.0015 & 7 \\
\hline 60 & 60 & 55 & 53.08 & 50 & 0.0015 & 1 \\
\hline 61 & 55 & 58 & 83.91 & 50 & 0.0015 & 1 \\
\hline 62 & 105 & 56 & 96.69 & 50 & 0.0015 & 1 \\
\hline 63 & 26 & 29 & 54 & 100 & 0.0015 & 1 \\
\hline 64 & 55 & 59 & 115.24 & 50 & 0.0015 & 1 \\
\hline 65 & 24 & 26 & 54 & 75 & 0.0015 & 1 \\
\hline 66 & 29 & 31 & 198 & 50 & 0.0015 & 1 \\
\hline 67 & 31 & 34 & 77.84 & 100 & 0.0015 & 1 \\
\hline 68 & 62 & 21 & 262 & 100 & 0.0015 & 1 \\
\hline 69 & 64 & 34 & 144.28 & 100 & 0.0015 & 1 \\
\hline 70 & 54 & 63 & 81.09 & 50 & 0.0015 & 1 \\
\hline 71 & 8 & 7 & 196 & 50 & 0.0015 & 1 \\
\hline 72 & 8 & 9 & 204 & 50 & 0.0015 & 1 \\
\hline 73 & 36 & 227 & 198 & 50 & 0.0015 & 1 \\
\hline 74 & 63 & 67 & 93.75 & 50 & 0.0015 & 1 \\
\hline 75 & 63 & 68 & 79.27 & 50 & 0.0015 & 1 \\
\hline 76 & 68 & 69 & 94.23 & 50 & 0.0015 & 1 \\
\hline 77 & 69 & 67 & 79.24 & 50 & 0.0015 & 1 \\
\hline 78 & 11 & 10 & 205 & 50 & 0.0015 & 1 \\
\hline 79 & 61 & 71 & 85.07 & 50 & 0.0015 & 1 \\
\hline 80 & 71 & 75 & 65 & 50 & 0.0015 & 1 \\
\hline 81 & 75 & 72 & 97.37 & 50 & 0.0015 & 1 \\
\hline 82 & 75 & 83 & 54.46 & 50 & 0.0015 & 1 \\
\hline 83 & 74 & 73 & 97.37 & 50 & 0.0015 & 1 \\
\hline 84 & 74 & 77 & 70.9 & 50 & 0.0015 & 1 \\
\hline 85 & 77 & 76 & 192.2 & 50 & 0.0015 & 1 \\
\hline 86 & 74 & 79 & 90.17 & 50 & 0.0015 & 1 \\
\hline 87 & 71 & 80 & 49.01 & 50 & 0.0015 & 1 \\
\hline 88 & 80 & 79 & 106.46 & 50 & 0.0015 & 1 \\
\hline 89 & 80 & 81 & 139.49 & 50 & 0.0015 & 1 \\
\hline 90 & 77 & 86 & 104.92 & 50 & 0.0015 & 1 \\
\hline 91 & 86 & 85 & 87.38 & 50 & 0.0015 & 1 \\
\hline 92 & 86 & 84 & 26.23 & 50 & 0.0015 & 1 \\
\hline 93 & 77 & 78 & 105.55 & 50 & 0.0015 & 1 \\
\hline 94 & 78 & 79 & 67.5 & 50 & 0.0015 & 1 \\
\hline 95 & 79 & 82 & 104.4 & 50 & 0.0015 & 1 \\
\hline 96 & 82 & 81 & 73.45 & 50 & 0.0015 & 1 \\
\hline 97 & 78 & 87 & 102.67 & 50 & 0.0015 & 1 \\
\hline 98 & 87 & 82 & 60.63 & 50 & 0.0015 & 1 \\
\hline 99 & 93 & 92 & 98.34 & 50 & 0.0015 & 7 \\
\hline 100 & 93 & 94 & 106.44 & 50 & 0.0015 & 1 \\
\hline
\end{tabular}




\begin{tabular}{|c|c|c|c|c|c|c|}
\hline Tubo & Nó Inicial & Nó Final & Comprimento (m) & Diâmetro $(\mathrm{mm})$ & \begin{tabular}{|c} 
Rugosidade \\
$(\mathrm{mm})$
\end{tabular} & Setor \\
\hline 101 & 94 & 90 & 95.59 & 50 & 0.0015 & 1 \\
\hline 102 & 90 & 89 & 106.01 & 50 & 0.0015 & 1 \\
\hline 103 & 89 & 88 & 79.21 & 50 & 0.0015 & 1 \\
\hline 104 & 88 & 67 & 98.82 & 50 & 0.0015 & 1 \\
\hline 105 & 88 & 91 & 105.84 & 50 & 0.0015 & 1 \\
\hline 106 & 91 & 90 & 79.18 & 50 & 0.0015 & 1 \\
\hline 107 & 94 & 95 & 66.11 & 50 & 0.0015 & 1 \\
\hline 108 & 90 & 96 & 65.93 & 50 & 0.0015 & 1 \\
\hline 109 & 91 & 97 & 66.09 & 50 & 0.0015 & 1 \\
\hline 110 & 97 & 96 & 79.16 & 50 & 0.0015 & 1 \\
\hline 111 & 96 & 95 & 96.69 & 50 & 0.0015 & 1 \\
\hline 112 & 95 & 98 & 115.06 & 50 & 0.0015 & 1 \\
\hline 113 & 96 & 100 & 117.79 & 50 & 0.0015 & 1 \\
\hline 114 & 97 & 101 & 146.63 & 50 & 0.0015 & 1 \\
\hline 115 & 11 & 12 & 196 & 50 & 0.0015 & 1 \\
\hline 116 & 11 & 13 & 59.04 & 100 & 0.0015 & 1 \\
\hline 117 & 102 & 103 & 86.06 & 50 & 3.5 & 4 \\
\hline 118 & 103 & 99 & 86.69 & 50 & 3.5 & 4 \\
\hline 119 & 38 & 104 & 189.99 & 50 & 0.0015 & 1 \\
\hline 120 & 104 & 92 & 95.65 & 50 & 0.0015 & 1 \\
\hline 121 & 104 & 105 & 98.1 & 50 & 0.0015 & 1 \\
\hline 122 & 102 & 157 & 122.78 & 50 & 3.5 & 4 \\
\hline 123 & 94 & 106 & 97.87 & 50 & 0.0015 & 1 \\
\hline 124 & 106 & 105 & 106.8 & 50 & 0.0015 & 1 \\
\hline 125 & 105 & 108 & 86.22 & 50 & 0.0015 & 1 \\
\hline 126 & 108 & 107 & 107.01 & 50 & 0.0015 & 1 \\
\hline 127 & 107 & 106 & 83.72 & 50 & 0.0015 & 1 \\
\hline 128 & 110 & 111 & 86.6 & 50 & 0.0015 & 1 \\
\hline 129 & 111 & 109 & 94.83 & 50 & 0.0015 & 1 \\
\hline 130 & 111 & 107 & 99.6 & 50 & 0.0015 & 1 \\
\hline 131 & 112 & 113 & 101.56 & 50 & 0.0015 & 1 \\
\hline 132 & 113 & 114 & 76.16 & 50 & 0.0015 & 1 \\
\hline 133 & 114 & 95 & 104.59 & 50 & 0.0015 & 1 \\
\hline 134 & 13 & 14 & 205 & 50 & 0.0015 & 1 \\
\hline 135 & 13 & 15 & 196 & 100 & 0.0015 & 1 \\
\hline 136 & 117 & 165 & 92.74 & 75 & 3.5 & 4 \\
\hline 137 & 19 & 20 & 186 & 50 & 0.0015 & 1 \\
\hline 138 & 115 & 118 & 61.63 & 50 & 3.5 & 4 \\
\hline 139 & 118 & 119 & 98.75 & 75 & 3.5 & 4 \\
\hline 140 & 119 & 116 & 82.91 & 50 & 0.0015 & 1 \\
\hline 141 & 119 & 120 & 80.92 & 75 & 3.5 & 4 \\
\hline 142 & 120 & 99 & 112.64 & 50 & 3.5 & 4 \\
\hline 143 & 117 & 161 & 85.82 & 50 & 3.5 & 4 \\
\hline 144 & 48 & 122 & 246.01 & 100 & 0.005 & 2 \\
\hline 145 & 108 & 123 & 97.76 & 50 & 0.0015 & 1 \\
\hline 146 & 19 & 17 & 54 & 75 & 0.0015 & 1 \\
\hline 147 & 104 & 123 & 91.34 & 50 & 0.0015 & 1 \\
\hline 148 & 17 & 18 & 186 & 50 & 0.0015 & 1 \\
\hline 149 & 81 & 124 & 117.8 & 50 & 0.0015 & 1 \\
\hline 150 & 126 & 125 & 80.63 & 37 & 0.025 & 3 \\
\hline 151 & 125 & 124 & 194.25 & 50 & 0.025 & 3 \\
\hline
\end{tabular}




\begin{tabular}{|c|c|c|c|c|c|c|}
\hline Tubo & Nó Inicial & Nó Final & Comprimento (m) & Diâmetro $(\mathrm{mm})$ & $\begin{array}{l}\text { Rugosidade } \\
\text { (mm) }\end{array}$ & Setor \\
\hline 152 & 17 & 16 & 186 & 50 & 0.0015 & 1 \\
\hline 153 & 127 & 129 & 103.13 & 50 & 0.005 & 2 \\
\hline 154 & 129 & 128 & 106.86 & 50 & 0.005 & 2 \\
\hline 155 & 128 & 124 & 133.58 & 50 & 0.0015 & 1 \\
\hline 156 & 17 & 22 & 54 & 75 & 0.0015 & 1 \\
\hline 157 & 122 & 130 & 117.1 & 100 & 0.005 & 2 \\
\hline 158 & 131 & 108 & 81.64 & 50 & 0.0015 & 1 \\
\hline 159 & 103 & 157 & 39.59 & 50 & 3.5 & 4 \\
\hline 160 & 22 & 23 & 186 & 50 & 0.0015 & 1 \\
\hline 161 & 129 & 134 & 81.83 & 50 & 0.0015 & 1 \\
\hline 162 & 128 & 133 & 127.25 & 50 & 0.0015 & 1 \\
\hline 163 & 132 & 118 & 110.63 & 150 & 3.5 & 4 \\
\hline 164 & 129 & 135 & 94.24 & 50 & 0.005 & 2 \\
\hline 165 & 136 & 137 & 102.13 & 50 & 0.005 & 2 \\
\hline 166 & 137 & 134 & 107.79 & 50 & 0.025 & 3 \\
\hline 167 & 132 & 139 & 45.94 & 50 & 0.0015 & 1 \\
\hline 168 & 106 & 114 & 66.16 & 50 & 0.0015 & 1 \\
\hline 169 & 216 & 214 & 138 & 50 & 0.0015 & 1 \\
\hline 170 & 111 & 112 & 66.36 & 50 & 0.0015 & 1 \\
\hline 171 & 107 & 113 & 66.26 & 50 & 0.0015 & 1 \\
\hline 172 & 132 & 134 & 129.6 & 50 & 0.005 & 2 \\
\hline 173 & 132 & 130 & 271.9 & 100 & 0.005 & 2 \\
\hline 174 & 137 & 37 & 89.76 & 50 & 0.025 & 3 \\
\hline 175 & 119 & 143 & 71.05 & 50 & 3.5 & 4 \\
\hline 176 & 37 & 254 & 105.02 & 75 & 0.005 & 2 \\
\hline 177 & 144 & 143 & 78.53 & 150 & 3.5 & 4 \\
\hline 178 & 278 & 259 & 81.2 & 75 & 3.5 & 4 \\
\hline 179 & 146 & 145 & 76.7 & 50 & 3.5 & 4 \\
\hline 180 & 143 & 145 & 104.58 & 50 & 3.5 & 4 \\
\hline 181 & 145 & 142 & 217.52 & 50 & 3.5 & 4 \\
\hline 182 & 137 & 149 & 110.08 & 50 & 3.5 & 4 \\
\hline 183 & 149 & 148 & 100.56 & 50 & 3.5 & 4 \\
\hline 184 & 149 & 147 & 51.08 & 50 & 3.5 & 4 \\
\hline 185 & 148 & 150 & 97.89 & 50 & 3.5 & 4 \\
\hline 186 & 150 & 142 & 90.72 & 50 & 0.025 & 3 \\
\hline 187 & 142 & 152 & 96.57 & 50 & 3.5 & 4 \\
\hline 188 & 152 & 151 & 91.76 & 50 & 3.5 & 4 \\
\hline 189 & 151 & 150 & 96.2 & 50 & 3.5 & 4 \\
\hline 190 & 152 & 154 & 101.33 & 50 & 3.5 & 4 \\
\hline 191 & 154 & 153 & 93.06 & 50 & 3.5 & 4 \\
\hline 192 & 153 & 151 & 102.06 & 50 & 3.5 & 4 \\
\hline 193 & 139 & 138 & 40 & 50 & 0.0015 & 1 \\
\hline 194 & 162 & 42 & 54 & 75 & 0.0015 & 1 \\
\hline 195 & 102 & 155 & 90.95 & 50 & 3.5 & 4 \\
\hline 196 & 158 & 160 & 74.53 & 50 & 3.5 & 4 \\
\hline 197 & 160 & 157 & 99.76 & 50 & 3.5 & 4 \\
\hline 198 & 160 & 161 & 52.31 & 50 & 3.5 & 4 \\
\hline 199 & 161 & 159 & 73.45 & 50 & 3.5 & 4 \\
\hline 200 & 140 & 36 & 54 & 75 & 0.0015 & 1 \\
\hline 201 & 161 & 164 & 85.29 & 50 & 3.5 & 4 \\
\hline 202 & 89 & 93 & 94.3 & 50 & 0.0015 & 1 \\
\hline
\end{tabular}




\begin{tabular}{|c|c|c|c|c|c|c|}
\hline Tubo & Nó Inicial & Nó Final & Comprimento (m) & Diâmetro (mm) & $\begin{array}{c}\text { Rugosidade } \\
(\mathrm{mm})\end{array}$ & Setor \\
\hline 203 & 164 & 165 & 89.02 & 150 & 3.5 & 4 \\
\hline 204 & 165 & 166 & 62.97 & 75 & 3.5 & 4 \\
\hline 205 & 121 & 114 & 96.21 & 50 & 0.0015 & 1 \\
\hline 206 & 22 & 24 & 54 & 75 & 0.0015 & 1 \\
\hline 207 & 167 & 48 & 544.8 & 150 & 0.005 & 2 \\
\hline 208 & 99 & 168 & 49.31 & 50 & 3.5 & 4 \\
\hline 209 & 144 & 168 & 111.46 & 150 & 3.5 & 4 \\
\hline 210 & 157 & 168 & 85.8 & 50 & 3.5 & 4 \\
\hline 211 & 279 & 223 & 43.64 & 150 & 3.5 & 4 \\
\hline 212 & 163 & 168 & 101.24 & 150 & 3.5 & 4 \\
\hline 213 & 163 & 146 & 111.09 & 50 & 3.5 & 4 \\
\hline 214 & 146 & 169 & 48.05 & 50 & 3.5 & 4 \\
\hline 215 & 169 & 164 & 111.34 & 50 & 3.5 & 4 \\
\hline 216 & 169 & 170 & 78.18 & 50 & 3.5 & 4 \\
\hline 217 & 170 & 145 & 47.38 & 75 & 3.5 & 4 \\
\hline 218 & 57 & 55 & 147.33 & 50 & 0.0015 & 1 \\
\hline 219 & 171 & 172 & 82.29 & 150 & 3.5 & 4 \\
\hline 220 & 172 & 165 & 110.66 & 50 & 3.5 & 4 \\
\hline 221 & 29 & 32 & 54 & 100 & 0.0015 & 1 \\
\hline 222 & 172 & 174 & 54.39 & 50 & 0.0015 & 1 \\
\hline 223 & 32 & 33 & 174 & 50 & 0.0015 & 1 \\
\hline 224 & 277 & 260 & 110.28 & 32 & 0.0015 & 1 \\
\hline 225 & 177 & 175 & 72.65 & 50 & 0.0015 & 1 \\
\hline 226 & 69 & 89 & 98.94 & 50 & 0.0015 & 1 \\
\hline 227 & 175 & 179 & 78.53 & 50 & 0.0015 & 1 \\
\hline 228 & 179 & 180 & 99.95 & 50 & 0.0015 & 1 \\
\hline 229 & 181 & 178 & 94.3 & 50 & 0.0015 & 1 \\
\hline 230 & 178 & 179 & 70.78 & 50 & 0.0015 & 1 \\
\hline 231 & 178 & 177 & 82.51 & 50 & 0.0015 & 1 \\
\hline 232 & 178 & 184 & 117.95 & 50 & 0.0015 & 1 \\
\hline 233 & 184 & 182 & 90.18 & 50 & 0.0015 & 1 \\
\hline 234 & 184 & 183 & 87.28 & 50 & 0.0015 & 1 \\
\hline 235 & 185 & 186 & 96.25 & 50 & 3.5 & 4 \\
\hline 236 & 276 & 253 & 102.05 & 75 & 3.5 & 4 \\
\hline 237 & 186 & 188 & 97.49 & 50 & 3.5 & 4 \\
\hline 238 & 188 & 189 & 21.3 & 50 & 0.0015 & 1 \\
\hline 239 & 173 & 120 & 61.93 & 50 & 3.5 & 4 \\
\hline 240 & 255 & 146 & 103.17 & 50 & 3.5 & 4 \\
\hline 241 & 32 & 34 & 198 & 50 & 0.0015 & 1 \\
\hline 242 & 193 & 194 & 222.88 & 150 & 3.5 & 4 \\
\hline 243 & 190 & 191 & 80.65 & 50 & 0.0015 & 1 \\
\hline 244 & 195 & 196 & 188.08 & 50 & 0.0015 & 1 \\
\hline 245 & 196 & 197 & 81.9 & 50 & 0.0015 & 1 \\
\hline 246 & 196 & 198 & 281.31 & 50 & 0.0015 & 1 \\
\hline 247 & 198 & 199 & 150 & 60 & 0.0015 & 1 \\
\hline 248 & 198 & 205 & 64 & 60 & 0.0015 & 1 \\
\hline 249 & 205 & 200 & 150 & 60 & 0.0015 & 1 \\
\hline 250 & 205 & 206 & 64 & 60 & 0.0015 & 1 \\
\hline 251 & 206 & 201 & 150 & 60 & 0.0015 & 1 \\
\hline 252 & 206 & 207 & 64 & 75 & 0.0015 & 1 \\
\hline 253 & 207 & 202 & 150 & 60 & 0.0015 & 1 \\
\hline
\end{tabular}




\begin{tabular}{|c|c|c|c|c|c|c|}
\hline Tubo & Nó Inicial & Nó Final & Comprimento $(\mathrm{m})$ & Diâmetro $(\mathrm{mm})$ & $\mid \begin{array}{c}\text { Rugosidade } \\
\text { (mm) }\end{array}$ & Setor \\
\hline 254 & 207 & 208 & 64 & 75 & 0.0015 & 1 \\
\hline 255 & 208 & 203 & 150 & 60 & 0.0015 & 1 \\
\hline 256 & 208 & 209 & 64 & 75 & 0.0015 & 1 \\
\hline 257 & 209 & 204 & 150 & 60 & 0.0015 & 1 \\
\hline 258 & 210 & 211 & 210.76 & 50 & 0.0015 & 1 \\
\hline 259 & 24 & 25 & 198 & 50 & 0.0015 & 1 \\
\hline 260 & 209 & 212 & 363.76 & 100 & 0.0015 & 1 \\
\hline 261 & 22 & 24 & 424 & 50 & 0.0015 & 1 \\
\hline 262 & 222 & 219 & 64 & 60 & 0.0015 & 1 \\
\hline 263 & 219 & 220 & 80 & 50 & 0.0015 & 1 \\
\hline 264 & 220 & 221 & 67 & 50 & 0.0015 & 1 \\
\hline 265 & 221 & 218 & 61 & 50 & 0.0015 & 1 \\
\hline 266 & 218 & 219 & 65.11 & 60 & 0.0015 & 1 \\
\hline 267 & 218 & 215 & 170 & 50 & 0.0015 & 1 \\
\hline 268 & 215 & 216 & 54 & 50 & 0.0015 & 1 \\
\hline 269 & 267 & 143 & 100.05 & 150 & 3.5 & 4 \\
\hline 270 & 118 & 156 & 82.06 & 150 & 3.5 & 4 \\
\hline 271 & 214 & 213 & 66 & 50 & 0.0015 & 1 \\
\hline 272 & 214 & 215 & 128 & 50 & 0.0015 & 1 \\
\hline 273 & 216 & 221 & 171 & 50 & 0.0015 & 1 \\
\hline 274 & 224 & 225 & 35.48 & 50 & 0.0015 & 1 \\
\hline 275 & 225 & 226 & 96.1 & 50 & 0.0015 & 1 \\
\hline 276 & 190 & 192 & 98.92 & 50 & 0.0015 & 1 \\
\hline 277 & 228 & 220 & 118.35 & 50 & 0.0015 & 1 \\
\hline 278 & 194 & 223 & 222.55 & 150 & 3.5 & 4 \\
\hline 279 & 172 & 169 & 87.85 & 50 & 3.5 & 4 \\
\hline 280 & 242 & 236 & 101.51 & 50 & 0.0015 & 1 \\
\hline 281 & 275 & 187 & 102.05 & 75 & 3.5 & 4 \\
\hline 282 & 234 & 148 & 94.01 & 50 & 3.5 & 4 \\
\hline 283 & 234 & 233 & 95.43 & 75 & 3.5 & 4 \\
\hline 284 & 233 & 150 & 93.5 & 50 & 3.5 & 4 \\
\hline 285 & 233 & 232 & 102.59 & 75 & 3.5 & 4 \\
\hline 286 & 232 & 151 & 93.46 & 50 & 3.5 & 4 \\
\hline 287 & 232 & 231 & 105.02 & 75 & 3.5 & 4 \\
\hline 288 & 231 & 153 & 93.49 & 50 & 3.5 & 4 \\
\hline 289 & 26 & 28 & 186 & 50 & 0.0015 & 1 \\
\hline 290 & 235 & 236 & 58.06 & 50 & 0.0015 & 1 \\
\hline 291 & 26 & 27 & 198 & 50 & 0.0015 & 1 \\
\hline 292 & 237 & 238 & 40.52 & 50 & 0.0015 & 1 \\
\hline 293 & 92 & 69 & 93.11 & 50 & 0.0015 & 1 \\
\hline 294 & 238 & 154 & 108.39 & 50 & 3.5 & 4 \\
\hline 295 & 229 & 211 & 193.92 & 150 & 3.5 & 4 \\
\hline 296 & 184 & 239 & 87.79 & 50 & 0.0015 & 1 \\
\hline 297 & 177 & 239 & 121.88 & 50 & 0.0015 & 1 \\
\hline 298 & 239 & 240 & 82.03 & 50 & 3.5 & 4 \\
\hline 299 & 230 & 236 & 100.76 & 50 & 0.0015 & 1 \\
\hline 300 & 241 & 176 & 124.03 & 200 & 3.5 & 4 \\
\hline 301 & 239 & 225 & 211.46 & 50 & 0.0015 & 1 \\
\hline 302 & 241 & 211 & 85.68 & 150 & 3.5 & 4 \\
\hline 303 & 32 & 36 & 54 & 100 & 0.0015 & 1 \\
\hline 304 & 231 & 243 & 105.02 & 75 & 3.5 & 4 \\
\hline
\end{tabular}




\begin{tabular}{|c|c|c|c|c|c|c|}
\hline Tubo & Nó Inicial & Nó Final & Comprimento (m) & Diâmetro $(\mathrm{mm})$ & $\begin{array}{c}\text { Rugosidade } \\
\text { (mm) }\end{array}$ & Setor \\
\hline 305 & 243 & 236 & 113.6 & 50 & 0.0015 & 1 \\
\hline 306 & 243 & 229 & 105.02 & 75 & 3.5 & 4 \\
\hline 307 & 244 & 246 & 90 & 50 & 3.5 & 4 \\
\hline 308 & 244 & 243 & 101.1 & 50 & 0.0015 & 1 \\
\hline 309 & 244 & 153 & 104.57 & 50 & 3.5 & 4 \\
\hline 310 & 237 & 244 & 49.53 & 50 & 0.0015 & 1 \\
\hline 311 & 237 & 245 & 89.02 & 50 & 0.0015 & 1 \\
\hline 312 & 247 & 248 & 110.98 & 75 & 0.0015 & 1 \\
\hline 313 & 249 & 250 & 109.5 & 50 & 3.5 & 4 \\
\hline 314 & 38 & 92 & 94.81 & 50 & 0.0015 & 1 \\
\hline 315 & 36 & 35 & 162 & 50 & 0.0015 & 1 \\
\hline 316 & 156 & 217 & 100.12 & 32 & 0.025 & 3 \\
\hline 317 & 156 & 251 & 108.43 & 50 & 3.5 & 4 \\
\hline 318 & 251 & 141 & 70.66 & 50 & 3.5 & 4 \\
\hline 319 & 251 & 142 & 106.02 & 50 & 3.5 & 4 \\
\hline 320 & 190 & 252 & 104.13 & 50 & 0.0015 & 1 \\
\hline 321 & 252 & 188 & 99.4 & 50 & 0.0015 & 1 \\
\hline 322 & 252 & 253 & 97 & 32 & 0.025 & 3 \\
\hline 323 & 192 & 253 & 102.05 & 75 & 3.5 & 4 \\
\hline 324 & 274 & 238 & 94.25 & 50 & 3.5 & 4 \\
\hline 325 & 253 & 254 & 96.93 & 32 & 0.025 & 3 \\
\hline 326 & 268 & 164 & 48.13 & 150 & 3.5 & 4 \\
\hline 327 & 234 & 254 & 102.59 & 75 & 3.5 & 4 \\
\hline 328 & 68 & 38 & 91.96 & 50 & 0.0015 & 1 \\
\hline 329 & 192 & 259 & 104.31 & 75 & 3.5 & 4 \\
\hline 330 & 273 & 177 & 117.88 & 50 & 0.0015 & 1 \\
\hline 331 & 66 & 48 & 174.66 & 100 & 0.0015 & 1 \\
\hline 332 & 259 & 258 & 22.53 & 50 & 0.0015 & 1 \\
\hline 333 & 192 & 256 & 76.3 & 75 & 3.5 & 4 \\
\hline 334 & 257 & 258 & 92.13 & 50 & 0.0015 & 1 \\
\hline 335 & 258 & 233 & 76.3 & 50 & 0.0015 & 1 \\
\hline 336 & 261 & 232 & 176.88 & 32 & 0.025 & 3 \\
\hline 337 & 231 & 262 & 110.65 & 32 & 0.025 & 3 \\
\hline 338 & 272 & 264 & 81.04 & 50 & 3.5 & 4 \\
\hline 339 & 263 & 266 & 81.67 & 50 & 3.5 & 4 \\
\hline 340 & 266 & 265 & 72.56 & 200 & 3.5 & 4 \\
\hline 341 & 265 & 176 & 72.56 & 200 & 3.5 & 4 \\
\hline 342 & 265 & 175 & 118.23 & 50 & 3.5 & 4 \\
\hline 343 & 266 & 171 & 118.4 & 150 & 3.5 & 4 \\
\hline 344 & 269 & 160 & 85.42 & 50 & 3.5 & 4 \\
\hline 345 & 280 & 241 & 63.28 & 200 & 3.5 & 4 \\
\hline 346 & 281 & 280 & 1 & 1000 & 1.0 & \\
\hline
\end{tabular}


Tabela Ap.2 - Características dos nós da rede do setor Zona Média

\begin{tabular}{|c|c|c|c|c|c|}
\hline Nó & Cota & Demanda (L/s) & Nó & Cota & Demanda (L/s) \\
\hline 1 & 627.658 & 0,0895 & 51 & 612.134 & 0,0083 \\
\hline 2 & 616.332 & 0,1509 & 52 & 615.789 & 0,0058 \\
\hline 3 & 600.385 & 0,0614 & 53 & 608.859 & 0,0454 \\
\hline 4 & 600.800 & 0,0331 & 54 & 611.435 & 0,0514 \\
\hline 5 & 616.310 & 0,0760 & 55 & 606.789 & 0,0341 \\
\hline 6 & 627.640 & 0,0429 & 56 & 611.904 & 0,0000 \\
\hline 7 & 627.580 & 0,0200 & 57 & 599.987 & 0,0000 \\
\hline 8 & 616.101 & 0,0200 & 58 & 605.067 & 0,0177 \\
\hline 9 & 600.632 & 0,0000 & 59 & 605.103 & 0,0000 \\
\hline 10 & 600.499 & 0,0164 & 60 & 607.341 & 0,0000 \\
\hline 11 & 615.896 & 0,0601 & 61 & 605.103 & 0,0000 \\
\hline 12 & 627.212 & 0,0437 & 62 & 621.486 & 0,0000 \\
\hline 13 & 615.868 & 0,0989 & 63 & 614.166 & 0,0533 \\
\hline 14 & 600.654 & 0,0335 & 64 & 614.166 & 0,0000 \\
\hline 15 & 626.493 & 0,0000 & 65 & 614.166 & 0,0000 \\
\hline 16 & 624.567 & 0,1117 & 66 & 614.166 & 0,0000 \\
\hline 17 & 614.963 & 0,2308 & 67 & 616.795 & 0,0978 \\
\hline 18 & 601.906 & 0,1188 & 68 & 610.546 & 0,0599 \\
\hline 19 & 615.047 & 0,2308 & 69 & 613.121 & 0,1251 \\
\hline 20 & 601.766 & 0,1251 & 70 & 605.134 & 0,0187 \\
\hline 21 & 625.002 & 0,1709 & 71 & 604.569 & 0,0348 \\
\hline 22 & 614.376 & 0,2866 & 72 & 600.346 & 0,0246 \\
\hline 23 & 621.006 & 0,0907 & 73 & 598.678 & 0,0737 \\
\hline 24 & 613.676 & 0,3013 & 74 & 596.346 & 0,1604 \\
\hline 25 & 622.785 & 0,1034 & 75 & 600.710 & 0,0591 \\
\hline 26 & 612.881 & 0,2143 & 76 & 592.459 & 0,1309 \\
\hline 27 & 621.444 & 0,1120 & 77 & 590.386 & 0,2297 \\
\hline 28 & 600.745 & 0,1003 & 78 & 586.292 & 0,1371 \\
\hline 29 & 612.007 & 0,2102 & 79 & 592.144 & 0,1661 \\
\hline 30 & 600.325 & 0,1034 & 80 & 598.872 & 0,1088 \\
\hline 31 & 621.486 & 0,1068 & 81 & 598.030 & 0,0887 \\
\hline 32 & 611.001 & 0,2680 & 82 & 593.288 & 0,1020 \\
\hline 33 & 600.594 & 0,1205 & 83 & 596.346 & 0,0000 \\
\hline 34 & 618.872 & 0,1475 & 84 & 582.387 & 0,0042 \\
\hline 35 & 600.612 & 0,1342 & 85 & 581.987 & 0,0067 \\
\hline 36 & 609.994 & 0,2918 & 86 & 587.174 & 0,0356 \\
\hline 37 & 596.575 & 0,0901 & 87 & 588.834 & 0,0859 \\
\hline 38 & 605.906 & 0,1153 & 88 & 619.304 & 0,0728 \\
\hline 39 & 626.493 & 0,0000 & 89 & 615.840 & 0,0681 \\
\hline 40 & 625.002 & 0,0000 & 90 & 618.445 & 0,0335 \\
\hline 41 & 616.101 & 0,0000 & 91 & 621.797 & 0,0749 \\
\hline 42 & 607.956 & 0,0133 & 92 & 608.711 & 0,0974 \\
\hline 43 & 606.567 & 0,0198 & 93 & 611.904 & 0,0418 \\
\hline 44 & 607.091 & 0,0570 & 94 & 614.671 & 0,0243 \\
\hline 45 & 600.756 & 0,0270 & 95 & 616.426 & 0,0472 \\
\hline 46 & 600.806 & 0,0526 & 96 & 620.177 & 0,0814 \\
\hline 47 & 598.448 & 0,0013 & 97 & 623.363 & 0,0939 \\
\hline 48 & 605.906 & 0,0000 & 98 & 618.898 & 0,0000 \\
\hline 49 & 609.067 & 0,0106 & 99 & 618.898 & 0,1324 \\
\hline 50 & 607.341 & 0,0231 & 100 & 622.560 & 0,0348 \\
\hline
\end{tabular}




\begin{tabular}{|c|c|c|}
\hline Nó & Cota & Demanda (L/s) \\
\hline 101 & 626.666 & 0,0000 \\
\hline 102 & 626.666 & 0,1234 \\
\hline 103 & 622.560 & 0,1167 \\
\hline 104 & 604.203 & 0,0830 \\
\hline 105 & 607.710 & 0,0912 \\
\hline 106 & 610.516 & 0,0737 \\
\hline 107 & 606.104 & 0,0554 \\
\hline 108 & 602.924 & 0,0635 \\
\hline 109 & 597.324 & 0,0033 \\
\hline 110 & 599.892 & 0,0377 \\
\hline 111 & 601.955 & 0,0687 \\
\hline 112 & 604.769 & 0,0822 \\
\hline 113 & 608.329 & 0,0947 \\
\hline 114 & 612.456 & 0,0743 \\
\hline 115 & 604.769 & 0,0000 \\
\hline 116 & 608.329 & 0,0000 \\
\hline 117 & 629.341 & 0,0807 \\
\hline 118 & 607.136 & 0,1247 \\
\hline 119 & 610.599 & 0,1109 \\
\hline 120 & 614.790 & 0,1186 \\
\hline 121 & 614.790 & 0,0000 \\
\hline 122 & 598.034 & 0,0000 \\
\hline 123 & 598.034 & 0,0000 \\
\hline 124 & 598.034 & 0,1965 \\
\hline 125 & 590.397 & 0,1634 \\
\hline 126 & 586.197 & 0,0445 \\
\hline 127 & 590.397 & 0,0000 \\
\hline 128 & 597.324 & 0,0884 \\
\hline 129 & 592.866 & 0,0951 \\
\hline 130 & 597.324 & 0,0252 \\
\hline 131 & 597.324 & 0,0000 \\
\hline 132 & 603.607 & 0,1018 \\
\hline 133 & 598.713 & 0,0000 \\
\hline 134 & 598.713 & 0,0601 \\
\hline 135 & 591.655 & 0,0393 \\
\hline 136 & 591.655 & 0,0083 \\
\hline 137 & 596.138 & 0,0745 \\
\hline 138 & 601.871 & 0,0089 \\
\hline 139 & 602.542 & 0,3122 \\
\hline 140 & 608.867 & 0,0000 \\
\hline 141 & 603.607 & 0,0462 \\
\hline 142 & 610.558 & 0,0812 \\
\hline 143 & 613.731 & 0,1777 \\
\hline 144 & 617.182 & 0,1371 \\
\hline 145 & 616.800 & 0,1199 \\
\hline 146 & 619.971 & 0,1016 \\
\hline 147 & 601.012 & 0,0152 \\
\hline 148 & 605.541 & 0,0776 \\
\hline 149 & 601.616 & 0,0809 \\
\hline 150 & 608.908 & 0,0735 \\
\hline & & \\
\hline
\end{tabular}

\begin{tabular}{|c|c|c|}
\hline Nó & Cota & Demanda (L/s) \\
\hline 151 & 611.235 & 0,1142 \\
\hline 152 & 614.197 & 0,0803 \\
\hline 153 & 613.476 & 0,0891 \\
\hline 154 & 616.866 & 0,0799 \\
\hline 155 & 628.538 & 0,0012 \\
\hline 156 & 611.294 & 0,1563 \\
\hline 157 & 624.146 & 0,1018 \\
\hline 158 & 626.410 & 0,0445 \\
\hline 159 & 630.272 & 0,0527 \\
\hline 160 & 626.251 & 0,1311 \\
\hline 161 & 627.318 & 0,1369 \\
\hline 162 & 608.867 & 0,0000 \\
\hline 163 & 623.036 & 0,1507 \\
\hline 164 & 624.086 & 0,1222 \\
\hline 165 & 626.465 & 0,1357 \\
\hline 166 & 628.132 & 0,0054 \\
\hline 167 & 620.845 & 0,0000 \\
\hline 168 & 620.845 & 0,1145 \\
\hline 169 & 621.175 & 0,0924 \\
\hline 170 & 618.253 & 0,0905 \\
\hline 171 & 621.009 & 0,1386 \\
\hline 172 & 623.663 & 0,1326 \\
\hline 173 & 617.182 & 0,0000 \\
\hline 174 & 624.893 & 0,0037 \\
\hline 175 & 622.943 & 0,0597 \\
\hline 176 & 621.773 & 0,1028 \\
\hline 177 & 624.649 & 0,1573 \\
\hline 178 & 627.269 & 0,1078 \\
\hline 179 & 625.391 & 0,0499 \\
\hline 180 & 628.132 & 0,0358 \\
\hline 181 & 629.484 & 0,0576 \\
\hline 182 & 631.794 & 0,0616 \\
\hline 183 & 630.726 & 0,0393 \\
\hline 184 & 629.562 & 0,1101 \\
\hline 185 & 596.575 & 0,0106 \\
\hline 186 & 595.612 & 0,1334 \\
\hline 187 & 594.629 & 0,0504 \\
\hline 188 & 589.250 & 0,0691 \\
\hline 189 & 588.403 & 0,0110 \\
\hline 190 & 590.534 & 0,0443 \\
\hline 191 & 592.606 & 0,0069 \\
\hline 192 & 598.129 & 0,0791 \\
\hline 193 & 598.336 & 0,0560 \\
\hline 194 & 601.281 & 0,0000 \\
\hline 195 & 626.347 & 0,0173 \\
\hline 196 & 627.043 & 0,0452 \\
\hline 197 & 622.267 & 0,0279 \\
\hline 198 & 615.486 & 0,2008 \\
\hline 199 & 626.715 & 0,0820 \\
\hline 200 & 627.530 & 0,0880 \\
\hline
\end{tabular}




\begin{tabular}{|c|c|c|}
\hline Nó & Cota & Demanda (L/s) \\
\hline 201 & 626.739 & 0,0629 \\
\hline 202 & 625.939 & 0,0624 \\
\hline 203 & 625.056 & 0,0778 \\
\hline 204 & 624.152 & 0,0454 \\
\hline 205 & 616.898 & 0,1178 \\
\hline 206 & 617.502 & 0,0878 \\
\hline 207 & 617.242 & 0,0851 \\
\hline 208 & 616.792 & 0,1065 \\
\hline 209 & 616.351 & 0,1538 \\
\hline 210 & 625.877 & 0,0210 \\
\hline 211 & 621.177 & 0,1779 \\
\hline 212 & 621.177 & 0,0000 \\
\hline 213 & 611.825 & 0,0279 \\
\hline 214 & 613.104 & 0,0870 \\
\hline 215 & 613.386 & 0,0676 \\
\hline 216 & 607.134 & 0,0936 \\
\hline 217 & 614.295 & 0,0345 \\
\hline 218 & 612.524 & 0,0693 \\
\hline 219 & 612.025 & 0,0329 \\
\hline 220 & 603.994 & 0,0252 \\
\hline 221 & 605.600 & 0,0732 \\
\hline 222 & 611.328 & 0,0000 \\
\hline 223 & 611.328 & 0,0647 \\
\hline 224 & 622.753 & 0,0017 \\
\hline 225 & 626.346 & 0,0529 \\
\hline 226 & 629.638 & 0,0231 \\
\hline 227 & 617.382 & 0,1444 \\
\hline 228 & 600.452 & 0,0023 \\
\hline 229 & 613.625 & 0,0793 \\
\hline 230 & 606.227 & 0,0474 \\
\hline 231 & 610.128 & 0,1417 \\
\hline 232 & 607.662 & 0,1299 \\
\hline 233 & 605.575 & 0,1013 \\
\hline 234 & 603.189 & 0,0672 \\
\hline 235 & 601.281 & 0,0029 \\
\hline 236 & 606.186 & 0,0803 \\
\hline 237 & 617.431 & 0,0462 \\
\hline 238 & 619.266 & 0,1022 \\
\hline 239 & 627.379 & 0,1615 \\
\hline 240 & 629.638 & 0,0472 \\
\hline 241 & 624.342 & 0,0279 \\
\hline 242 & 604.578 & 0,0218 \\
\hline 243 & 611.924 & 0,1176 \\
\hline 244 & 615.795 & 0,0893 \\
\hline 245 & 619.823 & 0,0287 \\
\hline 246 & 617.854 & 0,0252 \\
\hline 247 & 601.281 & 0,0000 \\
\hline 248 & 595.793 & 0,0000 \\
\hline 249 & 598.336 & 0,0000 \\
\hline 250 & 594.043 & 0,0039 \\
\hline & & \\
\hline
\end{tabular}

\begin{tabular}{|c|c|c|}
\hline Nó & Cota & Demanda (L/s) \\
\hline 251 & 607.192 & 0,1253 \\
\hline 252 & 589.314 & 0,0616 \\
\hline 253 & 596.863 & 0,0951 \\
\hline 254 & 600.105 & 0,0793 \\
\hline 255 & 617.182 & 0,0000 \\
\hline 256 & 601.285 & 0,0002 \\
\hline 257 & 601.321 & 0,0075 \\
\hline 258 & 600.023 & 0,0310 \\
\hline 259 & 599.669 & 0,0639 \\
\hline 260 & 592.606 & 0,0085 \\
\hline 261 & 600.102 & 0,0254 \\
\hline 262 & 604.576 & 0,0231 \\
\hline 263 & 614.935 & 0,0083 \\
\hline 264 & 616.986 & 0,0285 \\
\hline 265 & 619.835 & 0,1455 \\
\hline 266 & 617.945 & 0,0889 \\
\hline 267 & 611.294 & 0,0000 \\
\hline 268 & 623.036 & 0,0000 \\
\hline 269 & 623.036 & 0,0000 \\
\hline 270 & 621.009 & 0,0000 \\
\hline 271 & 622.943 & 0,0000 \\
\hline 272 & 619.835 & 0,0000 \\
\hline 273 & 621.773 & 0,0000 \\
\hline 274 & 621.177 & 0,0000 \\
\hline 275 & 595.612 & 0,0000 \\
\hline 276 & 595.612 & 0,0000 \\
\hline 277 & 599.669 & 0,0000 \\
\hline 278 & 598.336 & 0,0000 \\
\hline 279 & 613.625 & 0,0000 \\
\hline 280 & 625.456 & 0,0000 \\
\hline & & \\
\hline
\end{tabular}


APÊNDICE C - Informações da Rede de Abastecimento de Água da Cidade de itirapuã 
Tabela Ap.3 - Características das tubulações da rede da cidade de Itirapuã

\begin{tabular}{|c|c|c|c|c|c|c|}
\hline Tubo & Nó Inicial & Nó Final & Comprimento (m) & Diâmetro $(\mathrm{mm})$ & $\begin{array}{c}\begin{array}{c}\text { Rugosidade } \\
(\mathrm{mm})\end{array} \\
\end{array}$ & Setor \\
\hline 1 & 179 & 173 & 29.11 & 200 & 0.025 & 2 \\
\hline 2 & 39 & 38 & 70.53 & 50 & 0.025 & 2 \\
\hline 3 & 36 & 29 & 109.46 & 50 & 0.025 & 2 \\
\hline 4 & 28 & 40 & 87.62 & 75 & 0.025 & 2 \\
\hline 5 & 40 & 41 & 90 & 50 & 0.025 & 2 \\
\hline 6 & 5 & 6 & 329.87 & 50 & 0.0015 & 1 \\
\hline 7 & 31 & 42 & 87.19 & 50 & 0.025 & 2 \\
\hline 8 & 42 & 41 & 90.55 & 50 & 0.025 & 2 \\
\hline 9 & 115 & 43 & 70 & 50 & 0.0015 & 1 \\
\hline 10 & 42 & 44 & 74 & 50 & 0.025 & 2 \\
\hline 11 & 1 & 2 & 169.53 & 50 & 0.0015 & 1 \\
\hline 12 & 2 & 3 & 164.42 & 50 & 0.0015 & 1 \\
\hline 13 & 27 & 52 & 87.87 & 100 & 0.0015 & 1 \\
\hline 14 & 3 & 4 & 71.63 & 50 & 0.0015 & 1 \\
\hline 15 & 36 & 50 & 85.23 & 50 & 0.025 & 2 \\
\hline 16 & 49 & 48 & 96 & 100 & 0.025 & 2 \\
\hline 17 & 2 & 7 & 67.44 & 50 & 0.0015 & 1 \\
\hline 18 & 7 & 3 & 97.28 & 50 & 0.0015 & 1 \\
\hline 19 & 3 & 9 & 106.37 & 50 & 0.025 & 2 \\
\hline 20 & 41 & 47 & 96 & 50 & 0.025 & 2 \\
\hline 21 & 40 & 45 & 95.22 & 75 & 0.025 & 2 \\
\hline 22 & 9 & 6 & 85.93 & 50 & 0.0015 & 1 \\
\hline 23 & 45 & 48 & 108.55 & 100 & 0.025 & 2 \\
\hline 24 & 9 & 8 & 97.16 & 50 & 0.0015 & 1 \\
\hline 25 & 56 & 49 & 86.26 & 200 & 0.025 & 2 \\
\hline 26 & 64 & 134 & 314.52 & 50 & 0.0015 & 1 \\
\hline 27 & 8 & 7 & 106.19 & 50 & 0.025 & 2 \\
\hline 28 & 8 & 10 & 106.4 & 50 & 0.025 & 2 \\
\hline 29 & 62 & 54 & 92 & 100 & 0.025 & 2 \\
\hline 30 & 61 & 55 & 91.99 & 75 & 0.025 & 2 \\
\hline 31 & 61 & 62 & 107.97 & 50 & 0.025 & 2 \\
\hline 32 & 61 & 60 & 90 & 50 & 0.025 & 2 \\
\hline 33 & 60 & 59 & 100 & 50 & 0.0015 & 1 \\
\hline 34 & 46 & 60 & 91.22 & 50 & 0.025 & 2 \\
\hline 35 & 46 & 59 & 195.21 & 50 & 0.0015 & 1 \\
\hline 36 & 141 & 64 & 65 & 50 & 0.0015 & 1 \\
\hline 37 & 10 & 11 & 93.89 & 50 & 0.0015 & 1 \\
\hline 38 & 64 & 137 & 177.84 & 50 & 0.0015 & 1 \\
\hline 39 & 67 & 69 & 85.15 & 50 & 0.0015 & 1 \\
\hline 40 & 68 & 71 & 86 & 50 & 0.025 & 2 \\
\hline 41 & 71 & 60 & 94.78 & 50 & 0.025 & 2 \\
\hline 42 & 11 & 9 & 106.41 & 50 & 0.025 & 2 \\
\hline 43 & 6 & 12 & 107.65 & 50 & 0.0015 & 1 \\
\hline 44 & 12 & 11 & 87.67 & 50 & 0.0015 & 1 \\
\hline 45 & 13 & 12 & 81.38 & 50 & 0.0015 & 1 \\
\hline 46 & 14 & 20 & 88.41 & 75 & 0.025 & 2 \\
\hline 47 & 70 & 80 & 89.46 & 50 & 0.0015 & 1 \\
\hline 48 & 16 & 19 & 98.88 & 50 & 0.025 & 2 \\
\hline 49 & 72 & 71 & 90 & 50 & 0.0015 & 1 \\
\hline
\end{tabular}




\begin{tabular}{|c|c|c|c|c|c|c|}
\hline Tubo & Nó Inicial & Nó Final & Comprimento (m) & Diâmetro $(\mathrm{mm})$ & \begin{tabular}{|c} 
Rugosidade \\
$(\mathrm{mm})$
\end{tabular} & Setor \\
\hline 50 & 72 & 61 & 94.01 & 75 & 0.025 & 2 \\
\hline 51 & 27 & 32 & 220 & 100 & 0.0015 & 1 \\
\hline 52 & 19 & 18 & 92.84 & 50 & 0.0015 & 1 \\
\hline 53 & 18 & 17 & 96.66 & 50 & 0.025 & 2 \\
\hline 54 & 57 & 175 & 92.15 & 100 & 0.025 & 2 \\
\hline 55 & 75 & 58 & 94.85 & 50 & 0.025 & 2 \\
\hline 56 & 75 & 76 & 85.71 & 50 & 0.025 & 2 \\
\hline 57 & 76 & 77 & 62.42 & 50 & 0.0015 & 1 \\
\hline 58 & 17 & 16 & 93.34 & 50 & 0.025 & 2 \\
\hline 59 & 19 & 20 & 90.9 & 50 & 0.025 & 2 \\
\hline 60 & 122 & 81 & 169.42 & 50 & 0.0015 & 1 \\
\hline 61 & 79 & 86 & 94 & 100 & 0.0015 & 1 \\
\hline 62 & 86 & 85 & 108.55 & 50 & 0.0015 & 1 \\
\hline 63 & 26 & 16 & 94.63 & 50 & 0.025 & 2 \\
\hline 64 & 85 & 84 & 89.45 & 50 & 0.0015 & 1 \\
\hline 65 & 10 & 17 & 95.51 & 50 & 0.025 & 2 \\
\hline 66 & 84 & 83 & 84.65 & 50 & 0.0015 & 1 \\
\hline 67 & 83 & 67 & 91.63 & 50 & 0.025 & 2 \\
\hline 68 & 20 & 28 & 92.8 & 75 & 0.025 & 2 \\
\hline 69 & 83 & 89 & 97.97 & 50 & 0.025 & 2 \\
\hline 70 & 41 & 30 & 87.21 & 50 & 0.025 & 2 \\
\hline 71 & 89 & 91 & 78.31 & 50 & 0.0015 & 1 \\
\hline 72 & 31 & 30 & 90.81 & 50 & 0.025 & 2 \\
\hline 73 & 91 & 92 & 89.48 & 50 & 0.0015 & 1 \\
\hline 74 & 92 & 85 & 95.81 & 50 & 0.0015 & 1 \\
\hline 75 & 93 & 94 & 85.42 & 50 & 0.025 & 2 \\
\hline 76 & 94 & 86 & 98 & 100 & 0.0015 & 1 \\
\hline 77 & 16 & 15 & 88.98 & 50 & 0.025 & 2 \\
\hline 78 & 95 & 96 & 78.32 & 50 & 0.0015 & 1 \\
\hline 79 & 96 & 92 & 99.98 & 50 & 0.0015 & 1 \\
\hline 80 & 96 & 97 & 89.46 & 50 & 0.0015 & 1 \\
\hline 81 & 97 & 91 & 98 & 50 & 0.025 & 2 \\
\hline 82 & 97 & 98 & 78.89 & 50 & 0.0015 & 1 \\
\hline 83 & 19 & 90 & 92.61 & 50 & 0.025 & 2 \\
\hline 84 & 98 & 89 & 97.78 & 50 & 0.025 & 2 \\
\hline 85 & 95 & 100 & 62.38 & 50 & 0.0015 & 1 \\
\hline 86 & 96 & 101 & 87.23 & 50 & 0.0015 & 1 \\
\hline 87 & 101 & 108 & 253.53 & 50 & 0.0015 & 1 \\
\hline 88 & 107 & 106 & 66.53 & 50 & 0.0015 & 1 \\
\hline 89 & 106 & 101 & 89.02 & 50 & 0.0015 & 1 \\
\hline 90 & 101 & 102 & 89.46 & 50 & 0.0015 & 1 \\
\hline 91 & 102 & 97 & 88 & 50 & 0.025 & 2 \\
\hline 92 & 98 & 103 & 87.74 & 50 & 0.025 & 2 \\
\hline 93 & 103 & 102 & 78.94 & 50 & 0.0015 & 1 \\
\hline 94 & 102 & 105 & 90 & 50 & 0.025 & 2 \\
\hline 95 & 105 & 106 & 89.48 & 50 & 0.0015 & 1 \\
\hline 96 & 106 & 110 & 84.53 & 50 & 0.0015 & 1 \\
\hline 97 & 110 & 109 & 66.54 & 50 & 0.0015 & 1 \\
\hline 98 & 110 & 113 & 86.91 & 50 & 0.0015 & 1 \\
\hline 99 & 113 & 114 & 47.23 & 50 & 0.0015 & 1 \\
\hline 100 & 113 & 115 & 89.46 & 50 & 0.0015 & 1 \\
\hline
\end{tabular}




\begin{tabular}{|c|c|c|c|c|c|c|}
\hline Tubo & Nó Inicial & Nó Final & Comprimento (m) & Diâmetro $(\mathrm{mm})$ & $\begin{array}{c}\text { Rugosidade } \\
\text { (mm) }\end{array}$ & Setor \\
\hline 101 & 115 & 111 & 85.04 & 50 & 0.0015 & 1 \\
\hline 102 & 111 & 110 & 66 & 50 & 0.0015 & 1 \\
\hline 103 & 111 & 112 & 80.7 & 50 & 0.0015 & 1 \\
\hline 104 & 112 & 104 & 83.8 & 50 & 0.0015 & 1 \\
\hline 105 & 104 & 105 & 78.45 & 50 & 0.0015 & 1 \\
\hline 106 & 105 & 111 & 84.99 & 50 & 0.025 & 2 \\
\hline 107 & 104 & 103 & 90.62 & 50 & 0.0015 & 1 \\
\hline 108 & 112 & 116 & 86 & 50 & 0.0015 & 1 \\
\hline 109 & 116 & 115 & 79 & 50 & 0.0015 & 1 \\
\hline 110 & 116 & 117 & 145.37 & 50 & 0.0015 & 1 \\
\hline 111 & 99 & 38 & 87.25 & 100 & 0.025 & 2 \\
\hline 112 & 30 & 28 & 90.15 & 50 & 0.025 & 2 \\
\hline 113 & 122 & 120 & 118.59 & 50 & 0.0015 & 1 \\
\hline 114 & 20 & 34 & 108.1 & 50 & 0.025 & 2 \\
\hline 115 & 121 & 123 & 117.68 & 50 & 0.0015 & 1 \\
\hline 116 & 124 & 148 & 298.23 & 50 & 0.0015 & 1 \\
\hline 117 & 128 & 46 & 90 & 50 & 0.025 & 2 \\
\hline 118 & 65 & 136 & 40 & 50 & 0.0015 & 1 \\
\hline 119 & 34 & 38 & 117.79 & 50 & 0.025 & 2 \\
\hline 120 & 136 & 66 & 87.7 & 50 & 0.0015 & 1 \\
\hline 121 & 37 & 38 & 85.07 & 50 & 0.025 & 2 \\
\hline 122 & 130 & 129 & 44.85 & 50 & 0.0015 & 1 \\
\hline 123 & 129 & 132 & 64.62 & 50 & 0.0015 & 1 \\
\hline 124 & 131 & 133 & 96.11 & 50 & 0.0015 & 1 \\
\hline 125 & 133 & 134 & 68.6 & 50 & 0.0015 & 1 \\
\hline 126 & 134 & 135 & 96.11 & 50 & 0.0015 & 1 \\
\hline 127 & 138 & 63 & 71.56 & 50 & 0.0015 & 1 \\
\hline 128 & 62 & 73 & 94 & 100 & 0.025 & 2 \\
\hline 129 & 123 & 122 & 46.92 & 50 & 0.0015 & 1 \\
\hline 130 & 170 & 136 & 90 & 50 & 0.025 & 2 \\
\hline 131 & 141 & 134 & 162.63 & 50 & 0.0015 & 1 \\
\hline 132 & 139 & 141 & 68.6 & 50 & 0.0015 & 1 \\
\hline 133 & 139 & 133 & 162.63 & 50 & 0.0015 & 1 \\
\hline 134 & 171 & 84 & 94 & 50 & 0.025 & 2 \\
\hline 135 & 82 & 72 & 87.09 & 75 & 0.025 & 2 \\
\hline 136 & 78 & 80 & 108.55 & 0.025 & 0.0015 & 1 \\
\hline 137 & 18 & 31 & 92.49 & 50 & 0.025 & 2 \\
\hline 138 & 125 & 123 & 48.34 & 50 & 0.0015 & 1 \\
\hline 139 & 145 & 142 & 223.87 & 50 & 0.0015 & 1 \\
\hline 140 & 142 & 143 & 74.65 & 50 & 0.0015 & 1 \\
\hline 141 & 142 & 168 & 19.2 & 50 & 0.0015 & 1 \\
\hline 142 & 168 & 56 & 64.9 & 200 & 0.025 & 2 \\
\hline 143 & 161 & 155 & 161.1 & 50 & 0.0015 & 1 \\
\hline 144 & 150 & 149 & 323.71 & 50 & 0.0015 & 1 \\
\hline 145 & 85 & 80 & 92.85 & 50 & 0.0015 & 1 \\
\hline 146 & 150 & 146 & 403.9 & 50 & 0.0015 & 1 \\
\hline 147 & 27 & 21 & 223.41 & 100 & 0.0015 & 1 \\
\hline 148 & 36 & 34 & 92.19 & 50 & 0.025 & 2 \\
\hline 149 & 125 & 88 & 96.95 & 50 & 0.0015 & 1 \\
\hline 150 & 169 & 125 & 49.06 & 50 & 0.0015 & 1 \\
\hline
\end{tabular}




\begin{tabular}{|c|c|c|c|c|c|c|}
\hline Tubo & Nó Inicial & Nó Final & Comprimento (m) & Diâmetro $(\mathrm{mm})$ & $\begin{array}{c}\text { Rugosidade } \\
\text { (mm) }\end{array}$ & Setor \\
\hline 151 & 169 & 87 & 127 & 50 & 0.0015 & 1 \\
\hline 152 & 127 & 169 & 113.36 & 50 & 0.0015 & 1 \\
\hline 153 & 94 & 95 & 127.07 & 100 & 0.0015 & 1 \\
\hline 154 & 58 & 140 & 144.62 & 50 & 0.0015 & 1 \\
\hline 155 & 75 & 129 & 264 & 50 & 0.0015 & 1 \\
\hline 156 & 159 & 22 & 138.3 & 50 & 0.0015 & 1 \\
\hline 157 & 153 & 25 & 160.7 & 50 & 0.0015 & 1 \\
\hline 158 & 25 & 160 & 140.7 & 100 & 0.0015 & 1 \\
\hline 159 & 25 & 152 & 61.5 & 100 & 0.0015 & 1 \\
\hline 160 & 151 & 154 & 161.3 & 50 & 0.0015 & 1 \\
\hline 161 & 23 & 22 & 64.6 & 50 & 0.0015 & 1 \\
\hline 162 & 24 & 23 & 64.6 & 50 & 0.0015 & 1 \\
\hline 163 & 24 & 156 & 64.4 & 50 & 0.0015 & 1 \\
\hline 164 & 147 & 165 & 64.3 & 75 & 0.0015 & 1 \\
\hline 165 & 165 & 166 & 166 & 50 & 0.0015 & 1 \\
\hline 166 & 166 & 167 & 27.1 & 50 & 0.0015 & 1 \\
\hline 167 & 166 & 144 & 64.2 & 50 & 0.0015 & 1 \\
\hline 168 & 144 & 157 & 55.3 & 50 & 0.0015 & 1 \\
\hline 169 & 158 & 162 & 160.5 & 50 & 0.0015 & 1 \\
\hline 170 & 162 & 161 & 64.5 & 100 & 0.0015 & 1 \\
\hline 171 & 161 & 151 & 64.5 & 100 & 0.0015 & 1 \\
\hline 172 & 163 & 164 & 59.2 & 75 & 0.0015 & 1 \\
\hline 173 & 164 & 165 & 64.3 & 75 & 0.0015 & 1 \\
\hline 174 & 164 & 144 & 165.8 & 50 & 0.0015 & 1 \\
\hline 175 & 76 & 51 & 75 & 50 & 0.0015 & 1 \\
\hline 176 & 74 & 73 & 87.09 & 0.025 & 0.015 & 1 \\
\hline 177 & 126 & 53 & 647.77 & 150 & 0.025 & 2 \\
\hline 178 & 33 & 84 & 98 & 50 & 0.025 & 2 \\
\hline 179 & 76 & 119 & 179 & 50 & 0.025 & 2 \\
\hline 180 & 75 & 178 & 80 & 50 & 0.0015 & 1 \\
\hline 181 & 175 & 58 & 92.15 & 100 & 0.025 & 2 \\
\hline 182 & 116 & 117 & 331.03 & 50 & 0.0015 & 1 \\
\hline 183 & 117 & 118 & 35 & 50 & 0.0015 & 1 \\
\hline 184 & 73 & 174 & 100 & 50 & 0.025 & 2 \\
\hline 185 & 176 & 175 & 80 & 50 & 0.025 & 2 \\
\hline 186 & 177 & 175 & 75 & 50 & 0.025 & 2 \\
\hline 187 & 180 & 179 & 4 & 100 & 1 & \\
\hline
\end{tabular}


Tabela Ap.4 - Características dos nós da rede da cidade de Itirapuã

\begin{tabular}{|c|c|c|c|c|c|}
\hline Nó & Cota & Demanda (L/s) & Nó & Cota & Demanda (L/s) \\
\hline 1 & 855.000 & 0.000000 & 51 & 865.297 & 0.028935 \\
\hline 2 & 851.032 & 0.025077 & 52 & 866.995 & 0.000000 \\
\hline 3 & 857.170 & 0.081983 & 53 & 866.995 & 0.000000 \\
\hline 4 & 859.700 & 0.014082 & 54 & 867.646 & 0.000000 \\
\hline 5 & 863.330 & 0.049768 & 55 & 861.708 & 0.000000 \\
\hline 6 & 857.860 & 0.051505 & 56 & 870.204 & 0.071759 \\
\hline 7 & 849.634 & 0.026235 & 57 & 870.204 & 0.000000 \\
\hline 8 & 845.723 & 0.092592 & 58 & 870.812 & 0.070602 \\
\hline 9 & 854.000 & 0.096836 & 59 & 851.539 & 0.031829 \\
\hline 10 & 843.355 & 0.079282 & 60 & 856.742 & 0.093943 \\
\hline 11 & 851.230 & 0.101852 & 61 & 862.933 & 0.070602 \\
\hline 12 & 859.500 & 0.035494 & 62 & 868.285 & 0.067515 \\
\hline 13 & 857.009 & 0.005594 & 63 & 870.812 & 0.007523 \\
\hline 14 & 857.009 & 0.031636 & 64 & 860.436 & 0.043789 \\
\hline 15 & 855.576 & 0.015818 & 65 & 851.300 & 0.006559 \\
\hline 16 & 851.229 & 0.073302 & 66 & 855.500 & 0.025849 \\
\hline 17 & 845.518 & 0.053048 & 67 & 849.920 & 0.057677 \\
\hline 18 & 845.325 & 0.041281 & 68 & 855.632 & 0.077546 \\
\hline 19 & 852.439 & 0.069059 & 69 & 855.632 & 0.000000 \\
\hline 20 & 858.511 & 0.087191 & 70 & 855.632 & 0.000000 \\
\hline 21 & 864.890 & 0.028356 & 71 & 856.177 & 0.056520 \\
\hline 22 & 860.397 & 0.000000 & 72 & 862.983 & 0.060378 \\
\hline 23 & 861.331 & 0.000000 & 73 & 868.530 & 0.063272 \\
\hline 24 & 862.369 & 0.000000 & 74 & 867.385 & 0.000000 \\
\hline 25 & 868.571 & 0.000000 & 75 & 870.195 & 0.122492 \\
\hline 26 & 851.230 & 0.000000 & 76 & 867.587 & 0.076196 \\
\hline 27 & 866.026 & 0.000000 & 77 & 867.300 & 0.009838 \\
\hline 28 & 859.338 & 0.083526 & 78 & 867.385 & 0.031057 \\
\hline 29 & 859.338 & 0.000000 & 79 & 867.385 & 0.000000 \\
\hline 30 & 856.423 & 0.090278 & 80 & 862.148 & 0.079668 \\
\hline 31 & 848.149 & 0.042824 & 81 & 859.301 & 0.023148 \\
\hline 32 & 853.800 & 0.000000 & 82 & 862.148 & 0.000000 \\
\hline 33 & 853.025 & 0.000000 & 83 & 849.381 & 0.046682 \\
\hline 34 & 865.911 & 0.088542 & 84 & 854.330 & 0.065393 \\
\hline 35 & 853.800 & 0.000000 & 85 & 860.322 & 0.109954 \\
\hline 36 & 866.026 & 0.065393 & 86 & 864.230 & 0.045525 \\
\hline 37 & 866.026 & 0.000000 & 87 & 861.722 & 0.060957 \\
\hline 38 & 869.727 & 0.120370 & 88 & 861.000 & 0.060764 \\
\hline 39 & 872.000 & 0.054784 & 89 & 846.898 & 0.049190 \\
\hline 40 & 860.563 & 0.048032 & 90 & 853.923 & 0.000000 \\
\hline 41 & 854.919 & 0.072917 & 91 & 853.025 & 0.048225 \\
\hline 42 & 849.244 & 0.054012 & 92 & 858.220 & 0.076389 \\
\hline 43 & 862.500 & 0.011960 & 93 & 858.200 & 0.032600 \\
\hline 44 & 850.500 & 0.016975 & 94 & 862.216 & 0.048611 \\
\hline 45 & 861.708 & 0.065008 & 95 & 861.380 & 0.030093 \\
\hline 46 & 856.033 & 0.091049 & 96 & 857.935 & 0.080633 \\
\hline 47 & 856.033 & 0.000000 & 97 & 853.374 & 0.076389 \\
\hline 48 & 867.646 & 0.036844 & 98 & 847.773 & 0.049383 \\
\hline 49 & 866.995 & 0.055363 & 99 & 870.204 & 0.000000 \\
\hline 50 & 866.995 & 0.000000 & 100 & 860.865 & 0.007330 \\
\hline
\end{tabular}




\begin{tabular}{|c|c|c|}
\hline Nó & Cota & Demanda (L/s) \\
\hline 101 & 858.294 & 0.084876 \\
\hline 102 & 853.967 & 0.103974 \\
\hline 103 & 849.048 & 0.047839 \\
\hline 104 & 850.650 & 0.067901 \\
\hline 105 & 854.718 & 0.097029 \\
\hline 106 & 858.465 & 0.055170 \\
\hline 107 & 861.000 & 0.007330 \\
\hline 108 & 859.990 & 0.014275 \\
\hline 109 & 859.990 & 0.009645 \\
\hline 110 & 859.957 & 0.077546 \\
\hline 111 & 856.915 & 0.075038 \\
\hline 112 & 853.297 & 0.059606 \\
\hline 113 & 861.801 & 0.074460 \\
\hline 114 & 862.000 & 0.003665 \\
\hline 115 & 859.884 & 0.054977 \\
\hline 116 & 856.859 & 0.167245 \\
\hline 117 & 862.500 & 0.140432 \\
\hline 118 & 865.000 & 0.005980 \\
\hline 119 & 861.006 & 0.016975 \\
\hline 120 & 859.741 & 0.064622 \\
\hline 121 & 860.862 & 0.076389 \\
\hline 122 & 855.643 & 0.087770 \\
\hline 123 & 855.593 & 0.076389 \\
\hline 124 & 845.369 & 0.000000 \\
\hline 125 & 855.994 & 0.060764 \\
\hline 126 & 861.238 & 0.000000 \\
\hline 127 & 861.238 & 0.047261 \\
\hline 128 & 861.708 & 0.000000 \\
\hline 129 & 861.006 & 0.054012 \\
\hline 130 & 858.200 & 0.006366 \\
\hline 131 & 856.727 & 0.051505 \\
\hline 132 & 856.727 & 0.000000 \\
\hline 133 & 861.180 & 0.107446 \\
\hline 134 & 857.590 & 0.105324 \\
\hline 135 & 853.152 & 0.020255 \\
\hline 136 & 850.300 & 0.000000 \\
\hline 137 & 852.994 & 0.007716 \\
\hline 138 & 868.285 & 0.000000 \\
\hline 139 & 866.290 & 0.055941 \\
\hline 140 & 866.290 & 0.000000 \\
\hline 141 & 863.387 & 0.085069 \\
\hline 142 & 870.774 & 0.052083 \\
\hline 143 & 872.000 & 0.008488 \\
\hline 144 & 864.653 & 0.000000 \\
\hline 145 & 865.088 & 0.077932 \\
\hline 146 & 865.088 & 0.000000 \\
\hline 147 & 870.000 & 0.000000 \\
\hline 148 & 864.144 & 0.094907 \\
\hline 149 & 863.200 & 0.095679 \\
\hline 150 & 845.369 & 0.239776 \\
\hline & & \\
\hline
\end{tabular}

\begin{tabular}{|c|c|c|}
\hline Nó & Cota & Demanda (L/s) \\
\hline 151 & 868.533 & 0.000000 \\
\hline 152 & 868.533 & 0.000000 \\
\hline 153 & 860.397 & 0.000000 \\
\hline 154 & 861.331 & 0.000000 \\
\hline 155 & 862.369 & 0.000000 \\
\hline 156 & 863.870 & 0.000000 \\
\hline 157 & 863.870 & 0.000000 \\
\hline 158 & 863.870 & 0.000000 \\
\hline 159 & 864.890 & 0.000000 \\
\hline 160 & 864.890 & 0.000000 \\
\hline 161 & 868.748 & 0.000000 \\
\hline 162 & 869.407 & 0.000000 \\
\hline 163 & 869.407 & 0.000000 \\
\hline 164 & 868.589 & 0.000000 \\
\hline 165 & 867.329 & 0.000000 \\
\hline 166 & 865.213 & 0.000000 \\
\hline 167 & 864.000 & 0.000000 \\
\hline 168 & 871.544 & 0.029707 \\
\hline 169 & 855.410 & 0.094136 \\
\hline 170 & 849.920 & 0.000000 \\
\hline 171 & 855.632 & 0.000000 \\
\hline 172 & 862.148 & 0.000000 \\
\hline 173 & 872.974 & 0.000000 \\
\hline 174 & 862.983 & 0.023534 \\
\hline 175 & 870.444 & 0.076582 \\
\hline 176 & 867.600 & 0.026235 \\
\hline 177 & 871.500 & 0.011767 \\
\hline 178 & 868.500 & 0.029900 \\
\hline 179 & 873.000 & 0.000000 \\
\hline & & \\
\hline
\end{tabular}




\section{APÊNDICE D - Gráficos das Pressões}

Observadas no Setor Zona Média de Guariba 
Nó 8

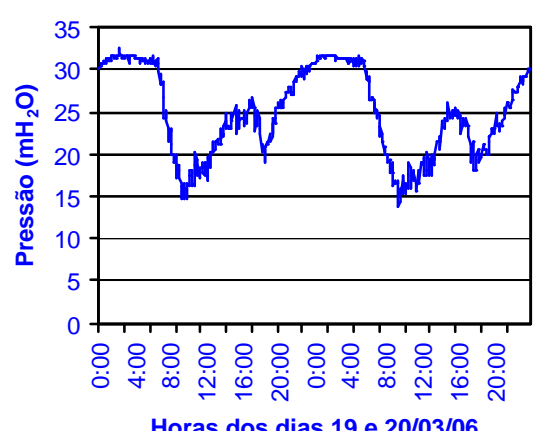

a)

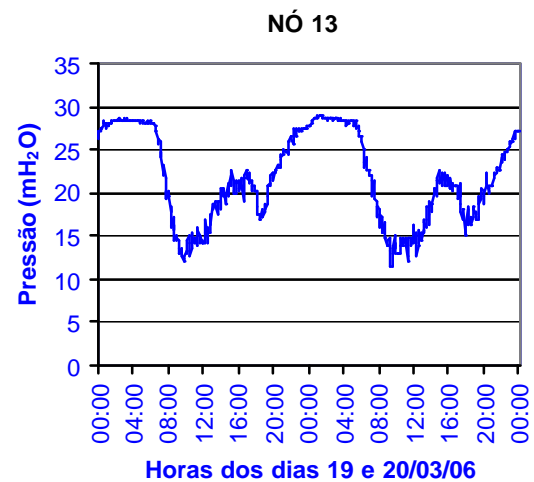

c)

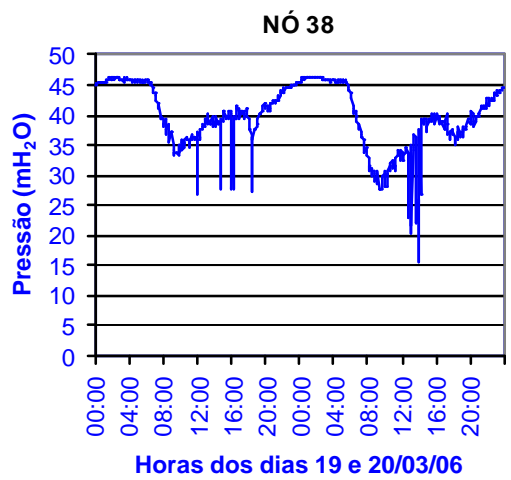

e)

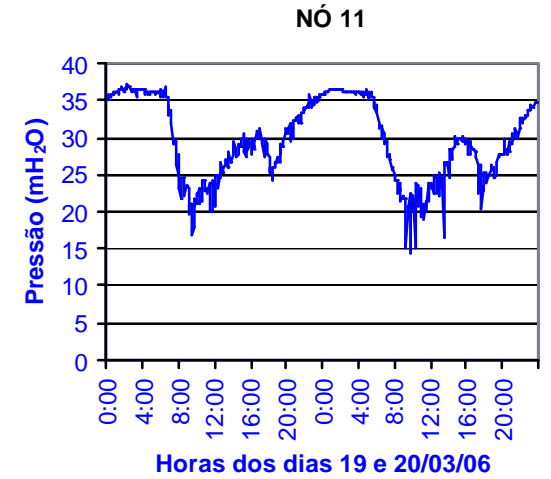

b)

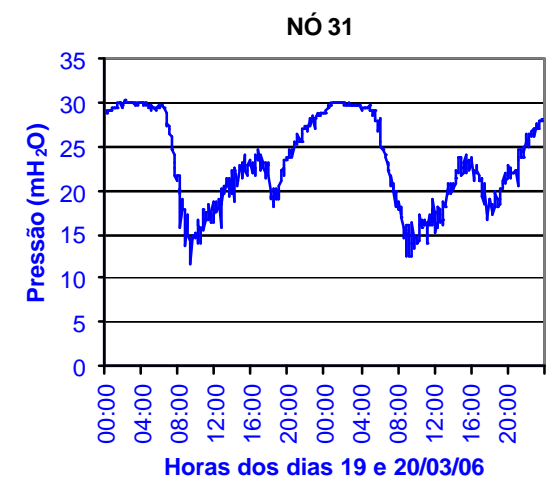

d)

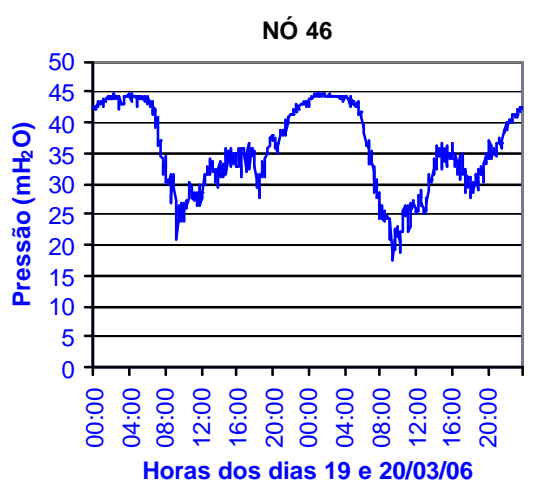

f)

Figura Ap.5 - Pressões nos nós 8, 11, 13, 31, 38 e 48 observadas na rede de Guariba 


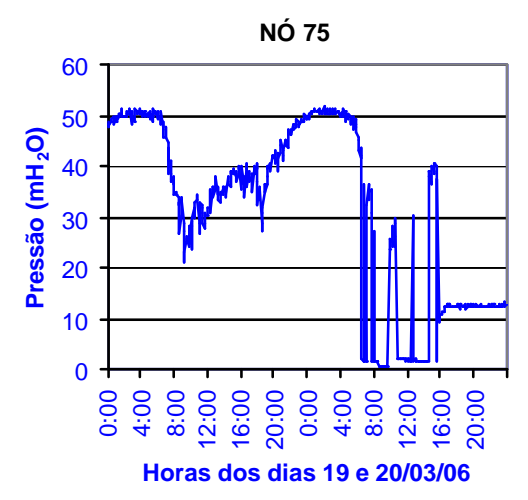

a)

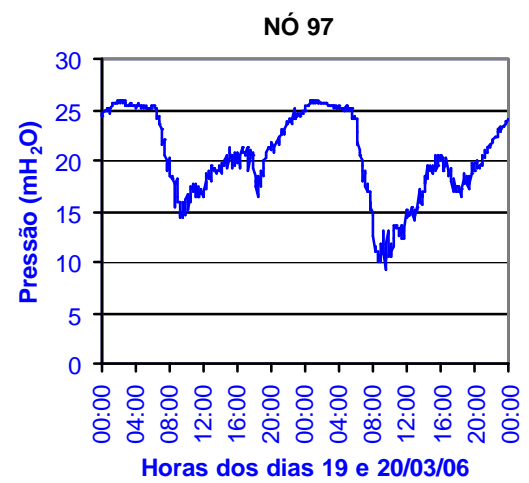

c)

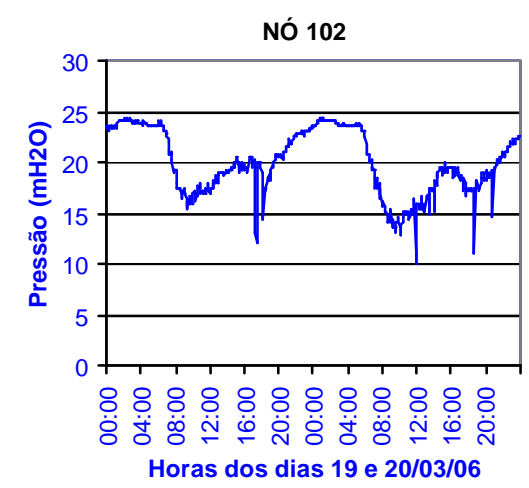

e)

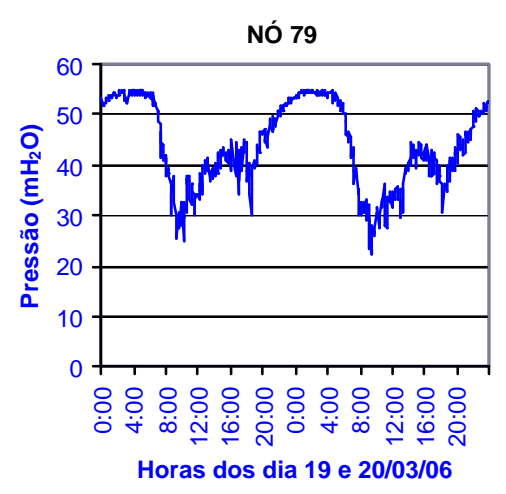

b)

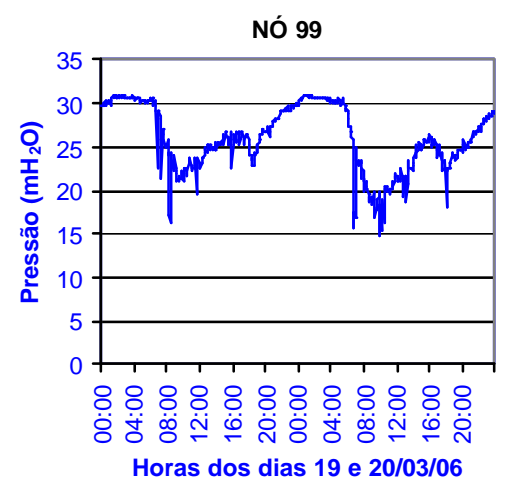

d)

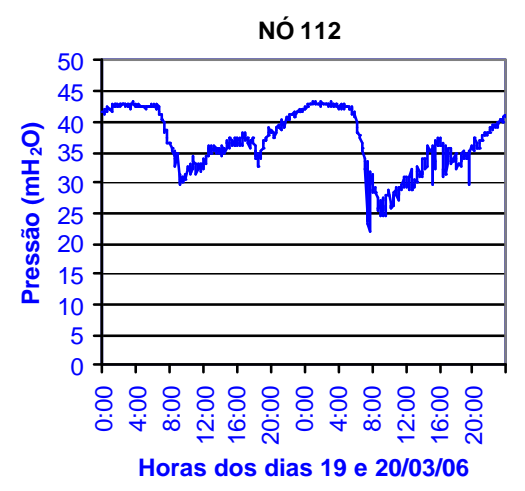

f)

Figura Ap.6 - Pressões nos nós 75, 79, 97, 99, 102 e 112 observadas na rede de Guariba 


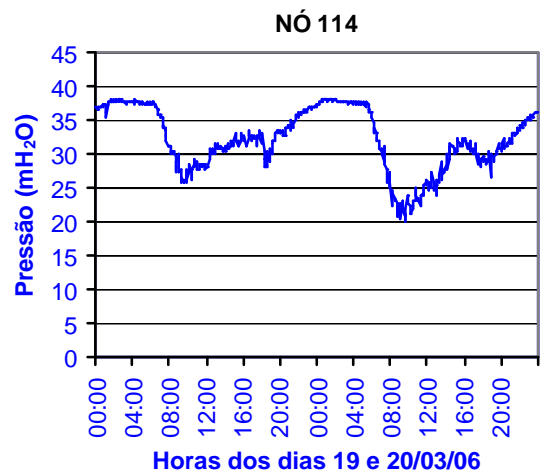

a)

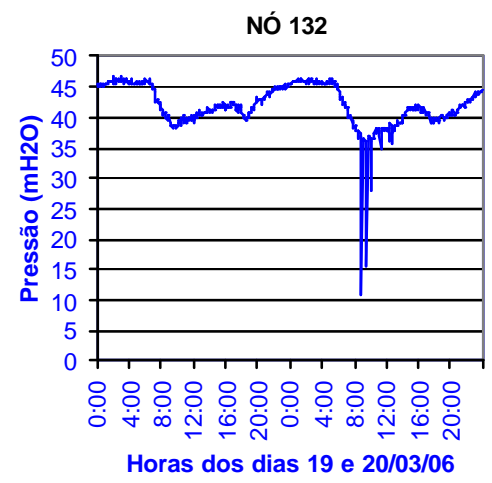

c)

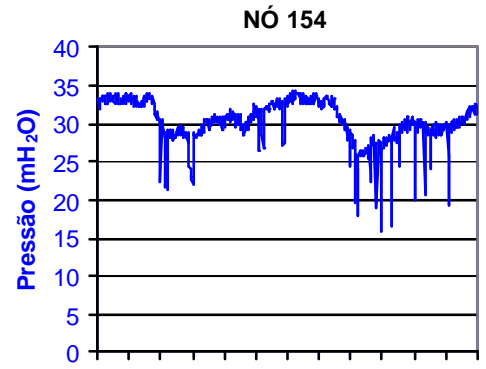

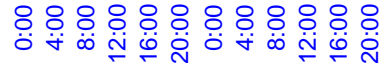

Horas dos dias 19 e 20/03/06

e)

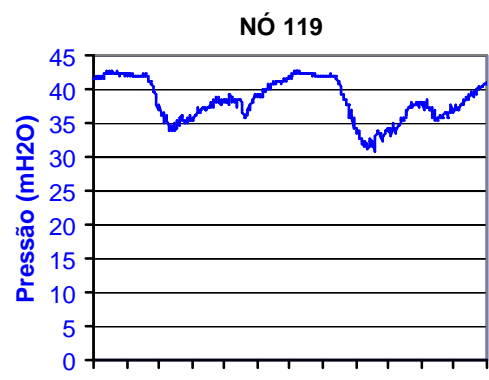

8ㅇㅇㅇㅇㅇㅇㅇㅇㅇㅇㅇㅇㅇ잉

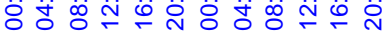

Horas dos dias 19 e 20/03/06

b)

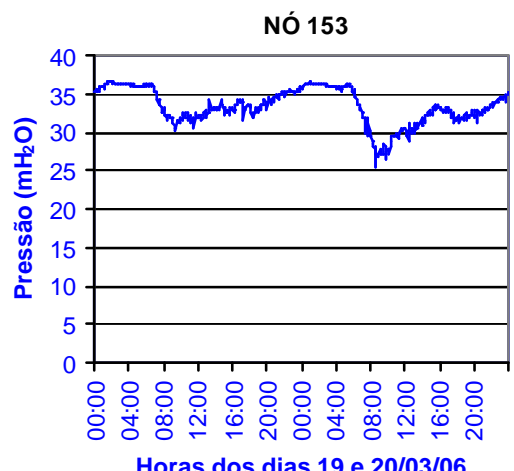

d)

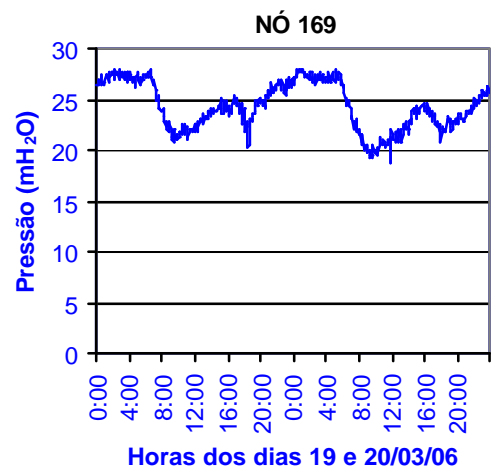

f)

Figura Ap.7 - Pressões nos nós 114, 119, 132, 153, 154 e 169 observadas na re de de Guariba 


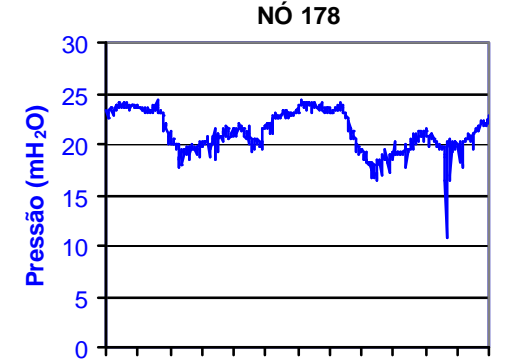

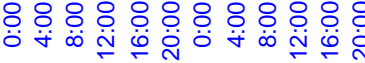

Horas dos dias 19 e 20/03/06

a)

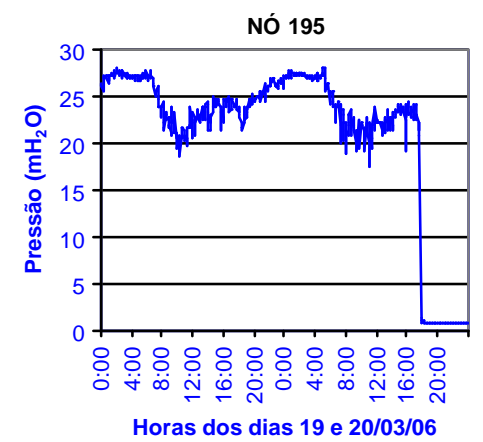

c)

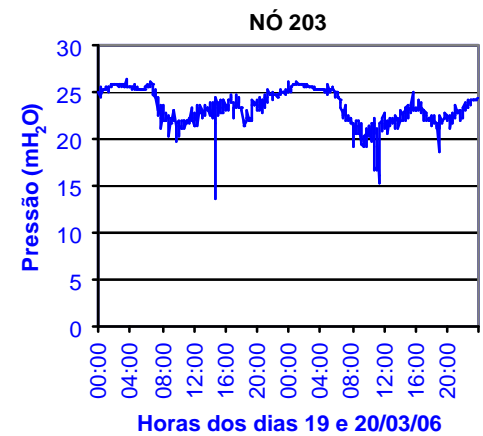

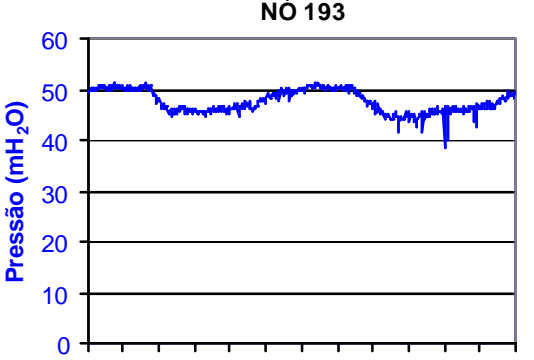

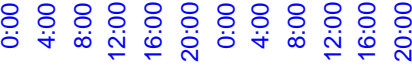

Horas dos dias 19 e 20/03/06

b)

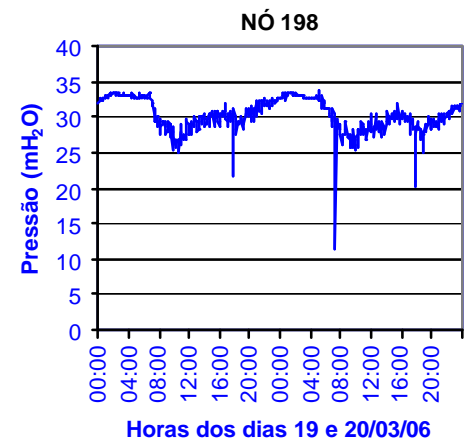

d)

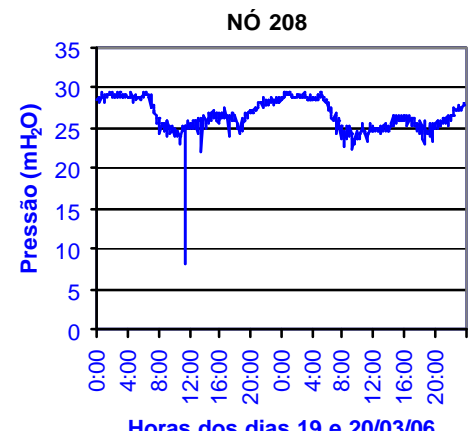

f)

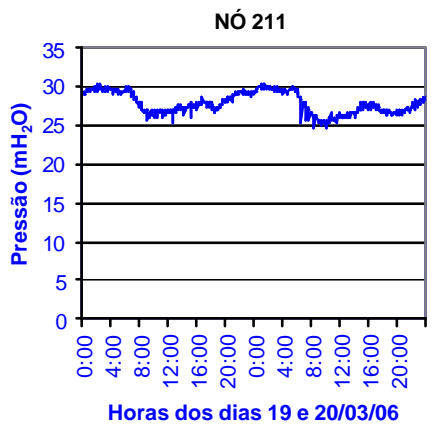

g)

Figura Ap.8 - Pressões nos nós 178, 193, 195, 198, 203, 208 e 211 observadas na rede de Guariba 


\section{APÊNDICE E - Gráficos das Pressões}

Observadas nos nós da Cidade de Itirapuã 


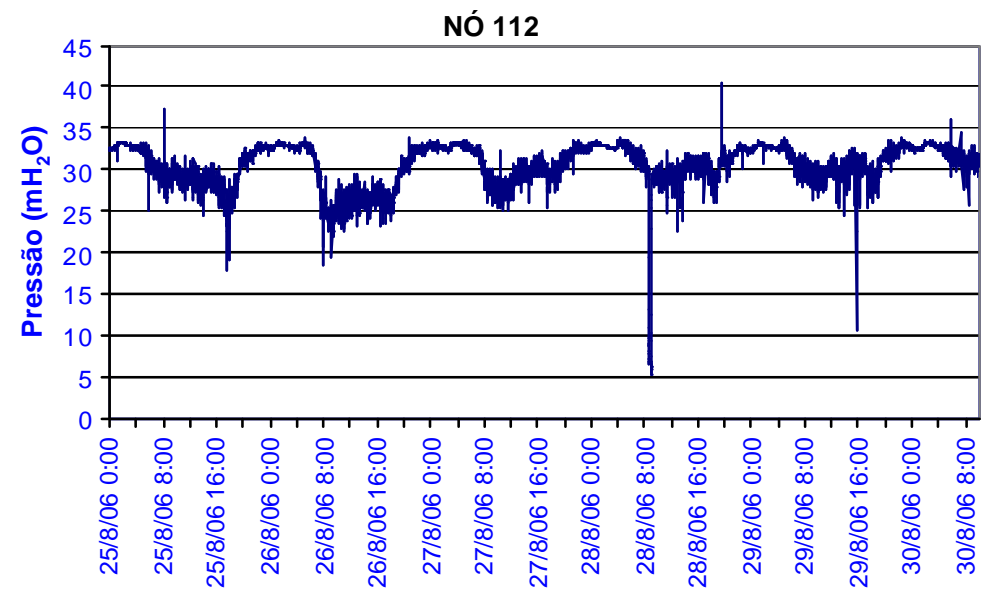

a)

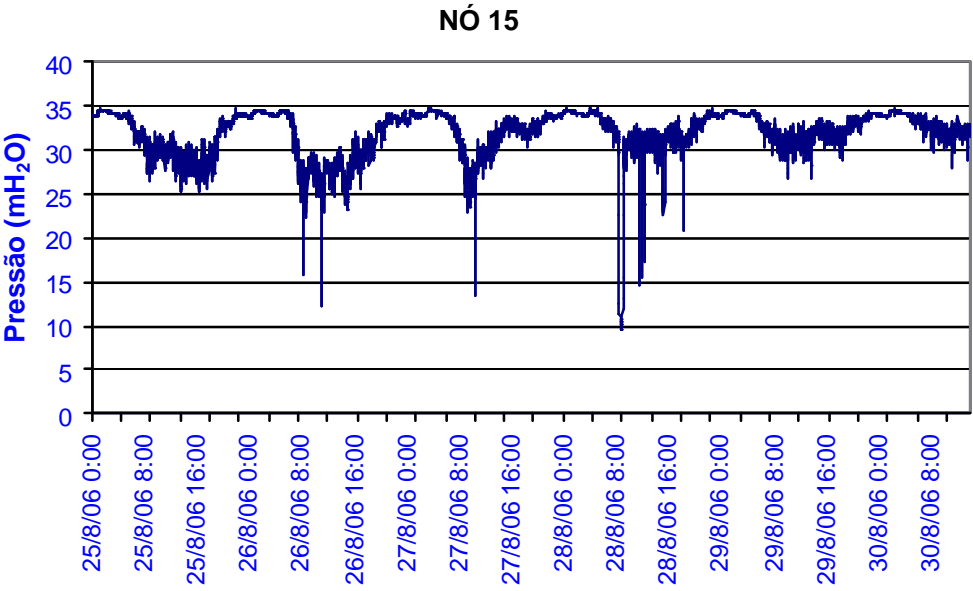

b)

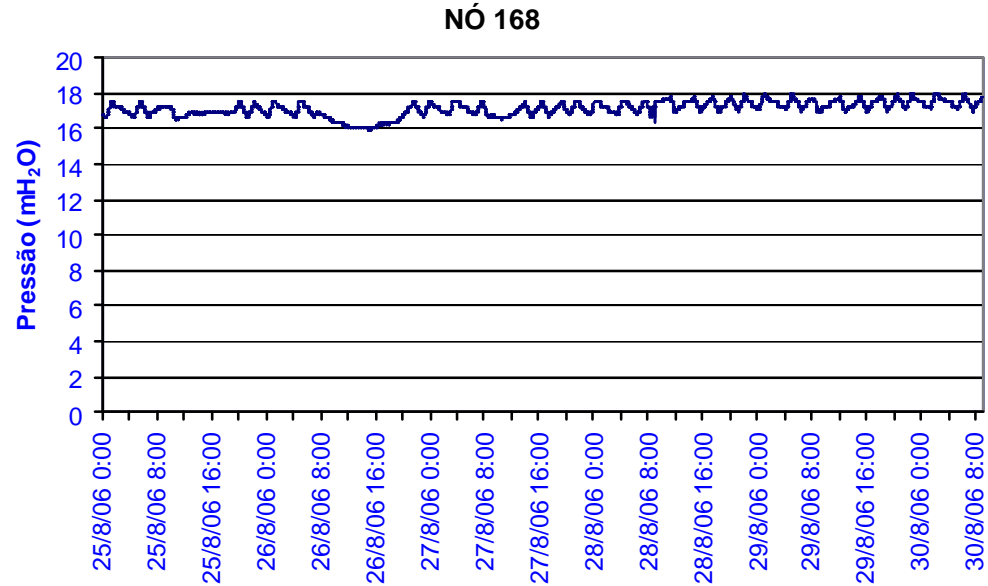

c)

Figura Ap.9 - Pressões nos nós 112, 15e 168 observadas na rede de Itirapuã 


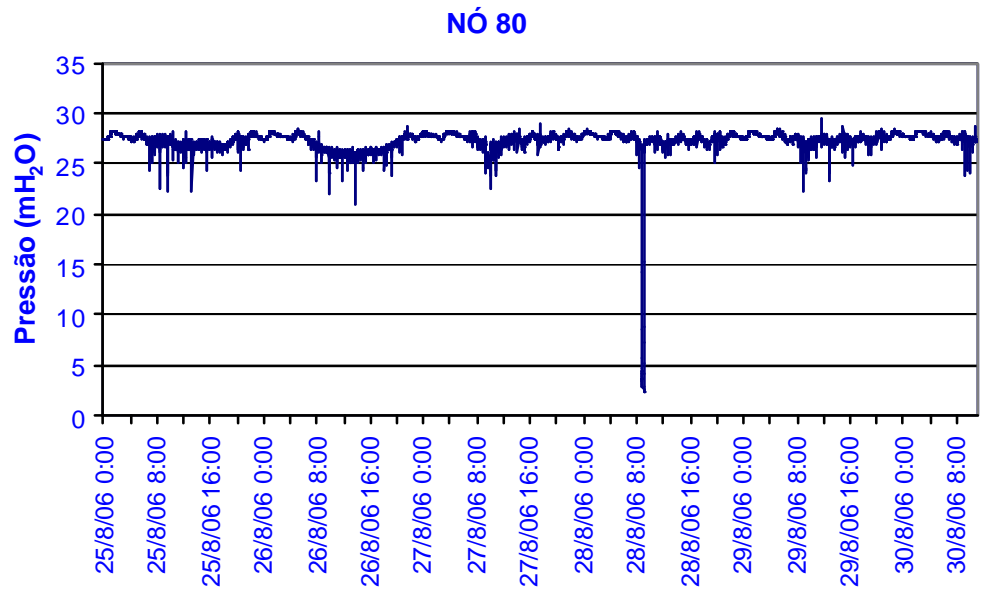

a)

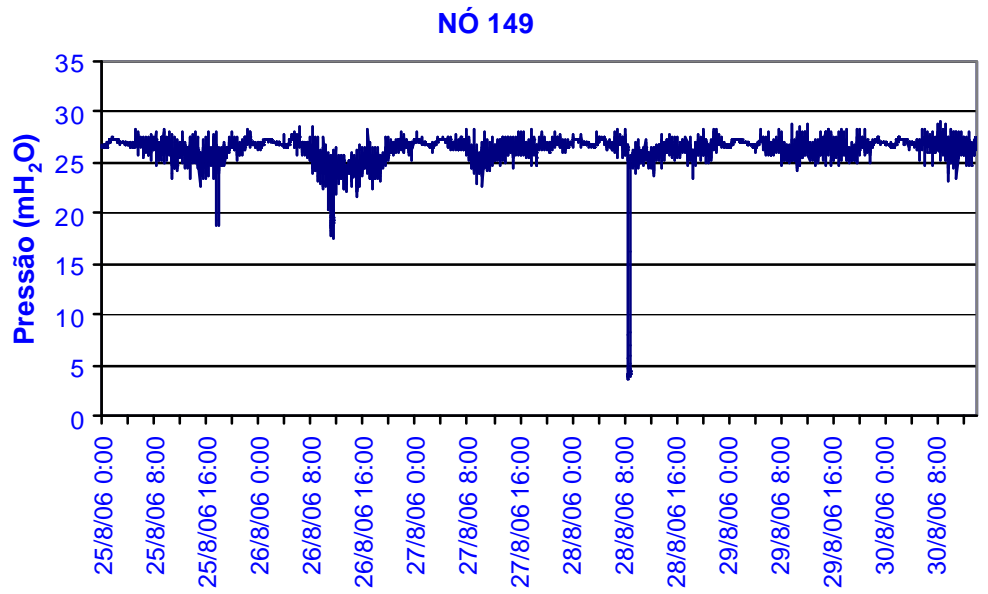

b)

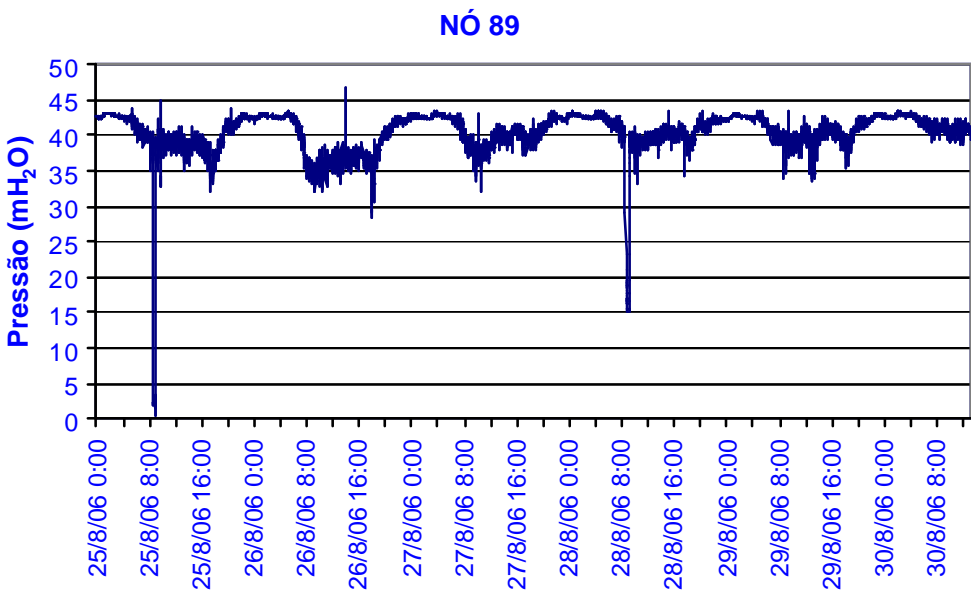

c)

Figura Ap.10 - Pressões nos nós 80, 149 e 89 observadas na rede de Itirapuã 


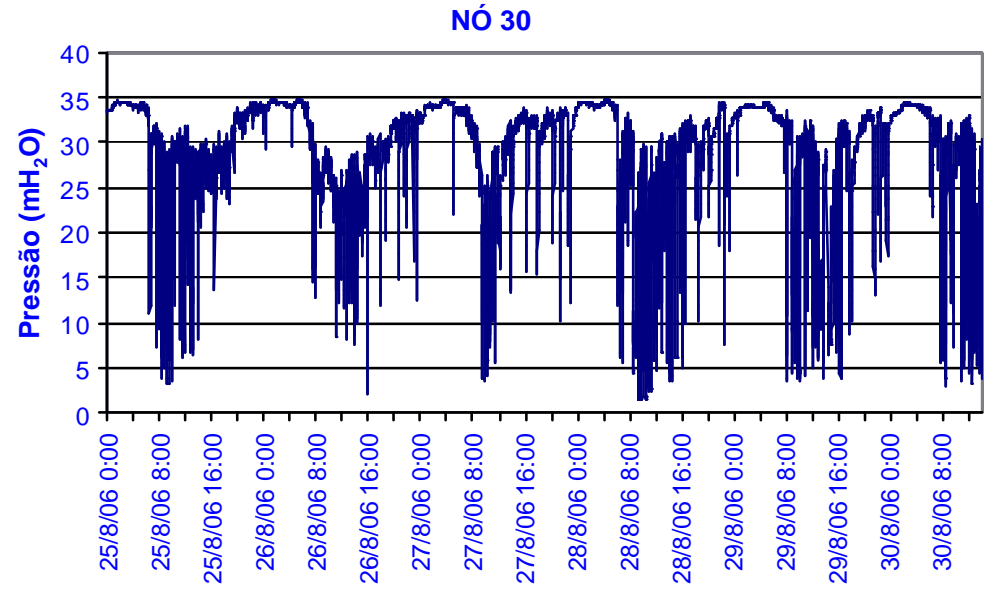

a)

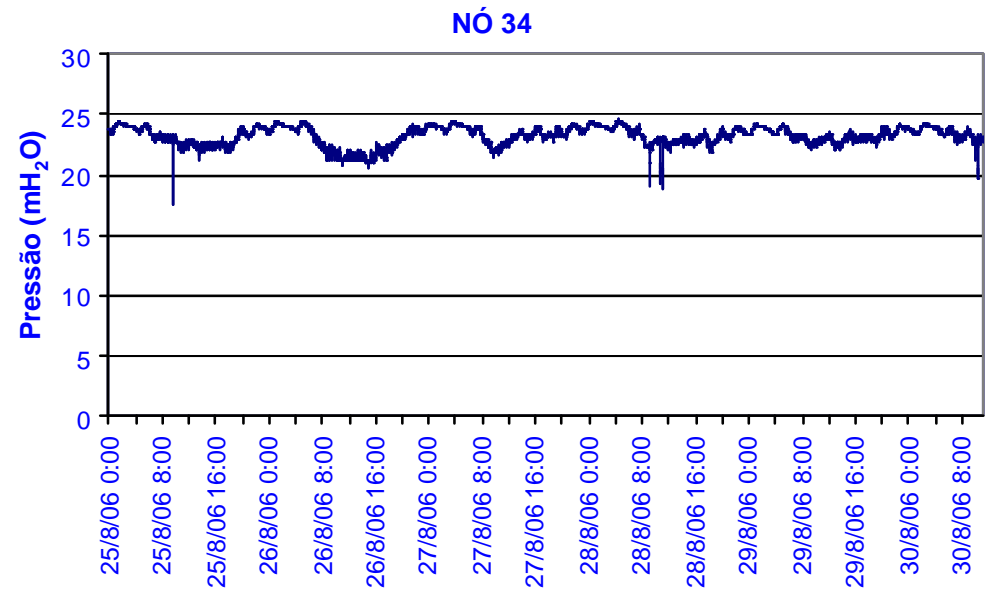

b)

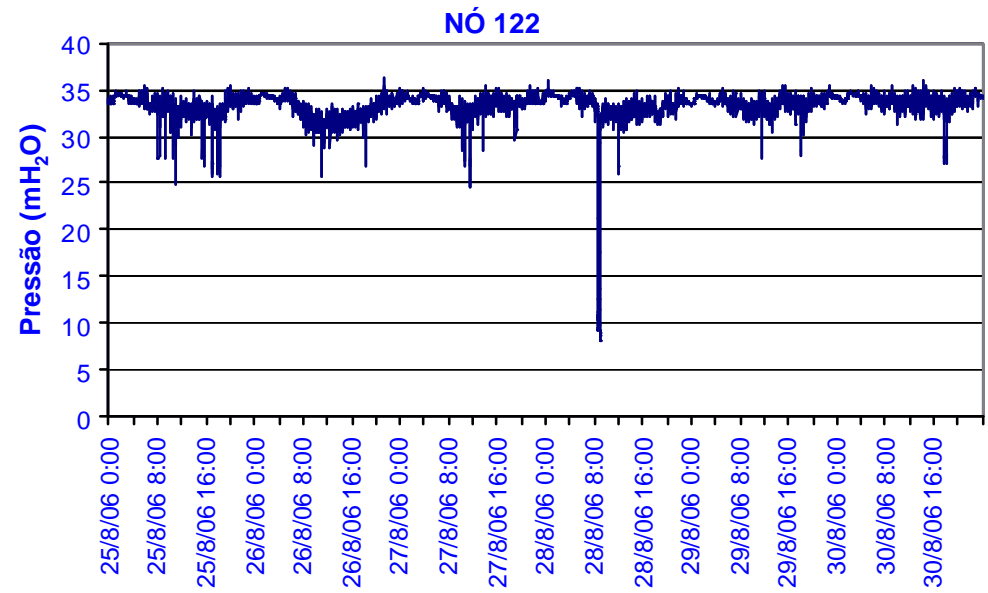

c)

Figura Ap.11 - Pressões nos nós 30, 34 e 122 observadas na rede de Itirapuã 


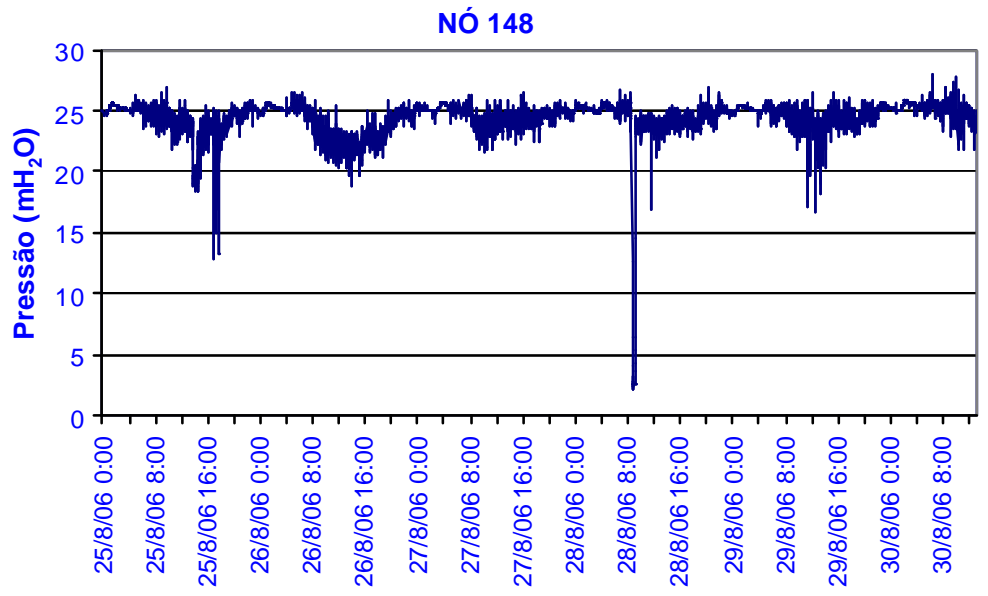

a)

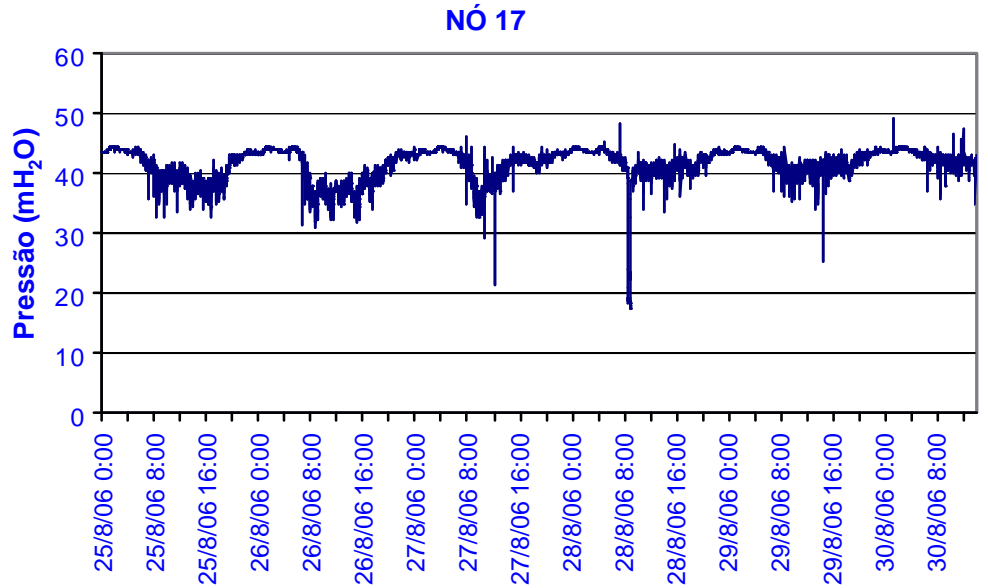

b)

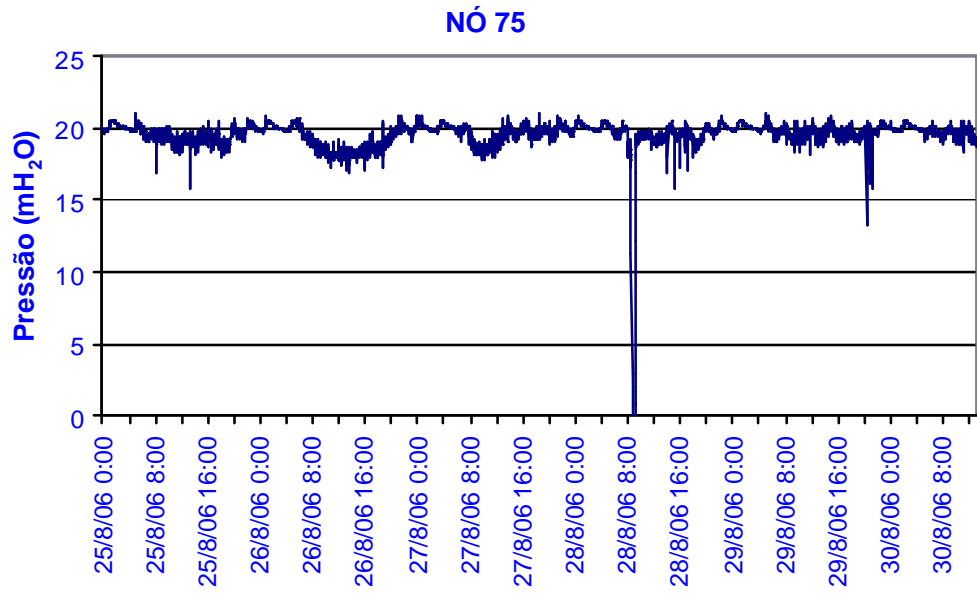

c)

Figura Ap.12 - Pressões nos nós 148, 17 e 75 observadas na rede de Itirapuã 


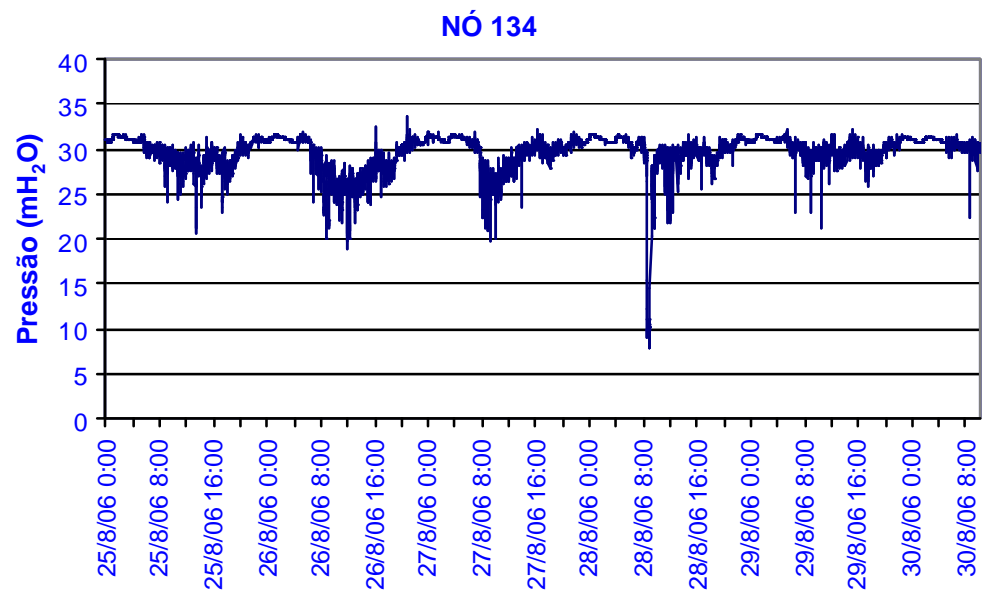

Figura Ap.13 - Pressão no nó 134 observada na rede de Itirapuã 


\section{APÊNDICE F - Curvas dos Padrões de Pressão}

Observadas e Estáticas da Cidade de Guariba 


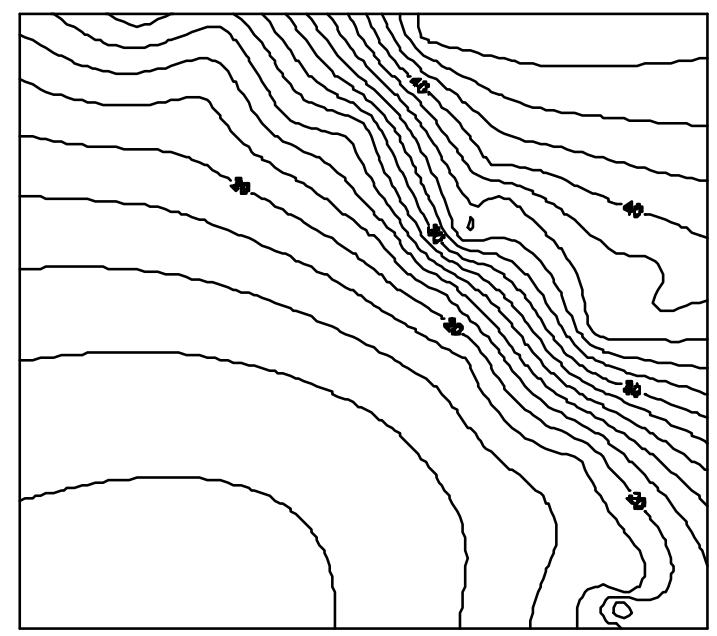

a) Curva das pressões dinâmicas do padrão 1

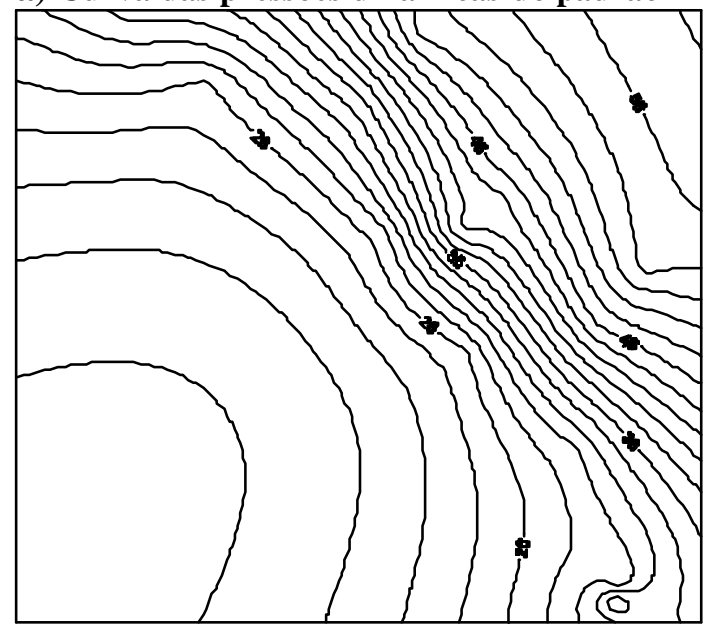

c) Curva das pressões dinâmicas do padrão 2

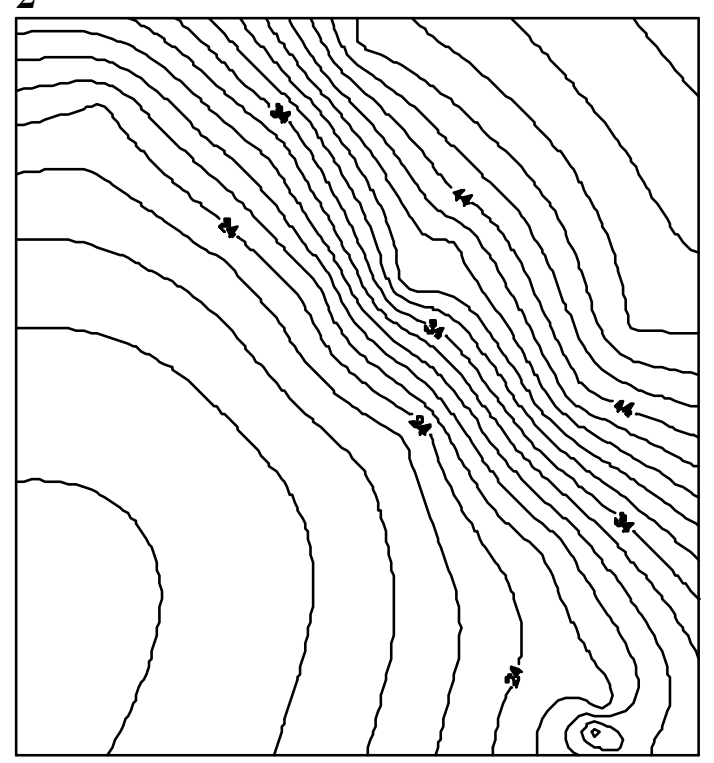

e) Curva das pressões dinâmicas do padrão

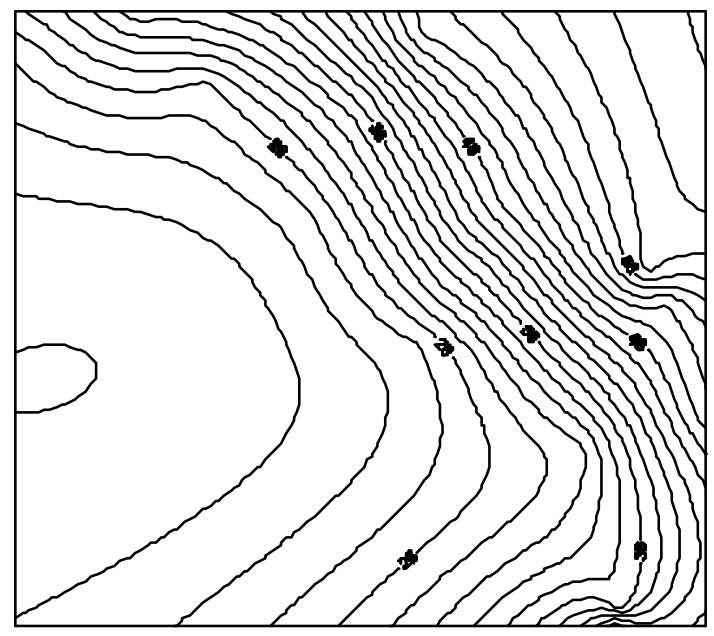

b)Curva das pressões estáticas do padrão 1

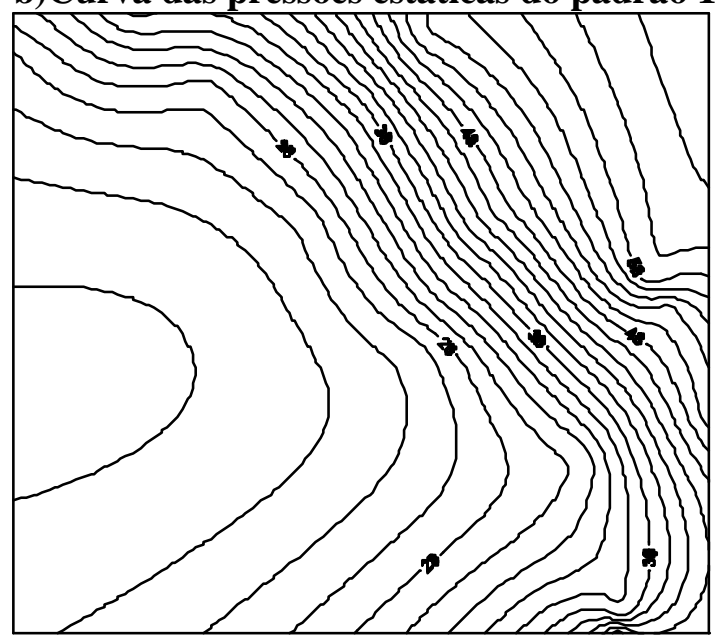

d)Curva das pressões estáticas do padrão 2

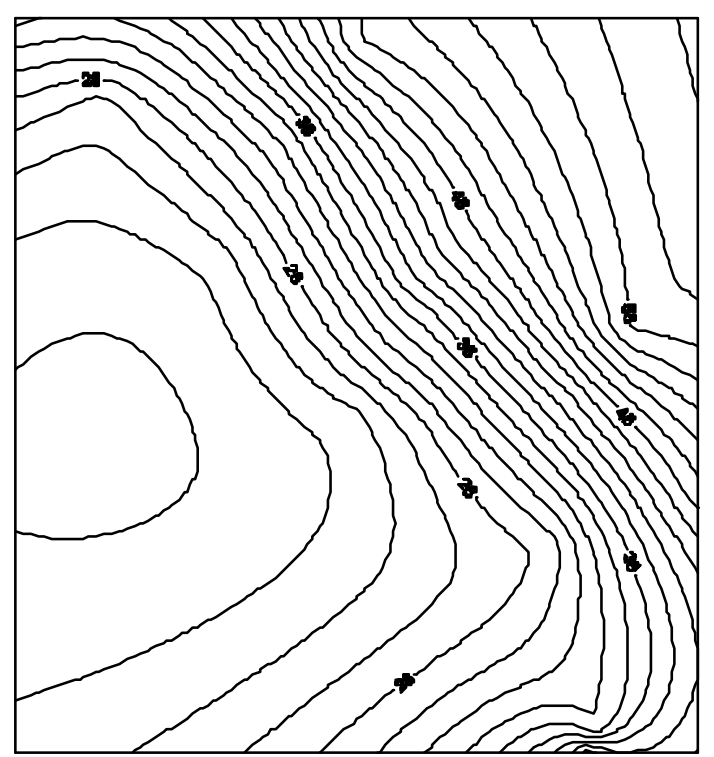

f)Curva das pressões estáticas do padrão 3 3

Figura Ap.14 - Curvas das pressões dinâmicas e estáticas observadas em Guariba para os padrões 1,2 e 3 


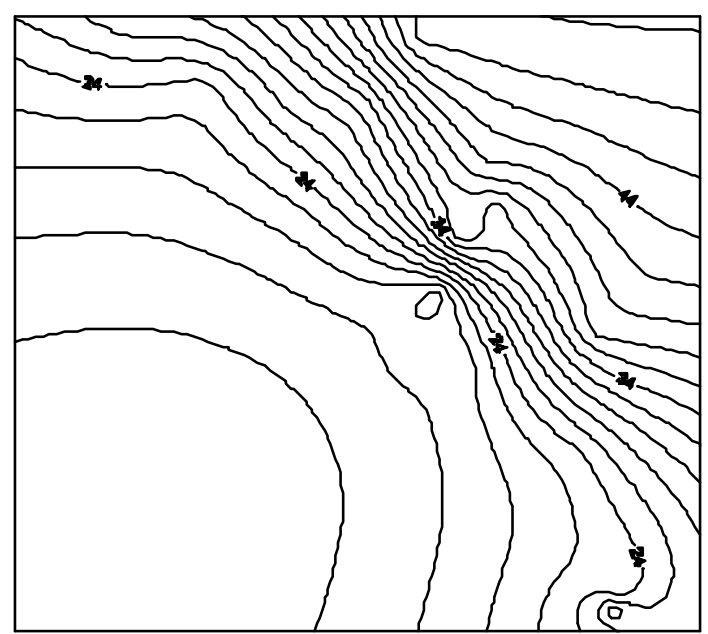

a) Curva das pressões observadas do padrão 4

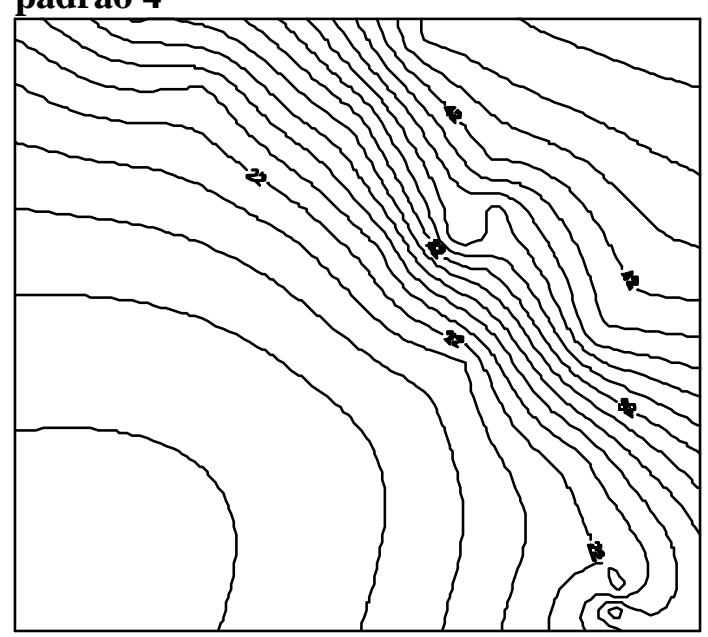

c) Curva das pressões observadas do padrão 5

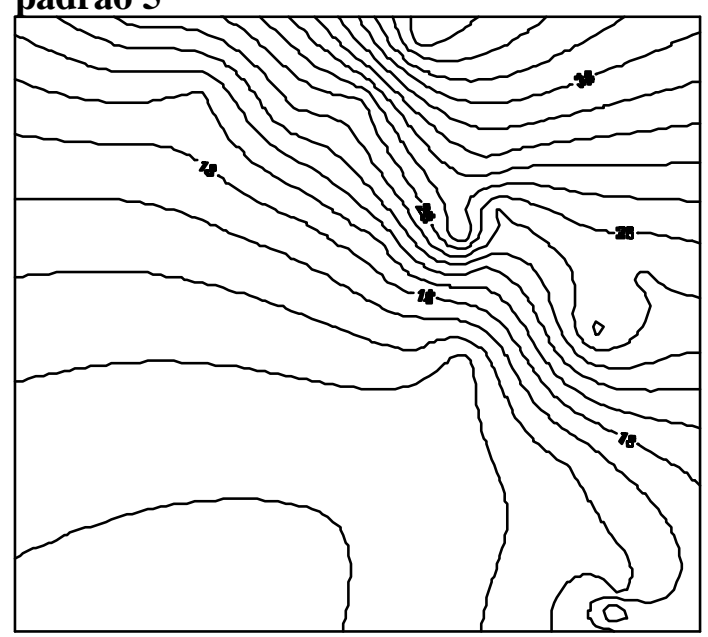

e) Curva das pressões observadas do padrão 6

Figura Ap.15 - Curvas das pressões dinâmicas e estáticas observadas em Guariba para os

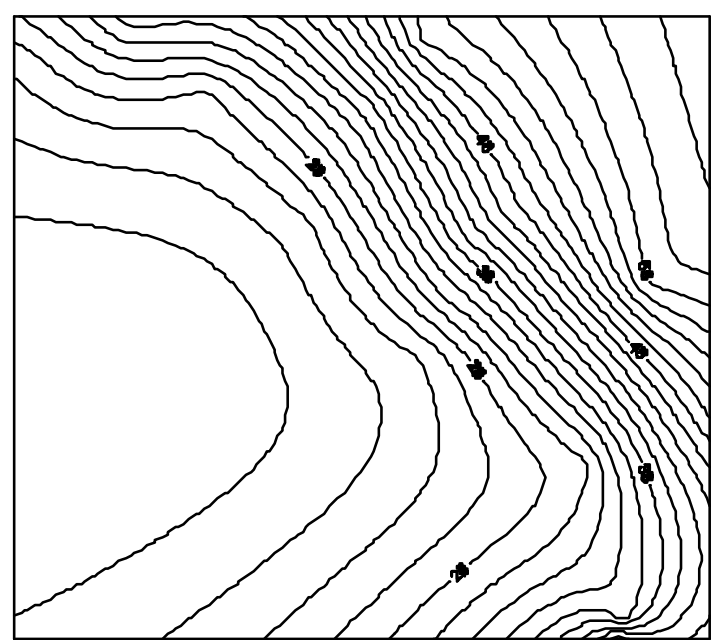

b) Curva das pressões observadas do padrão 4

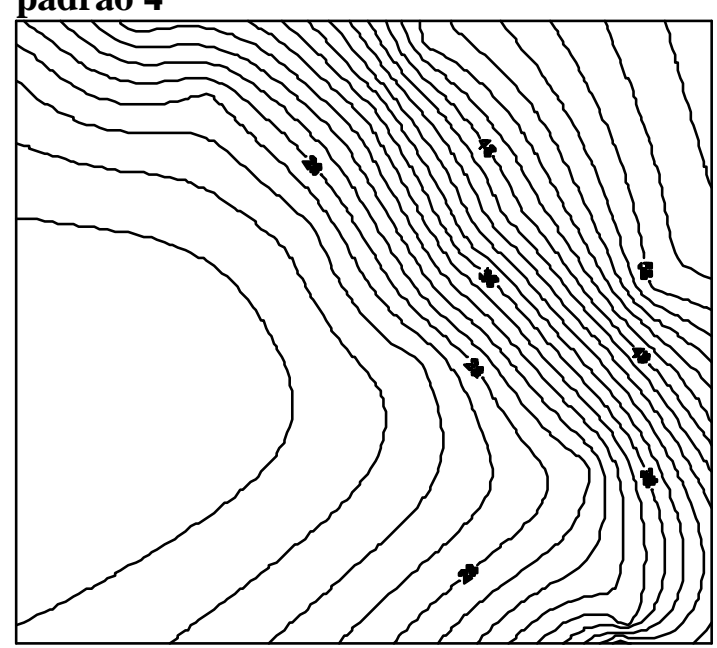

d) Curva das pressões observadas do padrão 5

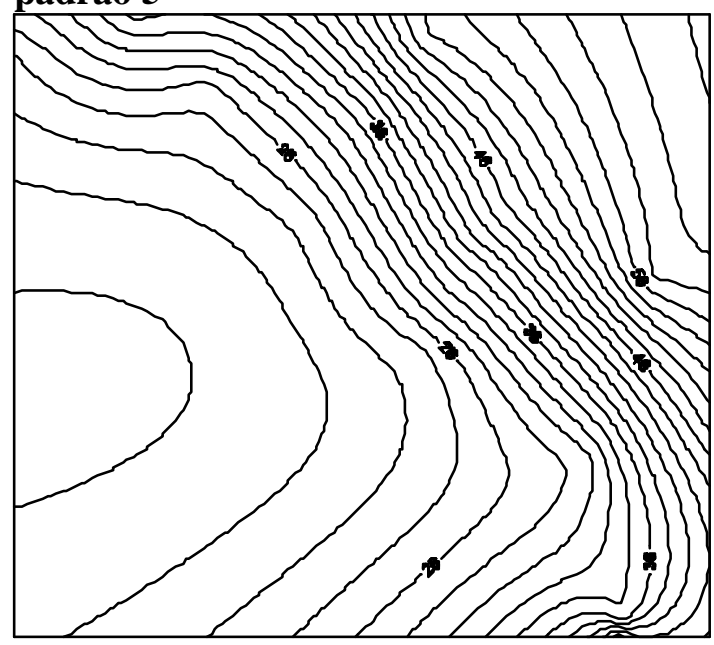

f) Curva das pressões observadas do padrão 6 padrões 4, 5 e 6 


\section{APÊNDICE G - Curvas dos Padrões de Pressão}

Observadas e Estáticas da Cidade de Itirapuã 

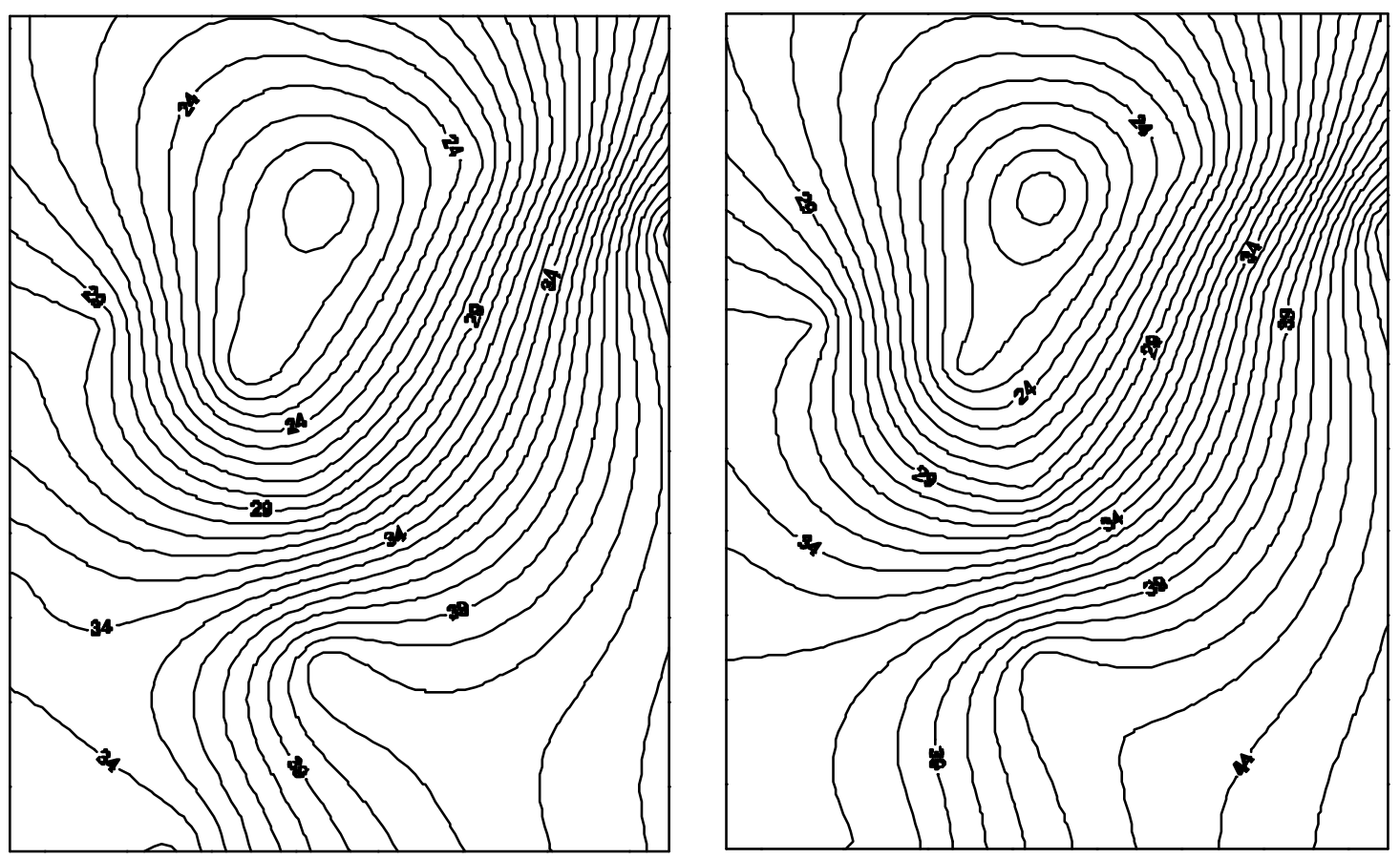

a) Curva das pressões dinâmicas do padrão b)Curva das pressões estáticas do padrão 1 1
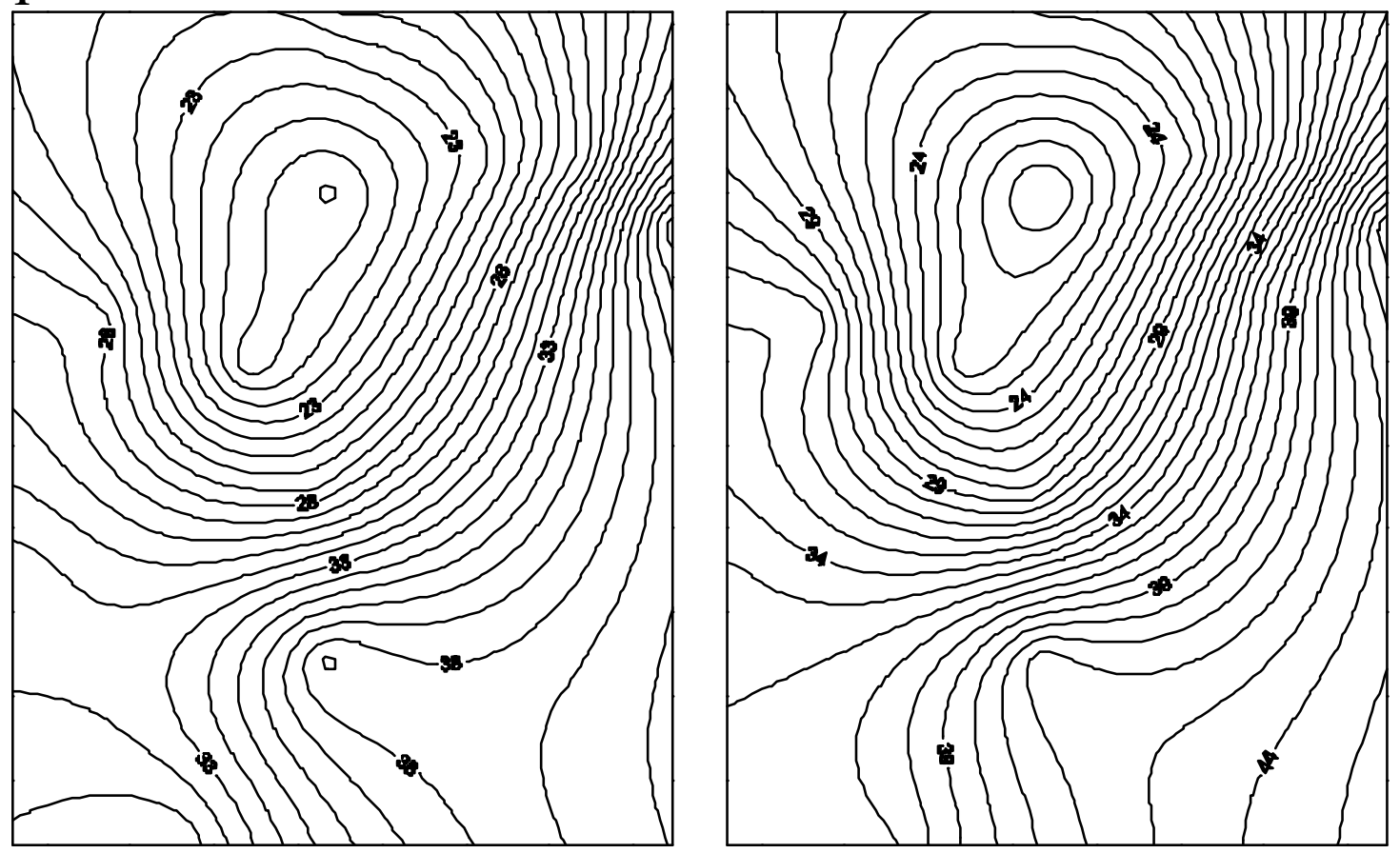

c) Curva das pressões dinâmicas do padrão d)Curva das pressões estáticas do padrão 2 2

Figura Ap.16 - Curvas das pressões dinâmicas e estáticas observadas em Itirapuã para os padrões 1 e 2 


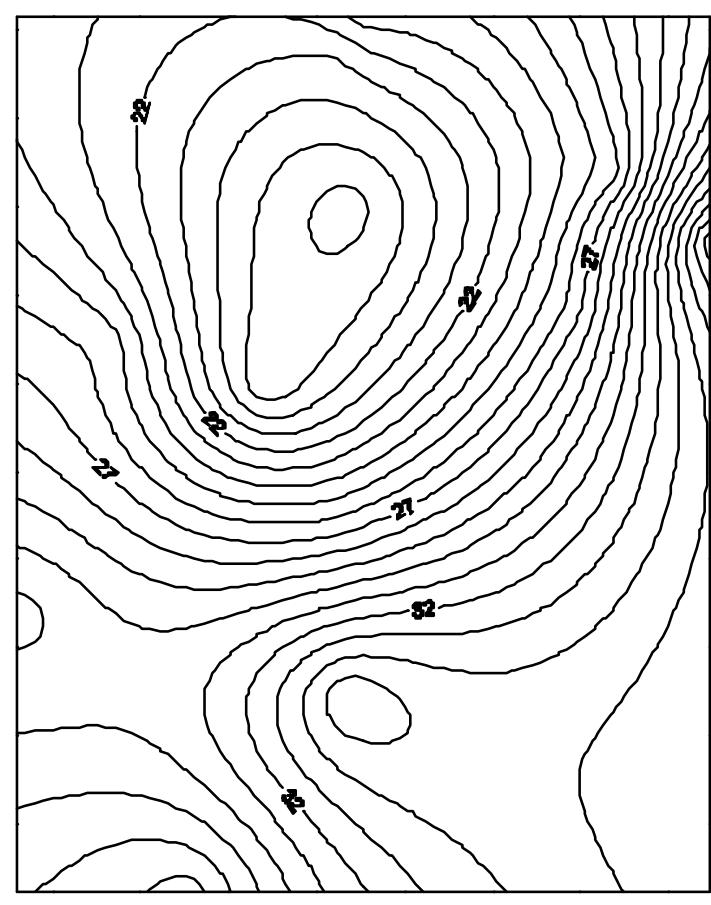

a) Curva das pressões dinâmicas do padrão 3

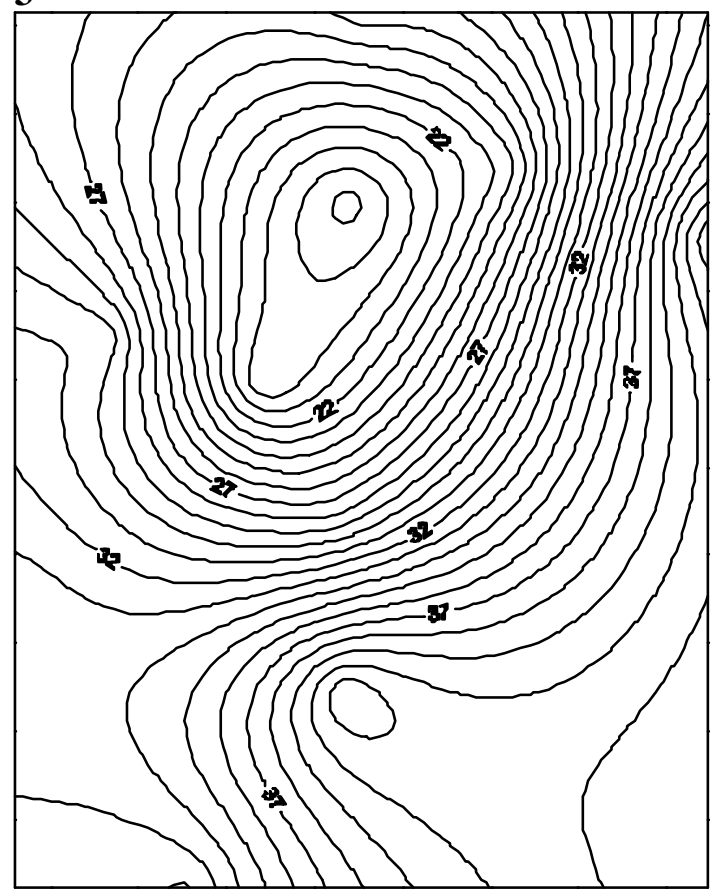

c) Curva das pressões dinâmicas do padrão

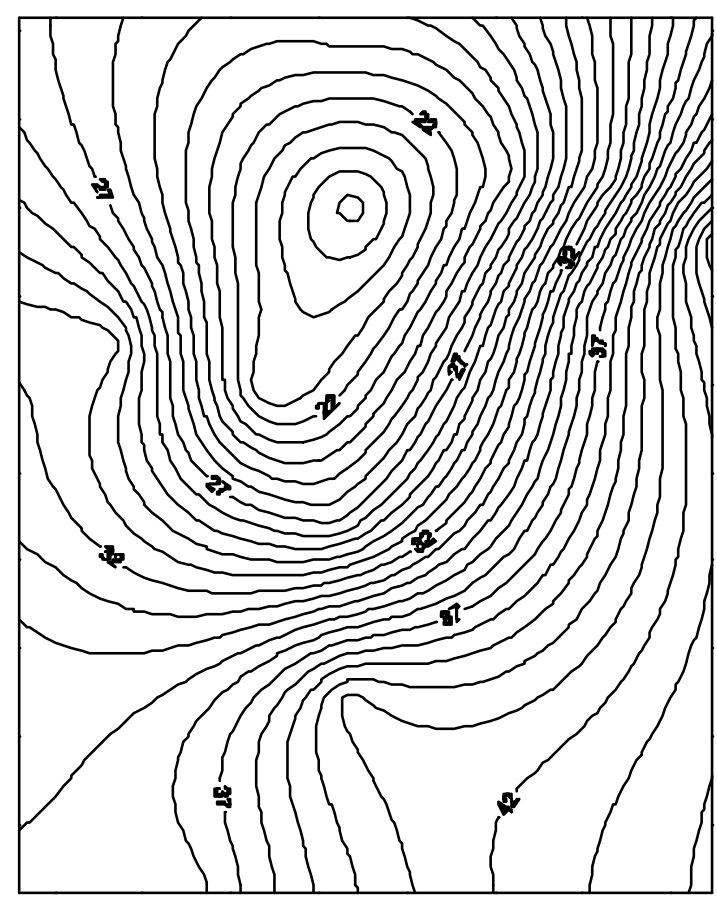

b)Curva das pressões estáticas do padrão 3

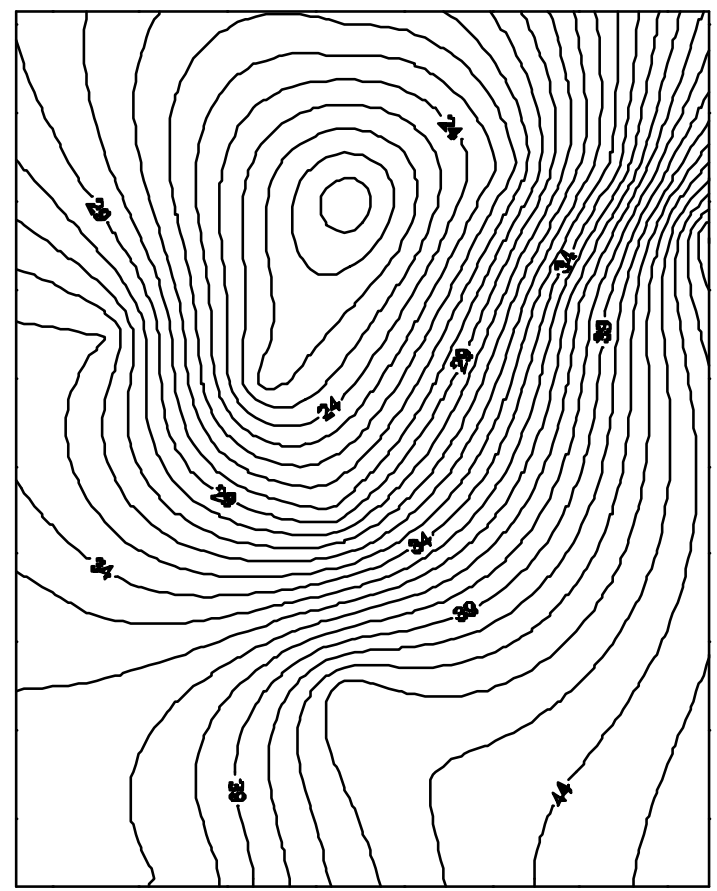

d)Curva das pressões estáticas do padrão 4 4

Figura Ap.17 - Curvas das pressões dinâmicas e estáticas observadas em Itirapuã para os padrões 3 e 4 